\title{
Effect of driving cycles on the particulate mass and number emissions from in-use heavy heavy-duty diesel vehicles
}

Sairam Thiagarajan

West Virginia University

Follow this and additional works at: https://researchrepository.wvu.edu/etd

\section{Recommended Citation}

Thiagarajan, Sairam, "Effect of driving cycles on the particulate mass and number emissions from in-use heavy heavy-duty diesel vehicles" (2004). Graduate Theses, Dissertations, and Problem Reports. 1562. https://researchrepository.wvu.edu/etd/1562

This Thesis is protected by copyright and/or related rights. It has been brought to you by the The Research Repository @ WVU with permission from the rights-holder(s). You are free to use this Thesis in any way that is permitted by the copyright and related rights legislation that applies to your use. For other uses you must obtain permission from the rights-holder(s) directly, unless additional rights are indicated by a Creative Commons license in the record and/ or on the work itself. This Thesis has been accepted for inclusion in WVU Graduate Theses, Dissertations, and Problem Reports collection by an authorized administrator of The Research Repository @ WVU. For more information, please contact researchrepository@mail.wvu.edu. 


\title{
Effect of Driving Cycles on the Particulate Mass and Number Emissions from In-use Heavy Heavy-Duty Diesel Vehicles
}

\author{
Sairam Thiagarajan
}

Thesis submitted to the

College of Engineering and Mineral Resources

at West Virginia University

in partial fulfillment of the requirements

for the degree of

\author{
Master of Science \\ in \\ Mechanical Engineering
}

Mridul Gautam, Ph.D., Chair

Nigel Clark, Ph.D.

W. Scott Wayne, Ph.D.

Department of Mechanical and Aerospace Engineering

\author{
Morgantown, West Virginia \\ 2004
}

Keywords: Particle Sizing, Chemical Speciation, Nano-Particles, Driving Cycles 


\section{ABSTRACT \\ Effect of Driving Cycles on the Particulate Mass and Number Emissions from In-use Heavy Heavy-Duty Diesel Vehicles \\ Sairam Thiagarajan}

With recent emission regulations aiming to cut down emissions by lowering heavy-duty vehicle particulate matter in terms of mass, there is concern regarding particle size being lowered. Nanoparticles have been known to penetrate to the lowest part of the lung, the alveolar region. Serious complications are known to occur when particles in large concentration tend to deposit in the alveolar region. Formation of these particles depends on various factors like engine operating conditions and dilution ratios.

This study focused primarily on the particle mass and number emission from various in-use heavy heavy-duty diesel vehicles operating on different driving cycles. Chemical speciation results are also presented to discuss the formation and composition of particles emitted during various cycles. Tests were performed with West Virginia University's Transportable Heavy Duty Vehicle Emissions Testing Laboratory located at Riverside, California. Five vehicles were selected to cover a wide range of model year from 1989 to 2004. All five vehicles were subjected to chemical speciation and analysis conducted by Desert Research Institute. WVU employed the use of the Scanning Mobility Particle Sizer (SMPS) to measure particle size distributions. Regulated gaseous emissions and total particulate matter from the exhaust were sampled from a full-flow CVS dilution tunnel system. A mini-dilution system was dedicated specifically for particle sizing, which samples partially from the raw exhaust. All vehicles were subjected to California's Heavy Heavy-Duty Diesel Truck (HHDDT) schedule which consisted of an idle, creep, transient and cruise mode. Particle size and chemical speciation data are presented only for the idle and cruise modes since the SMPS can measure a size distribution only during a steady engine operation. 
Particle number emissions were compared for the idle and cruise mode and it was clearly observed that the idle mode produced more nano-particles and cruise mode produced accumulation mode particles. Further analysis by chemical speciation yielded that during the idle mode, volatile compounds were the major contributors to the idle emissions. During the cruise mode, elemental carbon was observed to be the highest species emitted which was also clearly evident with an increase in mass emission. When chemical speciation results based on engine model year were compared, it was noted that old engines emit more elemental carbon and new engines emit more volatile compounds during the idle and cruise modes. 


\section{ACKNOWLEDGEMENTS}

I would like to express my deepest gratitude to my advisor Dr. Mridul Gautam for supporting me during my three years at West Virginia University. Your guidance and inspiration have provided an invaluable experience that will help me through the course of my career. Thank you for being patient with me all through these years.

My sincere appreciation goes to my committee members Dr. Nigel Clark and Dr. Scott Wayne for consenting to be on my committee and for guiding me through a lot of changes in my thesis. I would like to thank Sandeep Mehta for training me on the SMPS, MOUDI and all other aspects of emissions measurement. I would like to thank my team at the mobile lab (Chris Rowe, Andy Williams, Curt Leasor, Tom Long, Ryan Barnett, Jason and Gary England) for making my stay in California bearable.

A special thanks to my friend Shalini Rangarajan for supporting me and helping me through my thesis. Thanks to my friends and roommates, Venkatesh Parthasarathy, Kaarthik Sikkil, Mohan Krishnamurthy and Sundar Vishwanathan for making my stay in Morgantown very memorable. A final thanks to my parents for their unconditional love and support. 


\section{Table of Contents}

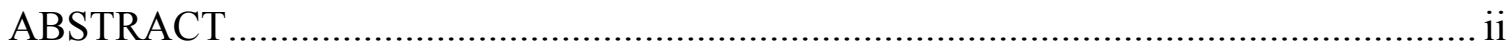

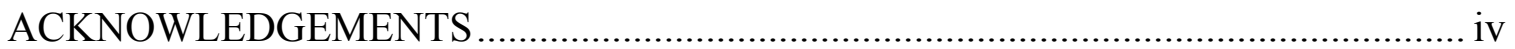

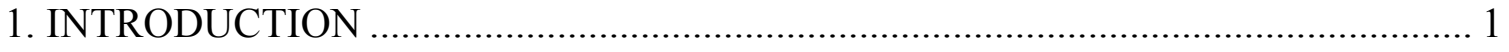

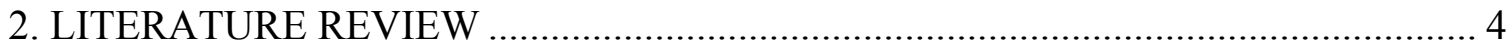

2.1 Properties and Composition of Diesel Exhaust Particles......................................... 5

2.2 Health Effects of Diesel Particles ..................................................................... 15

2.3 Nanoparticle Formation and Reduction Strategies ............................................. 19

2. 4 Particle Emissions from CNG Fueled Vehicles ................................................... 23

3. EXPERIMENTAL SETUP AND TEST PROCEDURES …………………….......... 25

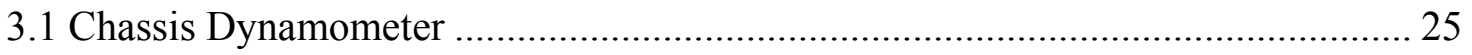

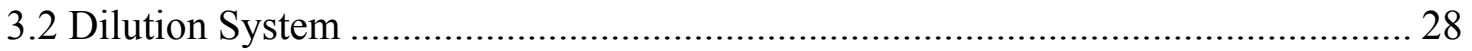

3.2.1 WVU Constant Volume Sampling System (CVS) ……….............................. 28

3.2.2 DRI's Residence Time Dilution Tunnel .......................................................... 31

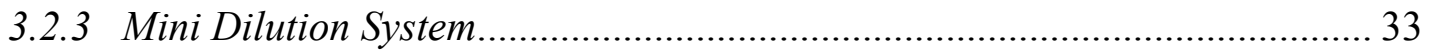

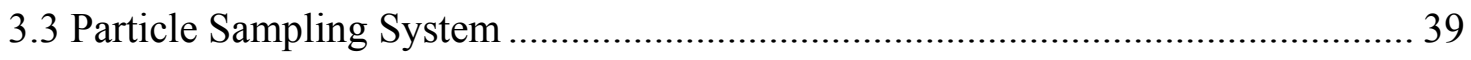

3.3.1 Total Particulate Matter ………………………….................................. 39

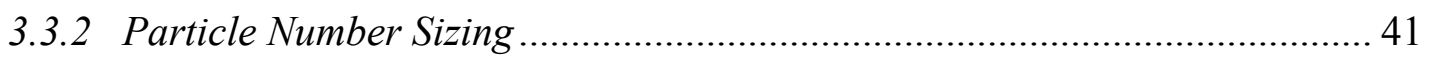

3.4 Unregulated Emissions (West Virginia University and Desert Research Institute)

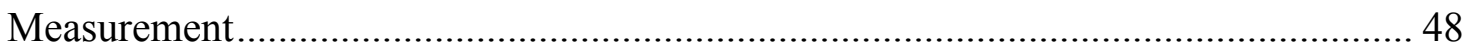

3.4.1 West Virginia University......................................................................... 48

3.4.2 Desert Research Institute ............................................................................... 49

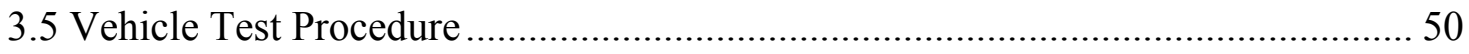


3.5.1 Preparation of the Vehicle for Testing............................................................ 50

3.5.2 Test Vehicle Mounting and Connections to the Laboratory ........................... 50

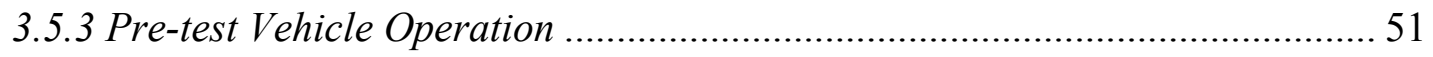

3.6 Test Vehicle, Fuel and Aftertreatment Devices.................................................. 52

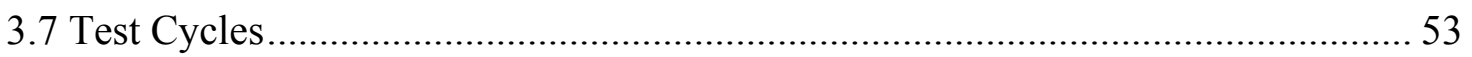

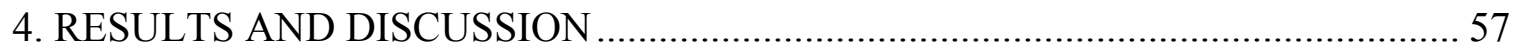

4.1 Particle Sizing and Chemical Speciation Results for CRC 39.............................. 58

4.2 Particle Sizing and Chemical Speciation Results for CRC 40.............................. 63

4.3 Particle Sizing and Chemical Speciation Results for CRC 42............................. 67

4.4 Particle Sizing and Chemical Speciation Results for CRC 43 ............................... 71

4.5 Particle Sizing and Chemical Speciation Results for CRC 44……...................... 75

5. CONCLUSIONS AND RECOMMENDATIONS …………………...................... 79

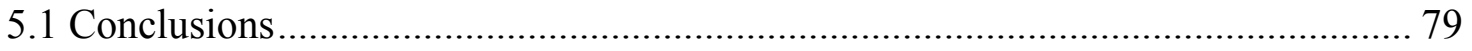

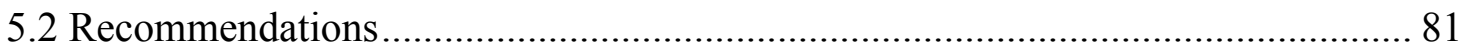

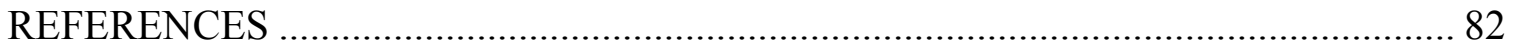

Appendix A - SMPS AND CPC REDUCTION PROGRAM.......................................... 87

Appendix B - CHEMICAL SPECIATION- SAMPLE COLLECTION AND

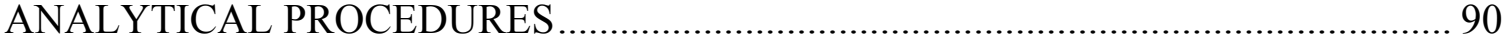

B.1.1 Particulate and Semi Volatile Organic Compounds .................................... 90

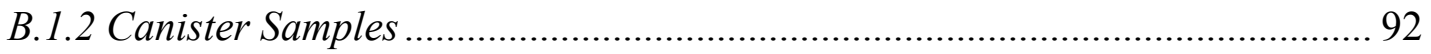

B.1.3 Carbonyl Compounds ............................................................................ 92

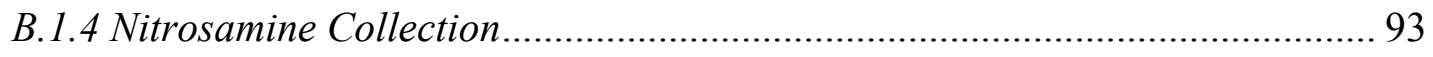

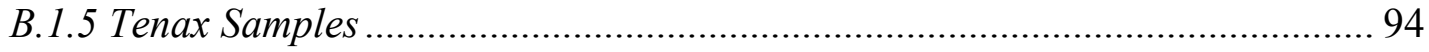


B.2 Chemical Speciation- Analytical Procedures ................................................ 95

B.2.1 Filters and PUF/XAD/PUF Cartridges..................................................... 95

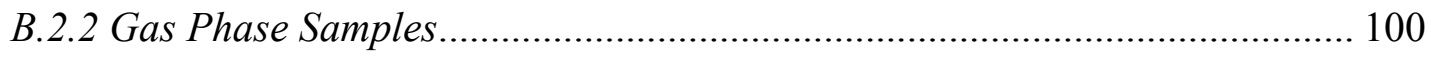

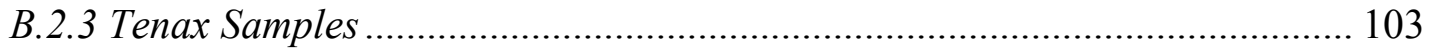

B.2.4 Particulate Phase Inorganic Ions......................................................... 105

B.2.5 Particulate Elemental Analysis .......................................................... 108

Appendix C - LIST OF TARGET CHEMICAL SPECIES ANALYZED.................... 115

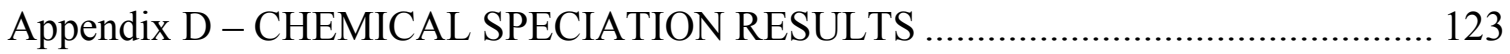




\section{List of Tables}

Table 1: Sampling System Description and Media Type ………………....................... 28

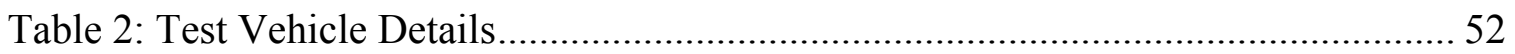

Table B1. List of Deuterated Internal Standards ………................................................ 96

Table B2. X-Ray Fluorescence Air Filter Analysis Interference-Free Minimum

Detectable Limits ${ }^{\mathrm{a}}$ Using DRI Standard Analysis Protocols .................................. 109

Table C1. List of Target Analytes in the Particulate and Semi-Volatile Fractions ....... 115

Table C2. List of Gas-phase Volatile Organic Compounds Quantified by GC/MS

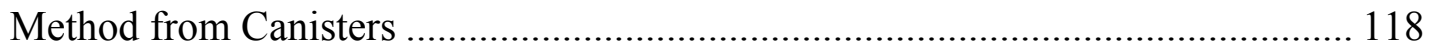

Table C3. List of Target Analytes in the Gas-Phase Carbonyl Compound Fraction..... 120

Table C4. Nitrosoamines Targeted for Analysis in the Vehicle Exhaust ...................... 120

Table C5. List of Heavy Hydrocarbons for Tenax Samples........................................... 121 


\section{List of Figures}

Figure 1: The Major Anatomical Features of the Human Respiratory System [14]........ 15

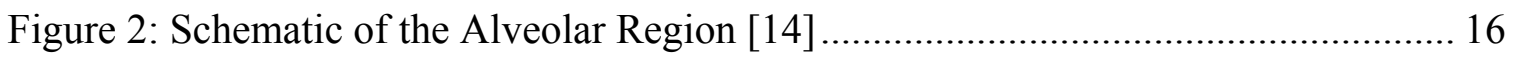

Figure 3: Side View of the Chassis Dynamometer .................................................. 26

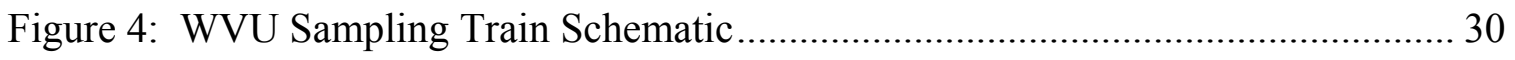

Figure 5: Schematic of the DRI Residence Time Dilution Tunnel [27] ......................... 32

Figure 5: West Virginia University-Mini Dilution System ....................................... 34

Figure 6: Exhaust Coupler with Sampling Probe ...................................................... 35

Figure 7: Schematic Representation of the Damping System .................................... 37

Figure 8: Exhaust Pulsation Damper ............................................................... 38

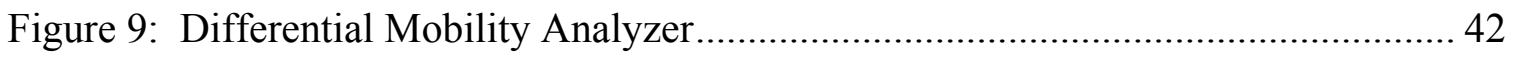

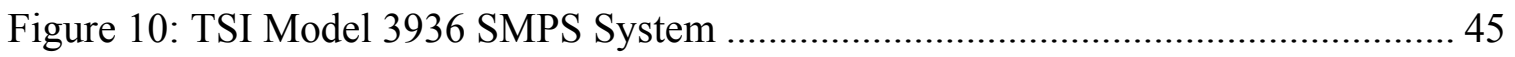

Figure 11: Target Speed Trace for CREEP Mode ................................................... 53

Figure 12: Target Speed Trace for TRANSIENT Mode ............................................ 54

Figure 13: Target Speed Trace for CRUISE Mode .................................................. 54

Figure 14: Target Speed Trace for HIGH SPEED CRUISE Mode ............................... 55

Figure 15: Particle Size Distribution for CRC 39 Operating on an Idle Mode................ 58

Figure 16: Particle Size Distribution for CRC 39 Operating on Various Steady Cycles . 59

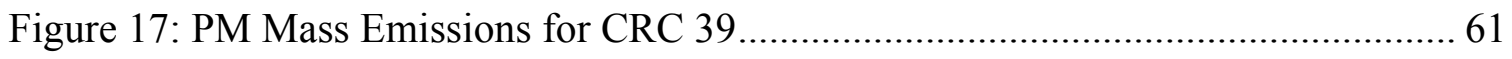

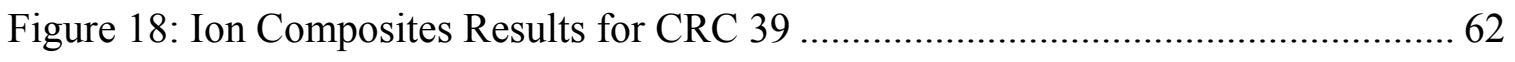

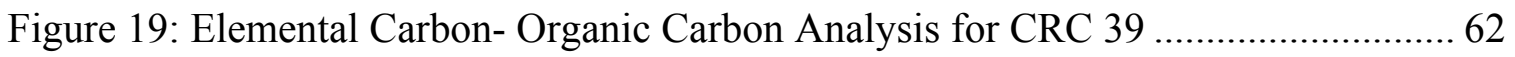

Figure 20: Particle Size Distribution for CRC 40 Operating on an Idle Mode................. 63

Figure 21: Particle Size Distribution for CRC 40 Operating on Various Steady Cycles . 64 


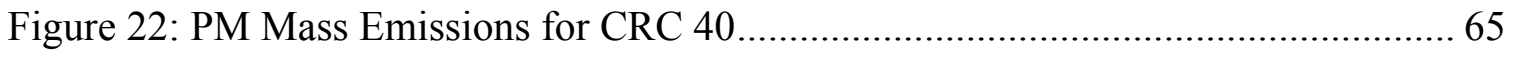

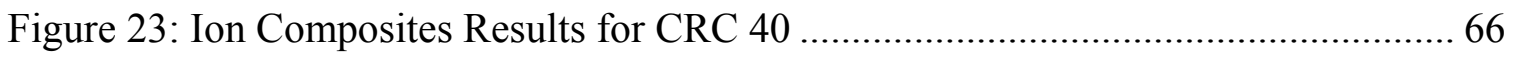

Figure 24: Elemental Carbon- Organic Carbon Analysis for CRC 40 ............................. 66

Figure 25: Particle Size Distribution for CRC 42 Operating on an Idle Mode.................. 67

Figure 26: Particle Size distribution for CRC 42 operating on various steady cycles...... 68

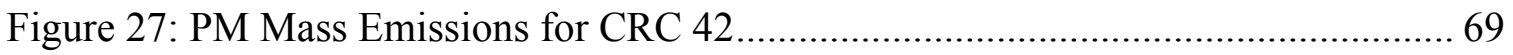

Figure 28: Ion Composites Results for CRC 42 ……………................................... 70

Figure 29: Elemental Carbon- Organic Carbon Analysis for CRC 42 ........................... 70

Figure 30: Particle Size Distribution for CRC 43 Operating on an Idle Mode................. 71

Figure 31: Particle Size Distribution for CRC 43 Operating on Various Steady Cycles . 72

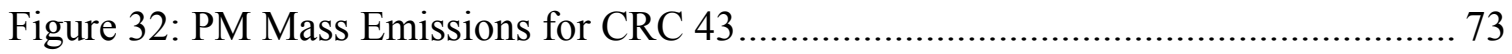

Figure 33: Ion Composites Results for CRC 43 ……………………….................... 74

Figure 34: Elemental Carbon- Organic Carbon Analysis for CRC 43 ............................ 74

Figure 35: Particle Size Distribution for CRC 44 Operating on an Idle Mode................. 75

Figure 36: Particle Size Distribution for CRC 44 Operating on Various Steady Cycles . 76

Figure 37: PM Mass Emissions for CRC 44.............................................................. 77

Figure 38: Ion Composites Results for CRC 44 .......................................................... 78

Figure 39: Elemental Carbon- Organic Carbon Analysis for CRC 44 ............................. 78

Figure D1: VOC Results (C2 to C5 Alkanes) for CRC 39 .......................................... 123

Figure D2: VOC Results (C2 to C5 Olefins) for CRC 39 .......................................... 123

Figure D3: VOC Results (C6 and higher alkanes) for CRC 39 ……............................ 124

Figure D4: VOC Results (C6 and higher olefins) for CRC 39 ..................................... 124

Figure D5: VOC Results (Aromatics) for CRC 39 ……….......................................... 125 


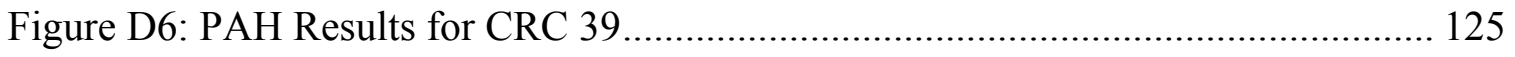

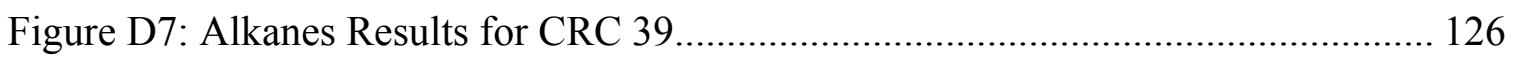

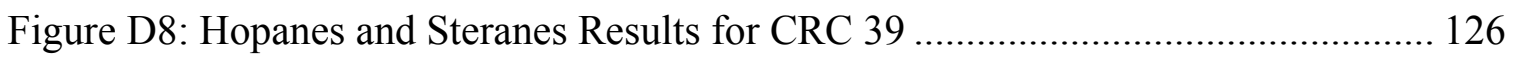

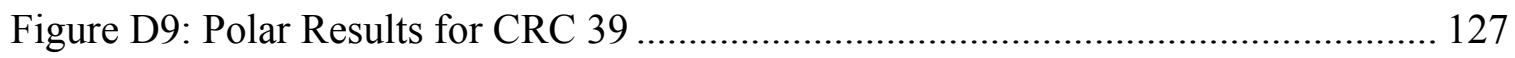

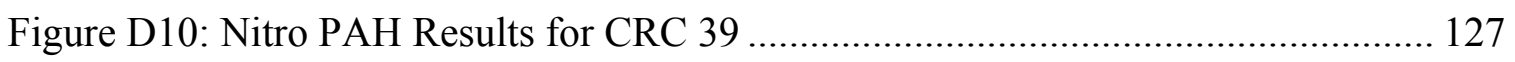

Figure D11: Carbonyl Results for CRC 39.......................................................... 128

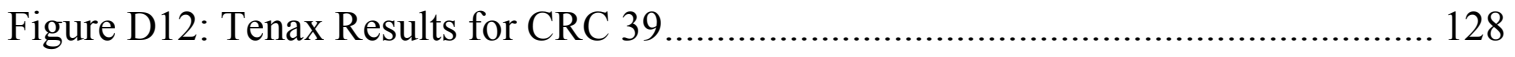

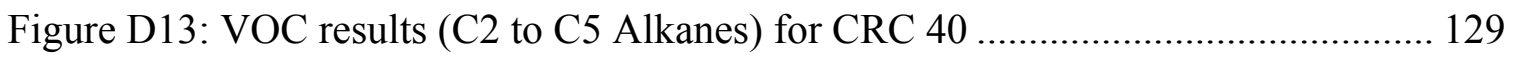

Figure D14: VOC results (C2 to C5 Olefins) for CRC 40........................................... 129

Figure D15: VOC Results (C6 and higher Alkanes) for CRC 40 .................................. 130

Figure D16: VOC Results (C6 and higher Olefins) for CRC 40 …….......................... 130

Figure D17: VOC Results (Aromatics) for CRC 40 ……………………………....... 131

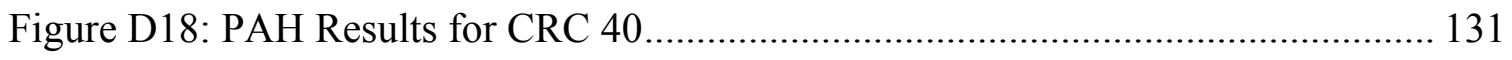

Figure D19: Alkanes Results for CRC 40.......................................................... 132

Figure D20: Hopanes and Steranes Results for CRC 40 ............................................. 132

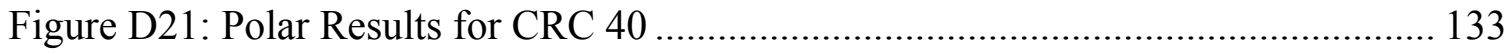

Figure D22: Nitro-PAH Results for CRC 40 .............................................................. 133

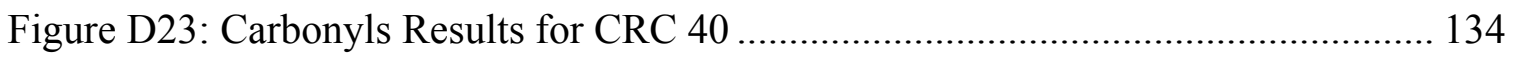

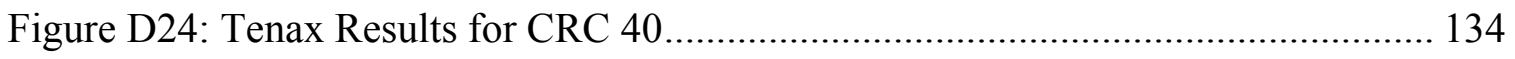

Figure D25: VOC Results (C2 to C5 Alkanes) for CRC 42 ........................................ 135

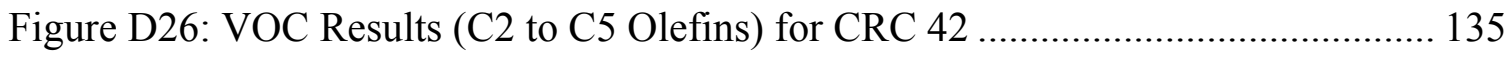

Figure D27: VOC Results (C6 and Higher Alkanes) for CRC 42 …............................ 136

Figure D28: VOC Results (C6 and Higher Olefins) for CRC 42 .................................. 136 
Figure D29: VOC Results (Aromatics) for CRC 42 ………........................................ 137

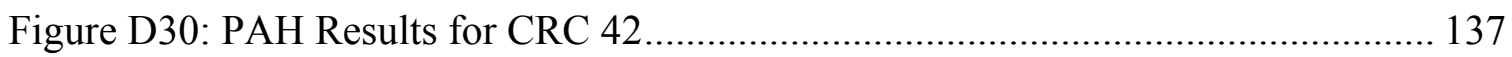

Figure D31: Alkanes Results for CRC 42 ........................................................ 138

Figure D32: Hopanes and Steranes Results for CRC 42 ............................................ 138

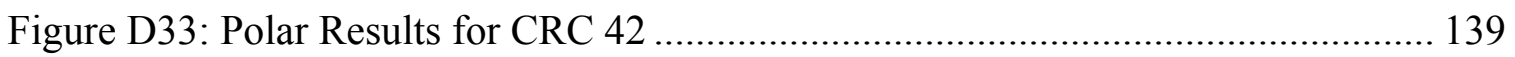

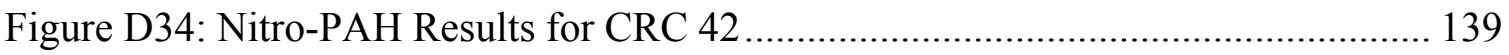

Figure D35: Carbonyl Results for CRC 42 ........................................................... 140

Figure D36: Tenax Results for CRC 42 ................................................................ 140

Figure D37: VOC Results (C2 to C5 Alkanes) for CRC 43 ......................................... 141

Figure D38: VOC Results (C2 to C5 Olefins) for CRC 43 .......................................... 141

Figure D39: VOC Results (C6 and higher Alkanes) for CRC 43 ................................ 142

Figure D40: VOC Results (C6 and higher Olefins) for CRC 43 .................................. 142

Figure D41: VOC Results (Aromatics) for CRC 43 ………....................................... 143

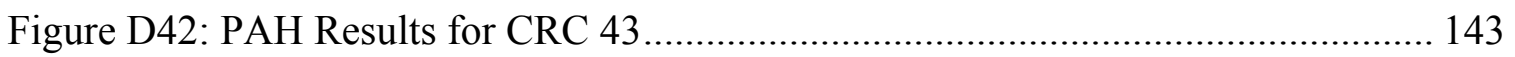

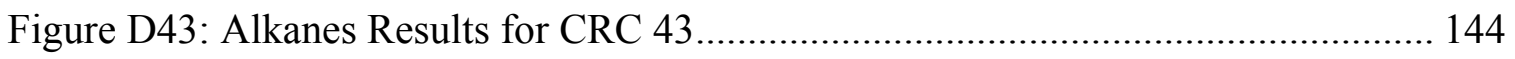

Figure D44: Hopanes and Steranes Results for CRC 43 ............................................. 144

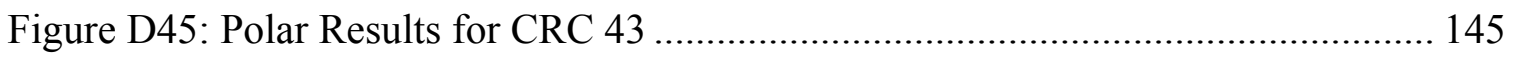

Figure D46: Nitro PAH Results for CRC 43 ............................................................ 145

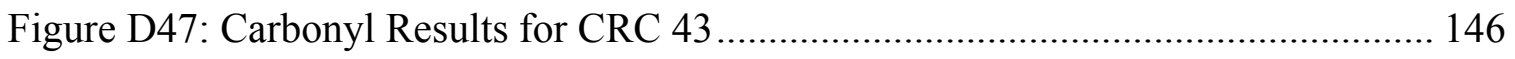

Figure D48: Tenax Results for CRC 43 .................................................................. 146

Figure D49: VOC Results (C2 to C5 Alkanes) for CRC 44 .......................................... 147

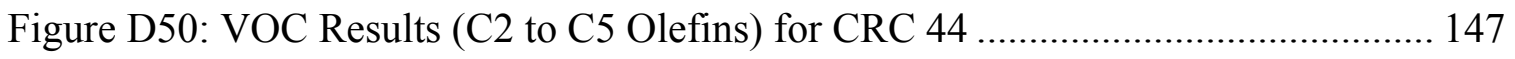

Figure D51: VOC Results (C6 and higher Alkanes) for CRC 44 .................................. 148 
Figure D52: VOC Results (C6 and higher Olefins) for CRC 44 ............................ 148

Figure D53: VOC Results (Aromatics) for CRC 44 ................................................ 149

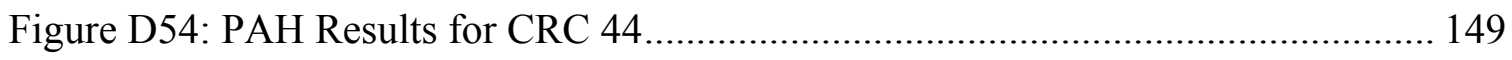

Figure D55: Alkanes Results for CRC 44 ........................................................ 150

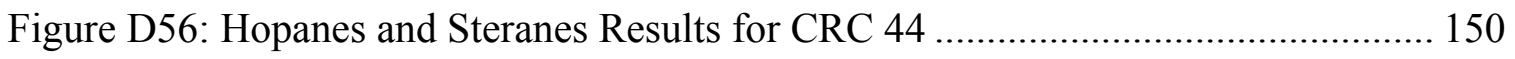

Figure D57: Polar Results for CRC 44 ............................................................ 151

Figure D58: Nitro-PAH Results for CRC 44 ....................................................... 151

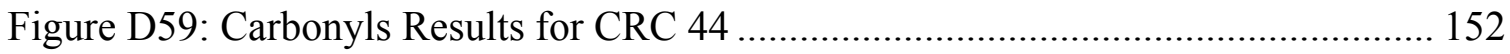




\section{INTRODUCTION}

Particulate Matter or simply PM is defined by the EPA as the material that collects on a filter in a stream of exhaust that is cooled and diluted below $52^{\circ} \mathrm{C}\left(125^{\circ} \mathrm{F}\right)$. This material collected, comprises of solid carbonaceous particles, solid insoluble particles and volatile compounds is collectively known as Total Particulate Matter (TPM). Particles are formed in diesel engines as a result of incomplete combustion of fuel, fuel and lubricating oil additives and lubricating oil combustion. Particles emitted from diesel engines typically consist of $41 \%$ carbon, $7 \%$ unburnt fuel, $25 \%$ unburnt oil, $14 \%$ sulfates and water and finally $13 \%$ of ash and other metallic compounds [2]. The fraction which contains unburnt fuel and lube oil is termed as Soluble Organic Fraction (SOF). According to Kittelson [2], the SOF varies with engine design and operating condition and the values are highest when engine load is low. This can be attributed to the fact that at low engine loads, the sealing between the piston ring and the cylinder wall is not very effective due to lower in-cylinder pressure. As the load increases, the cylinder pressure increases which help in sealing the compression ring. The design of the piston compression ring can be changed to accommodate an increase in initial ring pressure which can lead to proper sealing at low loads, but at higher loads ring pressure increases and may cause higher friction and a subsequent drop in engine power output. Alternatively, a nominal ring pressure can be maintained and aftertreatment devices like particulate traps and oxidation catalysts can help reduce such emissions.

Exhaust particles undergo a dramatic change in composition and subsequently, size as they are diluted in the atmosphere. There are three basic modes in which particles 
form and grow in the atmosphere, nuclei mode, accumulation mode and coarse mode [2]. Particles are also broadly classified according to their size. Particles below $2.5 \mu \mathrm{m}$ are considered as fine particles, below $100 \mathrm{~nm}$ are ultrafine particles and below $50 \mathrm{~nm}$ are nanoparticles. Current emission regulation standards for particulate emissions are mass based. Engine manufacturers have been improving engine technology to meet current emission standards. Recent studies $[2,6,9]$ have shown that new engines emit lower levels of PM mass emissions, but the number concentrations of nanoparticles is significantly higher. Nanoparticles do not contribute towards the total mass of emitted PM. Health effects studies $[12,14,15,16]$ have shown that deposition of particles inside the lung increases with decrease in particle size and the toxicological effects of ultrafine and nanoparticles are more profound than particles of larger size. Nanoparticles are deposited in the alveolar region of the lungs where gas exchange takes place.

Usually cilia present in the lungs help in frequent removal of foreign particles that deposit. Removal of these particles from the alveolar region is very difficult since the alveolar region is the only non-ciliated portion in the lungs. Nanoparticles from diesel engines mostly contain organic compounds which are highly carcinogenic in nature [11, 18]. Nanoparticles provide large surface area which leads to generation of oxidants due to the free radical effect and can lead to cell inflammation [18]. Due to these major health effects, it is important to study the formation, chemical composition and size distribution of particles emitted from diesel fueled vehicles operating under different driving conditions.

This study is a part of a large project (E55/59) funded by the department of energy (DOE) and the coordinative research council (CRC) for collecting and archiving 
emission profiles from various heavy-heavy duty diesel trucks operating in California. The vehicles tested for this study were selected by CRC based on engine model year and manufacturer. For the first phase of the project, twenty five heavy-heavy duty diesel vehicles were tested for regulated emissions out of which the first three vehicles were tested for both regulated and unregulated emissions. For the second phase of this project, twelve heavy-heavy duty vehicles and one medium duty vehicle were selected, out of which the first five heavy-heavy duty vehicles were tested for regulated and unregulated emissions. Particle sizing data were obtained for all the five vehicles. Results obtained for the first five vehicles from phase two of the project are discussed in this study. 


\section{LITERATURE REVIEW}

Air pollution in general has been the major focus of all environmental and health related studies for a long time. One of the major sources of air pollution is engines, either stationary or mobile. Emissions from engines can be broadly classified into two, gaseous emissions and particulate emissions. Regulatory bodies all around the world have been attempting to curtail these emissions by imposing laws which require engine and vehicle manufacturers to reduce emissions according to the set standards. Engine and vehicle manufacturers are modifying existing designs or using exhaust aftertreatment devices to comply with the current and also future emission standards. Engines emit various toxic gases and particles, of which carbon dioxide, carbon monoxide, oxides of nitrogen and total particulate matter (TPM) are being regulated and are termed as regulated emissions. These emissions are measured in accordance with the requirements of the Code of Federal Regulations [1]. Engine manufacturers look towards better and cleaner burning fuel like ultra-low sulfur diesel, biodiesel and also alternative fuels like compressed natural gas $(\mathrm{CNG})$ and liquefied natural gas (LNG) to comply with emission regulations. Engine design has also undergone major modifications with the introduction of computer controlled ignition, injection and throttle control. Engines with these technologies comply with current regulations with respect to regulated emissions.

Particulate matter emissions are mass based, that is, exhaust material is collected on a filter and weighed with a microbalance. According to recent studies [1] although new engines comply with emission regulations in terms of mass, in terms of number they emit very high concentrations of particles especially in the range below $100 \mathrm{~nm}$. These particles do not contribute much towards mass, but contribute significantly towards 
number concentrations. Particles below 100nm are termed as ultrafine particles, and particles below $50 \mathrm{~nm}$ are nanoparticles. The properties, composition, formation, health effects and reduction of such particles are discussed in the following sections in this chapter.

\subsection{Properties and Composition of Diesel Exhaust Particles}

Diesel exhaust particles mostly contain solid carbonaceous particles or soot; inorganic ash formed from burning lubrication oil, sulfates from oxidation of sulfur in diesel and volatile organic compounds from unburnt fuel and evaporated lube oil [2]. Measurement from diesel exhaust reveals particles mostly in the agglomeration range, that is, particles above 50nm and below 100nm in size. Agglomerated particles mostly contain a solid carbonaceous core onto which volatile organic compounds adsorb as soon as the exhaust is diluted and cooled in the atmosphere. Nanoparticles mostly contain nuclei mode particles which are typically below $50 \mathrm{~nm}$ in size. These particles are mostly made up of volatile compounds such as hydrocarbons, sulfuric acid and sulfates which self-nucleate to form particles. Composition of nanoparticles varies depending on dilution conditions, such as dilution temperature, humidity and presence of carbonaceous particles. Presence of carbonaceous particles is very important since nucleation is not favored when there are particles to adsorb on.

Earlier work by Kittelson [3] showed that most of the materials in the nuclei mode were volatile and mostly consisted of soluble organic fractions (SOF). A catalytic stripper was used for real time measurement of volatile particles. This catalyst was designed to remove all the volatile compounds from the exhaust stream without any removal of solid particles. Comparisons were made between the bypass stream which 
contained all of the SOF's and carbonaceous particles and the stripped stream with only solid particles to determine the total concentration of the volatile matter. The design of the catalytic stripper was simple containing two basic components, a small section of a catalyst from a diesel catalytic converter placed inside a heated stainless steel tube and a copper cooling coil to cool down the stream before it is sampled by the instruments. Tests were conducted on a diesel engine and the results showed that the total particle volume distribution in the diesel engine was bimodal, a nuclei mode in the range of 30 to $50 \mathrm{~nm}$ and an accumulation in the range of $150 \mathrm{~nm}$. The non-volatile distribution had little volume in the nuclei mode which suggests that nuclei mode particles mostly contain volatile materials.

The catalytic stripper is not a very accurate method to determine the exact concentration of the volatile materials since the stripper suffers from particle losses due to thermophoresis in the cooling tube downstream of the catalyst. Thermophoresis is the movement of aerosol particles due to a temperature gradient. The exhaust stream from the stripper is very hot and is subjected to sudden cooling by a cooling coil. Particles have a net motion towards the cooler wall of the coil where they get deposited, and this is a major cause for particle loss. To determine the actual concentration of volatile particles, a particle trap can be used in the exhaust stream to remove all the solid particles and the exhaust will only be left with volatile particles. Mayer et al. [4] have compared efficiencies for different particulate trap systems and a thermal denuder was used to differentiate solid particles from the volatile particles. The thermal denuder has two sections, one in which the gas is heated to approx $100^{\circ} \mathrm{C}\left(212^{\circ} \mathrm{F}\right)$ to evaporate the condensates and the other section contains activated carbon to adsorb the volatile 
particles and only let solid particles through. Particle losses are reduced through this method. Measurements were performed with and without the thermal denuder and the results indicate that nuclei mode particles contain mostly volatile compounds.

Baumgard [5] conducted tests on diesel engines with different fuels and varying model year to show the effect of fuel and engine design on particle size distribution. Two Cummins 10 liter engines, model year 1991 and 1988 were used for this study. Low sulfur (LS), conventional sulfur (CS) and doped sulfur (DS) diesel were used as fuel. The significant differences between these fuels were the percentage of sulfur in each grade. Aftertreatment devices were used on both engines. The 1991 engine had an oxidation catalyst and the 1988 engine had a ceramic particle trap. The results suggest that the number of nuclei mode particles formed from the 1988 engine while using CS and SD fuels were two orders of magnitude higher than while using LS fuel and the nanoparticles were mostly made up of sulfates and sulfuric acid particles. Comparison between the two engines tested with low sulfur (LS) fuel showed an increase of nuclei mode particles and a decrease in the accumulation mode particles for the 1991 engine equipped with an oxidation catalyst, suggesting that nanoparticles for the 1991 engine are mostly made up of solid carbon particles. Both engines were tested with and without the aftertreatment devices, which made no significant difference in the nanoparticle emission and the change in the composition can only be attributed to the difference in engine design between both the model years.

To measure real time PM formation from a heavy duty diesel truck exhaust, Gautam et al. [6] have conducted tests on a class-8 heavy duty diesel truck in a full-scale wind tunnel. The truck was mounted on a chassis dynamometer to load the engine during 
the steady state and transient runs. The full scale wind tunnel provided a steady headwind without any crosswinds to facilitate a steady exhaust plume formation. A preliminary study was conducted by measuring $\mathrm{CO}_{2}$ concentrations downstream of the exhaust, to determine the exhaust plume dispersion and the centerline of the exhaust plume. To maintain a steady $\mathrm{CO}_{2}$ concentration level throughout the preliminary study, the vehicle operated under a steady-state mode at $88.5 \mathrm{kmph}(55 \mathrm{mph})$ with a steady wind speed of $88.5 \mathrm{kmph}(55 \mathrm{mph})$ in the wind tunnel. Four locations were fixed downstream of the exhaust plume to measure particle sizing data. Particle size and concentration were measured using a scanning mobility particle sizer (SMPS). The SMPS was located inside a three axes gantry mounted container which enabled the SMPS to measure real time three dimensional particle sizing data.

Steady state modes at $88.5 \mathrm{kmph}(55 \mathrm{mph})$ were executed and the SMPS measured particle size distributions at the four fixed locations of the exhaust plume. For transient size distribution measurements, the SMPS was fixed to measure time varying concentration of one particle size of interest. Particle sizes which were fixed for the transient tests ranged from $12 \mathrm{~nm}$ to $300 \mathrm{~nm}$. Particle size distributions were measured even during idle mode operations. Background data was measured by another SMPS at a fixed location. No significant variation of particle size distributions were noted for the steady state modes, with a geometric mean diameter measured between 54 to $58 \mathrm{~nm}$. These particles measured during the steady state are mostly in the accumulation mode. Background data was also verified to ensure that background PM did not contribute to the accumulation mode formation during the steady state. 
Increased PM concentration was evident during vehicle acceleration of the transient test. The $65 \mathrm{~nm}$ particle dominated the count of the particle sizes selected for transient tests. Mostly accumulation mode particles were noted for steady state and transient runs. Under the idle mode operation, nuclei mode particles were measured with geometric mean diameter varying from 14 to $24 \mathrm{~nm}$. Lower exhaust stack temperatures and higher organic compound formation during the idle mode could be the reason for the formation of nuclei mode particles. No significant nuclei mode formation was noted during the steady state and transient operation. This could be attributed to the lower incylinder pressures during the idle mode and the lowered effectiveness of the oil-control ring leading to the combustion of lubrication oil. The products of partial combustion of lubrication oil during the idle mode could lead to the formation of nanoparticles in the exhaust.

To differentiate between the vapor phase and the particle phase of the exhaust, Gratz et al. [7] have conducted tests on a 1988 Cummins LTA10 heavy duty diesel engine with and without an un-catalyzed ceramic particulate trap and the particle size distribution was measured using an Electrical Aerosol Analyzer. Two steady state modes were executed in an engine dynamometer test cell to quantify emissions. Particle distribution data revealed the presence of both the nuclei mode and accumulation mode particles. The nuclei mode particles were more prominent downstream of the trap probably due to the nucleation of hydrocarbon particles during dilution, which typically cools the exhaust stream to increase the saturation ratio leading to homogenous nucleation. Without the trap, the accumulation particles were more prominent indicating 
the presence of carbonaceous particles and the reduction of nuclei mode particles due to the adsorption of volatile compounds onto the solid carbon particles.

Abdul-Khalek and Kittelson [8] suggested the presence of calcium from lube oil in the nanoparticle range. Steady state tests on an engine dynamometer were conducted on a Perkins T4.4 diesel engine which was equipped with a catalytic converter and fueled using low sulfur diesel. Particle size distribution from every test indicated that it was bimodal in nature. Chemical equilibrium calculations were run using FLAME, NASA's engineering utility software to determine the outcome of burning lube oil in the engine. Formation of calcium compounds was found to be very prominent during the expansion stroke. Lube oil typically contains high concentrations of calcium followed by zinc and magnesium. The final result suggested that lube oil which is burnt along with the main fuel, gives rise to calcium in a gas phase. When the exhaust is diluted and cooled, the calcium in the gas phase nucleates and forms particles which are typically inorganic ash and are measured as nanoparticles.

Hall et al. [9] have compared the particle size distributions from two heavy duty engines operating on three different diesel fuels. The mass distributions were measured using a berner low pressure impactor with ten stages, the minimum cut off size being $16 \mathrm{~nm}$. The particle number distributions were measured using an SMPS. Two engines with Euro 2 and 3 technologies were selected for comparison purposes. Three diesel fuels D1, D2 and D3 were selected to represent the commercial fuels available throughout Europe. D1 had sulfur content of $498 \mathrm{mg} / \mathrm{Kg}$; D2 was lower with $418 \mathrm{mg} / \mathrm{Kg}$ and the least sulfur content being D3 with less than $1 \mathrm{mg} / \mathrm{Kg}$ sulfur content. Particulate emissions were measured using a full flow dilution tunnel with a secondary dilution stage. 
Each engine was tested with two European regulated cycles and five extended mode cycles. Each engine was run with all three fuels and tests were duplicated to check for repeatability. The effect of dilution ratio was investigated and the accumulation mode particles were found to be insensitive to changes in the dilution ratio and the nucleation mode particles increased with increase in dilution ratio. The effect of residence time on the particle distributions were also studied by using a plenum after the secondary dilution tunnel. The plenum was used to increase the residence time of the aerosol which usually helps in the condensation of vapors on the nuclei mode particles and agglomeration of small particles. The accumulation mode particles were less sensitive to dilution ratio and residence time, but these parameters had a great effect on particles less than $30 \mathrm{~nm}$. Particle size distributions have shown a clear bimodal distribution for all runs with a clear split between the nucleation mode and the accumulation mode. The accumulation mode particles did not vary a lot between the three fuels, but the nucleation mode particles were significantly lower for D3 fuel due to low sulfur content. The same variation was not noted with the mass distribution since the nucleation mode particles do not contribute much towards mass emissions.

Lev-On et al. [10] conducted a detailed chemical characterization of exhaust particulate matter from several heavy-duty diesel engines. Two CNG transit buses and four diesel powered vehicles were tested on a chassis dynamometer and the exhaust was diluted by a full-flow CVS dilution system. For the diesel powered vehicles, four different grades of diesel fuel were used to evaluate and characterize the effect of fuel and sulfur content on exhaust emissions. CARB, ECD, ECD-1 and Fischer-Tropsch (F-T) diesel fuels were the four different fuels used, with CARB containing the highest sulfur 
content $(114.5 \mathrm{ppm})$ and F-T fuel containing the lowest $(<1.0 \mathrm{ppm})$. Each vehicle was subjected to a specific test cycle depending upon the vehicle utility. The city suburban heavy vehicle route (CSHVR) was executed for the school buses and grocery trucks and the central business district (CBD) cycle was executed for the transit buses. A very thorough sampling train was set up for chemical speciation. Two $\mathrm{PM}_{2.5}$ cyclones were used with Teflon and pre-fired quartz filters for elemental analysis and elemental carbon/organic carbon (EC/OC) analysis respectively. One $\mathrm{PM}_{10}$ cyclone was used with a glass fiber filter for gravimetric analysis. Particulate and semi-volatile organic compounds (SVOC) were collected using a TX-40 70mm filter followed by polyurethane foam (PUF) in combination with polystyrene-divinylbenzene resin (XAD-4) in PUF/XAD-4/PUF cartridges. Carbonyl compounds present in the exhaust were collected by drawing the exhaust sample through a cartridge impregnated with acidified 2, 4dinitrophenylhydrazine (DNPH). Volatile Organic Compounds (VOC) were sampled in tedlar bags. All chemical analysis was conducted off-site except for VOCs since 1, 3butadiene and the other olefinic Non-Methane Hydrocarbons (NMHC) are unstable if stored for a prolonged period of time. VOCs were sampled on-site using a gas chromatograph-mass spectrometer (GC-MS) system.

When comparing total particulate matter for all the vehicles, a $40 \%$ reduction in total PM was noted for the ECD-1 fuel when compared to CARB fuel. Further TPM reductions of $65 \%-85 \%$ were noted for emission results from vehicles running on either ECD or ECD-1 retrofitted with Johnson-Matthey's diesel particulate filter $\left(\mathrm{CRT}^{\mathrm{TM}}\right)$. Elemental analysis results were split into lubrication oil elements and engine wear elements. For all the runs with vehicles retrofitted with Engelhard's diesel particulate 
filter $\left(\mathrm{DPX}^{\mathrm{TM}}\right)$, sulfur emissions were a large portion of the particulate bound elements. Elements typically associated with engine wear such as iron, copper and lead were reduced with the use of a DPX. For the transit bus emissions, CARB diesel fueled vehicles presented a high level of sulfur content. Sulfur emissions were reduced by the use of ECD and ECD-1 fuels. These emissions were further reduced by retrofitting the vehicles with a CRT. Sulfur emissions were noted to be higher for vehicles retrofitted with the DPX rather than vehicles retrofitted with a CRT. The difference in sulfur emissions illustrates the different control strategies employed by the diesel particulate trap manufacturers. The particulate trap equipped transit buses and the CNG buses had the lowest $\mathrm{EC} / \mathrm{OC}$ emissions. For vehicles not equipped with a particulate filter, approximately $85 \%$ the particulates collected on the filter were elemental carbon. For the CNG transit buses, approximately $90 \%$ of the particulates collected contained organic carbon. The diesel particulate filters reduced benzene and BTEX emissions to very low levels. This study highlights the effectiveness of using a low sulfur diesel fuel combined with a particulate trap to reduce elemental and organic emissions to manageable levels.

Kweon et al. [11] conducted a detailed study of the chemical composition of a single cylinder diesel engine exhaust. In addition to chemical analysis, particle size distribution was also compared. The engine used was a Cummins N-14 series single cylinder diesel engine. A full-flow dilution system was used to simulate dilution conditions and a secondary dilution system with a residence time chamber was used to allow sufficient time for the condensation process to take place. Speciation samples were collected on seven different filters through two $\mathrm{PM}_{2.5}$ cyclones. The first sampling train consisted of three Teflon membrane filters and a quartz filter. The first Teflon filter was 
used for $\mathrm{PM}_{2.5}$ gravimetric analysis and analyzed for sulfate ions. The second was used as a check on the first filter. The third Teflon filter was used for analysis of trace metals. The quartz filter was used for elemental carbon/organic carbon analysis. The second sampling train used three sets of quartz filters followed by polyurethane foam (PUF) cartridges. The particle-phase organic compounds are analyzed from the quartz filters and the PUF cartridges are analyzed for semi-volatile organic compounds. The engine was exercised through a CARB 8 mode test on an engine dynamometer. The CARB 8 mode test ranges from light load at low speed to high load at high speed. The engine was run on low sulfur diesel fuel (352 ppm) throughout the study. Effects of operating conditions on the chemical compounds and particle size distributions were studied which yields useful information on the source of nuclei mode particles. The elemental carbon increased with an increase in engine load and the effect was inverse with the organic carbon. When comparing particle size distributions, the median particle diameter shifted towards the nuclei mode range with a decrease in engine speed. The particle size increased linearly towards the larger size range with the increase in load of the engine. The shift towards the nuclei mode and the increase in organic compounds with decreasing engine load suggest that the nuclei mode particles are mostly made up of organic material. As the injection pressure was increased for a particular load, the specific organic compounds decreased along with a shift towards a larger particle size. The effect of injection pressure on the organic carbon emission and particle size distribution confirm the fact that nuclei mode particles are mostly organic compounds. 


\subsection{Health Effects of Diesel Particles}

The hazard caused by nanaoparticles due to inhalation depends on the chemical composition of the particle and the region of deposition in the lungs [12]. The respiratory system is divided into three parts. The nose, mouth and pharynx make up the first part collectively known as head airways region, the region from the trachea to the bronchioles is the tracheobronchial region which is the second part and finally the terminal bronchioles which is known as the alveolar region where gas exchange takes place. Figure 1 shows the major anatomical features of the human respiratory system.

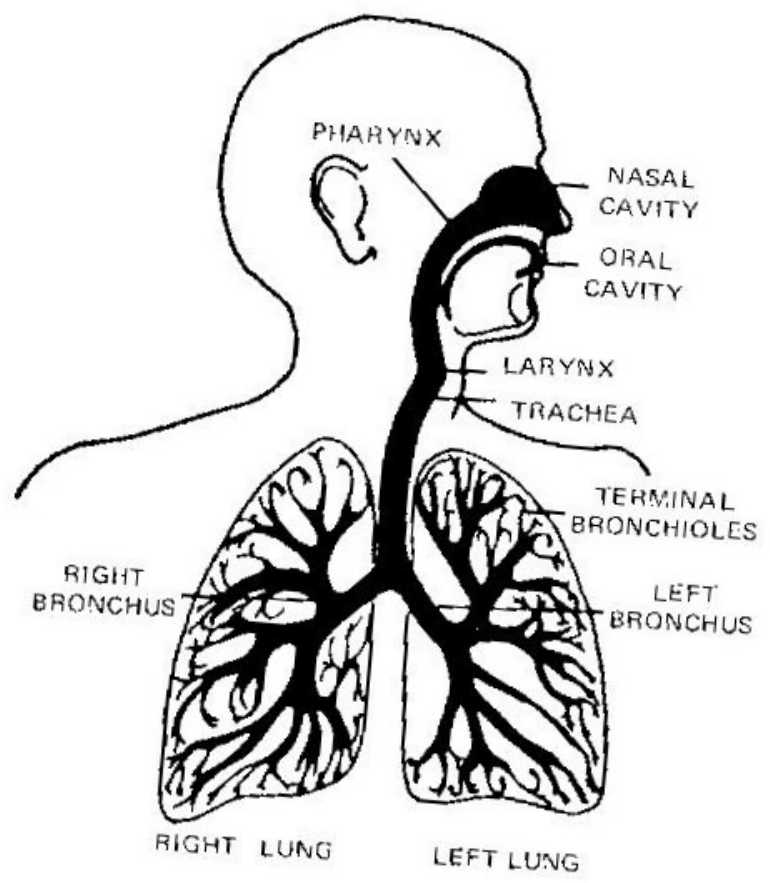

Figure 1: The Major Anatomical Features of the Human Respiratory System [14]

As particles are inhaled, they are deposited in these regions depending upon the size of the particle. Hinds [12] explains the various deposition theories and deposition 
models used to determine which particle size range is respirable and which size has the maximum penetration capability. From various models presented, it was clear that particles in the nanometer range around $10 \mathrm{~nm}$ had maximum deposition in the alveolar region [12]. Cheng et al. [13] have studied the deposition of ultrafine particles in the nasal and tracheobronchial airways using airway replica casts and sodium chloride aerosol particles. Human volunteer studies were conducted to verify the results from the replica. The results from the volunteer study and from the replica study were very similar suggesting that the deposition increased as the particle size decreased. Deposition in the alveolar region is of prime importance since it is the only non-ciliated portion of the lungs. Cilia are very helpful in removing particles from the lungs and act as a natural cleaning system for the lungs. The alveolar region is void of this cleaning system because gas exchange takes place in this region. When particles are deposited in these regions, inflammation and other respiratory effects occur. Figure 2 provides a schematic representation of the terminal bronchiole or the alveolar region.

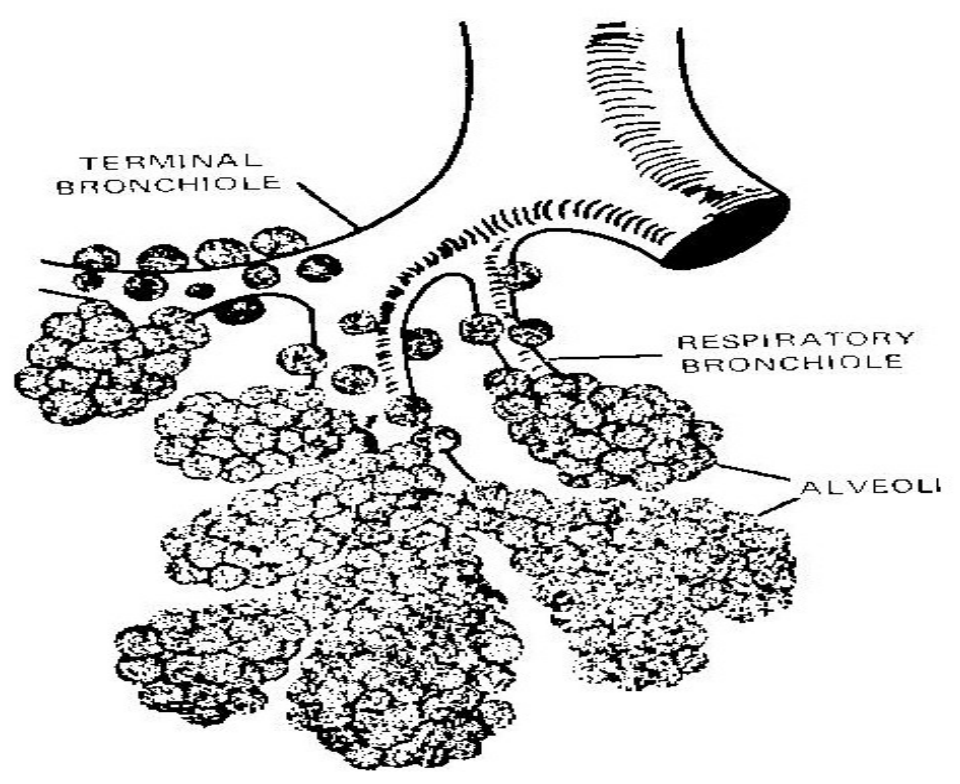

Figure 2: Schematic of the Alveolar Region [14] 
Various factors have been discussed regarding the clearance of particulate matter from the respiratory system [14]. The rate of deposition depends on the size of the particles, site of deposition and the chemical composition of the particles. The most important factor for the removal of any foreign particles in the lungs is the pathological response [14]. Particle-lung cell interactions have been studied [15] to observe the clearance mechanism by macrophages in removing particles from the alveolar region. Macrophages are the only defense and clearance mechanism in the alveolar region and the failure to do so results in serious consequences. The macrophages engulf the particle minimizing the interaction with the epithelium. The epithelium is the layer of cells which constitute the alveoli region. This layer is surrounded by capillaries which transport blood and exchange gases with the alveolar region. After the macrophage engulfs the particle, it migrates to the ciliary part of the lung where it leaves the lung along with other particles. This system is sometimes interrupted by toxic particles or overloading of particles, when this occurs particles transfer to the capillary or transfer to the lymph nodes which leads to inflammation, fibrosis and cancer in the long term.

Carbon particle as such do not present itself as a toxic material. High concentrations of carbon particles in the ultrafine range (particles below 100nm) have shown cell inflammation in rats due to overloading and oxidative stress [16]. Ultrafine particles have a large surface area and the macrophages try to engulf each particle and remove it from the alveolar region. When concentrations increase the macrophages work hard to remove these particles and this leads to overlaoading. Particles which are not removed, interact with the epithelial layer and leads to epithelial oxidative stress, permeability and injury. Oxidative stress is primarily caused by the free radical effect of 
ultrafine particles. Free radical is an atom with an unpaired electron. Free radicals are not very stable and collide with other molecules removing electrons from it to start a chain reaction. This chain reaction occurs in matter of nanoseconds and destruction of cells is the end result of such a reaction. Chronic bronchitis, cystic fibrosis, emphysema and asthma are the major lung disorders affecting people in the United States due to inhalation of ultrafine particles [17]. Toxicological studies of particulate matter are of prime importance due to the various chemical compounds present in diesel exhaust out of which Polynuclear Aromatic Hydrocarbons (PAH) are a suspected carcinogen [17]. Benzo-a-pyrene (BaP), one of the PAH compounds is suspected to be a known carcinogen. Benzo-a-pyrene is chemically stable and is usually present in their free state or adsorbed onto soot particles. The PAHs cannot be removed from the surface of very small particles. Particles less than $0.04 \mu \mathrm{m}$ will remove these compounds due to their high surface adsorption and particles greater than $0.04 \mu \mathrm{m}$ releases these compounds in presence of solvents like cytoplasmic proteins. Laboratory tests [14] have indicated that a high dose of BaPs could induce various malignant tumors in the lungs when combined with the inhalation of $\mathrm{SO}_{2}$. Mutagenic potential of particulate matter from diesel engines has been studied [14] and large particles were seen to exhibit larger mutagenic response than small size particles due to the reduced mutagenicity in regards to soluble organic fraction content. The same effect is also described in a different study [14] which shows that particles of sizes greater than $0.04 \mu \mathrm{m}$ release PAHs in greater extent and depending on the particle size, the adsorbates are released into the macrophages or onto the epithelium. 


\subsection{Nanoparticle Formation and Reduction Strategies}

Naoparticles are not necessarily emitted from the engine. These particles are formed during the dilution process which takes place as soon as the exhaust exits the stack. Studies have shown that most of the nanoparticles are made up of volatile organic compounds and some metallic additives $[2,3,5,6,7,10]$. Volatile organic and sulfur compounds are transformed to diesel particulate matter during dilution by nucleation, adsorption and condensation [19]. Homogenous nucleation is the formation of particles when the vapor is supersaturated. Supersaturation occurs when the saturation ratio reaches unity or greater. Saturation ratio is the ratio of partial pressure of vapor to the saturation vapor pressure in a system [12]. Partial pressure is defined as "The pressure that a gas or vapor in a mixture of gases would exert if it were to occupy the entire volume all by itself" [12]. The saturation pressure or the vapor pressure is the pressure required to maintain the vapor in its state at a particular temperature. When the temperature of the surrounding vapor drops, the vapor pressure also drops which increases the saturation ratio. Volatile organic compounds in the diesel exhaust reach supersaturation as soon as it's cooled and diluted by the atmosphere. This supersaturation leads to homogeneous nucleation and the formation of self-nucleated volatile particles with its size range being below $40 \mathrm{~nm}$. As far as dilution is concerned, laboratories try to simulate what happens in the atmosphere, but atmospheric dilution is of the order of a thousand which is very difficult to simulate. Researchers have tried simulating close to 1:1000 dilution ratios by using multiple stages of dilution [19].

Kittelson and Khalek [19] have studied the effect of dilution ratios in the formation of nanoparticles. A two stage micro-dilution system was constructed to 
simulate dilution conditions. The primary stage simulated dilutions up to 1:50 and the secondary about 1:60. A 1995 medium duty diesel engine with D2 diesel was used for this study. Particle size distributions were measured using a Scanning Mobility Particle Sizer (SMPS). Residence time was a major factor in the formation of nanoparticles. The concentrations of nanoparticles were found to vary by two orders of magnitude when the residence time was changed from 90 to $900 \mathrm{~ms}$. The concentrations also depended on the dilution temperature. At lower dilution temperatures, nanoparticles concentrations were higher because lowering the dilution temperature increases the saturation ratio and the volatile fraction tends to self nucleate and form particles. The concentrations of larger particles seem to have no effect regarding dilution temperature or residence time. Tests were also conducted with a particulate trap in place and the concentration of $10 \mathrm{~nm}$ particles were found to be higher downstream of the trap. Lubrication oil consumption was found to be closely related to nanoparticle emissions and lube oil could possibly be a major contributor towards nanoparticle emissions.

Mayer et al. [20] through a joint European project VERT have investigated various nanoparticle emission reduction strategies from diesel engines. The study highlights the fact that PM emission measurement by mass alone is not sufficient and number measurement techniques have to be standardized. Number measurement of emissions are very difficult to standardize since it is not a very linear process and changes could occur depending on various parameters like dilution ratio, temperature, humidity and residence time [19]. The influences of load and speed on particle number emissions are not very significant according to this study, but there is a significant reduction in the accumulation particles and increase in the nanoparticle emissions through engine design 
modifications. Engine manufacturers have incorporated changes in the engine design, such as high compression ratios, high injection pressures and shallow piston bowls. These changes have reduced mass emissions in engines but have increased the number emissions. The effect of fuel and the effect of cetane number and lower sulfur content were studied and there seem to be no effect of using special fuels in reducing nanoparticles. An oxidation catalytic converter was utilized to study its effect on particle emissions and it was concluded that the oxidation catalyst does not make any difference in the particle number emission which is contrary to most of the studies $[3,5,7]$ involving the reduction of nanoparticles using oxidation catalyst.

Particulate traps are used to effectively arrest large particles and deep bed filters are effective in eliminating fine particles. Comparisons of particulate traps have been done in various studies $[4,21]$ and the retention performances have been compared. Deep bed filters are found to be very effective in trapping particles down to $20 \mathrm{~nm}$ in contrast to surface filters which are only effective for particles greater than $100 \mathrm{~nm}$. Surface filters work well with high loading whereas the efficiency of deep bed filters tend to decrease with increased loading. Fuel additives have also played a major role in the reduction of particulate emissions. Three prominent additives available commercially are iron, cerium and copper. These additives are mixed with the fuel and during combustion, oxidize to produce a catalytic effect by adhering to the carbonaceous particles. The major problem facing fuel additives are the formation of oxides which increase the particle concentration in the nano range hence particulate traps should be used. The influence of fuel additives have also been studied by Kasper et al. [22]. Ferrocene, a common additive was found to reduce the formation of carbonaceous particles. The iron 
oxide formed may act as a catalyst onto which soot particles get deposited and finally oxidized in an oxygen rich region of the combustion system. Although soot formation and total particulate mass was found to reduce, number emissions especially in the ultrafine particle range were high. Fuel additives can be used to inhibit the formation of carbonaceous particles, but they have to be used in conjunction with particulate traps.

Schaberg et al. [23] studied the effect of different diesel fuels on the number and size distributions from heavy duty diesel engines. D2 diesel fuel was used as the baseline fuel and Fischer-Tropsch fuel was used for comparison. Steady state tests at four load/speed were conducted for the Caterpillar model C12 diesel engine. Particulate mass emissions were measured using $90 \mathrm{~mm}$ T60A20 teflon coated glass fiber filters and number emissions were measured using an SMPS. A two stage air ejector system was used for exhaust dilution and was dedicated primarily for the SMPS. On an overall emission trend, the highest emission was noted for the idle mode. Significant reductions between $29 \%$ and $53 \%$ were noted for the VOC emission at all test modes with the Fischer-Tropsch fuel. A clear bimodal distribution was noted for both fuels with both the accumulation and nucleation mode. The idle mode showed the least distinctive accumulation mode. With the Fischer-Tropsch fuel, the number of particles in the nucleation mode was lower when compared to D2 fuel. This reduction can be attributed to the reduction in the VOC emission when using Fischer-Tropsch fuel, since the nucleation mode particles mostly contain volatile compounds. A reduction between 38 and $83 \%$ were noted for the integrated particle number when tested with Fischer-Tropsch diesel fuel. The reduction in nuclei mode particle could also be attributed to the negligible sulfur content in the Fischer-Tropsch diesel fuel. 


\section{4 Particle Emissions from CNG Fueled Vehicles}

Compressed Natural Gas fueled vehicles are assumed to be a cleaner alternative to diesel. This is very true when PM is measured in terms of mass. Mass emissions measurements have always been the standard to measure the amount of particulate matter emitted from engines, but when particle number is considered CNG emits equal or even greater amounts of nanoparticles when compared with modern diesel engines [24, 25]. The nanoparticles are usually below $40 \mathrm{~nm}$ and do not contribute much towards mass and thus CNG appears cleaner.

Holmen and Ayala [24] have compared number emissions from three transit bus configurations. One $\mathrm{CNG}$ fueled bus with no aftertreament devices and one diesel bus tested with two different after-treatment devices. One after-treatment device was an OEM catalyzed muffler and the other was a Johnson-Matthey continuously regenerating trap (CRT). Vehicles were tested using a chassis dynamometer. Idle and steady states at $55 \mathrm{mph}$ were used to compare emissions between the vehicles. Particle number concentrations were measured using a SMPS. Two dilution systems, the Constant Volume Sampling (CVS) which is usually the standard and the ejector dilution system were used for dilution purposes and the changes in the particle size distribution between both systems were analyzed. The CVS system produced higher nanoparticle concentrations than the ejector diluter system. This difference could be due to the greater residence time in the CVS system as compared to the ejector system. Although the ejector system can be used in multiple stages to reach high dilution ratios up to 1:1000 or more, this is not representative of ambient dilution because of various parameters such as humidity, temperature and residence time. When idle emissions were compared, diesel 
OEM was found to be higher than CNG and diesel CRT. Under CVS dilution system, CNG displayed high nanopartice concentration during the steady state runs. These peaks of nanoparticles represent the semi-volatile hydrocarbons from lube oil. Usually, diesel fueled buses tend to have a bimodal distribution, but tests with ultra low sulfur diesel revealed that nanoparticles were not formed and the distribution was unimodal with the median diameter close to $50 \mathrm{~nm}$. CNG fueled buses can be made cleaner by incorporating aftertreatement technologies like oxidation catalysts to remove the volatile particles from lube oil which contribute to much of the nanopartice emissions.

So far, chassis dynamometer testing was discussed regarding CNG fueled vehicles. Two engines with different power ratings which ran on $\mathrm{CNG}$ fuel were compared using an engine dynamometer [25]. The engine was tested with various loads from $100 \%$ power down to $35 \%$. Both engines were equipped with an oxidation catalyst. A CVS system was used for dilution purposes. Particle size distributions were measured using a SMPS. A linear dependence of engine load on particle size was noted and the shift towards the smaller nano-sized range was very clear with decrease in engine load. It can very clearly be concluded from these studies $[24,25]$ that $\mathrm{CNG}$ cannot be considered a cleaner alternative and these engines need to be regulated regarding nanoparticles. Since CNG fueled vehicles emit nanoparticles at low loads and accumulation mode particles at higher loads, particulate traps in conjunction with oxidation catalysts can be considered a viable alternative for $\mathrm{CNG}$ vehicles. 


\section{EXPERIMENTAL SETUP AND TEST PROCEDURES}

This study employed the West Virginia University Transportable Heavy Duty Vehicle Emissions Testing Laboratory (WVU- THDVETL) for conducting research. This transportable lab was located at the Ralph's Grocery warehouse facility in Riverside, California. The transportable lab consisted of a chassis dynamometer trailer system and an analytic trailer that incorporated a full-scale dilution tunnel, along with auxiliary equipment. A team of four people (engineer, gas technician, driver and safety officer) were employed and were responsible for setting up and running the test vehicle and measuring regulated emissions. This chapter presents the details of the chassis dynamometer, dilution systems, test vehicle, test cycle, test procedure, particle measuring instruments, chemical speciation and the fuel used.

\subsection{Chassis Dynamometer}

The WVU chassis dynamometer was built on a $9.5 \mathrm{~m}$ (31 ft.) semi-trailer frame for transportable purposes. A side view of the chassis dynamometer is shown in Figure 3. The dynamometer is symmetrical with each side containing a face plate, lebow torque and speed transducer, a set of Mack differentials, flywheel sets and a power absorber. The vehicle's tire rest on four small diameter $(0.3 \mathrm{~m}(12.5 \mathrm{inch}))$ rollers, but the power was absorbed directly from the wheel through a test rim and hub adapter connected to the power absorber via drive shafts and differentials [26]. Two rollers were located behind the set of four rollers to accommodate a set of rear tandem wheels when necessary. The tires were water cooled by spraying water continuously throughout the test duration to

prevent tire tread damage due to overheating. The test vehicle was held in place by using 
a set of chains over the vehicle's axle and ratchets to secure the chains to the test bed frame. The chains were tightened just enough to prevent slippage between tires and rollers. Care was taken not to over tighten the chains. One wheel was removed from each side of the vehicle and replaced with test rims. The test rims were wheels rims of $0.5 \mathrm{~m}$ (1.8 feet) in diameter.

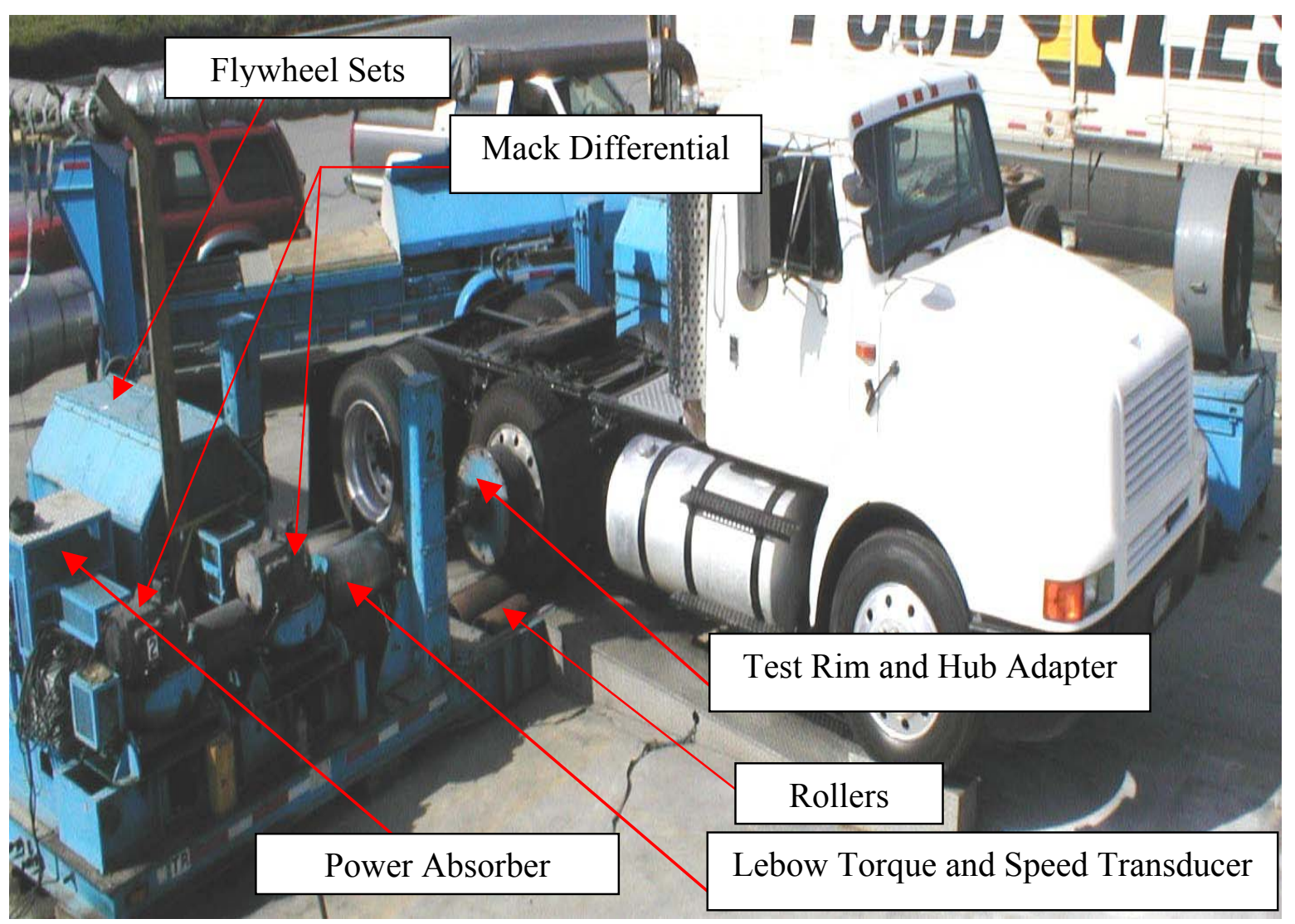

Figure 3: Side View of the Chassis Dynamometer

The hub adapters were connected to the power absorber through a $12.7 \mathrm{~mm}(0.5$ inch) thick aluminum face place incorporated with a set of universal joints and drive shafts. The hub adapter drove a set of Mack double reduction differentials of ratio 1:3.65 [26]. One differential was connected to a set of flywheels designed to simulate loads up to $22,680 \mathrm{~kg}(50,000 \mathrm{lbs})$ assuming a tire size of $1.06 \mathrm{~m}$ (42 inches). Each flywheel 
assembly consisted of four disks or drive rotors on the shaft connected to the differential. Eight flywheels of different sizes run along the same shaft supported by bearings on the shaft. If a particular flywheel was to be used to simulate the load, it was locked to the shaft through the drive rotors. This was done by bolting the flywheel to the drive shaft at four different locations along the perimeter of the flywheel and the drive shaft. The flywheels could simulate different loads by engaging or disengaging different combinations of the flywheels to the drive rotors. Additional loads could be provided through the power absorber which was connected to the second differential as seen in Figure 3. The Mustang model CC300 power absorbers were air cooled eddy-current type, rated at $300 \mathrm{hp}(224 \mathrm{KW})$ continuous and over $1000 \mathrm{hp}(750 \mathrm{KW})$ maximum load. Lebow shaft encoders located right before the first differential provided time- varying output torque and speed during each test at a $10 \mathrm{~Hz}$ resolution update. Torque and speed was controlled accurately during the test.

The speed was usually controlled by the driver and the torque was controlled two ways. The torque supplied by the flywheel was controlled by its own rotational speed and the torque supplied by the power absorber was controlled by a closed loop Proportional Integral Differential (PID) controllers. The controllers received set points during a test every 100 milliseconds from the control computer and it was sent to the power absorbers which simulated road losses and aerodynamic drag. The set point which was equal to the road load was calculated by the following equation [26]

$$
P_{r}=\left(C_{r} M g+1 / 2 \rho_{a} C_{D} A V^{2}\right) V
$$

$\begin{array}{cl}\text { Where } \mathrm{P}_{\mathrm{r}}=\text { Road load power } & \mathrm{A}=\text { Frontal area of vehicle } \\ \mathrm{C}_{\mathrm{D}}=\text { Drag Coefficient } & \mathrm{M}=\text { Vehicle gravitational mass } \\ V=\text { Vehicle speed } & \rho_{\mathrm{a}}=\text { Air density } \\ \mathrm{C}_{\mathrm{r}}=\text { Coefficient of rolling resistance } & \end{array}$




\subsection{Dilution System}

\subsubsection{WVU Constant Volume Sampling System (CVS)}

Dilution systems are usually employed to simulate the actual dilution conditions of the atmosphere. There are various methods by which dilution can be simulated, but standards have been set so that test results from various research facilities can be compared. The system employed by WVU is the Critical Flow Venturi-Constant Volume Sampler (CVS). This system is in accordance with the requirements of the Code of Federal Regulations 40 [1]. The CFR requires two basic conditions to be satisfied for measuring mass emissions; the total volume of both exhaust and dilution air must be measured and a proportional sample must be collected for analysis. Figure 4 shows the schematic of the WVU sampling train and Table 1 provides the sampling system description.

\begin{tabular}{|c|c|c|}
\hline ID & $\begin{array}{c}\text { Sample } \\
\text { Description }\end{array}$ & Media Type \\
\hline 1 & HC & Heated FID Analyzer \\
\hline 2 & CO/CO2 & NDIR Analyzers \\
\hline 3 & NOx & $\begin{array}{c}\text { Chemiluminescent } \\
\text { Analyzer }\end{array}$ \\
\hline 4 & TEOM & TEOM Filter \\
\hline 5 & TPM & 70 mm T60A20 \\
\hline 6 & $\begin{array}{c}\text { PM }_{10} \text { Fraction } \\
\text { for Gravimetric } \\
\text { Analysis }\end{array}$ & $\begin{array}{c}47 \text { mm TX40HI20WW } \\
\text { Filters }\end{array}$ \\
\hline 8 & $\begin{array}{c}\text { DRI Dilution } \\
\text { Chamber. }\end{array}$ & $\begin{array}{c}\text { Various media for } \\
\text { chemical speciation }\end{array}$ \\
\hline 9 & ATOFMS & $\begin{array}{c}\text { Mass spectrometer for } \\
\text { particle analysis }\end{array}$ \\
\hline
\end{tabular}

Table 1: Sampling System Description and Media Type

Further requirements include that the system should not artificially lower the engine back pressure. Continuous static pressure measurements are required. The 
temperature measuring system needs to have an accuracy of $\pm 3.4^{\circ} \mathrm{F}$ and the pressure measuring system $\pm 3 \mathrm{~mm}$ of $\mathrm{Hg}$. Tunnel flow must be kept turbulent to allow complete mixing of the exhaust gas and the dilution air and the length of the tunnel must be kept at least ten times the diameter to ensure fully developed turbulent flow. The tunnel should be fabricated of electrically conductive material and must be grounded so that particle losses do not occur due to electrostatic deposition.

The dilution tunnel was constructed of 22 gage 304 stainless steel and is $0.45 \mathrm{~m}$ (18 inches) in diameter and all sampling was done after $4.5 \mathrm{~m}$ (180 inches). The whole tunnel was wrapped by insulation blankets to minimize particle losses by thermophoretic deposition. A $56 \mathrm{KW}(75 \mathrm{hp})$ blower was used to draw the exhaust and dilution air. Dilution air was non-heated and the air was filtered through a HEPA filtration system. The flow was regulated by a $42475 \mathrm{lpm}(1500 \mathrm{scfm})$ critical flow venturi under choked conditions. A differential pressure gage monitored the pressure drop at the throat to ensure that choked flow occurred at the venturi throat. The volume cannot be maintained constant due to a variation in temperature. The equation for determining sonic flow rate is:

$$
Q=\frac{K v \times P}{\sqrt{T}}
$$

Where $\mathrm{K}_{\mathrm{v}}$ is the calibration coefficient, $\mathrm{P}$ is the absolute pressure and $\mathrm{T}$ is the absolute temperature. Both $\mathrm{P}$ and $\mathrm{T}$ were measured upstream of the $\mathrm{CFV}$. The total flow rate could be varied by changing out the venturi. Calibration checks were made according to the procedure stated in the CFR 40 [1] whenever a venturi was changed. Particulate sampling and gaseous sampling were done according to the standards specified. 


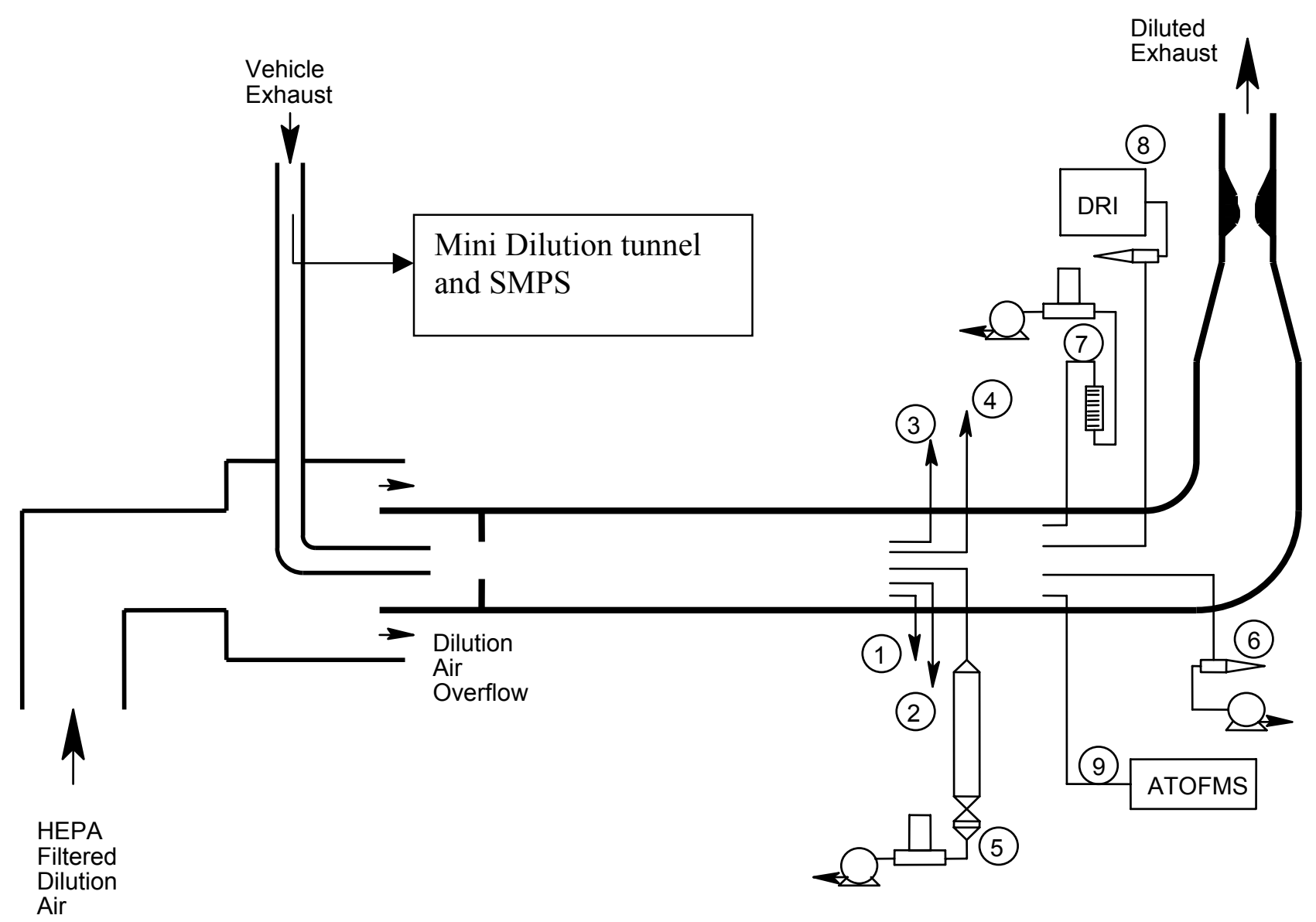

Figure 4: WVU Sampling Train Schematic 


\subsubsection{DRl's Residence Time Dilution Tunnel}

DRI dilution tunnel is based on a dilution stack sampler designed and tested by a group led by Dr. G.R. Cass [27]. Figure 5 shows a schematic of the DRI sampler. Samples were withdrawn from the stack through a cyclone $10 \mathrm{~mm}$ separator, inserted into the exhaust stream. The stack gases were transported through a heated Teflon line to the dilution tunnel. Additional dilution was not provided in this study due to insufficient quantity of sample collected on the filters and other media. After passing through a tunnel length equal to $\sim 10$ tunnel diameters, a fraction of the diluted exhaust entered a large chamber, where additional residence time was provided before the samples were collected. The samples were drawn through cyclone separators (Bendix-Unico 240) with a $50 \%$ cut-point of 2.5 micrometers aerodynamic diameter at a volumetric flow rate of 113 liters/minute and collected using the DRI Sequential Filter Sampler (for inorganic species) and/or the DRI Sequential Fine Particulate/Semi-Volatile Organic Compound

(PSVOC) Sampler for organic species. The rest of the diluted exhaust passed through a high-volume sampler filter before being exhausted.

Details of the sample collected by DRI for chemical analysis are listed below:

1. Volatile organic compounds (VOC) - Canisters; field GC

2. Methane - Canisters

3. Semi-volatile organic compounds (SVOC) - PUF/XAD and TIGF filters

4. SVOC, low molecular weight compounds - Tenax tubes

5. Nitro- PAHs - PUF/XAD and TIGF filters

6. Carbonyls - DNPH cartridges 
7. Nitrosamines - Thermosorb cartridges

8. PM soluble organic fraction (SOF): organic compounds - TIGF filters

9. Elemental analysis and gravimetric analysis $\left(\mathrm{PM}_{2.5}\right)$ - TIGF filters

10. Ammonium and Ions (Nitrate, Nitrite, Chloride and Sulfate)- Quartz filters

11. EC/OC- Quartz filters

12. $\mathrm{PM}_{2.5}$ fraction for gravimetric analysis

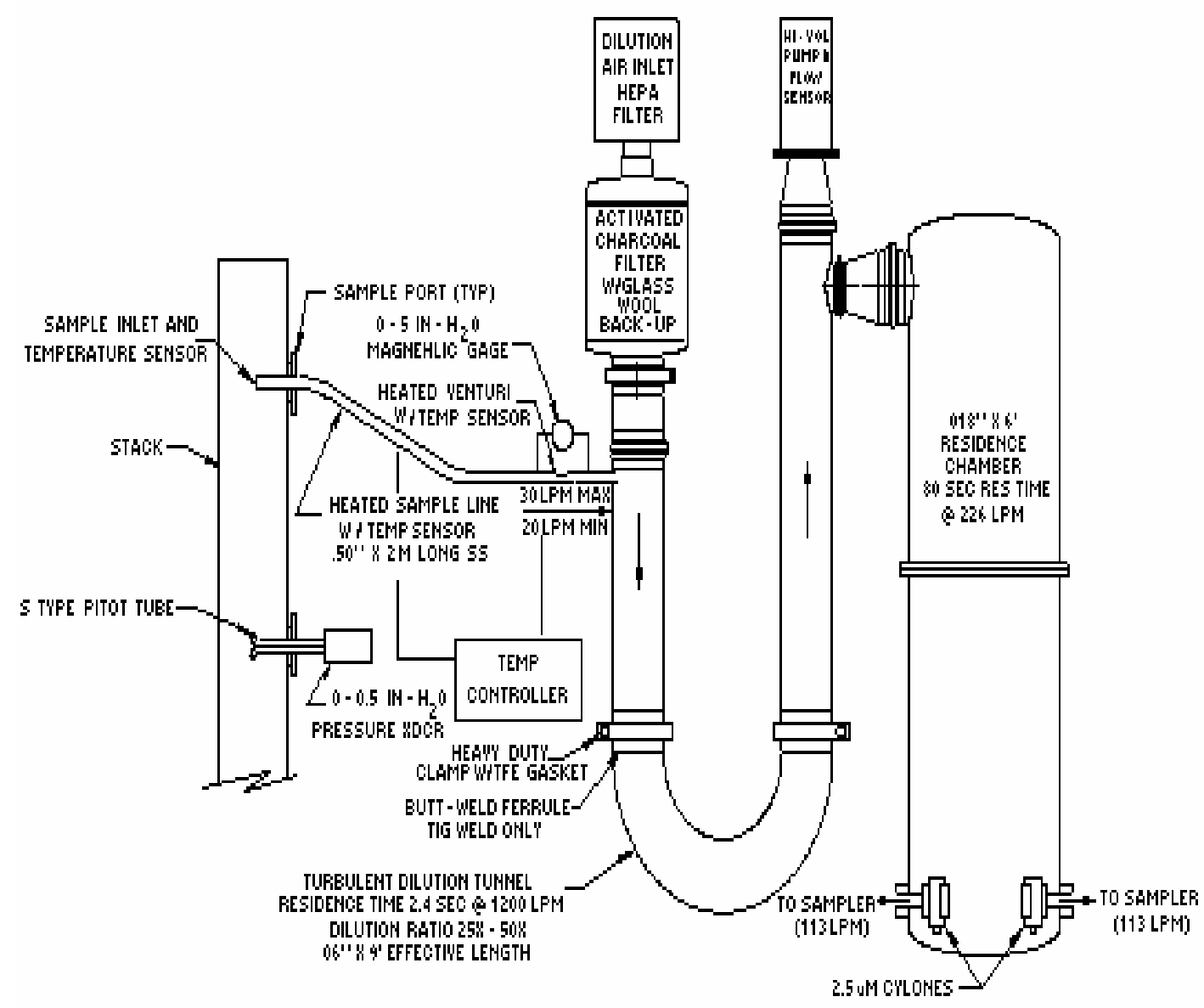

Figure 5: Schematic of the DRI Residence Time Dilution Tunnel [27] 


\subsubsection{Mini Dilution System}

Ejector type dilution systems have been used by various research organizations to achieve high dilution ratios. Though this type of dilution system can help achieve high dilution ratios, it should be noted that residence time in ejector type systems is very low. Residence time plays a major role in formation of particles; hence, a low residence time prevents the particle nucleation. This type of dilution system also offers high restriction, and the particle size distribution thus obtained is not representative of what really happens in real world conditions.

West Virginia University had developed a mini dilution system which was dedicated only for particle sizing purposes (Figure 5). The mini dilution system incorporated a tunnel with its length maintained at ten times its diameter to facilitate good mixing and uniform distribution at the sampling zone. An orifice plate was provided at the inlet of the dilution system to ensure proper turbulence. The tunnel was wrapped with heating tape and insulation to maintain a temperature of $46^{\circ} \mathrm{C}\left(115^{\circ} \mathrm{F}\right)$ to prevent water condensation. A dilution ratio of 1:30 was maintained throughout this study to prevent water condensation. A $12 \mathrm{~cm}$ (5 inch) exhaust coupling with a $2 \mathrm{~cm} \mathrm{(3/4} \mathrm{inch)} \mathrm{probe}$ welded on its body was used to draw a partial sample from the raw exhaust (Figure 6). One end of the probe had a quick disconnect fitting for ease of coupling the probe to the mini dilution tunnel. The sample line from the probe to the mini dilution tunnel was kept as short as possible and well insulated. Dilution air was supplied right before the mixing orifice by a separate pump. The dilution air was passed through a refrigerated dryer and a HEPA filter to provide particle and moisture free air. A separate vacuum pump was used to draw in the exhaust sample. 


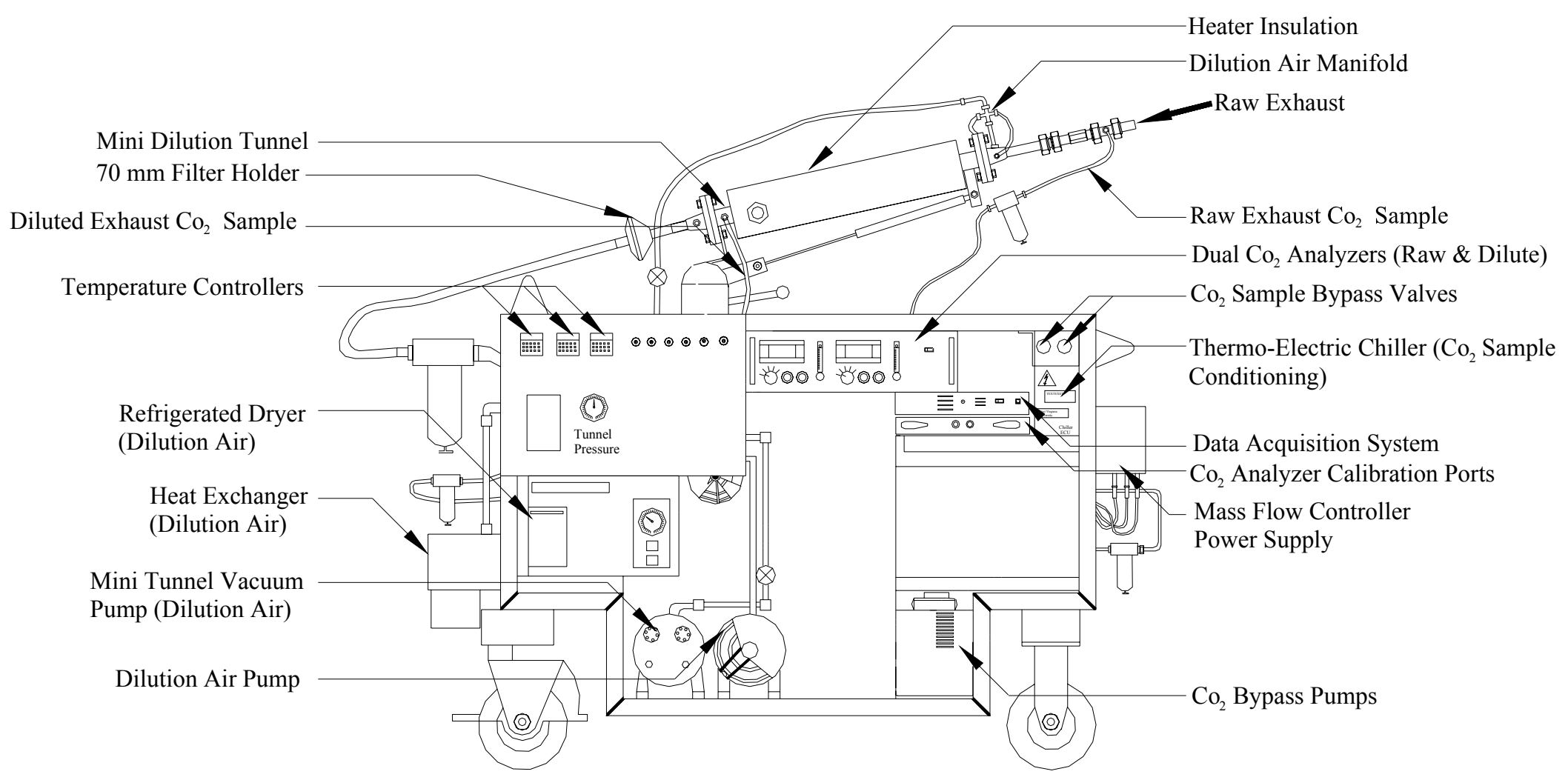

Figure 5: West Virginia University-Mini Dilution System 


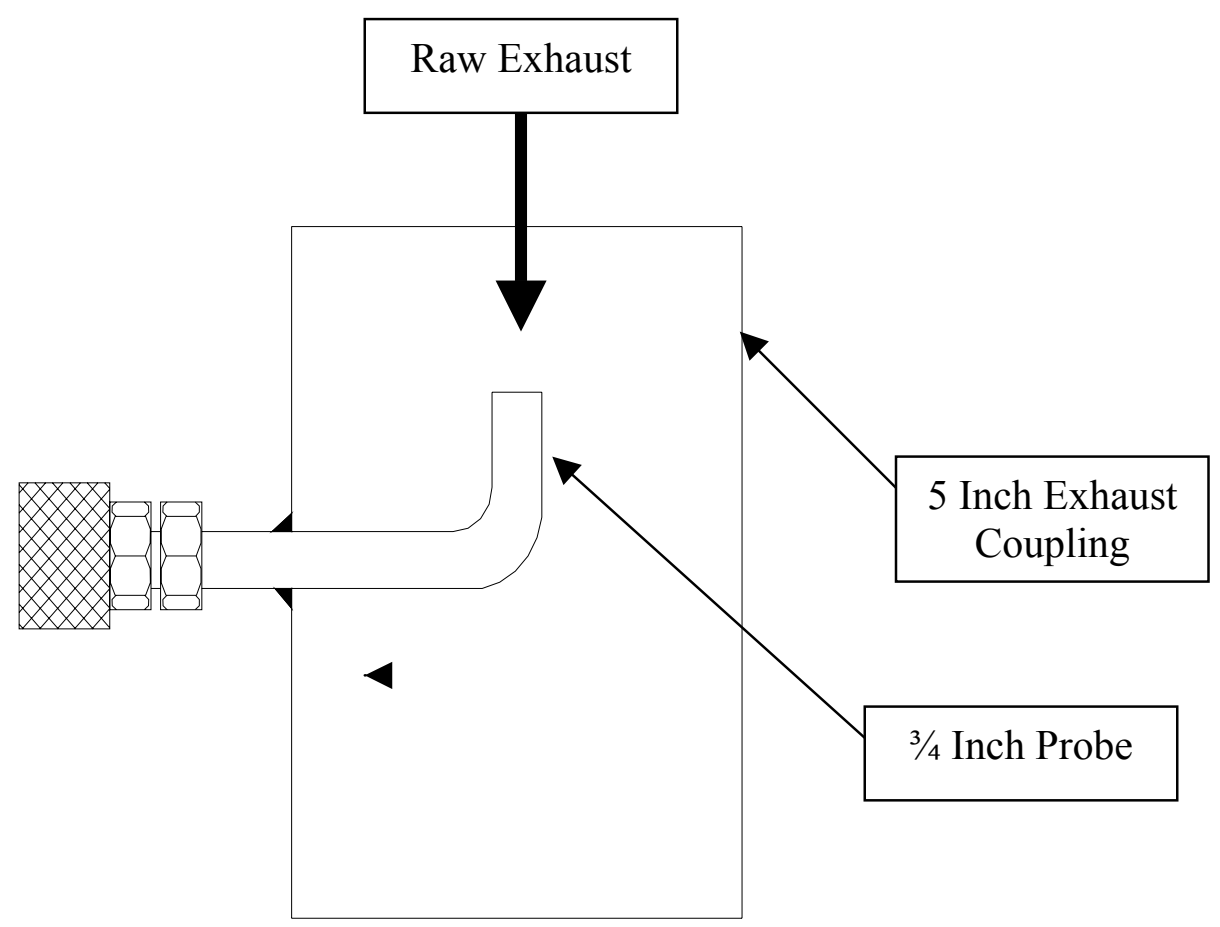

Figure 6: Exhaust Coupler with Sampling Probe

Both, the dilution air and total air flow rates were controlled by two Sierra mass flow controllers calibrated from 0 to $200 \mathrm{slpm}$ ( 0 to $7 \mathrm{scfm})$. Sampling probes were installed ten diameters downstream of the mixing orifice to ensure uniform concentration. A dual range $\mathrm{CO}_{2}$ analyzer was used to measure the raw and dilute $\mathrm{CO}_{2}$ concentrations. A 10-point analyzer calibration was done using $15 \%$ and $1 \% \mathrm{CO}_{2}$ bottles. The analyzer was checked everyday with a zero and span using nitrogen as zero gas and $15 \%$ and $1 \%$ $\mathrm{CO}_{2}$ bottles as span gas for the analyzers. The raw and dilute exhaust gases were filtered by inline filters and chilled by thermoelectric chillers for removal of particulates and moisture respectively. The filters were checked everyday and replaced if necessary. A purge air supply for the $\mathrm{CO}_{2}$ analyzers was provided by an external oil free compressor 
through a HEPA filter. This purge air was useful in flushing the analyzer of any residual gas present which may provide erroneous readings.

The mass flow controllers and the $\mathrm{CO}_{2}$ analyzers were connected to a data acquisition system (National Instruments DAQ 6020-E BNC). A program in visual basic was specially developed by WVU to control the DAQ pad and to save continuous data from the analyzer and the mass flow controller. Other parameters such as tunnel pressure, temperature were also recorded on a continuous basis. The DAQ pad also maintained the dilution ratio which was set by the user. The desired dilution ratios were achieved in two ways, first a flow based system and the other is a $\mathrm{CO}_{2}$ based system. With the flow based system, the dilution ratio was calculated using the following equation:

$$
\mathrm{DR}=\text { total } /(\text { total }- \text { dilute })
$$

The dilution ratio was maintained by adjusting both the flow rates. The total and dilute flow rates were measured and set by the mass flow controllers. The $\mathrm{CO}_{2}$ based system measures the raw and dilute $\mathrm{CO}_{2}$ concentrations and the dilution ratio was the simple ratio of raw to dilute concentration. The dilution ratio was maintained by controlling the mass flow controllers based on the $\mathrm{CO}_{2}$ readings. Through experience it has been determined by WVU that the flow based system was more accurate in controlling the dilution ratio and the $\mathrm{CO}_{2}$ readings were used to verify the set dilution ratio. One probe was installed next to the dilute $\mathrm{CO}_{2}$ probe for particle size distribution measurements. Carbon impregnated electrically conductive tygon tubing was used to transfer the sample from the tunnel to the particle sizing instrument (SMPS). This tubing was used to prevent any particle losses due to electrostatic deposition on the walls of the sampling tube. 
Exhaust pulsations from the engine were encountered during this study and an exhaust pulsation damper was devised to reduce pulsations due to the transient behavior of the engine during the test cycle (Figure 8). The damper was a simple 5 gallon tank with one end cut off and sealed with a rubber diaphragm. The rubber diaphragm was helpful in reducing the exhaust pulsations. The top of the tank had a tee connection which incorporated a straight probe as seen in Figure 7, to minimize particle losses into the damper. This system provided a pulsation free stream of sample with minimal particle loss. The damper was flushed with particle free air and evacuated after every test to remove any remaining particles or even volatile compounds which may have found their way into the damper. This was done because the volatile compounds may adhere to the walls of the damper and subsequently form particles and create sampling artifacts.

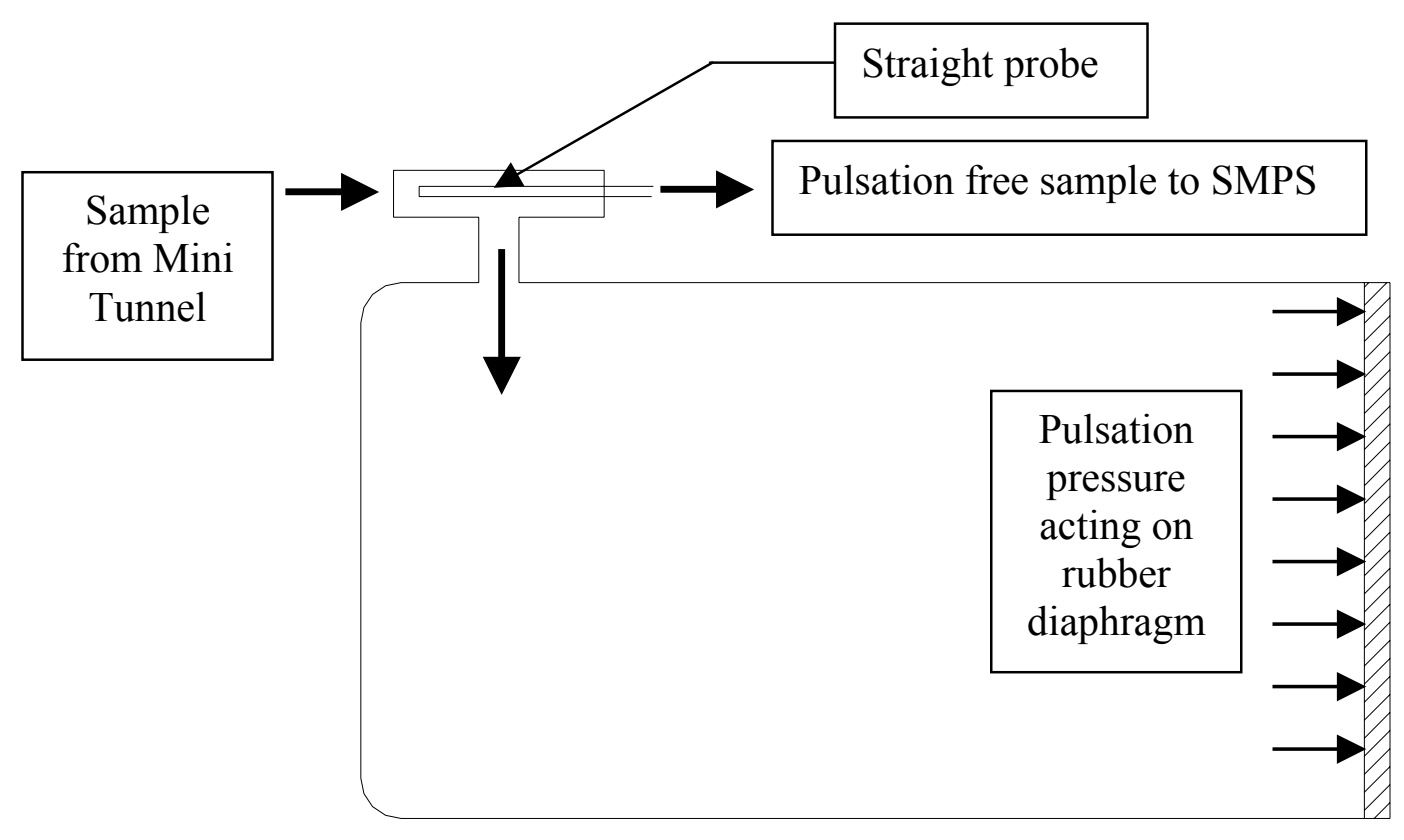

Figure 7: Schematic Representation of the Damping System 


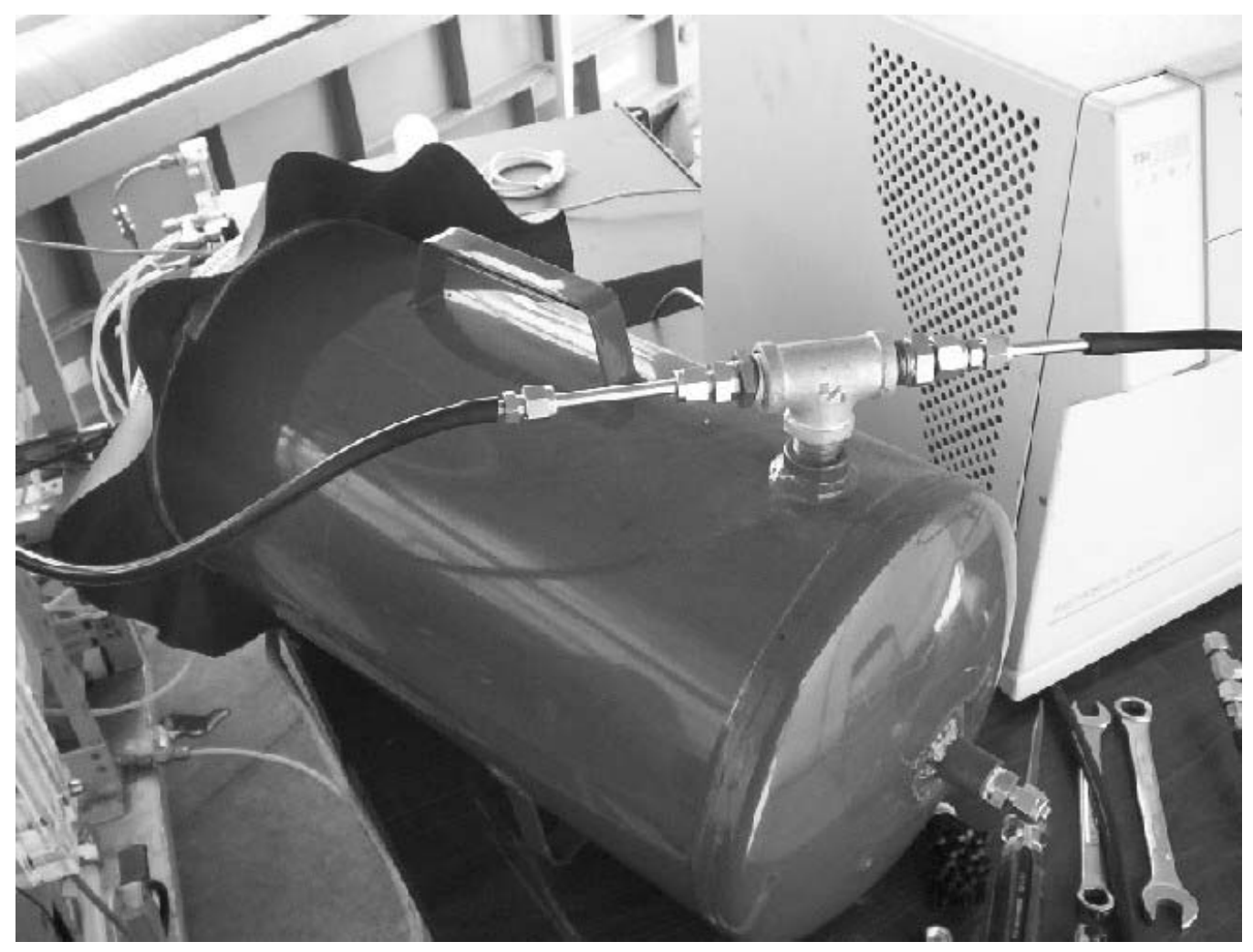

Figure 8: Exhaust Pulsation Damper 


\subsection{Particle Sampling System}

\subsubsection{Total Particulate Matter}

Total Particulate Matter, as defined by the US EPA, is sampled by filtering diluted diesel exhaust at filter face temperatures of less than $50^{\circ} \mathrm{C}\left(125^{\circ} \mathrm{F}\right)$. A partial sample was drawn into a secondary dilution tunnel through a $12.7 \mathrm{~mm}$ (0.5 inch) diameter probe located at the sampling zone in the primary dilution tunnel. The secondary dilution tunnel is usually used to further dilute the exhaust to maintain a filter face temperature of not more than $50^{\circ} \mathrm{C}\left(125^{\circ} \mathrm{F}\right)$. This is necessary because vapor phase organics will not get adsorbed at temperatures greater than $50^{\circ} \mathrm{C}\left(125^{\circ} \mathrm{F}\right)$; hence not be measured in TPM. For this study, secondary dilution air was not used since the filter face temperatures were close to $50^{\circ} \mathrm{C}\left(125^{\circ} \mathrm{F}\right)$ without any further dilution. The secondary dilution tunnel was $76.2 \mathrm{~mm}(3 \mathrm{inch})$ in diameter and $762 \mathrm{~mm}(30 \mathrm{inch})$ in length. The dilution tunnel was constructed from stainless steel, which is non corrosive and electrically conductive. An electrically conductive material is useful to ground the electrostatic charges since particle losses can occur if any electrical charges buildup in the dilution tunnel.

At the downstream end of the secondary dilution tunnel, a $70 \mathrm{~mm}$ filter holder was connected which contained two $70 \mathrm{~mm}$ T60A20 fiberglass filters, the primary and secondary filters. The tunnel was connected to a vane pump through a Sierra 740 series mass flow controller. The total flow rate could be varied from 0-200 slpm $(0-7 \mathrm{scfm})$ and the flow through the secondary dilution tunnel varied in proportion with the main dilution tunnel. The mass flow controller was calibrated using a laminar flow element which measured the flow rate by monitoring the pressure drop across the element. For calibration, specific set voltages were sent to the mass flow controller which opened a 
control valve. The valve was in a fully closed position when the voltage was at zero and the voltage was increased in steps of one volt and the pressure drop across the laminar flow element was noted. The calibration values were then entered into the lab's main computer which calculated the standard flow rate based on the temperature and pressure measured upstream of the laminar flow element. During a test run, the voltage from the mass flow controller and the temperature upstream of the sampling line was measured continuously. The voltage was converted to flow rate using the calibration curve and a set voltage was sent to the mass flow controller if the flow rate fluctuates. A continuous measurement was necessary for maintaining an accurate flow rate.

Two filters were used for each test, a primary filter which collects most of the particulate matter and a secondary filter which collected the particles which escape the primary filter. Before using the filters, they were conditioned for twelve hours at $50 \%$ relative humidity and $21^{\circ} \mathrm{C}\left(70^{\circ} \mathrm{F}\right)$ in an environmental chamber and then weighed in a microbalance to record a pre-weight. After the test, the filters were conditioned again before they were re-weighed. This process of conditioning the filters at the same relative humidity ensured the same amount of water trapped in the filter before and after testing. The CFR 40 requires the use of two blank reference filters to monitor the humidity control function. If the average weight of the filter changed between sample filter weighing by $\pm 5 \%$ of the nominal filter loading, then all the samples had to be discarded and the tests had to be repeated. If the average lied between \pm 1 and $5 \%$ then the field engineer had the option of either repeating the test or accept the values. If the average lied within $1 \%$ then all tests could be accepted. 


\subsubsection{Particle Number Sizing}

\subsubsection{Scanning Mobility Particle Sizer}

The SMPS comprises of two basic components, the Electrostatic Classifier or the Mobility Analyzer and a Condensation Particle Counter. The classifier or mobility analyzer separates particles based upon their electrical mobility and the resulting particles are transported to the particle counter to obtain number concentrations. In mobility analyzers particles are first charged, and then the aerosol is classified in a high electric field according to the electrical mobility of the particles. The particle size distribution is obtained on the basis of the relationship between mobility and sizes. The ultimate size parameter determined from electrical mobility measurements is the equivalent mobility diameter. A particle in a gas suspension is subjected to a drag force. If this drag force is an electrical field acting on a particle carrying an electric charge, then electrical mobility is defined as the relationship between the elementary particle charge "e" and the equilibrium velocity. The electrical mobility diameter is a close approximation of the Stokes diameter, which is defined as the diameter of a spherical particle having the same density and settling velocity as the measured particle.

In general, the mobility diameter is different from the aerodynamic diameter measured in aerodynamic particle sizers. The aerodynamic diameter provides good representation of the particle behavior in such processes as impaction and settling, i.e., processes characteristic for larger particles with high inertial forces (high Stokes numbers). The mobility or Stokes diameter, on the other hand, is more representative for describing diffusional processes, which dominate in small particles. The correlation between the aerodynamic and mobility diameters depends, among other factors, on 
particle density. Since densities of diesel particles are typically less than $1 \mathrm{~g} / \mathrm{cm}^{3}$, their aerodynamic diameter is less than the mobility diameter. The mobility diameter is more representative than the aerodynamic diameter to describe the movement of small diesel particles in the human lungs.

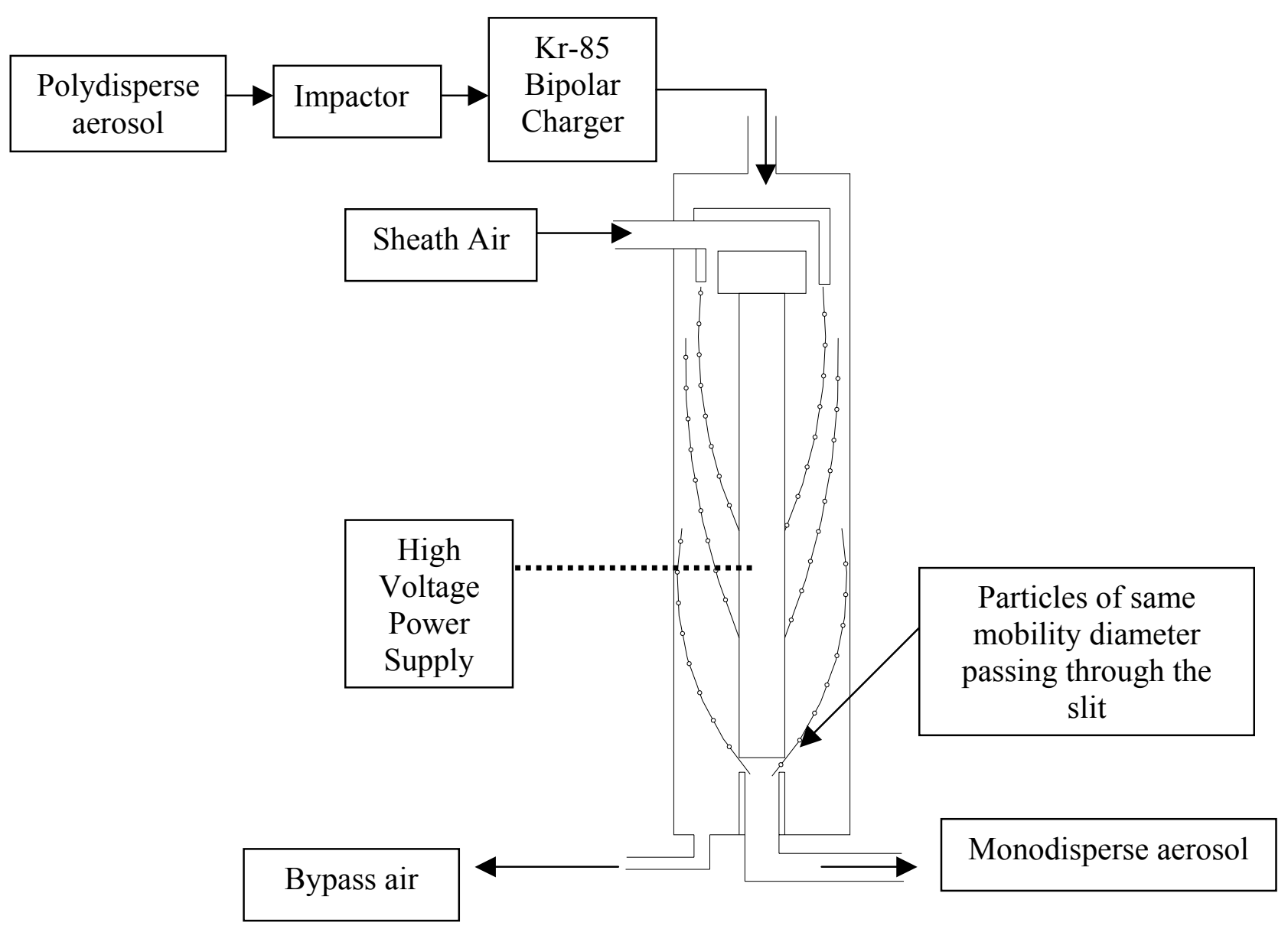

Figure 9: Differential Mobility Analyzer

A schematic of the Differential Mobility Analyzer (DMA) is shown in Figure_9. The inlet of the classifier has an impactor which removes all particles above $1 \mu \mathrm{m}$ since large particles tend to have multiple charges and stripping these charges is very difficult. The impactor has a nozzle and an impactor plate and different size orifices $(0.071$ and $0.0475 \mathrm{~cm}$ ) are used depending on the flow rate. The polydisperse aerosol passes through 
the bipolar charger containing a radioactive source (Krypton), which exposes the aerosol particles to high concentrations of bipolar ions. The particles and ions undergo frequent collisions due to random thermal motion of the ions. After reaching a state of equilibrium, the particles carry a bipolar charge distribution. The polydisperse aerosol passes into the DMA between the sheath flow which creates an air curtain and the outer cylinder. The central rod is charged with a high negative voltage and the positive particles are attracted to the rod. Particles with high mobility precipitate at the top end of the rod and particles with low mobility exit the DMA along with the bypass air. Only particles with a narrow mobility range exit the DMA through the slit as monodisperse aerosol which pass on to the Condensation Particle Counter for concentration measurements. To obtain a full scan of the particle sizes, the voltage in the central rod is increased exponentially which is termed as the up-scan of the DMA and the voltage is dropped to zero which is termed as the down-scan. The up-scan and down-scan times are typically 120 and 15 seconds, respectively. These times can be increased by the user to obtain a better resolution if the particle concentrations are steady.

The Condensation Particle Counter (CPC) also called the condensation nucleus counter $(\mathrm{CNC})$ is the most common instrument used to determine number concentrations of diesel particles. Upon entering the CPC the aerosol stream is saturated with alcohol (typically butanol) vapor. As the mixture is cooled in the condenser tube, the vapor becomes supersaturated and condenses on particles. As a result, the particles grow to a diameter of about $10 \mu \mathrm{m}$, allowing for optical detection. Particle size detection limit in the $\mathrm{CPC}$ is related to the increasing saturation ratio which is required with decreasing particle diameters. Modern CPCs have detection limits of around $10 \mathrm{~nm}$. 
CPCs can be operated in two modes: (1) the counting mode and (2) the opacity mode. In the counting mode, pulses of scattered light from individual particles are counted. This mode provides the most accurate measurements, but can be used only at low particle concentrations. In the opacity mode, used for concentrations of typically above $10^{4} / \mathrm{cm}^{3}$, number concentrations are determined from the total scattering intensity. This mode, generally subject to a bigger error, requires that all particles grow to the same diameter and that the optical system be frequently calibrated. The CPC instrument is very sensitive to the ambient temperature, which affects the degree of supersaturation, as well as to the positioning and vibrations. For these reasons, it is suitable primarily for laboratory measurements; its use for in-field measurements is more challenging. The $\mathrm{CPC}$ is used for particle detection in many aerosol size distribution measurement instruments.

Both the CPC and the Electrostatic Classifier make up the SMPS system. The $\mathrm{CPC}$ and the classifier are interfaced with an analog $\mathrm{BNC}$ connector cable. A personal computer with custom software provided by TSI was used to record data and control the classifier. TSI model 3936 SMPS system was used for this study (Figure 10). DMA models 3081 (Long DMA) and 3085 (Nano DMA) were used interchangeably to obtain a full particle size distribution down to $4 \mathrm{~nm}$ and up to $800 \mathrm{~nm}$. Model $3025 \mathrm{~A} \mathrm{CPC}$ was used for particle counting since it could detect particles with diameters as low as $3 \mathrm{~nm}$ and had a response time of one second. 


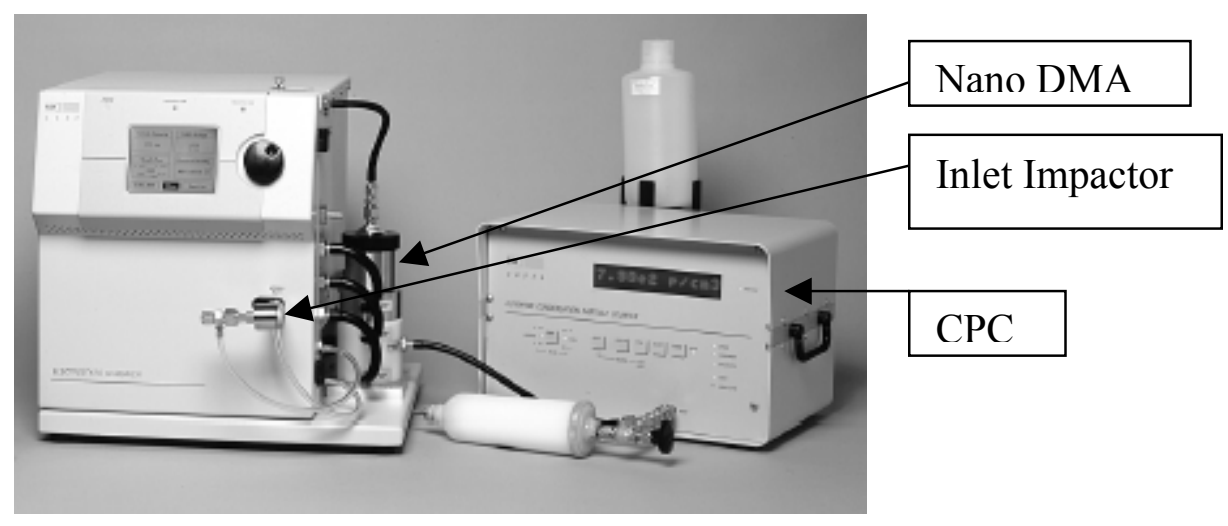

Figure 10: TSI Model 3936 SMPS System

The SMPS is basically designed for steady state operations, where the exhaust characteristics are invariant with time, that is, the engine is at a constant load and RPM or when the vehicle is operated at a constant speed. During these steady states, concentrations of all particles are almost constant, but the concentrations vary whenever the load or speed of the engine/vehicle varies. For transient measurements of the engine/vehicle, the engine/vehicle was first operated on a steady state mode and a full size scan was obtained. Particle sizes were chosen from the full scan and the number of particles chosen was dependent upon the number of times the vehicle was operated through the transient cycle. For transient tests, the classifier operated in manual mode which allowed the user to enter a particular particle size and track the concentration of that particular size for the entire test.

To assure accurate measurements, the SMPS was flow calibrated before the start of the project. An electrospray aerosol generator was used to calibrate the SMPS. The generator was capable of producing 15, 30 and 70nm sucrose particles. Leak checks were performed everyday to ensure that the SMPS had no potential leaks. Two types of leak checks were performed, a HEPA filter check and a zero voltage check. Since HEPA 
filters have high filtration efficiencies, a HEPA filter was connected to the inlet of the SMPS and a full size scan was performed. If any particles were detected above the noise level of the instrument which was typically $1 \times 10^{3}$ particles/cc, then a thorough leak check was performed according to the instrument instruction manual. The second method required the voltage on the collector rod to be set at zero and checked for any particles being measured by the CPC. Since the voltage on the collector rod determines the particle size which exits the classifier, a zero voltage on the rod should ensure no particles exit the classifier. Both these methods were used everyday to make sure the SMPS had no leaks. If any leak was detected in the system, the manufacturer's leak check procedure was used to track and solve the problem. The inlet nozzle on the classifier was cleaned everyday with alcohol to remove any particle deposits which may block the flow. The impactor plate was also cleaned with alcohol and a thin layer of vacuum grease was applied to prevent particle bounce.

\subsubsection{Data Reduction of SMPS and CPC data}

Particles are classified in the DMA by increasing the voltage exponentially and the particles leaving the classifier are increasing in size. The particles are then counted by the $\mathrm{CPC}$ and the values for concentrations for each particle size are stored in the $\mathrm{PC}$ as raw counts. The particle size obtained from the raw data assumes that each particle has a single charge on them after passing through a bipolar charger, which is not actually true. Multiple charges on a particle increase its mobility and can be incorrectly binned into the smaller diameter range. TSI uses an inbuilt algorithm in its SMPS software (Aerosol Instrument Manager-SMPS) to correct for multiple charges based on Fuchs-Gunn aerosol 
charging theory and a truncated triangular transfer function based on Knutson and Whitby [34].

The software provided by TSI to record only CPC concentrations (Aerosol Instrument Manager-CPC) does not provide any algorithm for the reduction of data. The single particle charge correction, transfer function and efficiencies of the CPC and impactor have to be applied to the raw data. Two programs were developed in MathCAD, one to reduce the CPC data and the other to correct the SMPS data for the dilution ratio [Appendix A]. The final data for the SMPS were presented as particle size based concentration variations with concentrations in normalized units of particles/ $\mathrm{cm}^{3}$ $(\mathrm{dN} / \mathrm{d} \log \mathrm{Dp})$. A $\log$ normal distribution was found to fit the data from the SMPS very well. The final data from the $\mathrm{CPC}$ were presented as time-based concentration variations of a selected particle size with concentrations in normalized particles $/ \mathrm{cm}^{3}$ (dN/dlogDp). 


\subsection{Unregulated Emissions (West Virginia University and Desert Research Institute) Measurement}

West Virginia University (WVU) and Desert Research Institute (DRI) (subcontractor to WVU) were jointly responsible for unregulated emissions measurement. Listed below are the specific tasks/activities conducted by WVU and DRI.

\subsubsection{West Virginia University}

In addition to the gaseous sampling probes and a secondary dilution tunnel, WVU installed the following on the primary dilution tunnel:

1. $\mathrm{PM}_{10}$ cyclone with $\mathrm{TX} 40$ filters for gravimetric analysis $\left(\mathrm{PM}_{2.5}\right.$ sampling was conducted by DRI using the DRI residence time chamber).

2. Probe for DRI's residence time dilution chamber.

WVU collected the $\mathrm{PM}_{10}$ fraction using a cyclone for all 5 vehicles. Sizeselective cyclone samplers (URG Model 2000-30 EA, 28.3 lpm, ${ }_{50} \mathrm{~d}_{\mathrm{ae}}=10 \mu \mathrm{m}$ ) were used to collect samples for $\mathrm{PM}_{10}$. The $\mathrm{PM}_{10}$ cyclone was an inertial particle separator that used centrifugal force to remove heavier particles from a gas stream $(>10 \mu \mathrm{m}$ and $>2.5 \mu \mathrm{m}$, respectively). The diluted exhaust sample entered the cyclone tangentially, and was drawn through the cyclone body and the in-line filter by a vacuum pump. Maintenance of this exact flow rate could be difficult if the conditions at which the samples were being collected are not near standard. Cyclone use in a dilution tunnel required a feedback control system to adjust the flow to account for variations in temperature and pressure. This signal was used to control a mass flow rate controller that would be responsible for maintaining the required constant actual flow rate. 


\subsubsection{Desert Research Institute}

Chemical speciation samples were collected by DRI, using the residence time dilution chamber. DRI used Model Bendix-Unico $240 \mathrm{PM}_{2.5}$ cyclones to draw dilute exhaust samples from WVU's dilution tunnel into the DRI's residence time dilution chamber. The cyclones were an integral part of the residence time chamber. The cyclone in the DRI residence time chamber operated at a volumetric flow rate of $113 \mathrm{lpm}(4 \mathrm{cfm})$. However, there was no additional dilution performed at the DRI chamber. The list of chemical compounds analyzed and the media used to collect them are given below:

1. Volatile organic compounds (VOC) - Canisters; field GC

2. Methane - Canisters

3. Semi-volatile organic compounds (SVOC) - PUF/XAD and TIGF filters

4. SVOC, low molecular weight compounds - Tenax tubes

5. Nitro- PAHs - PUF/XAD and TIGF filters

6. Carbonyls - DNPH cartridges

7. Nitrosamines - Thermosorb cartridges

8. PM soluble organic fraction (SOF): organic compounds - TIGF filters

9. Elemental analysis and gravimetric analysis $\left(\mathrm{PM}_{2.5}\right)$ - TIGF filters

10. Ammonium and Ions (Nitrate, Nitrite, Chloride, Sulfate) - Quartz filters

11. $\mathrm{EC} / \mathrm{OC}-$ Quartz filters

12. $\mathrm{PM}_{2.5}$ fraction for gravimetric analysis

Details of the sample collection and the analytical procedures followed by DRI are provided in Appendix B. 


\subsection{Vehicle Test Procedure}

This section documents procedures adopted by the West Virginia University Transportable Heavy-Duty Vehicle Testing Laboratory to test heavy heavyduty vehicles. The test and calibration procedures in Title 40, Part 86 of the Federal Register [1] relevant to chassis testing are followed whenever applicable. Vehicle preparation, mounting and pre-test operation were conducted by the engineer, driver and the safety officer.

\subsubsection{Preparation of the Vehicle for Testing}

As soon as the test vehicle was received, it was inspected for any abnormalities. Engine oil, coolant fluid and power steering fluid levels were checked to ensure compliance with manufacturer's specifications. The engine was inspected for any signs of oil and coolant leakage. Fuel and oil samples were collected prior to and after the vehicle being tested. Information regarding exhaust aftetreatment devices was noted. The engine was started up and checked for any irregular noises. The vehicle's tries were checked visually for any bulges or cuts and the vehicle was driven on a flat ground to check the response of the engine, transmission and brakes. The vehicle was photographed and a digital image recorded. The outer dual wheels were removed from the rear axle and the test rims were installed.

\subsubsection{Test Vehicle Mounting and Connections to the Laboratory}

The test vehicle was backed up onto the idle rollers of the chassis dynamometer using drive ramps and the vehicle was run in either forward or reverse to ensure that the drive axle was centered over the idle rollers. Once the vehicle was in place, chains were 
installed over the axle and it was secured to the test bed using ratchets. After the vehicle was secured by chains, the front axle was lifted and aluminum stands were placed to keep the vehicle level with the dynamometer. The test rims on the vehicle were attached to the hub adapters on the chassis dynamometer. Finally the chains were tightened to hold the vehicle in place.

The driver interface monitor and communication headset were installed. The exhaust from the vehicle was connected to the dilution tunnel using exhaust transfer tubes and the length was maintained as short as possible. The transfer tubes were insulated and checked for leaks. Flexes were used but care was taken to ensure that the length was not over $20 \%$ of the total exhaust length.

\subsubsection{Pre-test Vehicle Operation}

The proper venturi nozzle was installed and the blower was started and the blower engine was maintained at the specific speed to ensure a steady blower operation. The vehicle was run at a high speed to warm up the differential fluids in the chassis dynamometer to around $100^{\circ} \mathrm{F}$. A warm-up cycle which is the same as the test cycle was conducted to condition the tunnel before the start of an actual test. Gaseous emissions were measured during this warm-up test to check if the gas analyzers operated within range and if any analyzer measured emissions below or over the range for which it was calibrated, a ten point calibration was performed using the correct concentration span gas. After a twenty minute soak, the actual test was started. 


\subsection{Test Vehicle, Fuel and Aftertreatment Devices}

Five Heavy Heavy-Duty Diesel Trucks with a Gross Vehicle Weight Rating (GVWR) of 80,000 lbs were selected based on a wide range of engine and vehicle model year. Vehicles 1 to 5 were tagged as CRC 39, CRC 40, CRC 42, CRC 43 and CRC 44 respectively. CRC 41 was a medium duty vehicle and hence cannot be used for comparison purposes in this study. The details of the test vehicles, engines, model years and the test fuel used is given below in Table 2

Table 2: Test Vehicle Details

\begin{tabular}{|l|c|c|c|c|c|c|}
\hline $\begin{array}{l}\text { Vehicle } \\
\text { ID }\end{array}$ & $\begin{array}{c}\text { Vehicle } \\
\text { Manufacturer }\end{array}$ & $\begin{array}{c}\text { Vehicle } \\
\text { Model } \\
\text { Year }\end{array}$ & $\begin{array}{c}\text { Engine } \\
\text { Manufacturer }\end{array}$ & $\begin{array}{c}\text { Engine } \\
\text { Model }\end{array}$ & $\begin{array}{c}\text { Engine } \\
\text { Model } \\
\text { Year }\end{array}$ & $\begin{array}{c}\text { Primary } \\
\text { Fuel }\end{array}$ \\
\hline CRC 39 & Volvo & 2004 & Cummins & ISX 530 & 2004 & CARB \\
\hline CRC 40 & Freightliner & 2004 & Detroit Diesel & Series 60 & 2003 & CARB \\
\hline CRC 42 & Freightliner & 2000 & Caterpillar & 3406 & 1999 & CARB \\
\hline CRC 43 & Peterbilt & 1995 & Detroit Diesel & Series 60 & 1994 & CARB \\
\hline CRC 44 & Volvo & 1989 & Caterpillar & 3406 & 1989 & CARB \\
\hline
\end{tabular}

No aftertreatment devices were used in any vehicle. The vehicles were tested in an "as received tank fuel" condition. Fuel samples for every vehicle were collected at the end of the test period and were sent for chemical analysis to core laboratories for analysis of cetane number, total sulfur content, aromatic content and viscosity. Another sample of the fuel was sent to DRI for analysis of inorganic and organic compounds. Oil samples were collected for every vehicle and were sent to oil sciences laboratory for 27-point analysis and sulfur content. Another sample of the oil was sent to DRI for organic and inorganic analysis. 


\subsection{Test Cycles}

This study employed a new test schedule for Heavy Heavy-Duty Diesel Trucks (HHDDT) known as the HHDDT schedule. This schedule was derived from over 1600 hours of heavy-duty vehicle activity throughout the state of California [33]. The schedule was divided into four modes:

1. Idle

2. Creep

3. Transient

4. Cruise

Figure 11 to 14 provides a target trace for each mode.

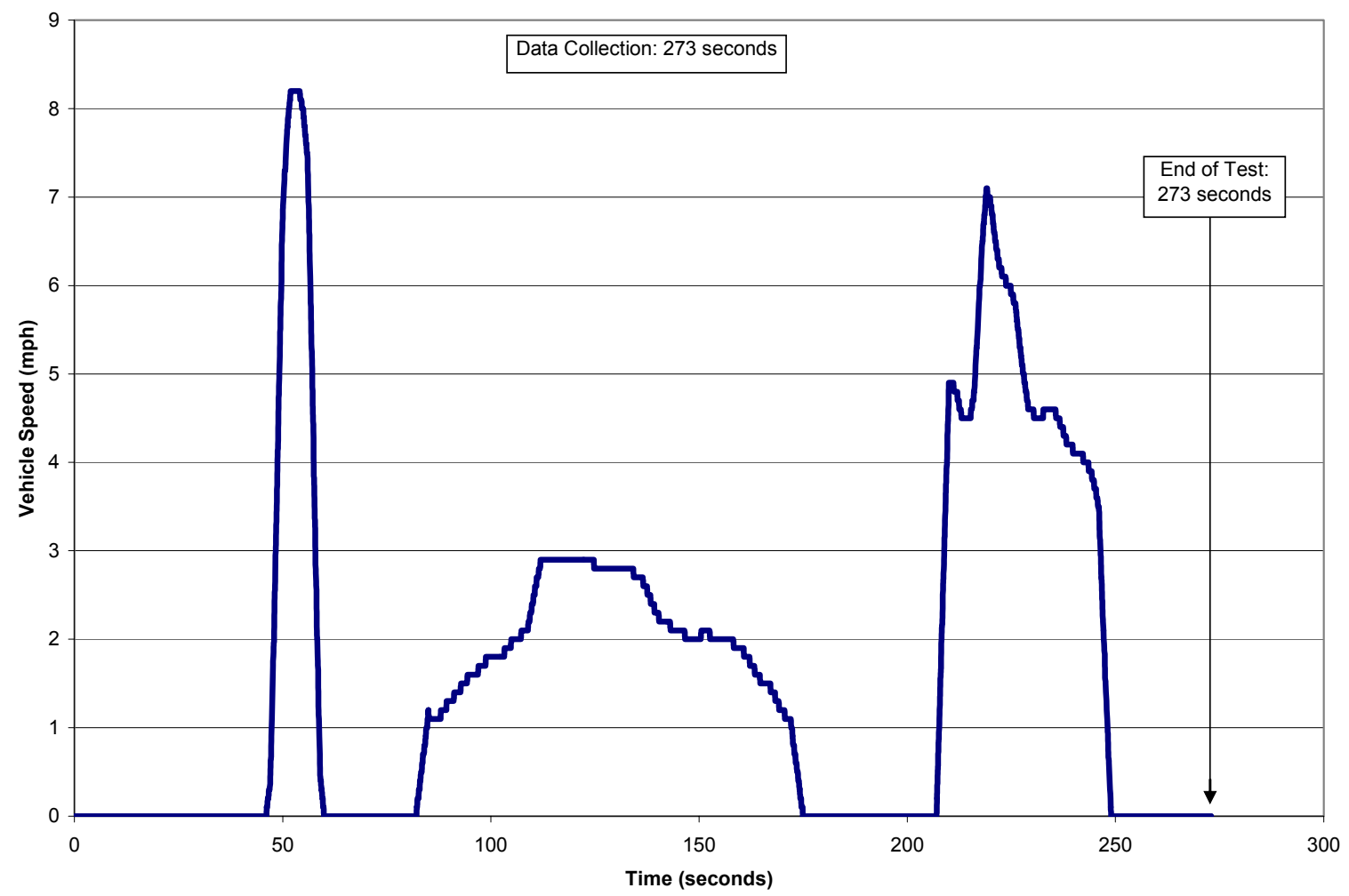

Figure 11: Target Speed Trace for CREEP Mode 


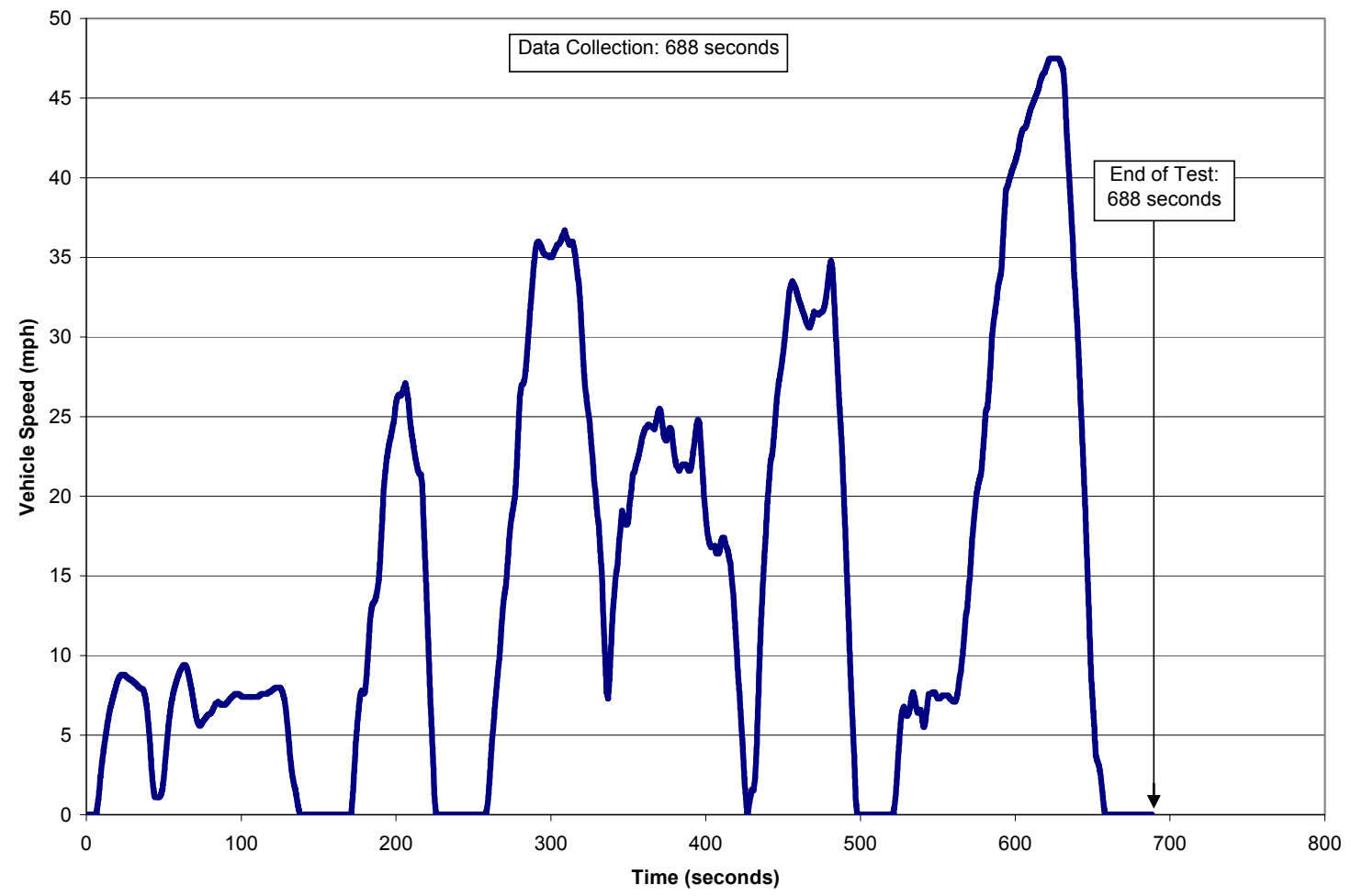

Figure 12: Target Speed Trace for TRANSIENT Mode

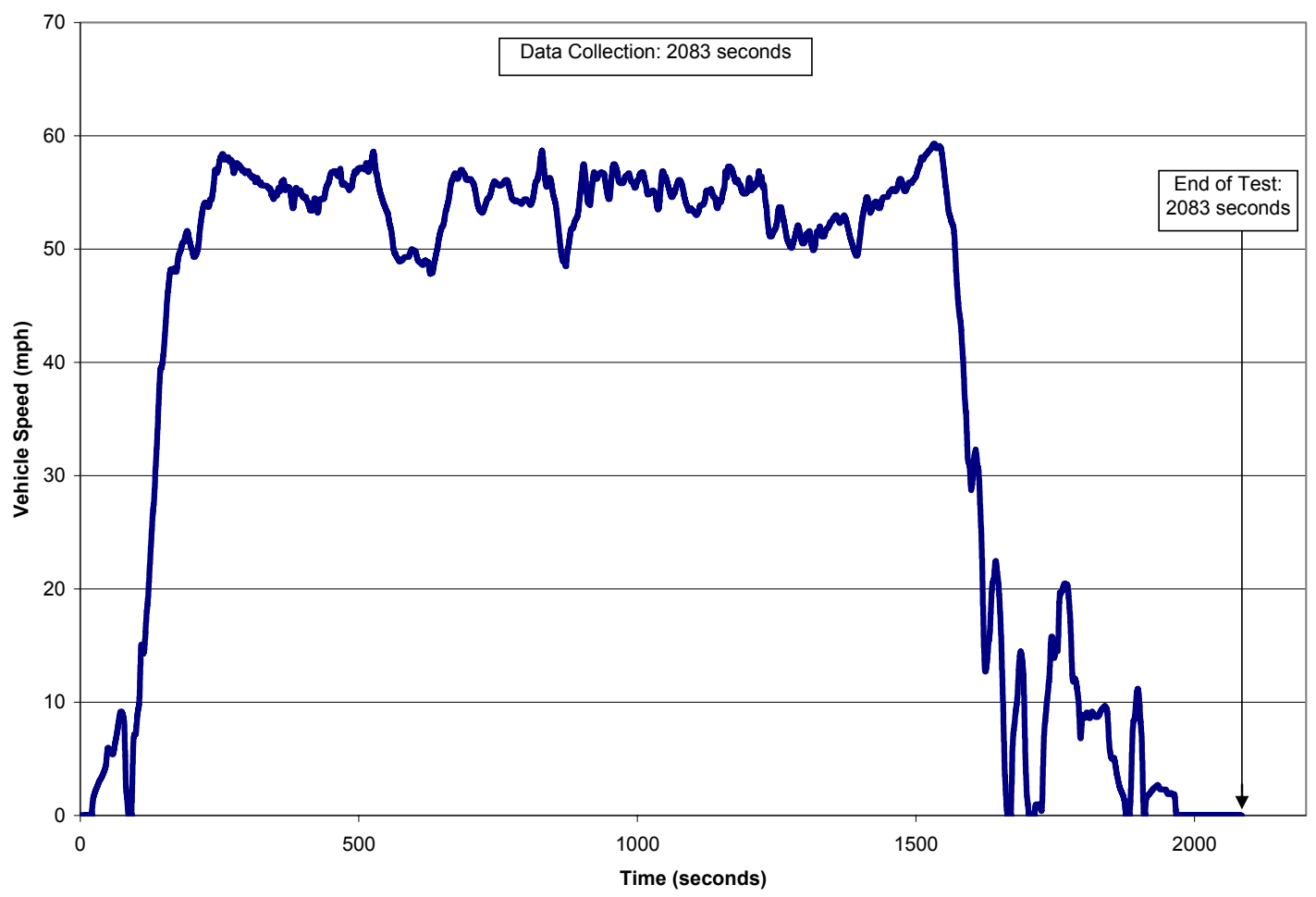

Figure 13: Target Speed Trace for CRUISE Mode 
The idle mode was extended to run three times longer than the normal mode to facilitate sufficient sample collection on the speciation media. No speciation or particle sizing data was recorded for the creep mode. The transient was run normally for 688 seconds. The cruise mode was run normally for 2083 seconds. A fifth HHDDT mode, a high speed cruise mode, representing a higher speed freeway operation was employed. This mode was similar to the cruise mode except for a higher maximum speed of $65 \mathrm{mph}$ (Figure 14). Chemical speciation and particle sizing data was recorded for the idle, transient, cruise and high speed cruise modes.

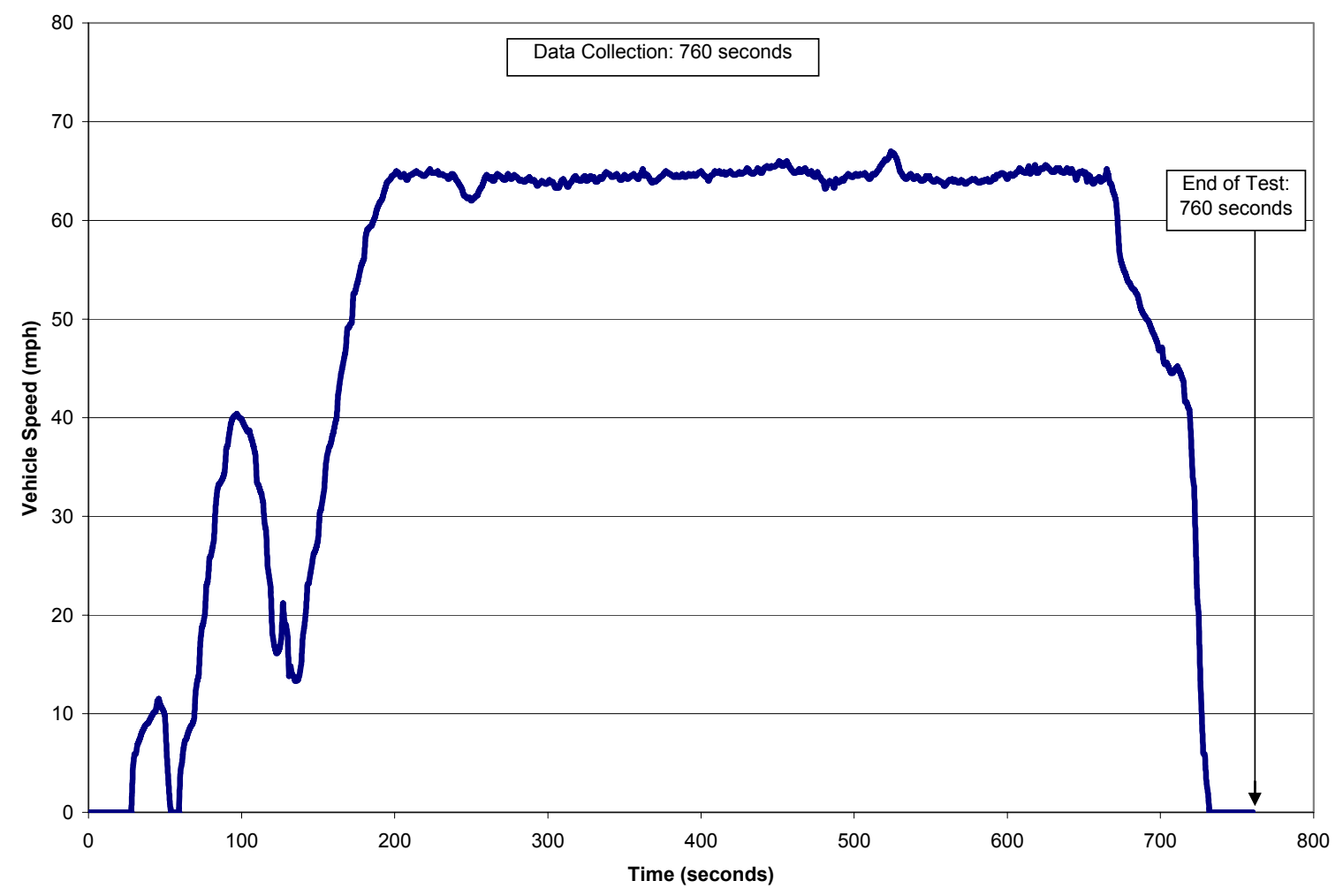

Figure 14: Target Speed Trace for HIGH SPEED CRUISE Mode

Each mode was repeated twice for every vehicle. Similar modes were composited by DRI on the same media to ensure sufficient sample collection. The SMPS operated in a full-scan mode during the idle, cruise and high speed cruise modes. For the transient 
mode, the SMPS was locked onto a particle size of interest and concentration variation for that mode was measured. Particle sizes were selected based on the steady state size distribution. A steady state at $40 \mathrm{kmph}(25 \mathrm{mph})$ was executed prior to any other tests for the sole purpose of obtaining a full particle size distribution by the SMPS. The steady state speed of $40 \mathrm{kmph}(25 \mathrm{mph})$ was selected based on the average speed of the transient cycle. 


\section{RESULTS AND DISCUSSION}

This chapter discusses exhaust particle size distributions and chemical speciation results for five heavy heavy-duty diesel trucks operating on various modes of the California HHDDT cycle. Particle size distribution results from the SMPS were corrected for dilution ratios. The raw uncorrected results obtained from DRI's analytical laboratory for chemical speciation were presented in $\mathrm{ng} / \mathrm{m}^{3}$. All speciation data were reduced by correcting for flow rates in the sampling system. Details of the mass calculations for chemical speciation are presented below:

g/cycle of chemical species $=\left(\right.$ Vtunnel $*$ Speciated sample in $\left.n g / m^{3}\right) / 1.00 E+09$.

Vtunnel $=$ Vmix + Total PMvolume + PM 10 volume + DRI volume $\left(m^{3}\right)$.

Vmix was the total integrated volume sampled from the venturi for a particular cycle. Total PM volume was the integrated volume sampled from the secondary dilution tunnel for a particular cycle. PM 10 volume was the integrated volume sampled from the PM 10 cyclone for a particular cycle. DRI operated three PM 2.5 cyclones at $113 \mathrm{lpm}$ each i.e $0.339 \mathrm{lpm}$ total. To obtain the total DRI sample volume, $0.339 \mathrm{lpm}$ was multiplied by the sample time.

Results presented for chemical speciation were not corrected for background values. Chemical speciation results are usually reported in $\mathrm{g} / \mathrm{mile}$, but since idle mode was also considered for comparison purposes, all speciation data are presented in $\mathrm{g} / \mathrm{hour}$. Only for chemical speciation, both the cruise modes are integrated and results reflect the combination of both the normal and high speed cruise modes. 


\subsection{Particle Sizing and Chemical Speciation Results for CRC 39}

CRC39 was a powered with a Cummins ISX 530 model year 2004 engine. Particle sizing and chemical speciation results are presented below for various modes of the HHDDT schedule. Figures 15 and 16 present the particle size distribution for idle and steady modes.

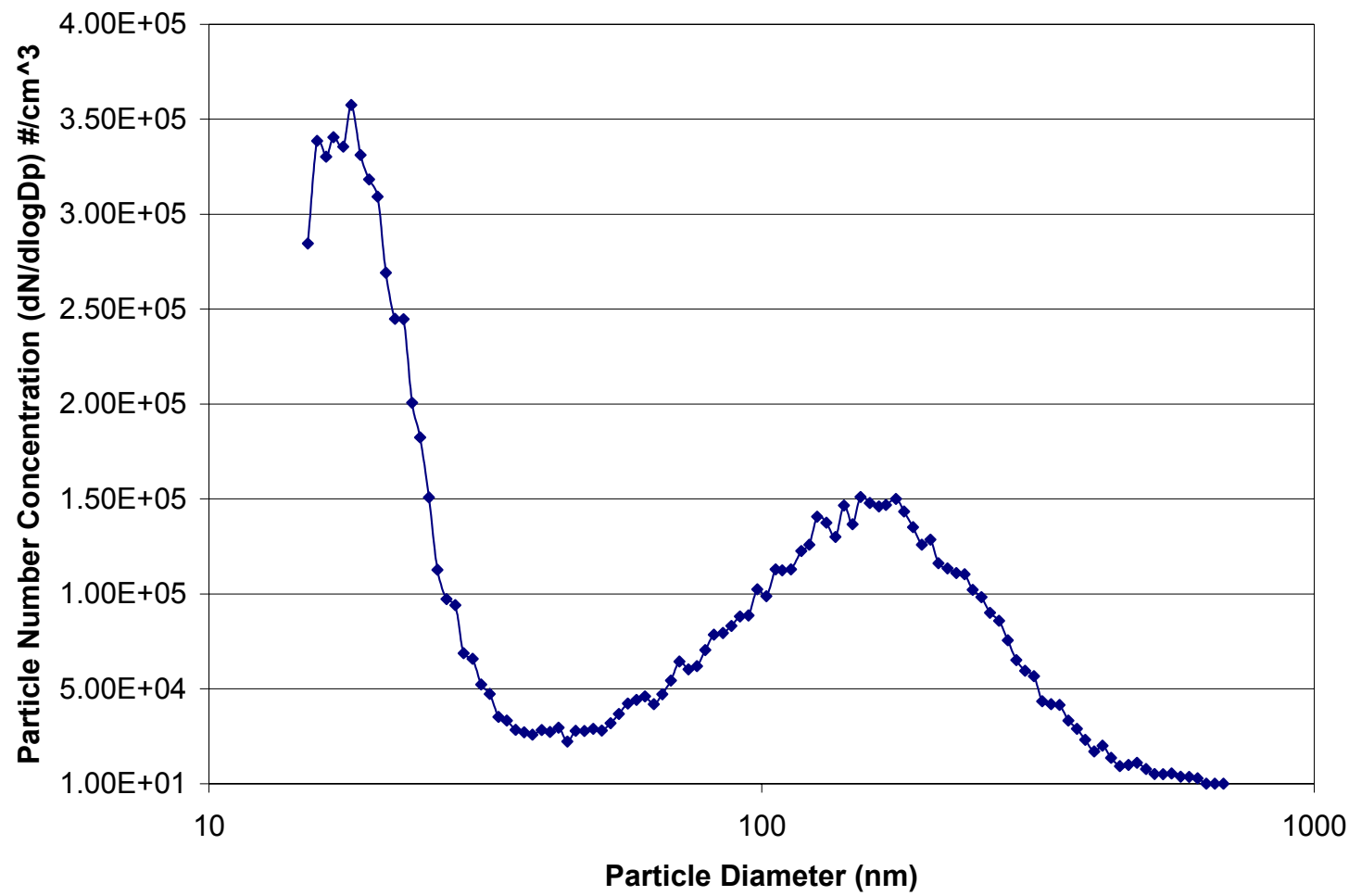

Figure 15: Particle Size Distribution for CRC 39 Operating on an Idle Mode

A clear bimodal distribution was noted for the idle mode with a nuclei mode in the particle size range of $18 \mathrm{~nm}$ and an accumulation mode of $157 \mathrm{~nm}$ with concentrations in the range of $3.5 \times 10^{5}$ and $1.5 \times 10^{5}$ respectively. The nuclei mode formation is attributed to low engine load at idle conditions. Exhaust temperatures are low under idling conditions, which lead to formation of higher levels of volatile organic compounds. 


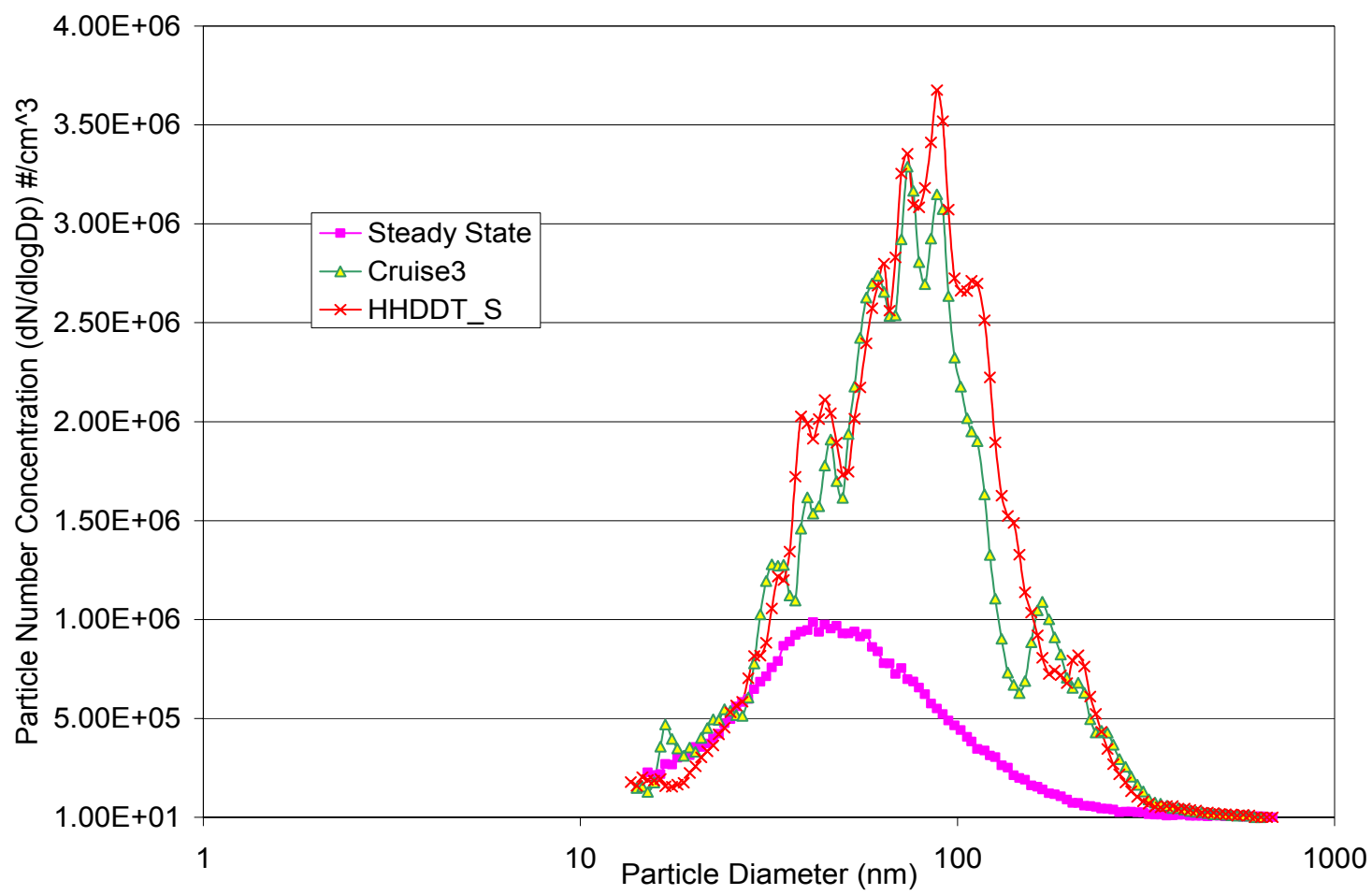

Figure 16: Particle Size Distribution for CRC 39 Operating on Various Steady Cycles

These volatile compounds are usually in the gas phase in the tail pile. As the exhaust is diluted and cooled in the atmosphere or the dilution system, these volatile compounds may either adsorb the nucleated sulfuric acid and/or undergo homogenous nucleation to form particles. Some semi-volatile particles adsorb onto existing soot particles and increase their size and these particles are measured as the agglomeration mode particles. Nuclei mode particles do not contribute much towards idle mass emissions as seen in Figure 17, but their number concentrations are high.

Volatile organic compounds were very high in the idle mode at $0.68 \mathrm{~g} /$ hour when compared to the cruise mode at $0.21 \mathrm{~g}$ /hour (Figure D1 to D5). In the semi-volatile group, polar compound emissions for the cruise were very close to idle mode emissions (Figure D9). The elemental carbon emissions for the cruise mode were very high at $8.3 \mathrm{~g} /$ hour 
when compared with the idle mode at $0.21 \mathrm{~g} /$ hour (Figure 19). As these volatile compounds experience lower temperatures after being emitted or in the tail pipe (under dilute idle mode conditions), they undergo homogenous nucleation. The saturation ratios (partial pressure/saturation pressure) are also higher in light of the fact that elemental carbon is present in very low quantities; hence the organic compounds have no media to adsorb onto thereby resulting in nuclei mode particles or nano-particles during the idle mode. These analyses clearly indicate that the nano-particles or nuclei mode particles which are measured during the idle mode, are mostly made up of volatile compounds. For the steady state mode at $40 \mathrm{kmph}(25 \mathrm{mph})$, the Count Median Diameter (CMD) of the particle size distribution was $48.89 \mathrm{~nm}$ with a maximum concentration level of $1 \times 10^{6}$ particles/cc. For the high speed cruise and normal cruise mode, the particle size distribution was very similar with a CMD of 75.91 and $71.84 \mathrm{~nm}$, respectively. The concentration levels for the cruise modes were almost twice that of the steady state mode and almost ten times that of the idle mode.

The geometric standard deviation (GSD) for the steady state, cruise and high speed cruise modes were 1.83, 1.84 and 1.79, respectively. The geometric standard deviation represents the distance of shift from the mean of the whole distribution. GSD values close to 1.8 represent a good distribution about the mean for diesel exhaust. For the idle mode the GSD was 2.9 which clearly indicates that the distribution is uneven and this can also be inferred from Figure 15. The particles seen in the cruise modes lie in the accumulation mode with higher concentrations. The shift towards a higher particle size is likely due to a higher concentration of carbonaceous soot in the exhaust which can be clearly noted from Figure 19. Sulfate emissions were almost 20 times higher in the cruise 
mode at $0.43 \mathrm{~g} /$ hour than in the idle mode at $0.021 \mathrm{~g}$ /hour (Figure 19). Acetone emissions were unusually high for the transient mode at $212.39 \mathrm{~g} /$ hour (Figure D11).

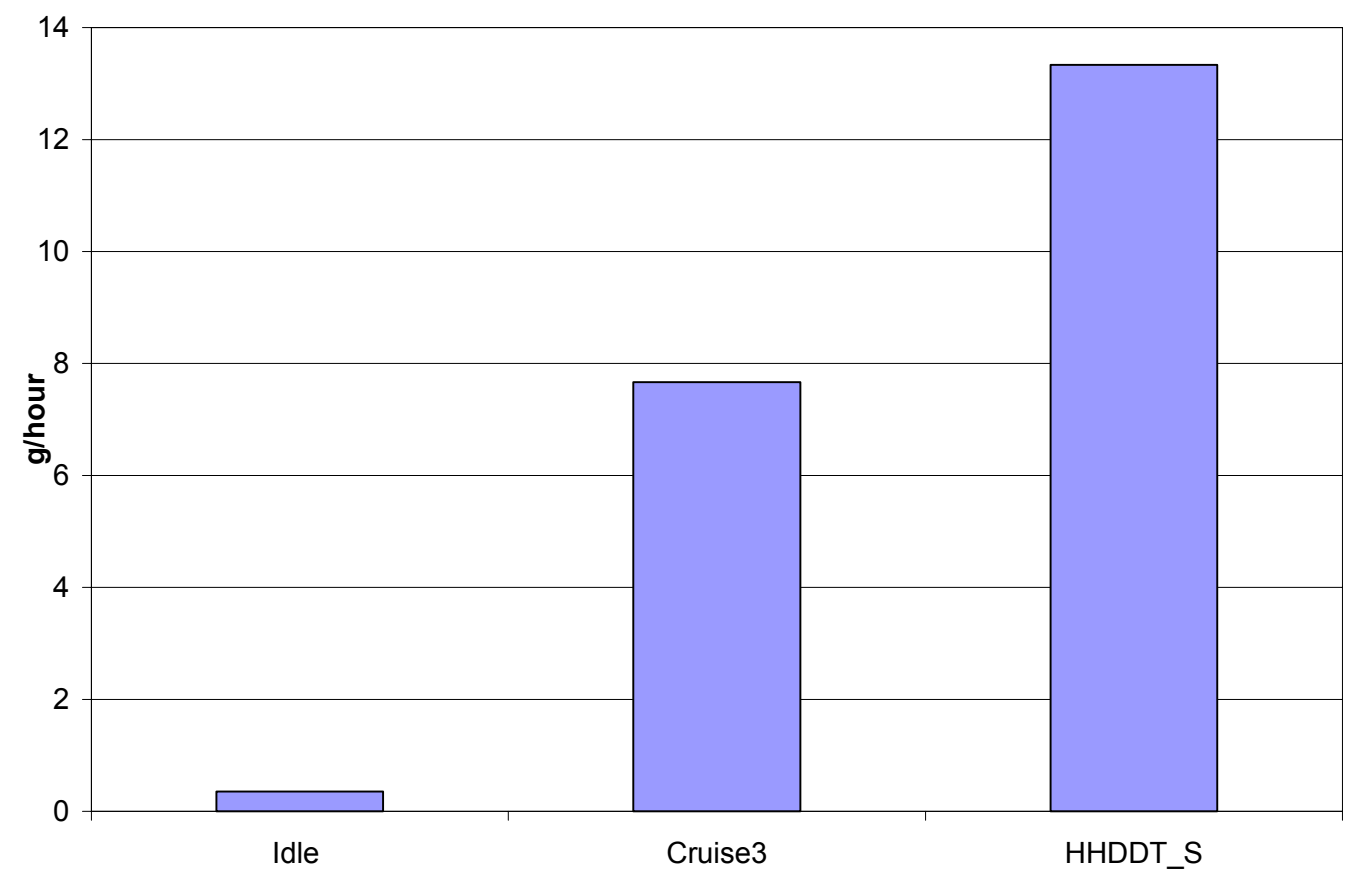

Figure 17: PM Mass Emissions for CRC 39

Contribution of nitro-PAH and hopanes \& steranes compounds (Figure D8 and D10) were not significant. Sulfates along with semi-volatile and carbonyl compounds usually adsorb onto carbon particles and form a cluster structure which increases the size of the particles and the size spectrum is shifted towards the larger accumulation mode which is evident from Figure 16. These analyses show that accumulation mode particles formed during the cruise mode are mostly made up of semi-volatile compounds with a solid carbonaceous core. The higher concentration of particles in the cruise modes can be attributed to the fact that elemental carbon, sulfates and other semi-volatile compounds are emitted in large quantities when compared to the idle mode. 


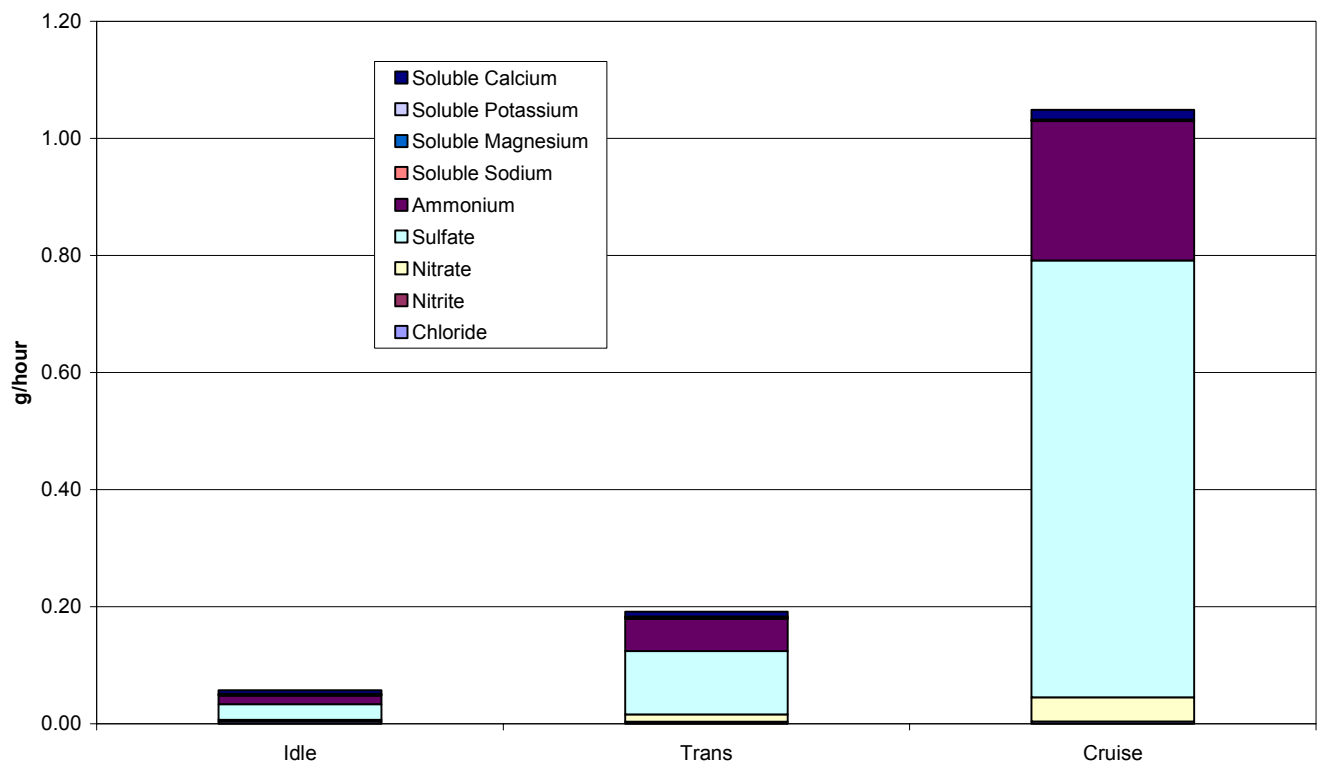

Figure 18: Ion Composites Results for CRC 39

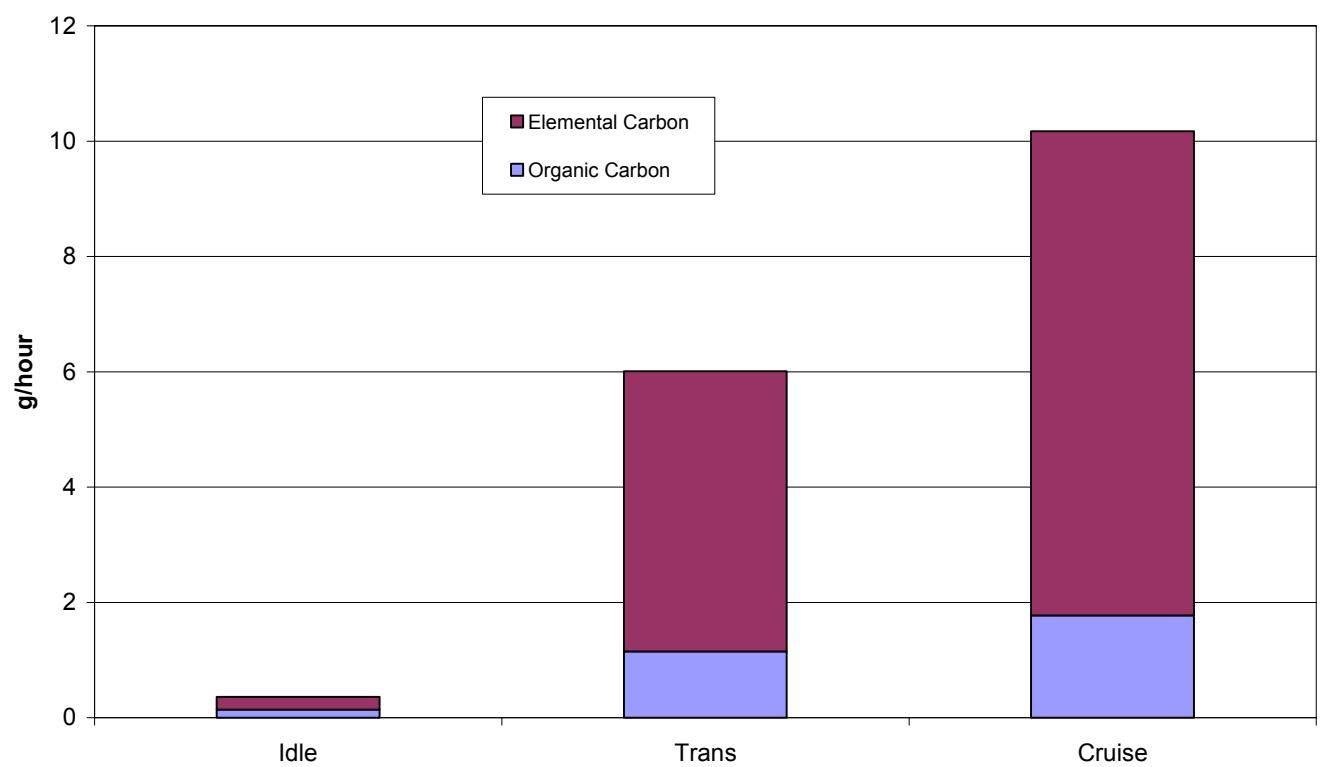

Figure 19: Elemental Carbon- Organic Carbon Analysis for CRC 39 


\subsection{Particle Sizing and Chemical Speciation Results for CRC 40}

CRC 40 was a powered by a Detroit Diesel Series 60, model year 2003 engine. Particle sizing and chemical speciation results are presented below for various modes of the HHDDT schedule. Figures 20 and 21 present the particle size distribution for idle and steady modes.

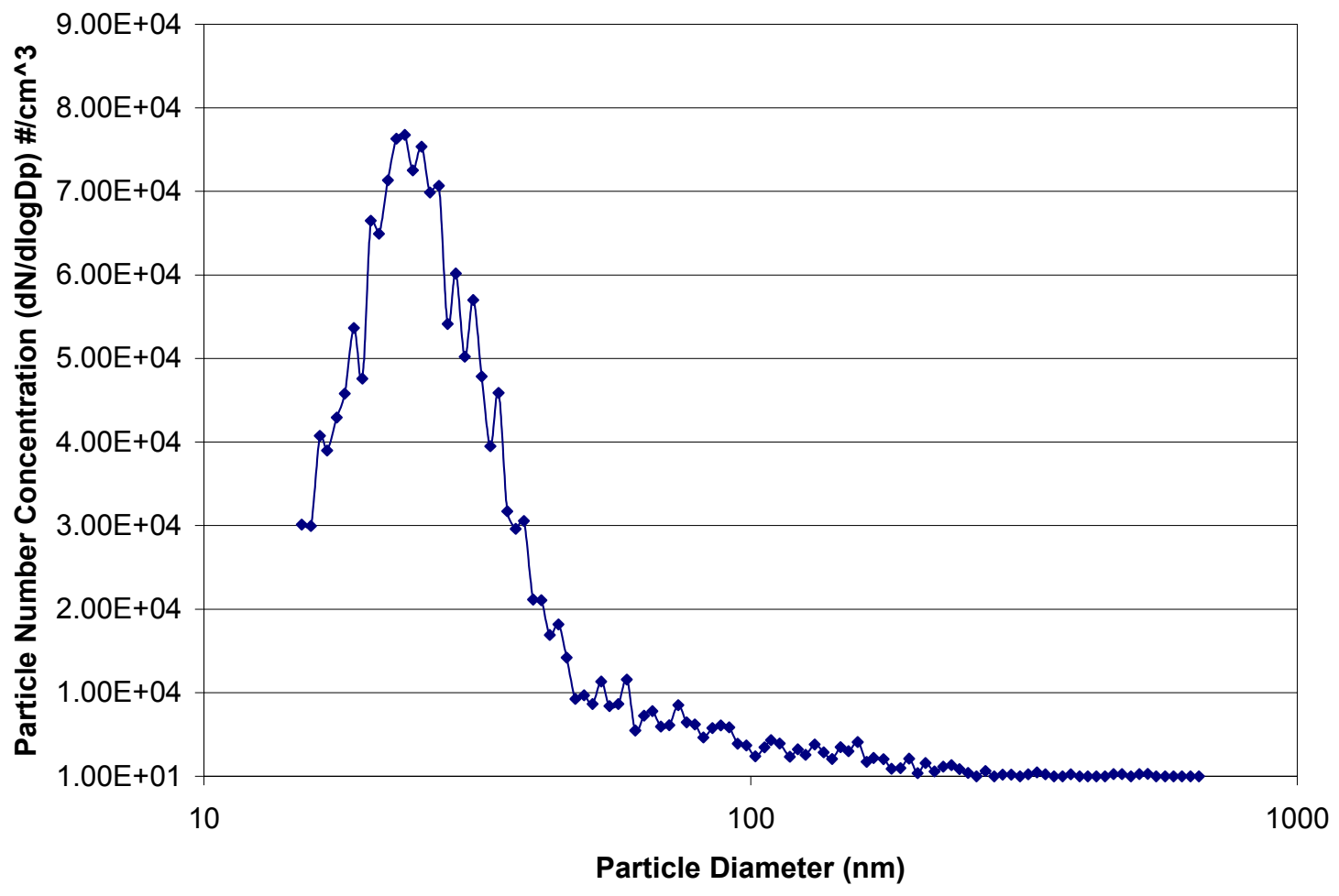

Figure 20: Particle Size Distribution for CRC 40 Operating on an Idle Mode

A unimodal distribution was seen for the idle mode with a count median diameter (CMD) of $25.88 \mathrm{~nm}$ with a concentration of $8 \times 10^{4}$ particles/cc and a geometric standard deviation of 1.64. These concentration levels were almost four times lower than those observed for CRC 39. This drop in concentration could be attributed to difference in the emissions of volatile organic compounds. The total VOC's emitted for CRC 40 at 2.01 
$\mathrm{g} /$ hour during the idle mode was almost eight times lower in magnitude as compared to CRC 39 at $15.51 \mathrm{~g} /$ hour.

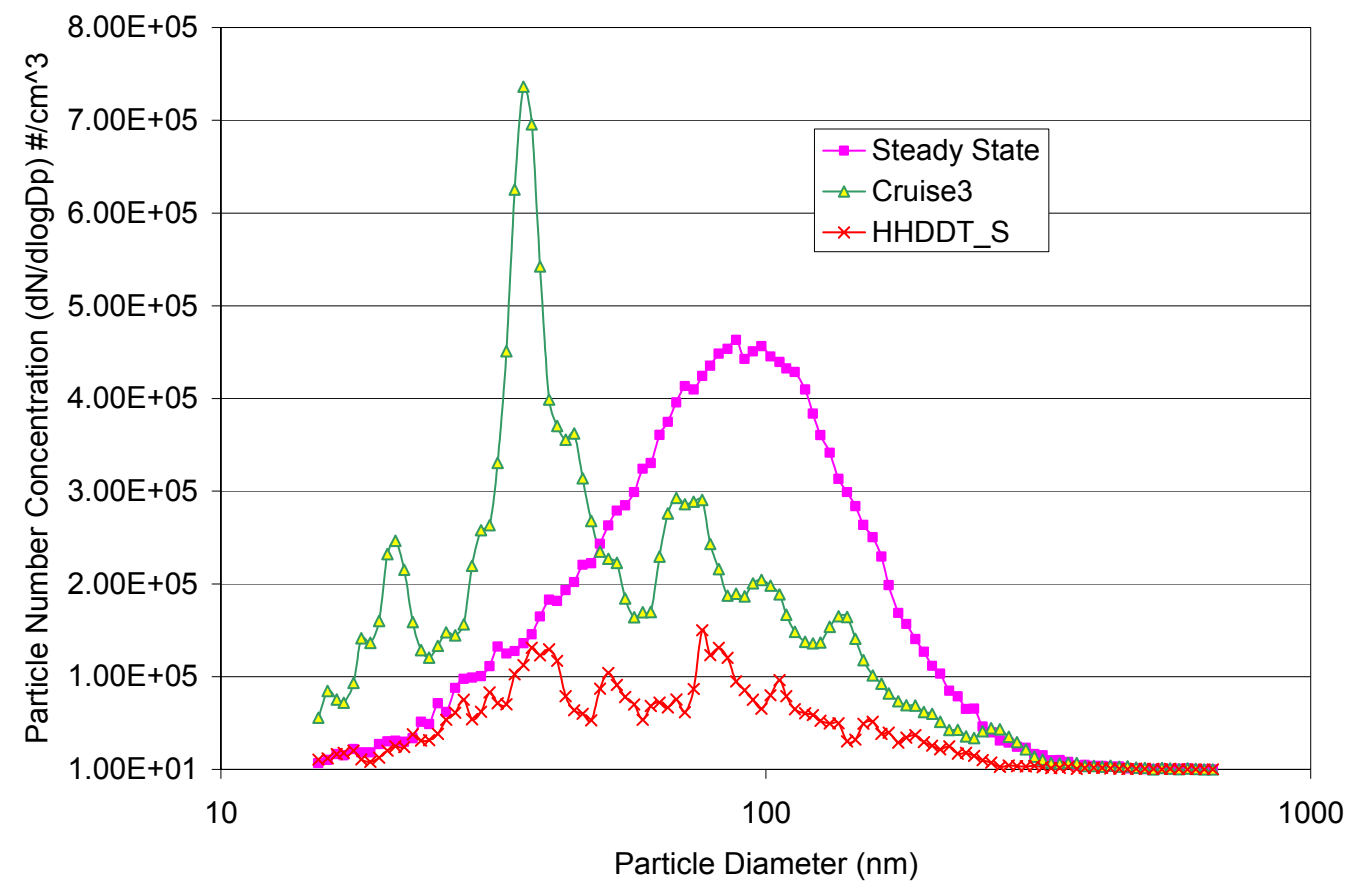

\section{Figure 21: Particle Size Distribution for CRC 40 Operating on Various Steady Cycles}

VOC results were very similar for CRC 40 when idle and cruise mode were compared (Figure D13 to D17). Emissions of n-hexane and 2-methyl-1-pentene were high during the transient mode when compared with the idle and cruise modes (Figure D15 and D16). For the steady state mode, the CMD for the particle size distribution was $84.96 \mathrm{~nm}$ with a concentration of $4.5 \times 10^{5}$ particles/cc and a GSD of 1.75. Particle size distributions were markedly different for the two cruise modes with a CMD of $45.1 \mathrm{~nm}$ for the normal cruise mode and $62.24 \mathrm{~nm}$ for the high speed cruise mode. Size distributions observed in the cruise modes were characterized by the accumulation mode particles. 
The shift of the size spectrum towards a higher accumulation range during the cruise modes when compared to the idle mode could be attributed to a high sulfate emission during the cruise mode. Sulfate emissions were very high during the cruise mode at $0.27 \mathrm{~g} /$ hour when compared with the idle mode at $0.015 \mathrm{~g}$ /hour (Figure 24). Sulfate emissions serve as the precursors of particle formation seen in nuclei mode. Sulfates would undergo a hetero-molecular nucleation with the water molecules to form a cluster. Subsequent adsorption of volatile organics and agglomeration with the elemental carbon results in the distribution seen in Figure 21. Elemental carbon emission for the cruise mode were very high at $5.5 \mathrm{~g} /$ hour when compared to the idle mode at $0.07 \mathrm{~g} /$ hour (Figure 24), which also contributed to most of the mass emissions (Figure 23). Semi volatile emissions were similar for idle and cruise modes except for alkanes and hopanes $\&$ steranes which were higher during the cruise mode (Figure D18 to D22).

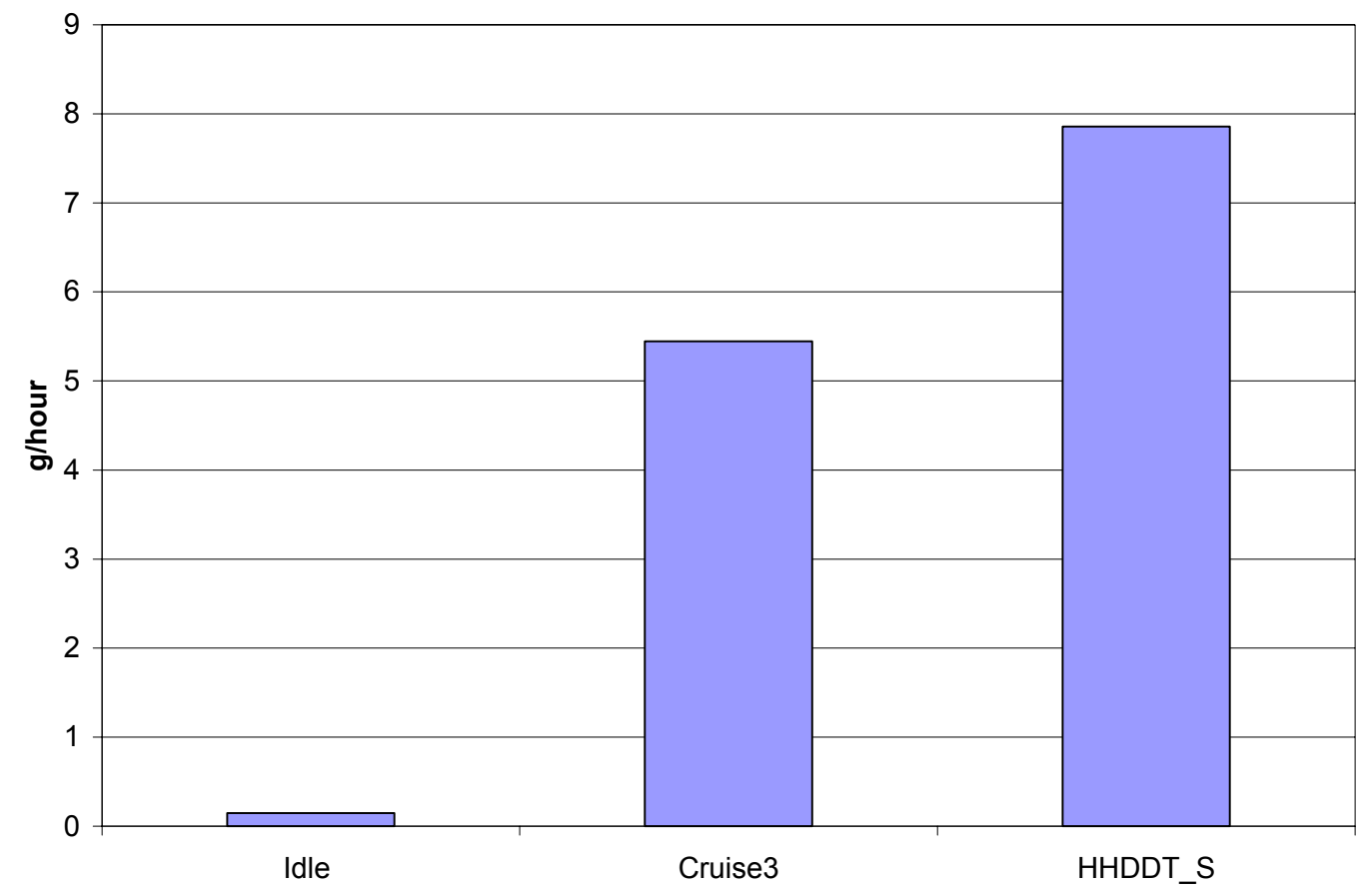

Figure 22: PM Mass Emissions for CRC 40 


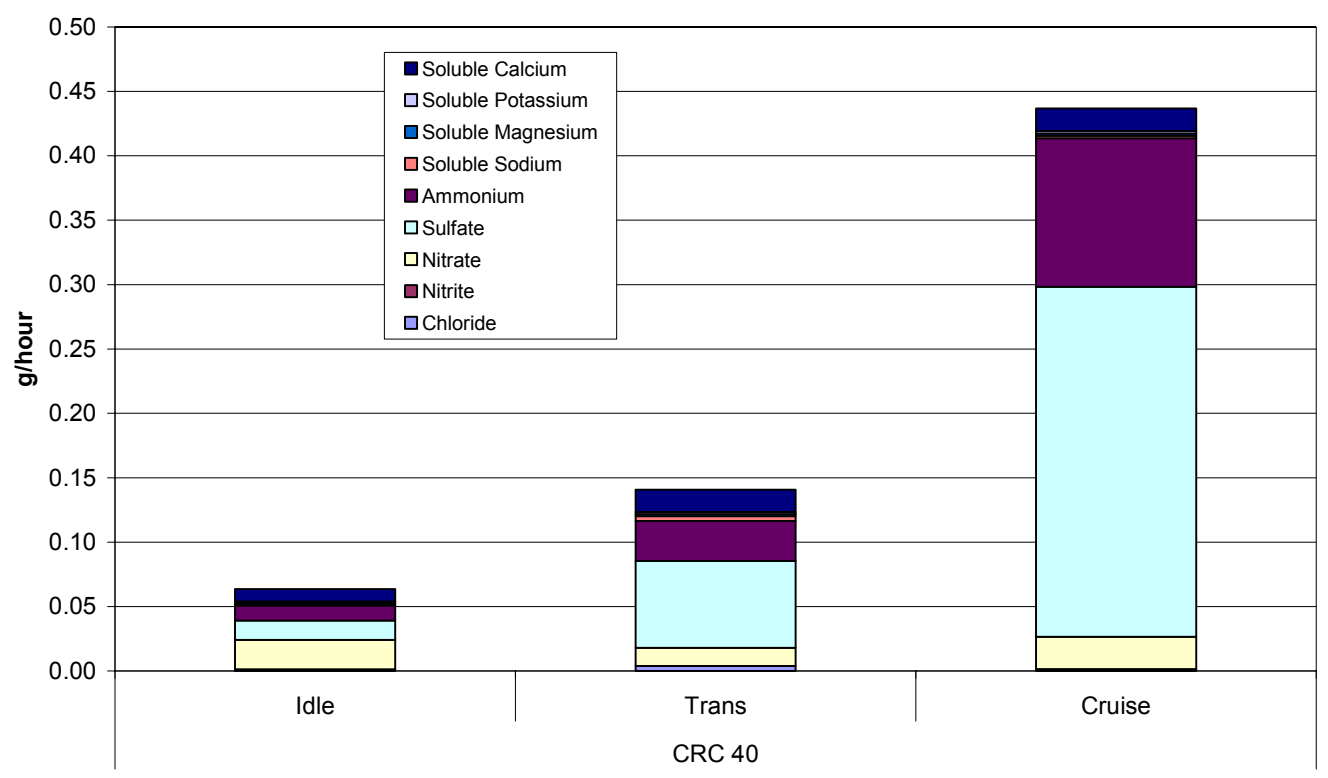

Figure 23: Ion Composites Results for CRC 40

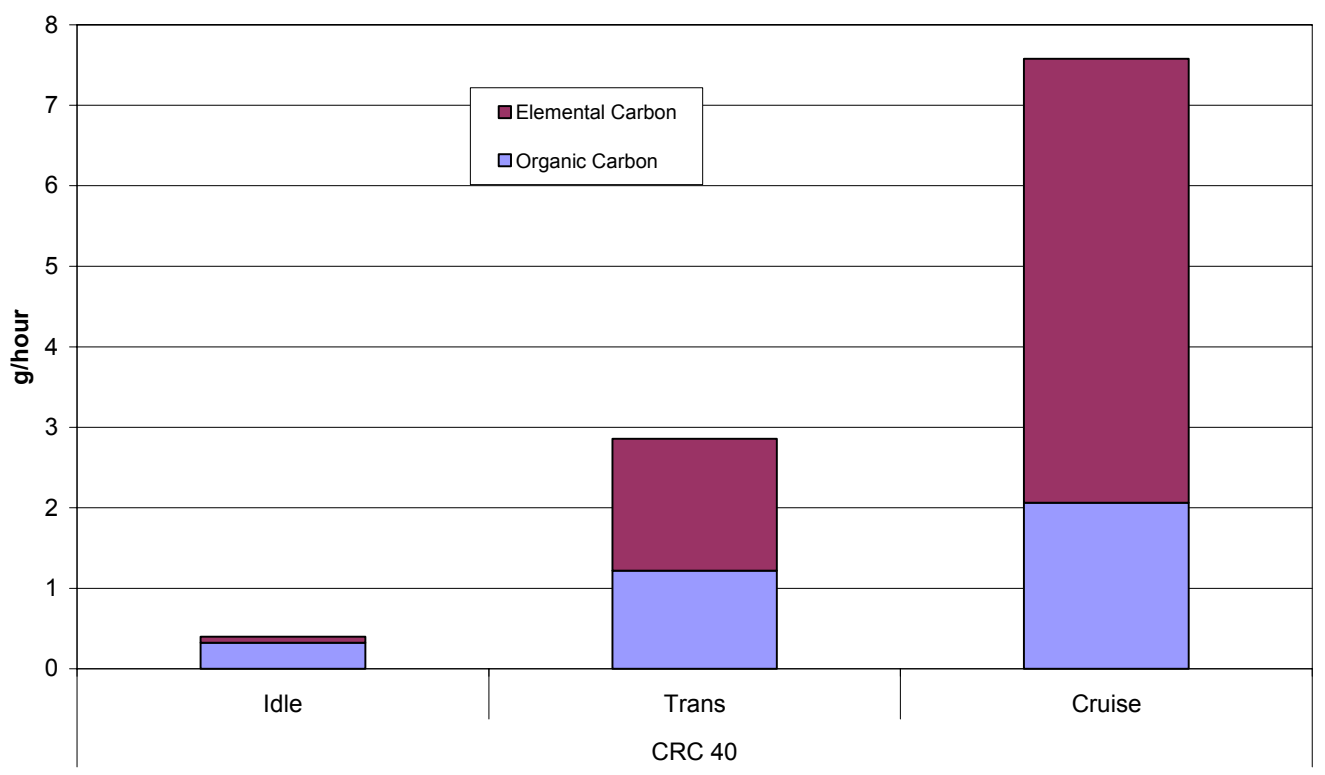

Figure 24: Elemental Carbon- Organic Carbon Analysis for CRC 40 


\subsection{Particle Sizing and Chemical Speciation Results for CRC 42}

CRC 42 was a powered by a Caterpillar 3406, model year 1999 engine. Particle sizing and chemical speciation results are presented below for various modes of the HHDDT schedule. Figures 25 and 26 present the particle size distribution for idle and steady modes.

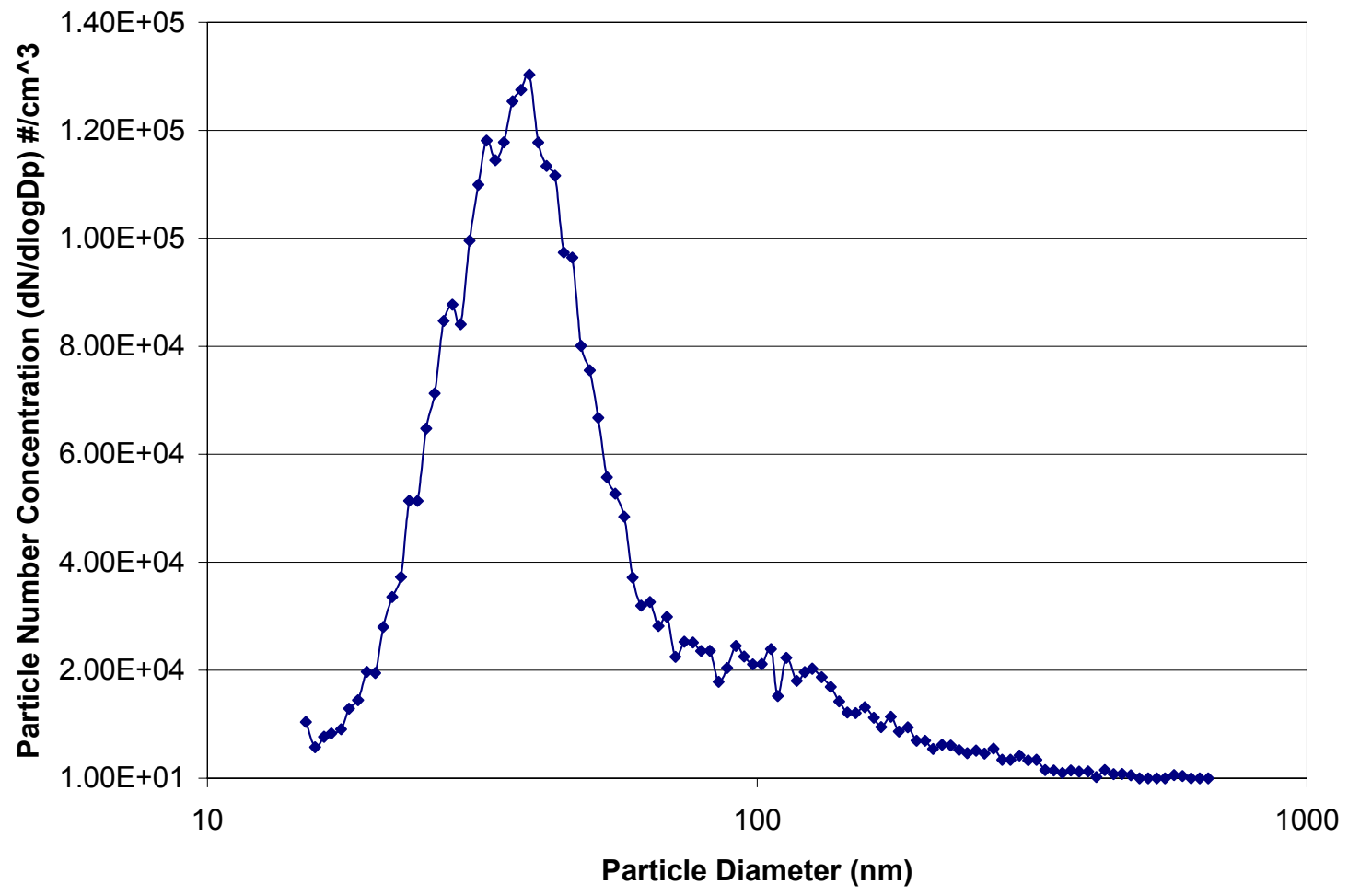

Figure 25: Particle Size Distribution for CRC 42 Operating on an Idle Mode

A typical uni-modal size distribution was noted for the idle mode for CRC 42 (Figure 26) with a CMD of $40 \mathrm{~nm}$ and concentration of $8 \times 10^{4}$ particles/cc. In comparison to CRC 39 and 40, the size distribution shifted towards a larger particle size for CRC 42 during the idle mode. In addition to the nuclei mode, the size distribution is also characterized by a mode with a CMD of $100 \mathrm{~nm}$. 


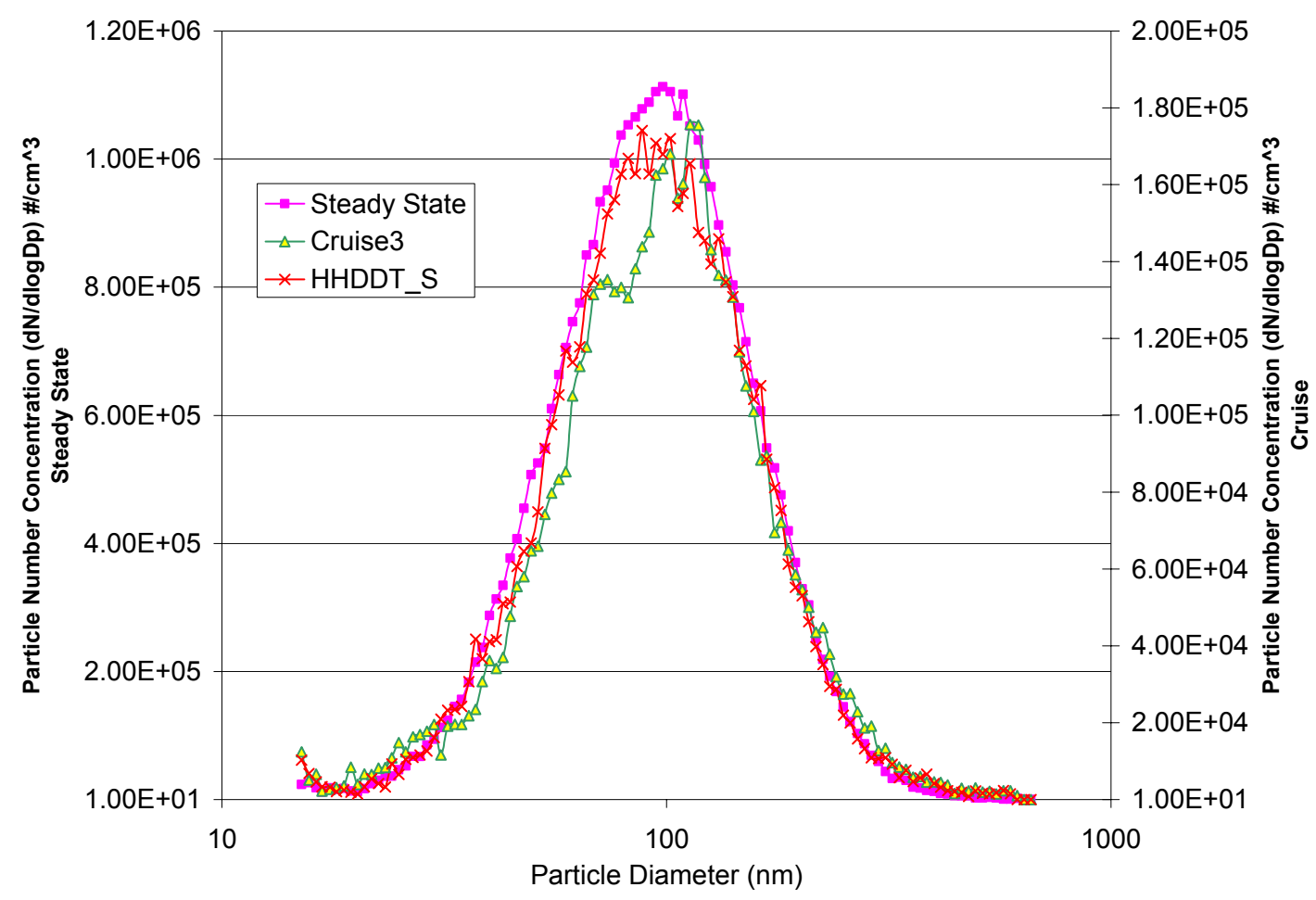

Figure 26: Particle Size distribution for CRC 42 operating on various steady cycles

The accumulation mode observed during the idle could be due to an increase in elemental carbon emission when compared to the previous vehicles tested. During the idle mode, the elemental carbon emitted by CRC 39 and 40 were $0.21 \mathrm{~g} /$ hour and 0.07 $\mathrm{g} /$ hour respectively and for CRC 42, the values were higher at $0.55 \mathrm{~g} /$ cycle (Figure 29). This increase in elemental carbon also increased the mass emission for the idle mode at $1.34 \mathrm{~g} /$ hour (Figure 27). Mass emissions during idle for CRC 39 and 40 were $0.35 \mathrm{~g} /$ hour and $0.14 \mathrm{~g} /$ hour respectively. Total Volatile organic compounds emitted by CRC 42 during the idle mode at $2.99 \mathrm{~g}$ /hour were much lower when compared with the cruise mode at $6.04 \mathrm{~g} /$ hour (Figure D25 to D29). The nature of particles emitted during the idle mode of this particular vehicle could be mostly carbonaceous particles with volatile compounds adsorbed onto the surface. 


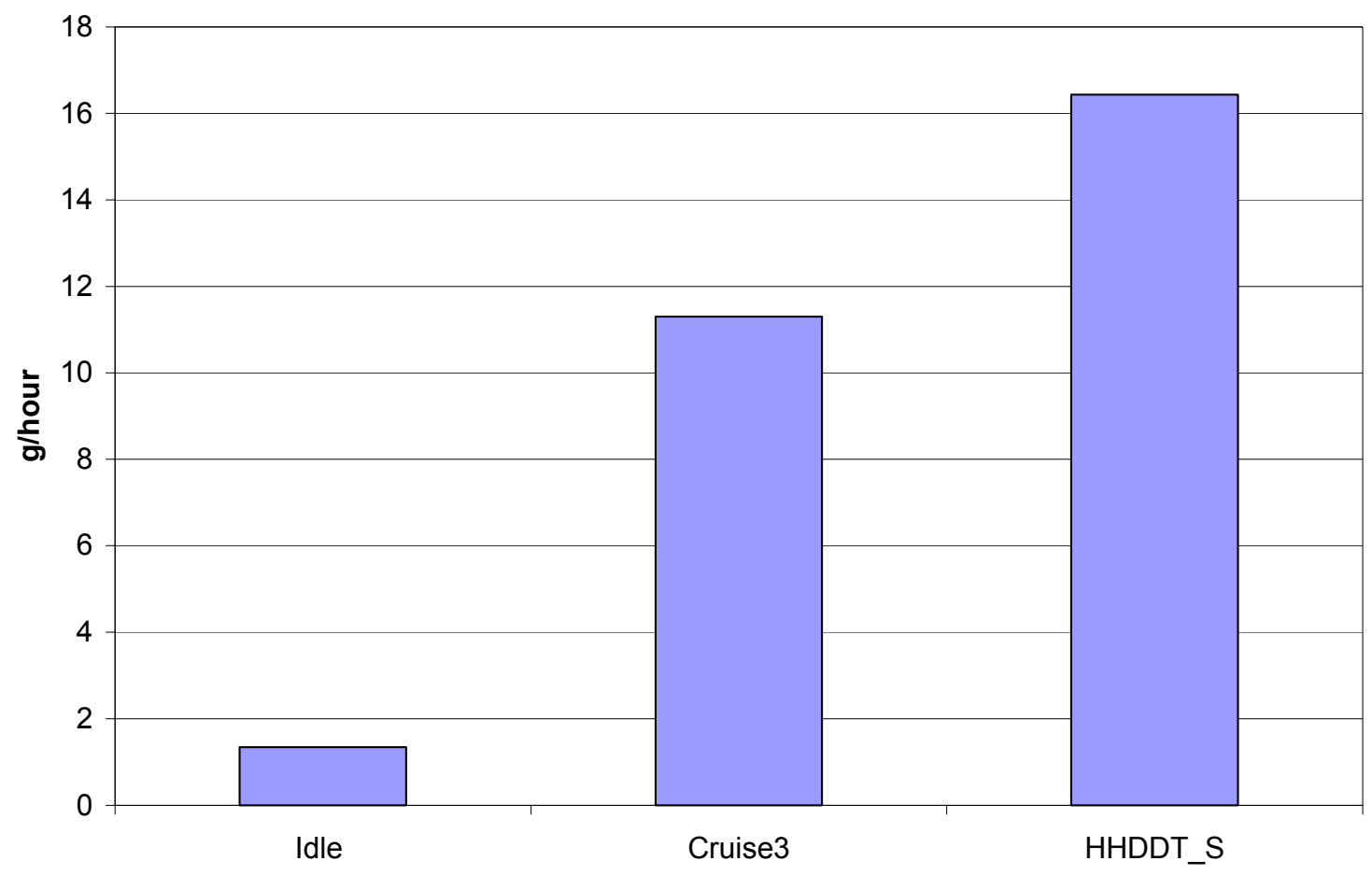

Figure 27: PM Mass Emissions for CRC 42

Particle sizes measured during the steady state and cruise mode were similar with a CMD of $93.6 \mathrm{~nm}, 98.39 \mathrm{~nm}$ and $93.71 \mathrm{~nm}$ for the steady state, normal cruise and high speed cruise modes respectively. Concentrations for the steady state mode were 6 times higher in magnitude as compared with both the cruise modes. Concentration drop for the cruise mode could be due to a higher exhaust temperature. Sulfate emissions were higher during the cruise mode at $0.54 \mathrm{~g} /$ hour when compared to idle mode at $0.06 \mathrm{~g} /$ hour (Figure 29). Carbonaceous particles along with sulfates and an adsorbed layer of volatile and semi-volatile particles mostly constitute the nature of the particles emitted during the steady cycles. 


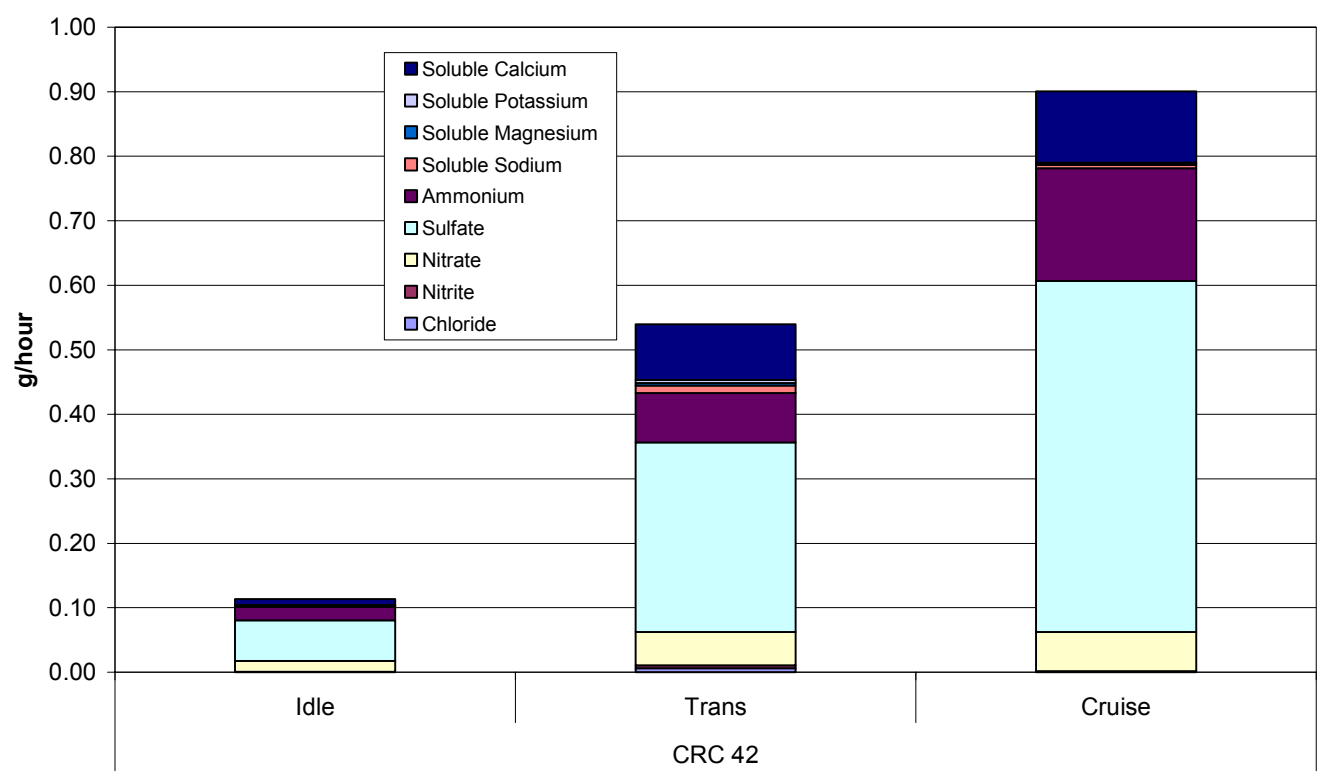

Figure 28: Ion Composites Results for CRC 42

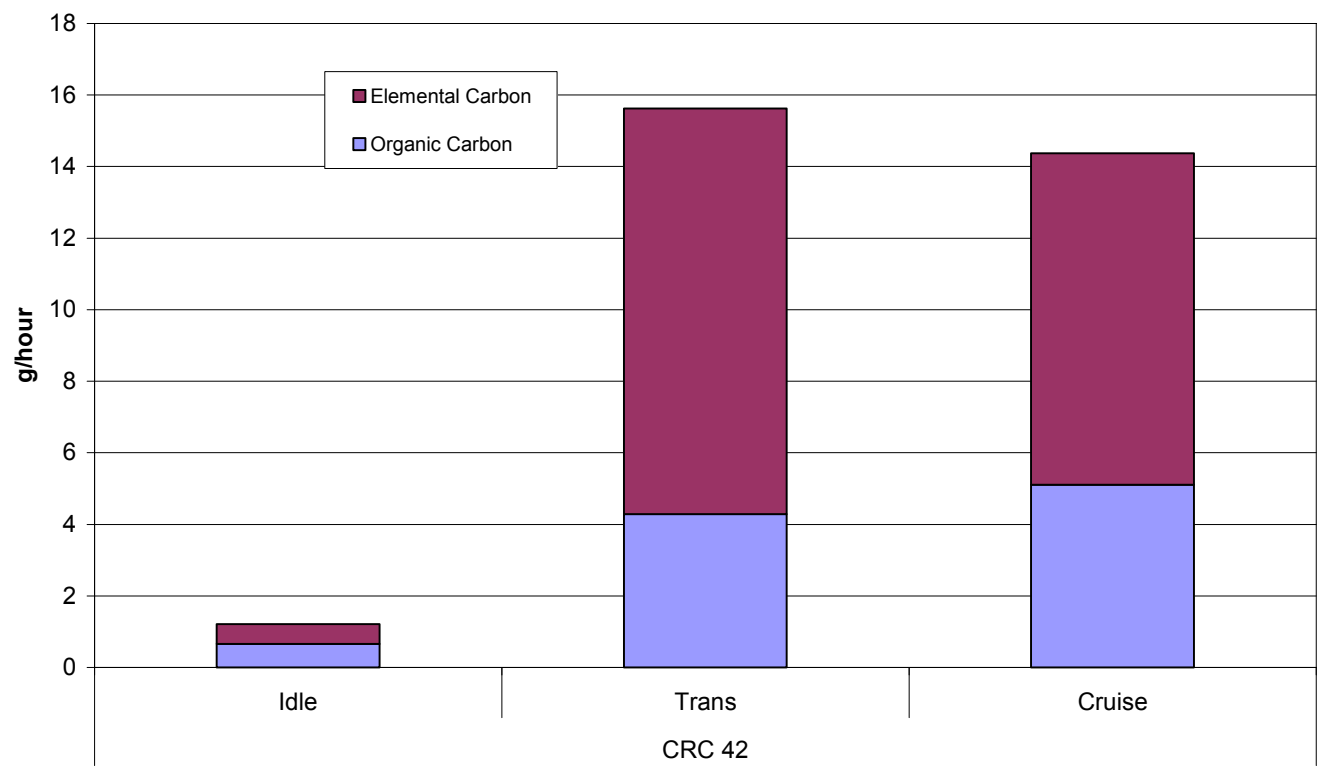

Figure 29: Elemental Carbon- Organic Carbon Analysis for CRC 42 


\subsection{Particle Sizing and Chemical Speciation Results for CRC 43}

CRC 43 was a powered by a Detroit Diesel Series 60, model year 1994 engine. Particle sizing and chemical speciation results are presented below for various modes of the HHDDT schedule. Figures 30 and 31 present the particle size distribution for idle and steady modes.

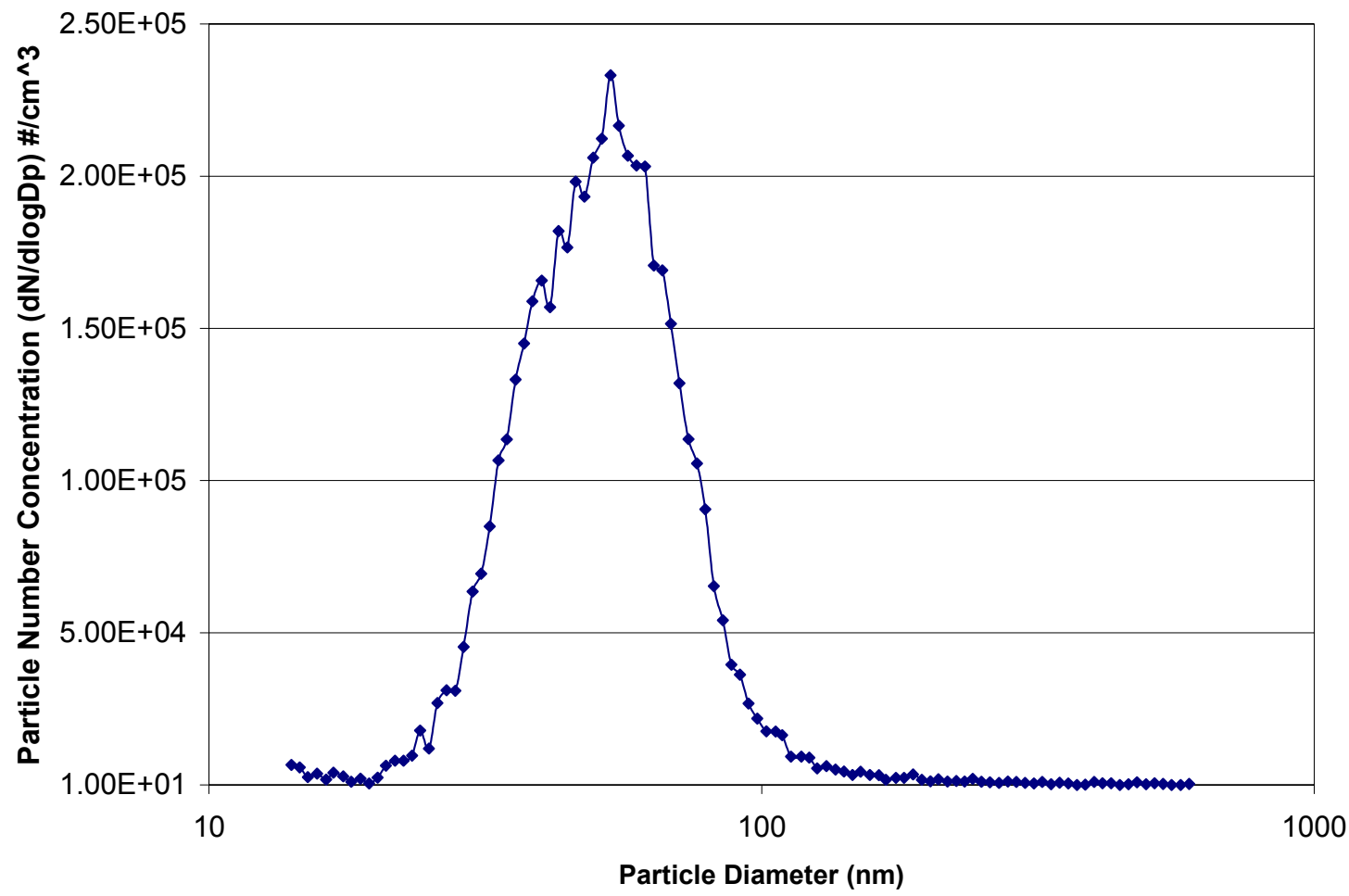

Figure 30: Particle Size Distribution for CRC 43 Operating on an Idle Mode

Particle size distribution for idle mode was unimodal with a CMD of 51.43nm and a GSD of 1.44 which indicates a good distribution about the mean. Maximum concentration level was around $2.25 \times 10^{5}$ particles/cc. These particles are mostly accumulation mode particles as observed for CRC 42. Reasons for this accumulation mode are similar to those listed for CRC 42. 


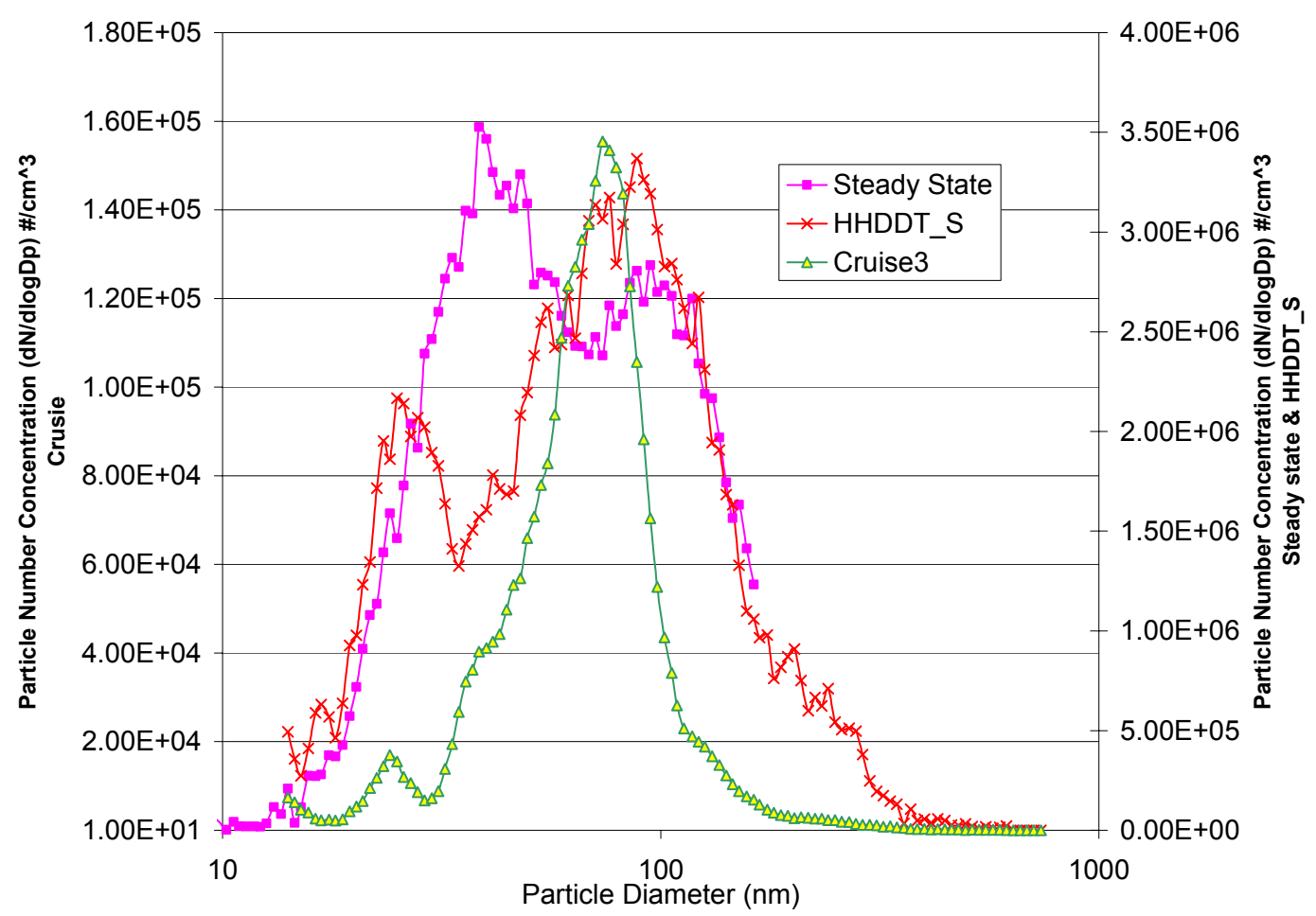

Figure 31: Particle Size Distribution for CRC 43 Operating on Various Steady Cycles

The total volatile organic compounds emitted by this particular vehicle were 2.28 $\mathrm{g} /$ hour for idle and $3.39 \mathrm{~g} /$ hour for cruise. Volatile compounds decreased by $20 \%$ for idle emissions when compared with the previous vehicle (CRC 42). A shift in the particle size was noted for the steady cycles. For the steady state and high speed cruise modes, the GSD were 1.88 and 2.6 respectively, which is higher than the normal GSD which denotes a random distribution about the mean which can be clearly observed from Figure 31. The CMD noted for the steady state, normal cruise and high speed cruise modes were $54.32,68.5$ and $69.56 \mathrm{~nm}$ respectively. Elemental carbon emissions were very high during the cruise mode at $3.17 \mathrm{~g} /$ hour when compared to idle mode emissions at 0.25 $\mathrm{g} /$ hour. Organic carbon emissions were higher during the cruise mode at $6.15 \mathrm{~g} /$ hour when compared to idle mode emissions at $1.03 \mathrm{~g} /$ hour. 


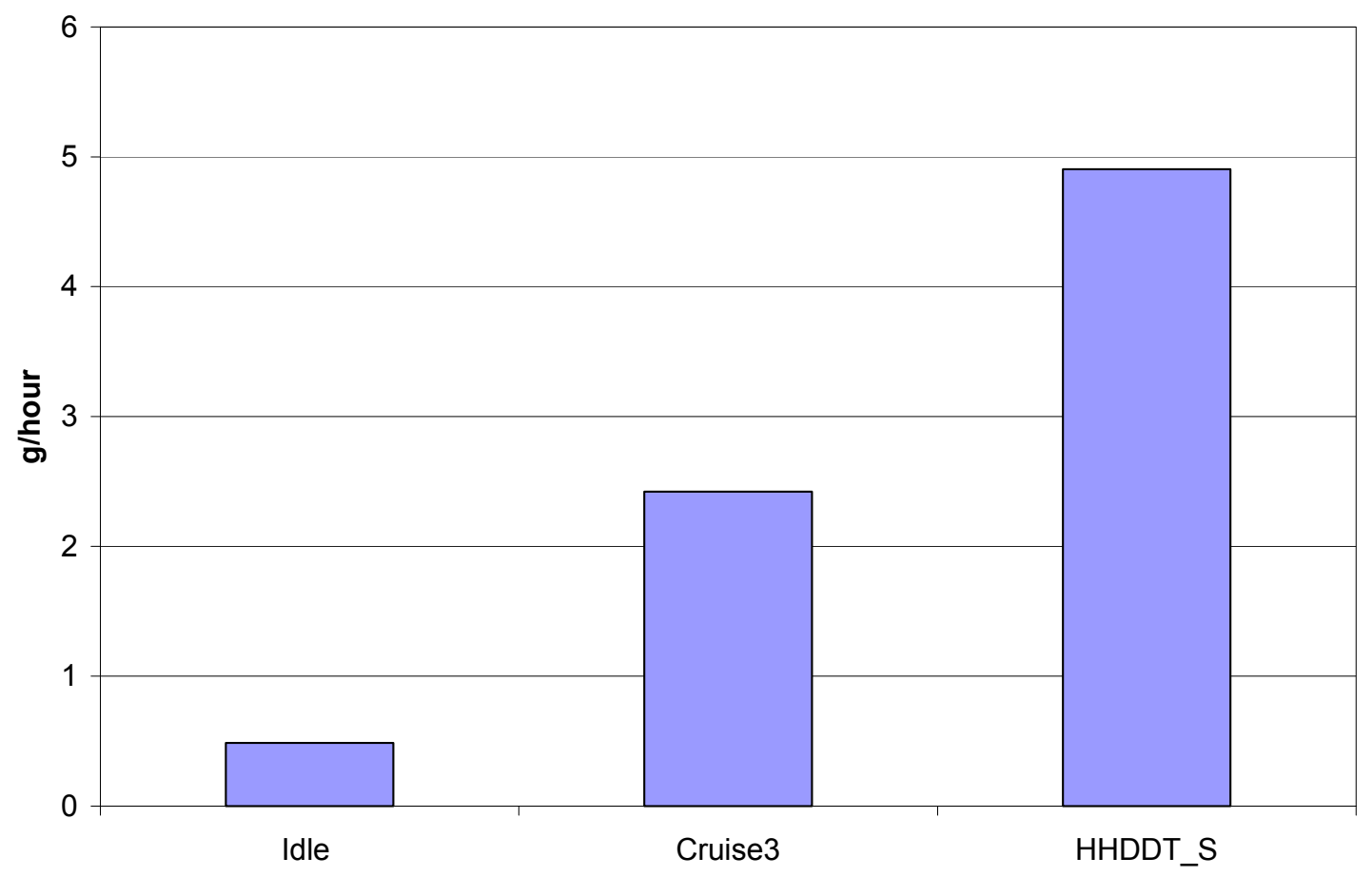

Figure 32: PM Mass Emissions for CRC 43

The increase in the size range and the concentration in the cruise modes could be due to a very high increase in the elemental carbon emission. A slight increase by $12 \%$ in the VOC emission was noted for the cruise mode (Figure D37 to D41). An 85\% increase in the sulfate emission was noted for the cruise mode (Figure 33). Calcium was also a major contributor to the inorganic species with an increase of $91 \%$ for the cruise mode. Calcium could be possibly formed from the combustion of lubrication oil, since calcium is a major constituent in lube oil. Particles measured during the cruise mode of this particular vehicle could be mostly carbonaceous soot with heavy hydrocarbons adsorbed onto the surface. 


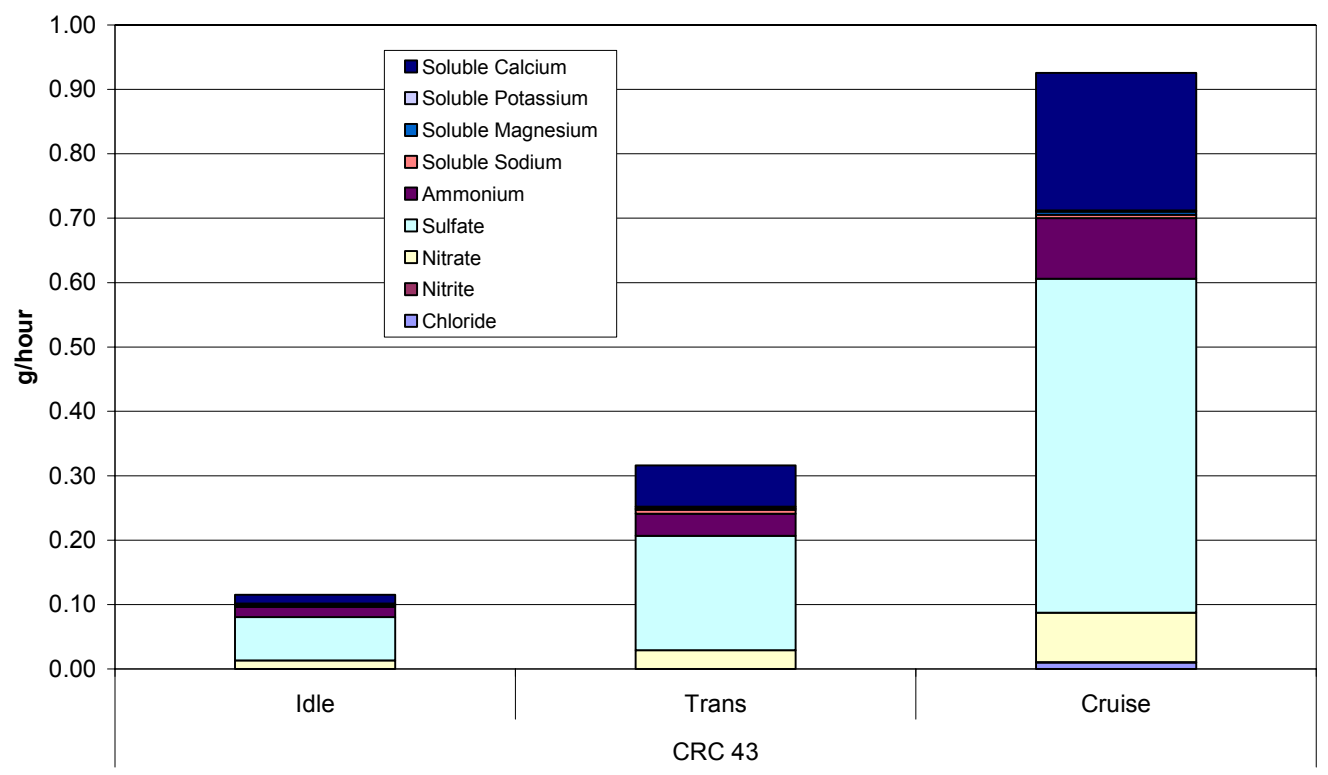

Figure 33: Ion Composites Results for CRC 43

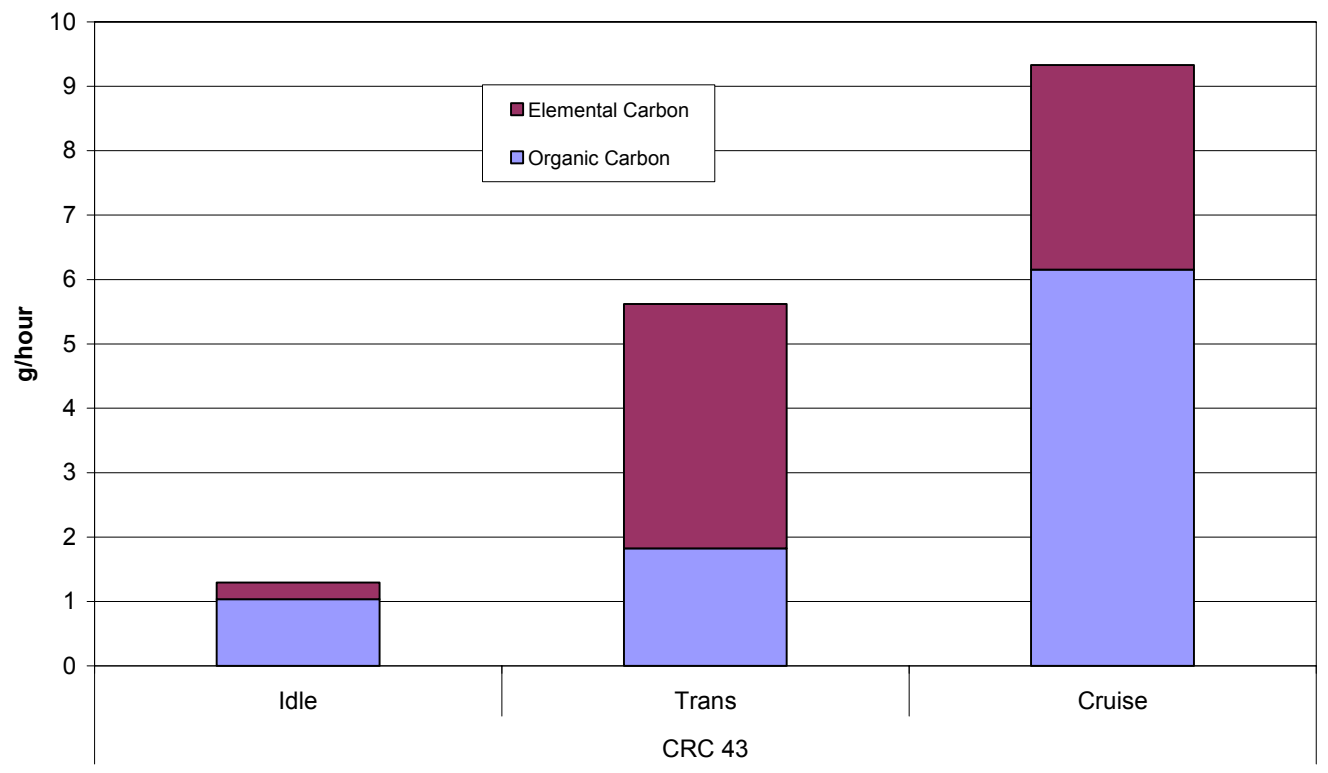

Figure 34: Elemental Carbon- Organic Carbon Analysis for CRC 43 


\subsection{Particle Sizing and Chemical Speciation Results for CRC 44}

CRC 44 was a powered by a Caterpillar 3406, model year 1989 engine. Particle sizing and chemical speciation results are presented below for various modes of the HHDDT schedule. Figures 36 and 37 present the particle size distribution for idle and steady modes.

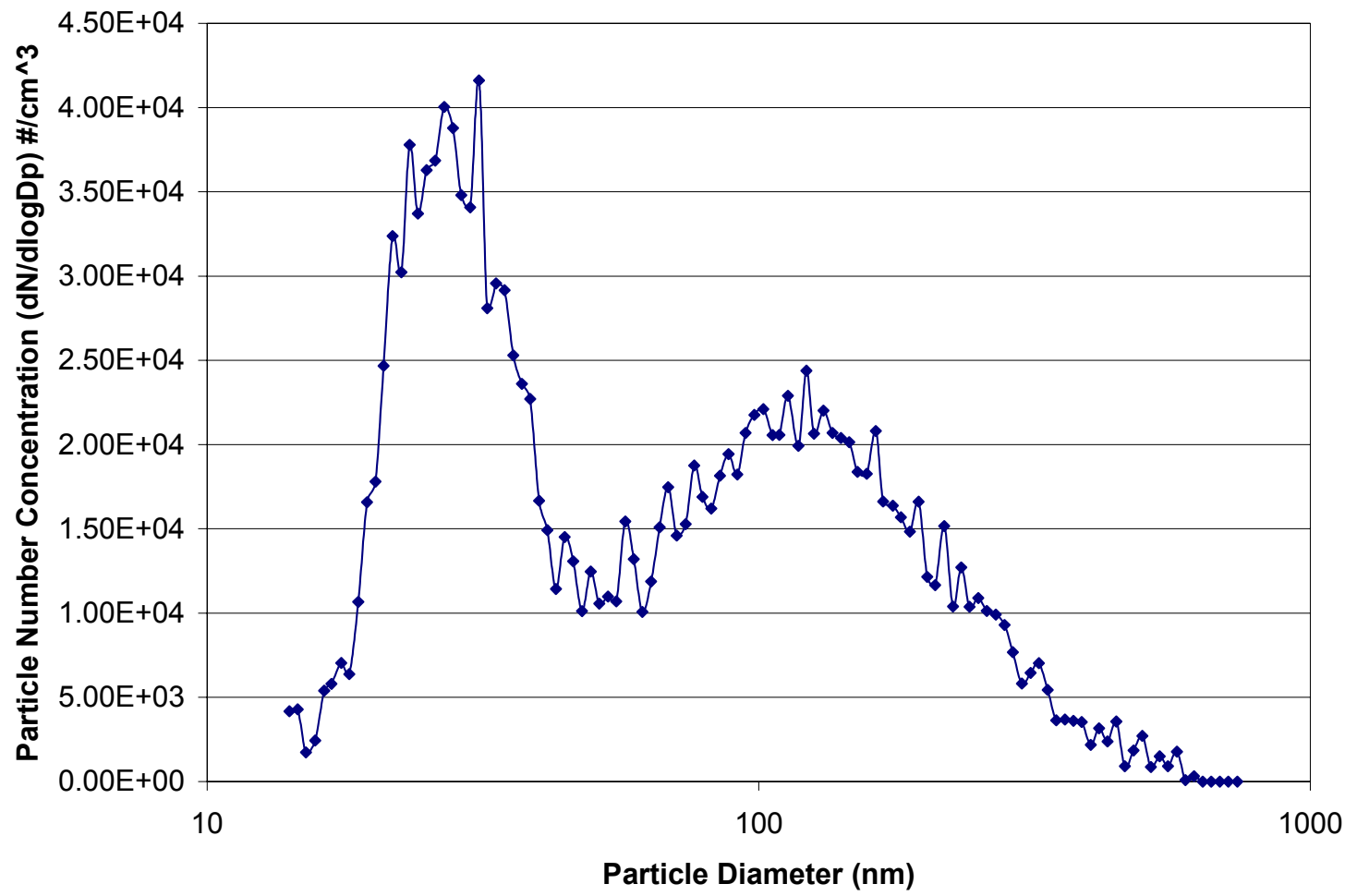

Figure 35: Particle Size Distribution for CRC 44 Operating on an Idle Mode

A bimodal distribution was noted for this particular vehicle during the idle mode, with one nano-particle peak at $26.9 \mathrm{~nm}$ and another accumulation mode peak at 122nm. The only other vehicle where a bimodal distribution was observed was CRC39 which was a 2004 year model engine. The reason for the bimodal distribution for CRC39 was due to high levels of volatile compounds and elemental carbon during the idle mode. The elemental carbon contributed to the accumulation mode. 


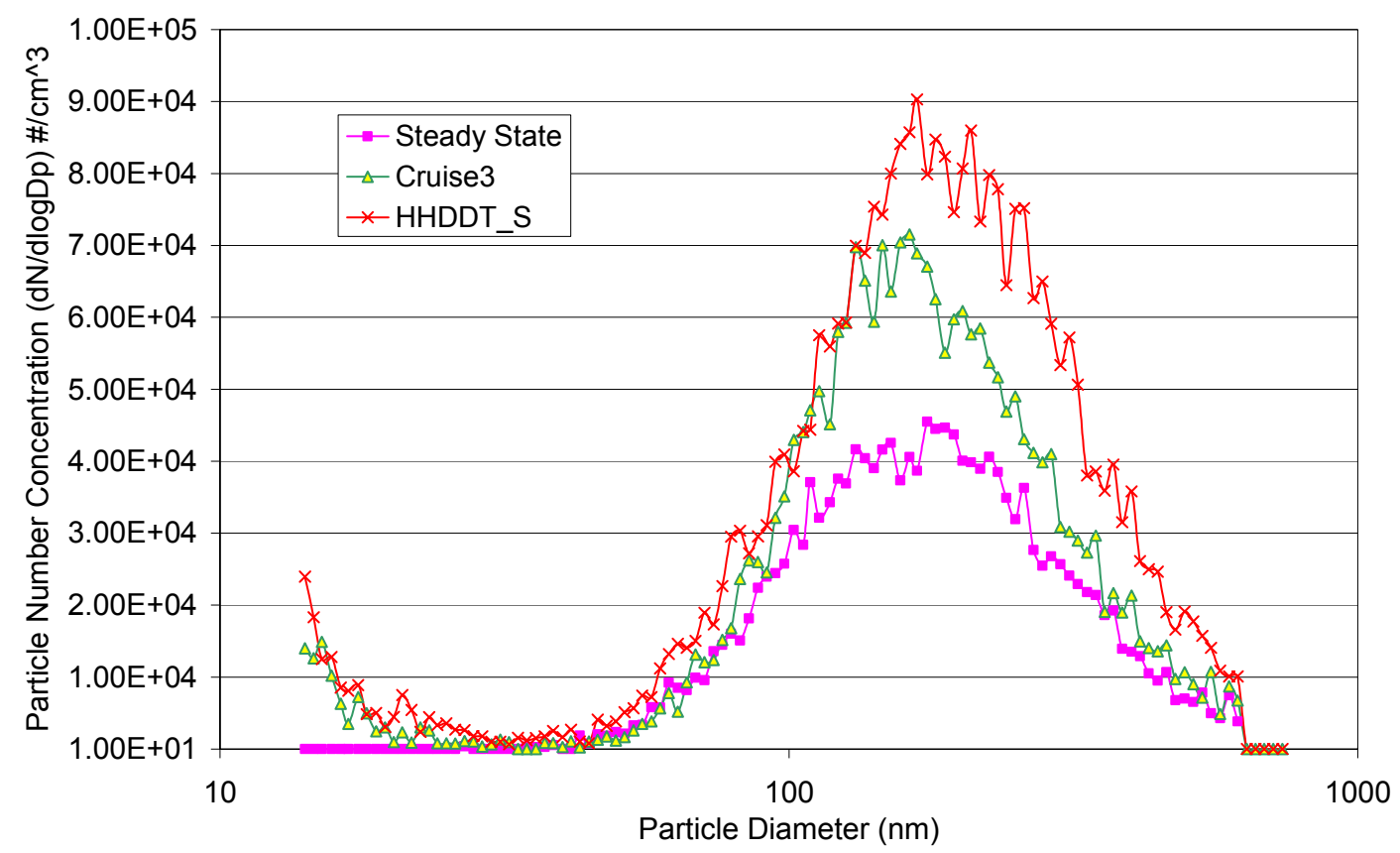

Figure 36: Particle Size Distribution for CRC 44 Operating on Various Steady
Cycles

The nano-particle peak could be due to high emissions of semi-volatile compounds (Figure D54 and D55). The total volatile compound emission for this vehicle was $25 \%$ higher than CRC 43 and 35\% higher than CRC 40 . Further analysis yields that aromatic emissions during the idle mode, especially benzene was prominent for CRC 39 and CRC 44 when compared with the rest of the vehicles in the study (Figure D53). The accumulation mode in the idle is attributed to the presence of carbonaceous particles, with elemental carbon emission during the idle mode being the highest among all the vehicles at $1.22 \mathrm{~g} /$ hour. 


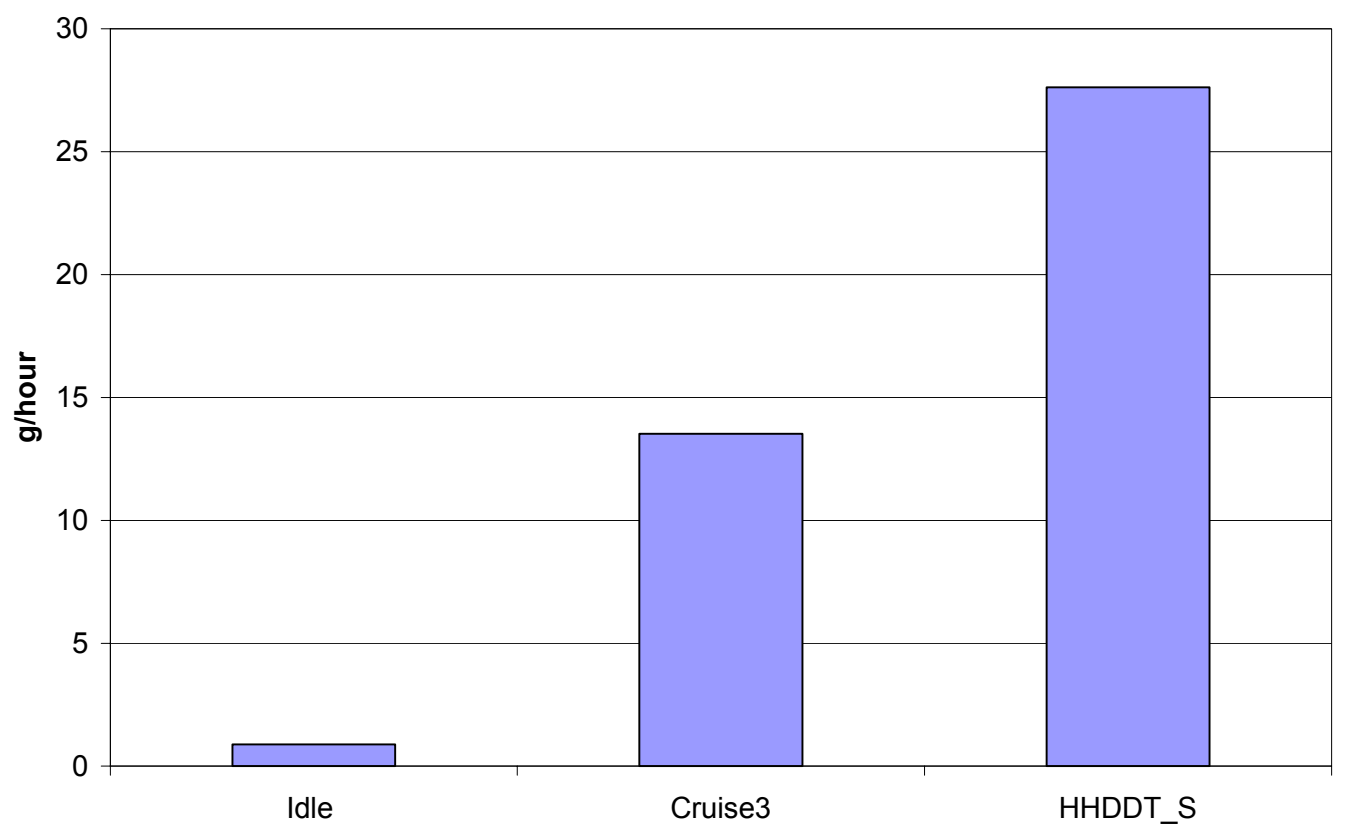

Figure 37: PM Mass Emissions for CRC 44

The steady state particle size distributions were compatible with vehicle speed. Particle concentrations were increasing, though minimally, with increasing speed without much variation in the particle size. The count median diameter for the steady state, normal cruise and high speed cruise were 173, 166 and 178nm respectively. Particles of these sizes are considered to be fine particles since the size range measured was above 100nm. Mass emissions were highest during the cruise and high speed cruise modes when compared to other vehicles (Figure 38). Elemental carbon which is basically soot was noted to be the highest among all the vehicles during the cruise mode (Figure 40) was also a major contributor to the mass emission. This would also contribute to low saturation ratios. Sulfate emissions were among the least emitted when compared with all other vehicles (Figure 39). Results from these data suggest that the fine particles measured during the cruise mode were mostly solid carbonaceous particles. 


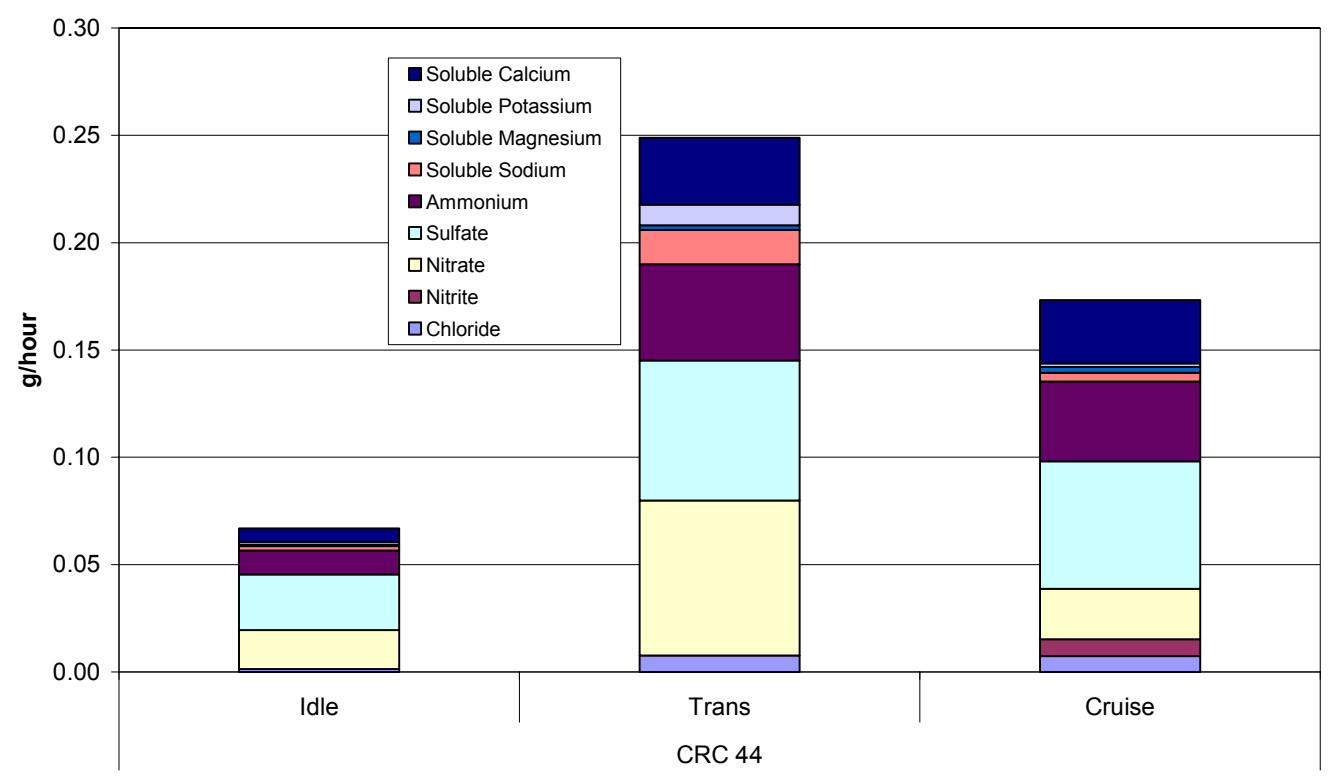

Figure 38: Ion Composites Results for CRC 44

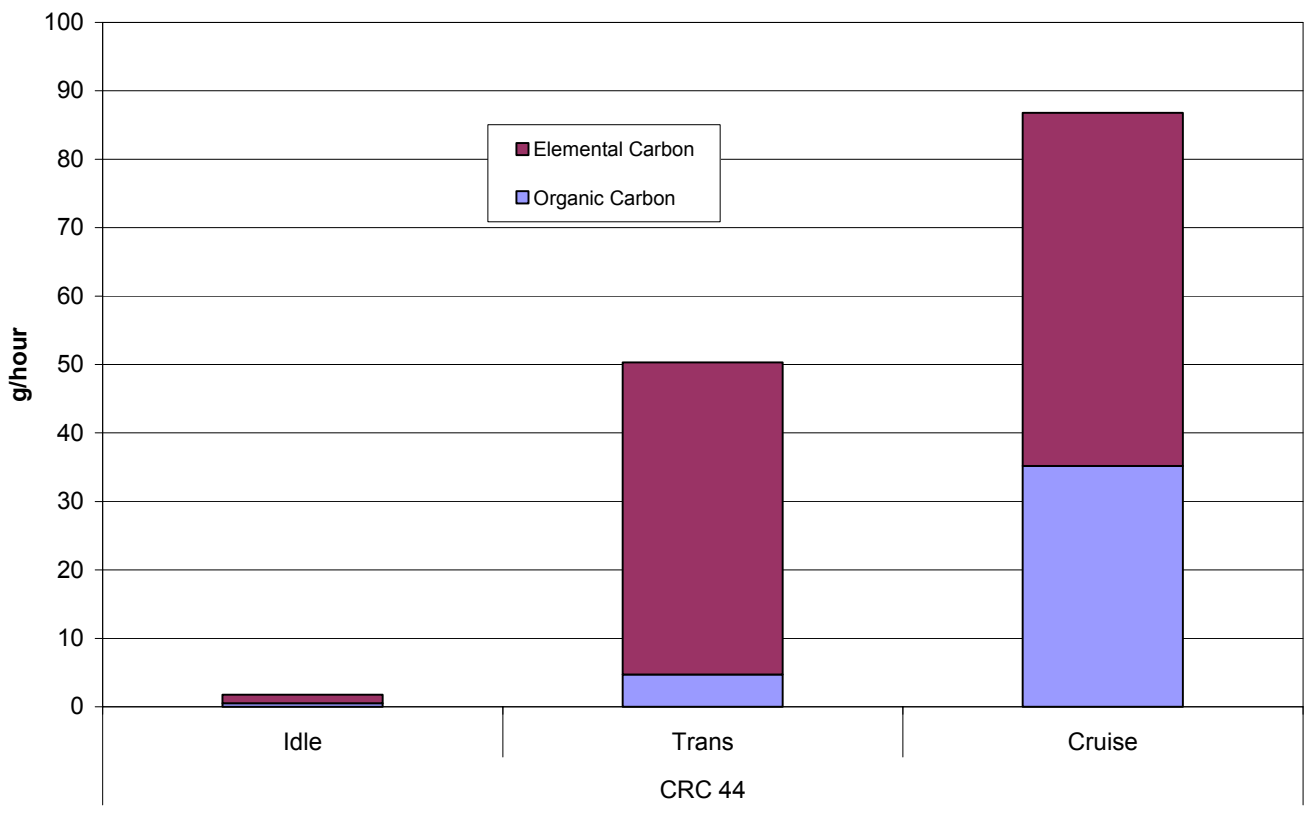

Figure 39: Elemental Carbon- Organic Carbon Analysis for CRC 44 


\section{CONCLUSIONS AND RECOMMENDATIONS}

\subsection{Conclusions}

The objective of this study was to evaluate the effects of different driving cycles on the PM size distributions and concentrations. Since the SMPS can measure the full spectrum of PM size distributions and concentrations only during a steady engine operation, only the idle, steady state and cruise modes were compared. The data presented clearly shows that idle emissions were characterized by a distinct nuclei mode for all vehicles, with a CMD in the range of 30 to $40 \mathrm{~nm}$. The cruise and steady state mode emissions from all vehicles were characterized by accumulation mode particles with a CMD in the range of 60 to $100 \mathrm{~nm}$. Detailed chemical analysis showed that volatile compound emissions tend to be high during the idle mode and that the emission levels were comparable to the cruise mode. Nucleation is usually favored when saturation ratios are high, that is, when solid particulate matter emissions are low. During the idle modes it was noted that elemental carbon emissions were very low and the exhaust temperatures were also lower compared to the cruise mode. In the absence of carbon particles, the soluble organic fraction tends to undergo homogeneous nucleation' hence, forming nano-particles, which are measured during the idle mode. Idle mode mass emissions were very low when compared to the cruise mode. This is attributed to nuclei-mode particles or nano-particles, which are mostly organic compounds. These particles do not significantly contribute towards mass emissions, but in terms of numbers they are very high.

The formation of the nano-particles greatly depends on the concentration of the condensable vapors in the exhaust, exhaust temperature, dilution air temperature and 
dilution ratio. If high amounts of volatile compounds are emitted, the partial pressure of the condensable species increases which increase the saturation ratio greater than unity. When super-saturation occurs, the gas-phase particles tend to self-nucleate to form droplets or nuclei-mode particles. The presence of carbonaceous particles tends to suppress the formation of nuclei-mode particles. Carbonaceous particles provide a large surface area for the adsorption of supersaturated vapors, which in turn lowers the saturation ratio to suppress nucleation.

Very high dilution ratios also tend to lower the concentration of the condensable species, which lowers the partial pressure, hence nucleation is not favored. However, higher dilution ratios do lower the exhaust temperatures, which may cause the condensation of heavy vapors. For soluble organic fractions, maximum saturation ratio is achieved typically at dilution ratios between 5 and 30 . For reasons stated above, an optimal dilution ratio of 1:30 was maintained throughout this study.

Particles measured during the cruise modes and the steady state modes were higher in concentration and size when compared with the idle mode. These particles measured during the cruise mode are mostly accumulation mode particles. Elemental carbon emissions were very high during the cruise mode, and higher levels of sulfates and calcium are emitted during the cruise modes. For most of the vehicles, volatile and semi-volatile organic compounds were noted to be higher during the cruise mode. Since elemental carbon presents a surface area for adsorption, nucleation of volatile compounds are suppressed. Conclusions could be drawn from the chemical speciation analysis that particles formed during the cruise mode could be mostly carbonaceous particles with an adsorbed layer of organic compounds. 


\subsection{Recommendations}

Engine manufacturers design new engines to meet the current regulations, which are mass based. These engines emit a very low amount of PM mass, mostly due to improved combustion of carbonaceous particles within the cylinder and improved oil control. However the newer engines do emit high levels of volatile compounds which lead to the formation of nano-particles. In this particular study, benzene which is highly carcinogenic, was noted to be one of the major contributors to volatile emissions.

It is very difficult to define a standard for measuring and regulating particle emissions in terms of number because number varies drastically with dilution, dilution conditions and sampling. Future emission regulations for 2007 are very stringent, requiring a $90 \%$ reduction in particulate mass emissions. These regulations could be met with the use of after-treatment devices, such as particulate traps and diesel oxidation catalysts. Traps are very effective in removing solid accumulation mode particles which form during the cruise modes and oxidation catalysts are effective in removing volatile particles formed during the idle mode. A combination of a particulate trap and an oxidation catalyst could be effective in lowering particulate emission, both in terms of mass and number irrespective of the engine operating condition. 


\section{REFERENCES}

1. "Code of Federal Regulations 40, Part 86, Subpart N”, Environment Protection Agency (2001).

2. Kittelson, D. B., (1998) "Engines and Nanoparticles: A Review", Journal of Aerosol Science, Vol. 29 No. 5/6, pp 575-588

3. Khalek, I. S., and Kittelson, D. B., (1995) "Real Time Measurement of Volatile Solid Exhaust Particles Using a Catalytic Stripper”, SAE 950236

4. Mayer, A., Egli, H., Burtscher, H., Czerwinski, J. and Gehrig, D., (1995) "Particle Size Distribution Downstream Traps of Different Design”, SAE 950373

5. Baumgard, J. K., and Johnson, J. H., (1996) "The Effect of Fuel and Engine Design on Diesel Exhaust Particle Size Distributions”, SAE 960131

6. Gautam, M., Clark, N. N., Mehta, M., Boyce, J. A., Rogers, F., and Gertler, A., (2003) "Concentrations and Size Distributions of Particulate Matter Emissions from a Class-8 Heavy-duty Diesel Truck Tested in a Wind Tunnel”, SAE 200301-1894

7. Gratz, L. D., Bagley, S. T., King, K. S., Baumgard, K. J., Leddy, D. G., and Johnson, J. H., (1991) “The Effect of Ceramic Particulate Trap on the Particulate and Vapor Phase Emissions of a Heavy-Duty Diesel Engine”, SAE 910609

8. Khalek, I. S., Kittelson, D. B., Graskow, B. R., and Wei, Q., (1998) “Diesel Exhaust Particle Size: Measurement Issues and Trends", SAE 980525 
9. Hall, D. E., Stradling, R. J., Zemroch, P. J., Rickeard, D. J., Mann, N., Heinze, P., Martini, G., Hagemann, R., Rantanen, L., and Szendefi, J., (2000) "Measurement of the Number and Size Distribution of Particle Emissions from Heavy Duty Engines", SAE 2000-01-2000

10. Lev-On, M., Le Tavec, C., Uihlein, J., Alleman, T. L., Lawson, D. R., Vertin, K., Thompson, G. J., Gautam, M., Wayne, S., Zielinska, B., Sagebiel, J., Chatterjee S., and Hallstrom, K., (2002) "Chemical Speciation of Exhaust Emissions from Trucks and Buses on Ultra-Low Sulfur Diesel and CNG”, SAE 2002-01-0432

11. Kweon, C. B., Foster, D E., Schauer, J. J., and Okada, S., (2002) "Detailed Chemical Composition and Particle Size Assessment of Diesel Engine Exhaust", SAE 2002-01-2670

12. Hinds, W. C., Aerosol Technology- Properties, Behavior and Measurement of Airborne Particles, John Wiley and Sons, New York, 1999.

13. Cheng, Y. S., Yeh, H. C., and Smith, S. M., (2001) "Deposition of Ultrafine Particles in Human Tracheobronchial Airways of Adults and Children”, Journal of Aerosol Science, Vol. 3, pp697-709

14. “Air Quality Criteria for Particulate Matter”, U.S. National Air Pollution Control Administration (1969)

15. Donaldson, K., Li, X. Y., and Mac Nee, W., (1998) 'Ultrafine (Nanometer) Particle Mediated Lung Injury", Journal of Aerosol Science, Vol. 29 No. 5/6, pp $\underline{553-560}$

16. Donaldson, K., Stone, V., Clouter, A., Renwick, L., Mac Nee, W., (2001) "Ultrafine Particles", Journal of Occupation and Environmental Medicine, Vol. $\underline{58, p p ~ 211-216}$ 
17. "The Lungs in Health and Disease", National Institute of Health publication No. 97-3279 (1997)

18. McMillan, M. H., Cui, M., Gautam, M., Keane, M., Ong, T., Wallace, W., and Robey, E., (2002) "Mutagenic Potential of Particulate Matter from Diesel Engine Operating on Fischer-Tropsch Fuel as a Function of Engine Operating Conditions and Particle Size”, SAE 2002-01-1699

19. Kittelson, D. B., and Khalek, I. S., (1999) "Formation of Nanoparticles during Exhaust Dilution”, EFI members conference, January 18-20 1999

20. Mayer, A., Matter, U., Scheidegger, C., Wyser, J., Kieser, M., Weidhofer, D., (1998) "VERT: Diesel Nano-Particulate Emissions: Properties and Reduction Strategies", SAE 980539

21. Mayer, A., Czerwinski, J., Scheidegger, P., (1996) “Trapping Efficiency Depending on Particulate Size", SAE 960472

22. Kasper, M., Sattler, K., Siegmann, K., Matter, U., and Siegmann, H. C., (1999) "The Influence of Fuel Additives on the Formation of Carbon during Combustion", Journal of Aerosol Science, Vol. 30 No. 2, pp 217-225

23. Schaberg, P. W., Zarling, D. D., Waytulonis, R. W., and Kittelson, D. B., (2002) "Exhaust Particle Number and Size Distributions with Conventional and FischerTropsch Diesel Fuels", SAE 2002-02-2727.

24. Brit, H. A., and Alberto, A., (2002) "Ultrafine PM Emissions from Natural Gas, Oxidation-Catalyst Diesel, and Particle-Trap Diesel Heavy-Duty Transit Buses", Environmental Science and Technology, Vol 36, No 23, 2002 
25. Ristovski, Z. D., Morawska, L., Hitchins, J., Thomas, S., Greenaway, C., and Gilbert, D., (2000) "Particle Emissions from Compressed Natural Gas Engines", Journal of Aerosol Science, Vol. 31 No. 4, pp 403-413

26. Ferguson, D. H., (1993) "Design, Fabrication and Testing of an Emissions Measurement System for a Transportable Heavy Duty Vehicle Emissions Testing Laboratory", M.S. Thesis, Department of Mechanical and Aerospace Engineering, West Virginia University.

27. Hildemann, L. M., Cass, G. R., and Markowski, G. R., (1989) “A dilution stack sampler for collection of organic aerosol emissions: design, characterization and field tests", Journal of Aerosol Science and Technology, Vol. 10, pp 193-204

28. Zielinska, B., Fujita, E., Sagebiel, J., Harshfield, G., Uberna, E., Hayes, T., and Keene, F., (1998) “Arizona Hazardous Air Pollutants Monitoring Program”, Journal of Air and Waste Management Association, 48, 1038-1050.

29. Chuang, J.C., Kuhlman, M. R., and Wilson, N., (1990) "Evaluation of methods for simultaneous collection and determination of nicotine and polynuclear aromatic hydrocarbons in indoor air", Environmental Science and Technology, 24, $\underline{661-665 .}$

30. Zielinska, B., Arey, J., Atkinson, R., and McElroy, P. A., (1989) “Formation of Methylnitronaphthalenes from the Gas-Phase Reactions of 1- and 2Methylnaphthalene with $\mathrm{OH}$ Radicals and $\mathrm{N}_{2} \mathrm{O}_{5}$ and Their Occurrence in Ambient Air", Environmental Science and Technology ,23, 723-729.

31. Atkinson, R., Arey, J., Winer, A. M., and Zielinska, B., (1988) “A survey of ambient concentrations of selected polycyclic aromatic hydrocarbons (PAH) at various locations in California”, Final Report, prepared under Contract No. A5185-32, for the California Air Resources Board, Sacramento, CA, by Statewide Air Pollution Research Center, University of California, Riverside, CA 
32. Fung, K., and Grosjean, D., (1981) "Determination of Nanogram Amounts of Carbonyls as 2, 4-Dinitrophenylhydrazones by High Performance Liquid Chromatography" Analytical Chemistry 53, 168-171.

33. Gautam, M., Clark, N. N., Wayne, W. S., Thompson, G. J., Lyons, D. W., Riddle, W. C., and Nine, R. D., "Qualification of the Heavy Heavy-Duty Diesel Truck Schedule And Development of Test Procedures", Final Report, CRC Project No. E-55-2, March 2002 a.

34. TSI model 3936 SMPS Instruction Manual, 1999. 


\section{Appendix A - SMPS AND CPC REDUCTION PROGRAM}

CPC reduction Program

Particle Concentration Calculation when using DMA and CPC at a single diameter

Input Dp (Particle Diameter in $\mathrm{nm}$ )

$\mathrm{Dp}:=175 \cdot \mathrm{nm}$

Number of Charges on Particle

$\mathrm{N}:=1$

Dilution Ratio

$\mathrm{DR}:=30$

Input Sheath Flow Rate

qc : $=3 \cdot 1 \mathrm{pm}$

Input Aerosol Flow Rate

qa $:=0.3 \cdot 1 \mathrm{pm}$

CONSTANTS

$\eta \equiv 1.81 \cdot 10^{-4} \cdot$ dyne $\cdot \frac{\mathrm{sec}}{\mathrm{cm}^{2}}$

$\mathrm{T}=295 \cdot \mathrm{K}$

$\mathrm{nm}=10^{-9} \cdot \mathrm{m}$

$\mathrm{kB}=1.38 \cdot 10^{-23} \cdot \frac{\text { joule }}{\mathrm{K}}$

$\mathrm{lpm}_{\min }{ }_{\operatorname{liter}}^{\min }$

$\mathrm{E} 0=8.85418781710^{-12} \cdot \frac{\mathrm{farad}}{\mathrm{m}}$

$\lambda \mathrm{atm}=0.066 \cdot 10^{-4} \cdot \mathrm{cm}$

$\mathrm{qe}=1.6021773310^{-19}$

$\mathrm{qa}=$

qc

Slip Correction

$\operatorname{Cc}(\lambda, \mathrm{Dp}):=1+\frac{\lambda}{\mathrm{Dp}} \cdot\left[2.514+0.800 \mathrm{e}^{-0.55 \cdot\left(\frac{\mathrm{Dp}}{\lambda}\right)}\right]$

Particle Mobility

$\mathrm{Zp}(\mathrm{Dp}):=\left[\frac{1}{3} \cdot \mathrm{qe} \cdot\left[\frac{\mathrm{Cc}(\lambda \mathrm{atm}, \mathrm{Dp})}{\pi \cdot(\eta \cdot \mathrm{Dp})}\right]\right]$

Guesses for mathcad root function

TOL $:=0.0001$

$\mathrm{x}:=1 \cdot \mathrm{nm}$

$\mathrm{y}:=1 \cdot \mathrm{nm}$

Dplus $:=\operatorname{root}\left[\frac{Z p(D p)}{Z p(x)}-\left(1+\frac{q a}{2 \cdot q c}\right), x\right]$ 


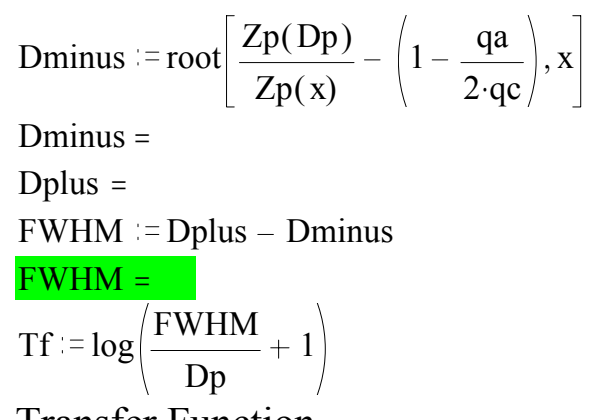

\section{Transfer Function}

$\mathrm{Tf}=$

Fuchs / Gunn Aerosol Charging

$\mathrm{a}:=\left[\begin{array}{ccccc}-26.3328 & -2.3197 & -0.0003 & -2.3484 & -44.4756 \\ 35.9044 & 0.6175 & -0.1014 & 0.6044 & 79.3772 \\ -21.4608 & 0.6201 & 0.3073 & 0.4800 & -62.8900 \\ 7.0867 & -0.1105 & -0.3372 & 0.0013 & 26.4492 \\ -1.3088 & -0.1260 & 0.1023 & -.1553 & -5.7480 \\ 0.1051 & 0.0297 & -0.0105 & 0.0320 & 0.5049\end{array}\right]$

$f(N, D p):=10^{\left[\sum_{i=0}^{5} a_{i, N+2} \cdot\left(\log \left(\frac{D p}{n m}\right)^{i}\right)\right]}$

Probability of Charge $\mathrm{N}$ on particle dia Dp $\mathrm{f}(\mathrm{N}, \mathrm{Dp})=$

Select Raw CPC file

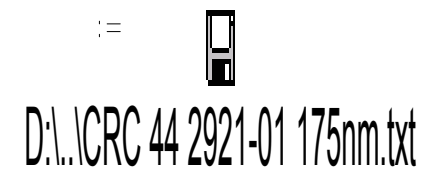

Select Output reduced file

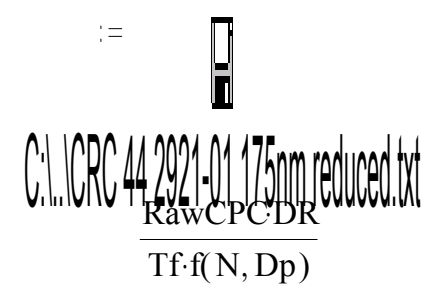

\section{Reduction Program for SMPS}

Input Dilution Ratio

DR : $=20$

Select Raw data File 


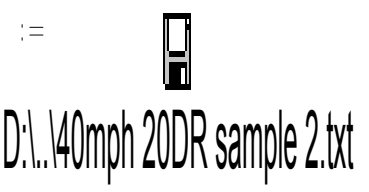

-

Rowsize := rows $($ Raw $)$

$\mathbf{N}:=$ Rowsize -26

Raw1 := submatrix $(\operatorname{Raw}, 1, \mathbf{N}, 1,2)$

Rawcount $:=\operatorname{Raw1}^{<2>}$

Size $:=\operatorname{Raw1}^{<1>}$

C := Rawcount DR

Reduced : $=\operatorname{augment}($ Size, $\mathbf{C})$

Select output reduced data file

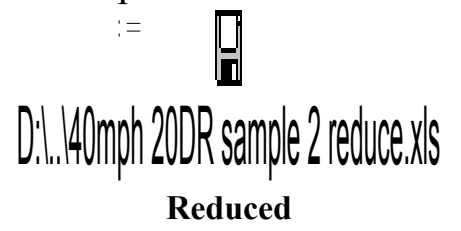




\section{Appendix B - CHEMICAL SPECIATION- SAMPLE COLLECTION AND ANALYTICAL PROCEDURES}

This section documents procedures adopted by Desert Research Institute for sample preparation, collection and post-test chemical analysis. DRI were responsible for pre-test sample preparation, sample collection during the whole study and post-test chemical analysis.

\section{B.1 Sample Collection}

\section{B.1.1 Particulate and Semi Volatile Organic Compounds}

The DRI sequential fine particulate/semi-volatile organic compound (PSVOC) samplers were used in this study to collect particulate and semi-volatile organic compounds. Two PSVOC samplers were employed, with one sampler dedicated to the nitro-PAH collection. This was a multiple-event sampler, with the pump downstream of the PUF/XAD/PUF cartridge, allowing unattended collection of up to four samples. Flow rate could be individually adjusted for each sample.

Particulate and semi-volatile organic compounds (SVOC) were collected using teflon-impregnated glass-fiber filters (TIGF) followed by polyurethane foam (PUF) in combination with polystyrene-divinylbenzene resin (XAD-4) in PUF/XAD-4/PUF cartridges [28]. Prior to sampling, new XAD-4 were washed with liquinox soap and rinsed with hot water, followed by de-ionized water and technical grade. The XAD-4 were extracted using a dionex accelerated solvent extractor (ASE) for $15 \mathrm{~min} / \mathrm{cell}$ with $\sim 170 \mathrm{ml}$ of dichloromethane $\left(\mathrm{CH}_{2} \mathrm{Cl}_{2}\right)$ at $1054604 \mathrm{~kg} / \mathrm{m}^{2}(1500 \mathrm{psi})$ and $100^{\circ} \mathrm{C}\left(212^{\circ} \mathrm{F}\right)$, followed by acetone. The XAD- 4 were dried in a vacuum oven at -15 to -20 inch $\mathrm{Hg}$ 
and $50^{\circ} \mathrm{C}\left(122^{\circ} \mathrm{F}\right)$, and stored in clean 1 liter glass jars in aluminum cans with activated charcoal.

PUF plugs were cleaned by first washing with distilled water, followed by Dionex ASE extraction for $15 \mathrm{~min} /$ cell with $\sim 170 \mathrm{ml}$ acetone at $1054604 \mathrm{~kg} / \mathrm{m}^{2}$ (1500 psi) and $100^{\circ} \mathrm{C}\left(212^{\circ} \mathrm{F}\right)$, followed by Dionex ASE extraction for $15 \mathrm{~min} /$ cell with $\sim 170 \mathrm{ml}$ of $10 \%$ diethyl ether in hexane under the same conditions. The extracted PUF plugs were dried in a vacuum oven at -15 to $-20 \mathrm{in}$. $\mathrm{Hg}, 50^{\circ} \mathrm{C}\left(122^{\circ} \mathrm{F}\right)$ for approximately 3 days or until no solvent odor were detected and stored in clean 1 liter glass jars with Teflon lined lids wrapped in aluminum foil.

Teflon-impregnated glass fiber (TIGF) filters (Pall Life Sciences, Type T60A20) were cleaned by sonication for 10 minutes in dichloromethane $\left(\mathrm{CH}_{2} \mathrm{Cl}_{2}\right)$ twice, with the solvent replaced and drained, and sonicated for 10 minutes in methanol twice with the solvent replaced. Filters were then dried in a vacuum oven at -15 to $-20 \mathrm{in} . \mathrm{Hg}, 50^{\circ} \mathrm{C}$ $\left(122^{\circ} \mathrm{F}\right)$ for minimum of 24 hours, weighed (if necessary), placed in Uline metallic ZipTop static shielding bags and stored in a freezer.

Each batch of precleaned XAD-4 resin and $\sim 10 \%$ of precleaned TIGF filters and PUF plugs were checked for purity by solvent extraction and GC/MS analysis of the extracts. The PUF plugs and XAD-4 resins were assembled into glass cartridges (10 $\mathrm{g}$ of XAD between two PUF plugs) and stored at room temperature prior to shipment to the field. All samples were stored in a freezer after receiving them from the field and prior to extraction. 


\section{B.1.2 Canister Samples}

Prior to collection, electropolished canisters were cleaned by alternating evacuation and flushing with humid ultra high purity air at $140^{\circ} \mathrm{C}\left(284^{\circ} \mathrm{F}\right)$ through seven cycles. Ten percent of the cleaned canisters were pressurized with humid ultra high purity air, allowed to equilibrate over night, then analyzed by gas chromatography with flame ionization detection (GC/FID). For a blank value, the total non-methane hydrocarbon concentration was approximately 5 ppbC, which was well within acceptable values.

Each sample was collected over the appropriate cycle by pressurized sampling to 20-25 psi in stainless steel canisters, and was analyzed on-site within 2 hours of sample collection by a GC/MS method. A portable system consisting of a gas chromatograph/mass spectrometer and a flame ionization detector (GC/MS/FID) equipped with a cryogenic pre-concentrator was used in the field for these sample analyses following a modified EPA method TO-15 technique. Further details of the method are provided in Section B.2.1 This on-site GC/MS/FID system was viewed as essential to allow for analysis of the collected canister samples within a very short window of time to prevent, or at least minimize, degradation of the samples, in particular 1,3-butdiene.

\section{B.1.3 Carbonyl Compounds}

Carbonyl compounds present in the exhaust were collected by drawing air through a cartridge containing silica gel, which was impregnated with acidified 2, 4dinitrophenylhydrazine (DNPH), available commercially from Waters. The resulting 
products (hydrazones) in the cartridge were measured in the laboratory using high performance liquid chromatography (see Section B.2). The DRI multi-event sampling system was used for sample collection. This sampler consisted of the check valves, solenoid valves and pump. The six-port manifold and flow control device allowed six cartridges to be attached at once. Flow could be individually adjusted and measured for each cartridge. Each solenoid was controlled separately by the timer and could be sampled independently. There was one check valve for each individual solenoid valve, to protect the cartridge from any contamination when it was not used for sampling. Timers that allow unattended operation (activation and deactivation) of the six independent solenoids in the collection system were located in the unit. A 120 Volt A.C vacuum pump was capable of drawing sample through the cartridges at up to 5 liters per minute.

When the exposed cartridges were removed, they were immediately plugged, put into the vials, and stored in a can designated for exposed cartridges. The exposed cartridges were stored inside a refrigerator and returned to the laboratory in a cooler.

\section{B.1.4 Nitrosamine Collection}

Nitrosoamines were collected using modified EPA Method TO-7. Samples were collected on a Thermosorb/ $\mathrm{N}$ adsorbent cartridge, purchased from Thermo Electron Corp., Beverly, MA. A one-channel carbonyl sampler was used for sample collection. Only one integrated sample was collected per each diesel vehicle tested. The exposed cartridges were stored inside a refrigerator and returned to the laboratory in a cooler. 


\section{B.1.5 Tenax Samples}

Tenax sampling and analysis were employed for compounds that were too heavy to be quantitatively retrieved from canisters, yet too volatile to be quantitatively collected on PUF/XAD/PUF cartridges. Prior to use, the Tenax-TA solid adsorbent was cleaned by Soxhlet extraction with hexane/acetone mixture (4/1 v/v) overnight, and dried in a vacuum oven at $\sim 80^{\circ} \mathrm{C}$. The dry Tenax was packed into Pyrex glass tubes ( $4 \mathrm{~mm}$ i.d. $\mathrm{x} 15 \mathrm{~cm}$ long, each tube containing $0.2 \mathrm{~g}$ of Tenax) and thermally conditioned for four hours by heating in an oven at $300^{\circ} \mathrm{C}\left(572^{\circ} \mathrm{F}\right)$ under a nitrogen purge $(25 \mathrm{ml} / \mathrm{min}$ nitrogen flow). Approximately $10 \%$ of the precleaned Tenax cartridges were tested by GC/MS for quality assurance prior to sampling. After cleaning, the Tenax cartridges were capped tightly using clean Swagelok caps (brass) with graphite/vespel ferrules, placed in metal containers with activated charcoal on the bottom, and kept in a clean environment at room temperature.

The DRI Sequential Tenax sampler was used in this study to collect heavy hydrocarbon samples. This is a multiple-event sampler, with the pump downstream of the Tenax, allowing unattended collection of up to six samples. The six-port manifold and flow control device allowed six cartridges to be attached at once. Since Tenax tubes were analyzed by the thermal desorption technique and thus each sample could only be analyzed once, two parallel samples (channel A and B) were collected for security purposes. Flow could be individually adjusted for each cartridge pair, using mass flow controllers. Tenax cartridges installed in the sampler were protected by a check valve upstream, and a solenoid valve downstream. They were only exposed to the ambient 
stream during the period of sampling. Each solenoid was controlled separately by the timer and could be sampled independently.

When the exposed cartridges were removed, they were immediately plugged with Swagelok caps, and stored in a can designated for exposed cartridges with activated charcoal on the bottom. The exposed cartridges were stored inside a refrigerator and returned to the laboratory in a cooler with a blue ice. As mentioned above two parallel samples, A and B, were collected for each run for security purposes. However, it was determined in the laboratory during sample analysis, that the sample B tubes were invalid as very little material was collected on the tubes in comparison with samples A. Thus, only sample A was analyzed, and in a few cases when sample A was damaged in transport (glass cartridges) data was not reported.

\section{B.2 Chemical Speciation- Analytical Procedures}

This section presents details of chemical analyses that were conducted by the Desert Research Institute.

\section{B.2.1 Filters and PUF/XAD/PUF Cartridges}

For each sample, PUF/XAD/PUF cartridges and TIGF filters were extracted and analyzed together. Prior to extraction, the following deuterated internal standards were added to each filter and PUF/XAD sorbent (Table B1). 
Table B1. List of Deuterated Internal Standards

\begin{tabular}{|c|c|c|c|c|}
\hline PAH & H\&S & Alkanes & Polars & N-PAH \\
\hline naphthalene- $\mathrm{d}_{8}$ & cholestane- $\mathrm{d}_{6}$ & dodecane- $\mathrm{d}_{26}$ & $\begin{array}{c}\text { cholesterol- } \\
2,2,3,4,4,6-\mathrm{d}_{6}\end{array}$ & $\begin{array}{c}2- \\
\text { nitrodiphenyl- } \\
\mathrm{d}_{9}\end{array}$ \\
\hline biphenyl- $\mathrm{d}_{10}$ & & hexadecane- $\mathrm{d}_{34}$ & $\begin{array}{c}\text { levoglucosan-u- } \\
13 \mathrm{C}_{6}\end{array}$ & $\begin{array}{c}\text { 1-nitropyrne- } \\
\mathrm{d}_{9}\end{array}$ \\
\hline acenaphthene- $\mathrm{d}_{10}$ & & eicosane- $\mathrm{d}_{42}$ & $\begin{array}{l}\text { hexanoic-d } d_{11} \\
\text { acid }\end{array}$ & \\
\hline phenanthrene- $\mathrm{d}_{10}$ & & octacosane- $\mathrm{d}_{58}$ & benzoic- $\mathrm{d}_{3}$ acid & \\
\hline anthracene- $\mathrm{d}_{10}$ & & tetracosane- $\mathrm{d}_{50}$ & $\begin{array}{l}\text { decanoic-d } d_{19} \\
\text { acid }\end{array}$ & \\
\hline pyrene- $d_{12}$ & & $\begin{array}{c}\text { hexatriacontane- } \\
\mathrm{d}_{74}\end{array}$ & palmitic- $\mathrm{d}_{31}$ acid & \\
\hline benz(a)anthracene- $d_{12}$ & & & $\begin{array}{c}\text { heptadecanoic- } \\
\mathrm{d}_{33} \text { acid }\end{array}$ & \\
\hline chrysene- $\mathrm{d}_{12}$ & & & myristic- $\mathrm{d}_{27}$ acid & \\
\hline $\begin{array}{l}\text { benzo[k]fluoranthene- } \\
\mathrm{d}_{12}\end{array}$ & & & succinic- $\mathrm{d}_{4}$ acid & \\
\hline benzo[e]pyrene- $\mathrm{d}_{12}$ & & & $\begin{array}{c}\text { phthalic } 3,4,5,6- \\
\mathrm{d}_{4} \text { acid }\end{array}$ & \\
\hline \multicolumn{5}{|l|}{ benzo[a]pyrene- $\mathrm{d}_{12}$} \\
\hline \multicolumn{5}{|l|}{$\begin{array}{c}\text { benzo[g,h,i]perylene- } \\
\mathrm{d}_{12}\end{array}$} \\
\hline coronene- $\mathrm{d}_{12}$ & & & & \\
\hline
\end{tabular}

Filters and XAD-4 were extracted with dichloromethane using the Dionex ASE followed by acetone extraction under the same conditions. The dichloromethane extraction method was reported to yield high recovery of PAH [29] and nitro-PAH [30, 31]. Since PUF media degrades when extracted with dichloromethane, the PUF were extracted twice with acetone using the Dionex ASE. This method gave good recovery for PAH, aliphatic hydrocarbons (alkanes), hopanes and steranes, and polar organic compounds.

All extracts were then concentrated by rotary evaporation at $35^{\circ} \mathrm{C}\left(95^{\circ} \mathrm{F}\right)$ under gentle vacuum to $\sim 1 \mathrm{ml}$ and filtered through $0.2 \mu \mathrm{m}$ PTFE disposal filter device 
(Whatman Pura disc ${ }^{\mathrm{TM}} 25 \mathrm{TF}$ ). The extract was concentrated to $1 \mathrm{ml}$ and split into two fractions, as follows:

1. The first fraction was precleaned by the solid-phase extraction technique, using Superclean LC-SI SPE cartridges (Supelco) with sequential elution with hexane, and hexane/benzene (1:1). The hexane fraction contained the non-polar aliphatic hydrocarbons (alkanes), and hopanes and steranes, and the hexane/benzene fraction contained the PAH. These two fractions were combined and concentrated to $\sim 100 \mu \mathrm{L}$ and analyzed by GC/MS technique for hydrocarbons, hopane, steranes, PAH and oxy-PAH.

2. The second fraction was utilized for the polar compound analysis without precleaning. It was derivatized using a mixture of bis (trimethylsilyl) trifluoroacetamide and pyridine to convert the polar compounds into their trimethylsilyl derivatives for analysis of organic acids and diacids, cholesterol, sitosterol, and levoglucosan.

The samples collected for nitro-PAH analyses were extracted with dichloromethane as described above. The extracts were precleaned by the solid-phase extraction technique, using Aminopropyl $\left(\mathrm{NH}_{2}\right) \mathrm{SPE}$ cartridges (Waters), with sequential elution with hexane/DCM, 98/2 v/v and hexane/DCM 80/20 v/v. For nitro- and dinitroPAH analysis, these fractions were combined and further cleaned by semi-preparative normal-phase high performance liquid chromatography (HPLC) technique (Waters). The Chromegabond Amino Cyano $25 \mathrm{~cm}$ x $9.6 \mathrm{~mm}$ column (ES Industries, West Berlin, NJ) and isocratic elution with $20 \%$ DCM in hexane was used. The fraction corresponding to 
nitro- and dinitro-PAH were collected and analyzed by negative ion chemical ionization GC/MS.

The filters and PUF/XAD extracts were analyzed by gas chromatography/mass spectrometry (GC/MS); using Varian CP-3800 GC equipped with a CP8400 autosampler and interfaced to a Varian Saturn 2000 ion trap operating in electron impact (EI) ionization mode. Injections $(1 \mu \mathrm{L})$ were made in the splitless mode onto a $30 \mathrm{~m}$ long $5 \%$ phenylmethylsilicone fused-silica capillary column (DB-5ms, J\&W Scientific or equivalent). Quantification of the individual compounds was obtained by selective ion storage (SIS) technique, monitoring the molecular (or the most characteristic) ion of each compound of interest and the corresponding deuterated internal standard. Calibration curves for the GC/MS quantification were made for the most abundant and characteristic ion peaks of the compounds of interest (Table B1) using the deuterated species most closely matched in volatility and retention characteristics as internal standards. National Institute of Standards and Technology (NIST) Standard Reference Material (SRM) 1647 (certified PAH) with the addition of deuterated internal standards and of those compounds not present in the SRM (i.e., oxy-PAH, nitro-PAH, hopane, sterenes, carpanes, hydrocarbons, cycloalkanes) were used to make calibration solutions. A six- to eight-level calibration was performed for each compound of interest and the calibration check (using median calibration standards) was run every 10 samples to check for accuracy of analyses. If the relative accuracy of measurement (defined as a percent difference from the standard value) was less than $20 \%$, the instrument was recalibrated.

The nitro-and dinitro-PAH were analyzed using the Varian 1200 triple quadrupole gas chromatograph/mass spectrometer (GC/MS/MS) system with CP-8400 autosampler. 
The tandem MS/MS system allowed for structural elucidation of unknown compounds with precursor, product and neutral loss scan. The GC interface allowed for sensitive analyses of complex mixtures in electron impact (EI) as well as positive and negative chemical ionization (CI) mode. Negative CI offered a superior sensitivity for the analysis of nitro-PAH (approximately 100 times higher than EI or positive $\mathrm{CI}$ ) that could be emitted from combustion sources, including motor vehicle engines. For negative CI, 10 $\mathrm{fg} / \mathrm{ul}$ of octafluoronaphthalene gave $\mathrm{S} / \mathrm{N}$ of $20: 1$. This superior sensitivity offered the advantage of analyzing small samples collected during a short sampling time. Injections (1 $\mu \mathrm{L}$ ) were made in the splitless mode onto a $30 \mathrm{~m}$ long $\times 0.25 \mathrm{~mm}$ id $50 \%$ phenylmethylsilicone fused-silica capillary column (DB-17ms, CP-Sil-24ms or equivalent). Quantification of the individual compounds was obtained by multiple ion detection (MID) technique, monitoring the molecular ion of each compound of interest and the corresponding deuterated internal standard. Calibration curves for the GC/MS quantification were made for the most abundant and characteristic ion peaks of the compounds of interest using the deuterated species most closely matched in volatility and retention characteristics as internal standards and the authentic standards of quantified nitro-PAH. A six- to eight-level calibration was performed for each compound of interest and the calibration check (using median calibration standards) was run every 10 samples to check for accuracy of analyses. If the relative accuracy of measurement (defined as a percent difference from the standard value) was less than $20 \%$, the instrument was recalibrated. 


\section{B.2.2 Gas Phase Samples}

\section{B.2.2.1 Volatile Organic Compounds}

Since the analysis for 1, 3-butadiene and the other olefinic Non Methane Hydrocarbons (NMHC), which were unstable if stored for a prolonged period of time in a diluted auto exhaust sample, was required, the canister samples were analyzed on site within 2 hours from sample collection using our portable GC/MS system. The advantage of using the GC/MS system on-site was that all samples were analyzed for 1, 3-butadiene and simultaneously for other VOCs immediately after sample collection. In addition, mass spectrometric analysis has several advantages over FID detection; it provided unique identification of compounds based on their mass spectra, had the ability of quantifying non-resolved or partially-resolved compounds, and offers high sensitivity in the range of $0.1 \mathrm{ppb}$.

For the analysis of all VOC, a 2D-chromatography method was employed. Gaseous sample was preconcentrated on the three stages of Entech preconcentrator (glass beads with Tenax, Tenax and capillary tube) and injected into the head of a DB-1 type column ( $60 \mathrm{~m}$ long $0.32 \mathrm{~mm}$ i.d., $1 \mu \mathrm{m}$ film thickness) at room temperature. This column was connected through a three-way valve with two other columns; a 15 m DB-1 type column ( $0.32 \mathrm{~mm}$ i.d., $0.5 \mu \mathrm{m}$ film thickness), leading to the MS and a $30 \mathrm{~m} \times 0.32 \mathrm{~mm}$ i.d. GasPro column (a PLOT type column, J\&W Scientific) leading to the FID. During the first few minutes after injection, the sample was eluted through the $60 \mathrm{~m}$ DB-1 and 30 m GasPro column and peaks were detected by the FID. After suitable time (approximately $6-10 \mathrm{~min}$ ), the valve was switched and the sample was directed through the $15 \mathrm{~m} \mathrm{DB}-1$ column to the MS detector. This way, the very light hydrocarbons (C2 up 
to C4) were clearly separated on the Gas-Pro column and detected by the FID, and the heavier hydrocarbons (up to C12), were unequivocally identified and quantified by the ion trap MS.

The GC/FID and GC/MS response was calibrated in ppbv, using a 74 component mixture (Air Environmental, Inc., Denver, CO) in the ppbv range of concentrations, traceable to the NIST Standard Reference Materials (SRM). A three-level calibration was performed for each compound of interest and the calibration check (using median calibration standards) was analyzed every 10 samples to check for accuracy of analyses. If the relative accuracy of measurement (defined as a percent difference from the standard value) was less than $20 \%$, the instrument was recalibrated. Blanks were performed once daily. The analysis plan and data processing standards call for the replicate analysis of approximately $10 \%$ of the samples. The replicate analyses were flagged in the database and the programs for data processing extract these replicates and determine a replicate precision. These were then converted into an absolute precision for each measurement, which could be reported if required.

\section{B.2.2.2 Gaseous Carbonyl Compounds}

$\mathrm{C}_{1}$ through $\mathrm{C}_{7}$ carbonyl compounds were collected with Sep-Pak cartridges, which were impregnated with an acidified 2, 4-dinitrophenylhydrazine (DNPH) reagent (Waters, Inc). When a sample was drawn through the cartridge, carbonyls in the sample were captured by reacting with DNPH to form hydrazones, which were separated and quantified using HPLC in the laboratory [32].

After sampling, the cartridges were eluted with acetonitrile. An aliquot of the eluent was transferred into a 2-ml septum vial and injected with an autosampler into a 
high performance liquid chromatograph (Waters 2690 Alliance System with 996 Photodiode Array Detector) for separation and quantitation of the hydrazones [31]. The samples were analyzed for the carbonyl compounds listed in TableC3. The carbonyl concentrations, in ppb, were computed from the amounts measured after blank correction and the volume of air sampled using the following equation:

$$
\mathrm{ppb}_{\mathrm{i}}=\frac{m_{i}-b_{i}}{f \times t} \times 1000 \times \frac{24.45}{M W_{i}}
$$

Where $\mathrm{ppb}_{\mathrm{i}}=$ concentration in $\mathrm{ppb}$ of carbonyl species, $\mathrm{i}$,

$\mathrm{m}_{\mathrm{i}}=\mu \mathrm{g}$ of $\mathrm{i}$ measured in the sample,

$b_{i}=$ average ug of $i$ in the blank,

$\mathrm{t}=$ sampling duration, in minutes,

$\mathrm{f}=$ sampling flow rate, in liters $/ \mathrm{min}$,

$\mathrm{MW}_{\mathrm{i}}=$ molecular weight of $\mathrm{i}$.

Since the HPLC system was equipped with the photodiode array detector, the identification of carbonyl compounds were much more accurate than with standard UV/VIS detector. Also, the sensitivity of the analysis was enhanced by using the photodiode array detector.

\section{B.2.2.3 Nitrosamines}

Nitrosoamines were collected and quantified using a modified EPA Method TO-7. This method called for collection of a sample on a thermosorb/N adsorbent cartridge and analysis by GC/MS. The cartridges were eluted with a mixture of $25 \%$ methanol and $75 \%$ dichloromethane. The first $1.8 \mathrm{ml}$ were collected for the GC/MS analysis, using the Varian $1200 \mathrm{GC} / \mathrm{MS} / \mathrm{MS}$ system operating in negative CI mode. Injections $(1 \mu \mathrm{l})$ were made in splitless mode onto CP WAX 51 capillary column ( $25 \mathrm{~m}$ long, $0.25 \mathrm{~mm}$ id). 
Quantification of the individual compounds were obtained by multiple ion detection (MID) technique, monitoring the molecular ion of each compound of interest and the corresponding deuterated internal standard.

Calibration curves for the GC/MS quantification were made for the most abundant ion peaks of the compounds of interest using the deuterated species which closely matched in volatility and retention characteristics as internal standards and the authentic standards of quantified nitrosoamines (purchased from Aldrich). A six -level calibration was performed for each compound of interest and the calibration check (using median calibration standards) was run every 10 samples to check for accuracy of analyses. If the relative accuracy of measurement (defined as a percent difference from the standard value) was less than $20 \%$, the instrument was recalibrated.

\section{B.2.3 Tenax Samples}

Tenax sampling was used for compounds that were too heavy to be quantitatively retrieved from canisters, yet too volatile to be quantitatively collected on PUF/XAD/PUF cartridges. These compounds included some aromatic C4-C5 substituted benzene derivatives and higher carbonyls. Also, C13-C18 hydrocarbons, present predominantly in the gas phase could be more accurately quantified from tenax.

The tenax samples were analyzed by thermal desorption-cryogenic preconcentration, using the chrompack CP4020 thermal desorption cold trap injector unit with the stand alone CP4010/4020 controller (Chrompack International BV), followed by high resolution gas chromatography and Fourier transform infrared detection (IRD) mass spectrometry detection (MSD) (Hewlett Packard 5890II GC, 5965 IRD and 5970 MSD). Samples were desorbed at $300^{\circ} \mathrm{C}\left(572^{\circ} \mathrm{F}\right)$ for 14 minutes, cryogenically pre- 
concentrated at $-150^{\circ} \mathrm{C}\left(-238^{\circ} \mathrm{F}\right)$ on $30 \mathrm{~cm}$ deactivated silica capillary tubing $(0.52 \mathrm{~mm}$ i.d.) packed with a small amount of glass wool, followed by secondary desorption at $280^{\circ} \mathrm{C}\left(536^{\circ} \mathrm{F}\right)$ for one minute. Separation of the target VOCs were achieved using a 60 mm x $0.32 \mathrm{~mm}$ DB-1 capillary column (J \& W Scientific, Inc.). The temperature program consisted of $30^{\circ} \mathrm{C}\left(86^{\circ} \mathrm{F}\right)$ for two minutes; followed by a temperature increase of $6^{\circ} \mathrm{C} / \mathrm{min}$ to $280^{\circ} \mathrm{C}\left(536^{\circ} \mathrm{F}\right)$, and finally $280^{\circ} \mathrm{C}\left(536^{\circ} \mathrm{F}\right)$ was held for 10 minutes. Before analysis, each sample was spiked with $1 \mathrm{ml}$ of an internal standard, 1-fluoronaphthalene, and then flushed with ultra high purity helium for two minutes. Compounds were quantified using the mass spectrometer. A standard mixture was analyzed each day to account for any detector drift.

For calibration of the GC/MS standard, tenax cartridges were prepared by spiking cartridges with a methanol solution of standard hydrocarbons, prepared from high-purity commercially available $\mathrm{C} 8 \mathrm{-C} 20$ aliphatic, oxygenated and aromatic hydrocarbons. The solvent was then removed with a stream of $\mathrm{N} 2(2 \mathrm{~min}, 100 \mathrm{ml} / \mathrm{min}$ at room temperature) and the tenax cartridges were thermally desorbed into the GC system, as described above. Three concentrations of each standard compound were employed. Two to three repeated sample injections per calibration level were made. Area response factors per nanogram of compound per tenax cartridge were calculated for each concentration. All response factors were recorded in the chemstation software program and the mean or median value taken. It was also verified that the variations in the response factors for individual hydrocarbons in the $\mathrm{C} 8 \mathrm{-C} 20$ range did not exceed $\sim 10 \%$ with the exception of the straight chain alkanes, for which daily calibrations were recorded. 


\section{B.2.4 Particulate Phase Inorganic lons}

\section{B.2.4.1 Filter Extraction}

Water-soluble nitrate, nitrite, sulfate, chloride and ammonium were obtained by extracting the quartz-fiber particle filter in $15 \mathrm{ml}$ of deionized-distilled water (DDW). The filter was placed in a $16 \times 150 \mathrm{~mm}$ polystyrene extraction vial with a screw cap (e.g., Falcon \#2045). Each vial was labeled with a bar code sticker containing the filter ID code. The extraction tubes were placed in tube racks, and the extraction solutions were added. The extraction vials were capped and sonicated for 60 minutes, shaken for 60 minutes, then aged overnight to assure complete extraction of the deposited material in the solvent. The ultrasonic bath water was monitored to prevent temperature increase from the dissipation of ultrasonic energy in the water. After extraction, these solutions were stored under refrigeration prior to analysis.

\section{B.2.4.2 Ion Chromatographic Analysis for Inorganic Ions}

Water-soluble nitrate $\left(\mathrm{NO}_{3}^{-}\right)$, nitrite, chloride and sulfate $\left(\mathrm{SO}_{4}^{=}\right)$were measured with the Dionex 2020i (Sunnyvale, CA) ion chromatograph (IC). In IC, an ion-exchange column separates the sample ions in time for individual quantification by a conductivity detector. Prior to detection, the column effluent entered a suppressor column where the chemical composition of the component was altered, resulting in a matrix of low conductivity. The ions were identified by their elution/retention times and were quantified by the conductivity peak area.

Approximately $2 \mathrm{ml}$ of the filter extract were injected into the ion chromatograph. The resulting peaks were integrated and the peak integrals were converted to 
concentrations using calibration curves derived from solution standards. The Dionex system for the analysis of $\mathrm{Cl}^{-}, \mathrm{NO}_{3}^{-}$and $\mathrm{SO}_{4}^{=}$contained a guard column (AG4a column, Cat. No. \#37042) and an anion separator column (AS4a column, Cat. No. \#37041) with a strong basic anion exchange resin, and an anion micro membrane suppressor column (250 x $6 \mathrm{~mm} \mathrm{ID)} \mathrm{with} \mathrm{a} \mathrm{strong} \mathrm{acid} \mathrm{ion} \mathrm{exchange} \mathrm{resin.} \mathrm{The} \mathrm{anions} \mathrm{eluent} \mathrm{consisted} \mathrm{of}$ sodium carbonate $\left(\mathrm{Na}_{2} \mathrm{CO}_{3}\right)$ and sodium bicarbonate $\left(\mathrm{NaHCO}_{3}\right)$ prepared in DDW. The DDW was verified to have a conductivity of less than $1.8 \times 10^{-5} \mathrm{ohm} / \mathrm{cm}$ prior to preparation of the eluent. For quantitative determinations, the ion chromatograph was operated at a flow rate of $2.0 \mathrm{ml} / \mathrm{min}$.

The primary standard solutions containing $\mathrm{NaNO}_{3}, \mathrm{NaNO}_{2}, \mathrm{NaCl}$, and $\mathrm{Na}_{2} \mathrm{SO}_{4}$ were prepared with reagent grade salts which were dried in an oven at $105^{\circ} \mathrm{C}\left(221^{\circ} \mathrm{F}\right)$ for one hour and then brought to room temperature in desiccators. These anhydrous salts were weighed to the nearest $0.10 \mathrm{mg}$ on a routinely calibrated analytical balance under controlled temperature $\left(\sim 20^{\circ} \mathrm{C}\right)$ and relative humidity $( \pm 30 \%)$ conditions. These salts were diluted in precise volumes of DDW. Calibration standards were prepared at least once each month by diluting the primary standard solution to concentrations covering the range of concentrations expected in the filter extracts. The calibration concentrations prepared were at $0.1,0.2,0.5,1.0$, and $2.0 \mu \mathrm{g} / \mathrm{ml}$ for each of the analysis species. The standards were stored in a refrigerator.

Calibration curves were performed weekly. Chemical compounds were identified by matching the retention time of each peak in the unknown sample with the retention times of peaks in the chromatograms of the standards. A DDW blank was analyzed after every 20 samples and a calibration standard was analyzed after every 10 samples. These 
quality control checks verified the baseline and calibration, respectively. Environmental Research Associates (ERA, Arvada, CO) standards were used daily as an independent quality assurance (QA) check. These standards (ERA Wastewater Nutrient and ERA Mineral WW) were traceable to NIST simulated rainwater standards. If the values obtained for these standards did not coincide within a pre-specified uncertainty level (typically three standard deviations of the baseline level or $\pm 5 \%$ ), the samples between that standard and the previous calibration standards were re-analyzed.

\section{B.2.4.3 Automated Colorimetric Analysis for Ammonium}

The technicon (Tarrytown, NY) TRAACS 800 automated colorimetric system (AC) was used to measure ammonium concentrations by the indolphenol method. The heart of the automated colorimetric system was a peristaltic pump, which introduced air bubbles into the sample stream. Each sample was mixed with reagents and subjected to appropriate reaction periods before submission to a colorimeter. The liquid's absorbency was related to the amount of the ion in the sample by Beer's Law. This absorbency was measured by a photomultiplier tube through an interference filter, which was specific to the species being measured.

Ammonium in the extract was reacted with phenol and alkaline sodium hypochlorite to produce indolphenol, a blue dye. The reaction was catalyzed by the addition of sodium nitroprusside. The absorbency of the solution was measured at 630 nm. Two milliliters of extract in a sample vial was placed in an autosampler, which was controlled by a computer. Five standard concentrations were prepared from ACS reagent-grade $\left(\mathrm{NH}_{4}\right)_{2} \mathrm{SO}_{4}$ following the same procedure as that for IC standards. Each set of samples consisted of two distilled water blanks to establish a baseline, 5 calibration 
standards and a blank, then sets of 10 samples followed by analysis of one of the standards and a replicate from a previous batch. The computer control allowed additional analysis of any filter extract to be repeated without the necessity of loading the extract into more than one vial.

The system determined carry-over by analysis of a low concentration standard following a high concentration. The percent carry-over was then automatically calculated and applied to the samples analyzed during the run. Technicon software operating on an IBM/XT microcomputer controlled the sample throughput, calculated concentrations, and recorded data on the DRI data base. Formaldehyde was found to interfere with the measurements when it was present in an amount, which exceeded $20 \%$ of the ammonium content. Hydrogen sulfide interfered with the measurements when it was present in concentrations which exceed $1 \mathrm{mg} / \mathrm{ml}$. Nitrate and sulfate were also potential interferents when present at levels which exceed 100 times the ammonium concentration. These levels were rarely exceeded in ambient samples. The precipitation of the hydroxides of heavy metals such as calcium and magnesium was prevented by the addition of disodium ethylenediamine-tetra-acetic acid (EDTA) to the sample stream.

\section{B.2.5 Particulate Elemental Analysis}

\section{B.2.5.1 Gravimetric Analysis}

Unexposed and exposed Teflon-membrane filters were equilibrated at a temperature of $20 \pm 5^{\circ} \mathrm{C}$ and a relative humidity of $30 \pm 5 \%$ for a minimum of 24 hours prior to weighing. Weighing was performed on a Cahn 31 electro microbalance with $\pm 0.001 \mathrm{mg}$ sensitivity. The charge on each filter was neutralized by exposure to a

polonium source for 30 seconds prior to the filter being placed on the balance pan. The 
balance was calibrated with a $20 \mathrm{mg}$ Class $\mathrm{M}$ weight and the tare was set prior to weighing each batch of filters. After every 10 filters were weighed, the calibration and tare were re-checked. If the results of these performance tests deviate from specifications by more than $\pm 5 \mu \mathrm{g}$, the balance was re-calibrated. If the difference exceeds $\pm 15 \mu \mathrm{g}$, the balance was recalibrated and the previous 10 samples were re-weighed. At least $30 \%$ of the weights were checked by an independent technician and samples were re-weighed if these check-weights did not agree with the original weights within $\pm 0.015 \mathrm{mg}$. Pre- and post-weights, check weights, and re-weights (if required) were recorded on data sheets as well as being directly entered into a database via an RS232 connection.

\section{B.2.5.2 X-Ray Fluorescence}

X-ray fluorescence (XRF) analysis was performed on Teflon-membrane filters using an energy dispersive x-ray fluorescence (EDXRF) analyzer. Table B2 lists the elements, together with their Minimum Detectable Limits (MDL), for three different analytical protocols. Protocol B was used for this study since it was least expensive.

Table B2. X-Ray Fluorescence Air Filter Analysis Interference-Free Minimum Detectable Limits ${ }^{a}$ Using DRI Standard Analysis Protocols

\begin{tabular}{|c|c|c|c|c|}
\hline Element & $\begin{array}{c}\text { Protocol A } \\
\mathbf{n g} / \mathrm{cm}^{2}\end{array}$ & $\begin{array}{c}\text { Protocol B } \\
\mathbf{n g} / \mathrm{cm}^{2}\end{array}$ & $\begin{array}{c}\text { Protocol C } \\
\mathrm{ng} / \mathrm{cm}^{2}\end{array}$ & $\begin{array}{c}\text { Protocol D } \\
\mathbf{n g} / \mathrm{cm}^{2}\end{array}$ \\
\hline $\mathrm{Al}$ & 10 & 7.2 & 3.6 & 2.5 \\
\hline $\mathrm{Si}$ & 6.3 & 4.4 & 2.2 & 1.4 \\
\hline$P$ & 5.6 & 4.0 & 2.0 & 1.4 \\
\hline $\mathrm{S}$ & 5.0 & 3.5 & 1.8 & 1.2 \\
\hline $\mathrm{Cl}$ & 10 & 7.4 & 3.7 & 2.6 \\
\hline $\bar{K}$ & 6.1 & 4.3 & 2.2 & 1.5 \\
\hline $\mathrm{Ca}$ & 4.5 & 3.2 & 1.6 & 1.1 \\
\hline $\mathrm{Ti}$ & 2.9 & 2.1 & 1.0 & 0.73 \\
\hline $\mathrm{V}$ & 2.5 & 1.7 & 0.87 & 0.62 \\
\hline $\mathrm{Cr}$ & 1.9 & 1.4 & 0.67 & 0.48 \\
\hline $\mathrm{Mn}$ & 1.6 & 1.1 & 0.56 & 0.40 \\
\hline
\end{tabular}




\begin{tabular}{|c|c|c|c|c|}
\hline Element & $\begin{array}{c}\text { Protocol A } \\
\mathrm{ng} / \mathrm{cm}^{2}\end{array}$ & $\begin{array}{c}\text { Protocol B } \\
\mathrm{ng} / \mathrm{cm}^{2}\end{array}$ & $\begin{array}{c}\text { Protocol C } \\
\mathrm{ng} / \mathrm{cm}^{2}\end{array}$ & $\begin{array}{c}\text { Protocol D } \\
\text { ng/ } / \mathrm{cm}^{2}\end{array}$ \\
\hline $\mathrm{Fe}$ & 1.5 & 1.1 & 0.54 & 0.38 \\
\hline $\mathrm{Co}$ & 0.88 & 0.62 & 0.31 & 0.22 \\
\hline $\mathrm{Ni}$ & 0.89 & 0.63 & 0.31 & 0.22 \\
\hline $\mathrm{Cu}$ & 1.1 & 0.76 & 0.38 & 0.27 \\
\hline $\mathrm{Zn}$ & 1.1 & 0.76 & 0.38 & 0.27 \\
\hline $\mathrm{Ga}$ & 1.9 & 1.4 & 0.68 & 0.48 \\
\hline As & 1.6 & 1.1 & 0.56 & 0.39 \\
\hline $\mathrm{Se}$ & 1.2 & 0.86 & 0.43 & 0.31 \\
\hline $\mathrm{Br}$ & 1.0 & 0.72 & 0.36 & 0.25 \\
\hline $\mathrm{Rb}$ & 1.0 & 0.68 & 0.34 & 0.24 \\
\hline $\mathrm{Sr}$ & 1.1 & 0.78 & 0.39 & 0.28 \\
\hline $\mathrm{Y}$ & 1.3 & 0.92 & 0.46 & 0.33 \\
\hline $\mathrm{Zr}$ & 1.7 & 1.2 & 0.59 & 0.42 \\
\hline Mo & 2.7 & 1.9 & 0.95 & 0.67 \\
\hline $\mathrm{Pd}$ & 11 & 7.6 & 3.8 & 2.7 \\
\hline $\mathrm{Ag}$ & 12 & 8.6 & 4.3 & 3.0 \\
\hline $\mathrm{Cd}$ & 12 & 8.6 & 4.3 & 3.0 \\
\hline In & 13 & 9.5 & 4.8 & 3.4 \\
\hline $\mathrm{Sn}$ & 17 & 12 & 6.2 & 4.4 \\
\hline $\mathrm{Sb}$ & 18 & 13 & 6.4 & 4.5 \\
\hline $\mathrm{Ba}$ & 52 & 37 & 18 & 13 \\
\hline $\mathrm{La}$ & 62 & 44 & 22 & 16 \\
\hline $\mathrm{Au}$ & 3.1 & 2.2 & 1.1 & 0.77 \\
\hline $\mathrm{Hg}$ & 2.6 & 1.8 & 0.91 & 0.65 \\
\hline $\mathrm{Tl}$ & 2.5 & 1.8 & 0.88 & 0.62 \\
\hline $\mathrm{Pb}$ & 3.0 & 2.2 & 1.1 & 0.76 \\
\hline $\mathrm{U}$ & 2.3 & 1.7 & 0.83 & 0.59 \\
\hline
\end{tabular}

${ }^{\mathrm{a}}$ MDL defined as 3 times the standard deviation of the blank for a filter of 1 $\mathrm{mg} / \mathrm{cm}^{2}$ area density.

XRF analyses were performed on Kevex Corporation Model 700/8000 energy dispersive $\mathrm{x}$-ray fluorescence (EDXRF) analyzer using a side-window, liquid-cooled, 60 $\mathrm{keV}, 3.3$ milliamp rhodium anode $\mathrm{x}$-ray tube and secondary fluorescers. The $\mathrm{x}$-ray output stability was within $0.25 \%$ for any 8 -hour period within 24 -hour duration. The silicon detector had an active area of $30 \mathrm{~mm}^{2}$, with a system resolution better than $165 \mathrm{eV}$. The analysis was controlled, spectra were acquired, and elemental concentrations were calculated by software implemented on an LSI 11/23 microcomputer, which was 
interfaced to the analyzer. Five separate XRF analyses were conducted on each sample to optimize the detection limits for the specified elements.

Three types of XRF standards were used for calibration, performance testing, and auditing:

1. Vacuum-deposited thin-film elements and compounds (Micromatter, Deer Harbor, WA) 2. Polymer films

3. NIST thin-glass films.

The vacuum deposit standards covered the largest number of elements and were used as calibration standards. The polymer film and NIST standards were used as quality control standards. NIST standards were the definitive standard reference material, but these were only available for the species $\mathrm{Al}, \mathrm{Ca}, \mathrm{Co}, \mathrm{Cu}, \mathrm{Mn}$, and $\mathrm{Si}(\mathrm{SRM} 1832$ ) and $\mathrm{Fe}$, Pb, K, Si, Ti, and Zn (SRM 1833). A separate Micromatter (Deer Harbor, WA) thin-film standard was used to calibrate the system for each element.

During XRF analysis, filters were removed from their petri slides and placed with their deposit sides down into polycarbonate filter cassettes. A polycarbonate retainer ring kept the filter flat against the bottom of the cassette. These cassettes were loaded into a carousel in the x-ray chamber which contains 16 openings. The filter identifications were recorded on a data sheet to correspond to the numbered positions in the carousel. The sample chamber was evacuated to $10^{-3}$ torr and a computer program controlled the positioning of the samples and the excitation conditions. Complete analysis of 16 samples under five excitation conditions required approximately 6 hours. The vacuum in the x-ray chamber and the heat induced by the absorption of x-rays could cause certain materials to volatilize. For this reason, labile species such as nitrate and organic carbon 
were measured on a quartz-fiber filter rather than on the Teflon-membrane filter, which was subjected to XRF analysis.

A quality control standard and a replicate from a previous batch were analyzed with each set of 14 samples. When a quality control value differed from specifications by more than $\pm 5 \%$ or when a replicate concentration differed from the original value (when values exceeded 10 times the detection limits) by more than $\pm 10 \%$, the samples were reanalyzed. If further tests of standards showed that the system calibration had changed by more than $\pm 2 \%$, the instrument was re-calibrated as described above. All XRF results were directly entered into the DRI databases.

\section{B.2.5.3 Thermal/Optical Reflectance Carbon Analysis}

The thermal/optical reflectance (TOR) method measured organic (OC) and elemental (EC) carbon. The TOR method is based on the principle that different types of carbon-containing particles are converted to gases under different temperature and oxidation conditions. The different carbon fractions from TOR are useful for comparison with other methods, which are specific to a single definition for organic and elemental carbon. These specific carbon fractions also help distinguish among seven carbon fractions reported by TOR:

1. The carbon evolved in a helium atmosphere at temperatures between ambient and 120 ${ }^{\circ} \mathrm{C}(\mathrm{OC} 1)$

2. The carbon evolved in a helium atmosphere at temperatures between 120 and $250^{\circ} \mathrm{C}$ (OC2)

3. The carbon evolved in a helium atmosphere at temperatures between 250 and $450 \mathrm{C}$ (OC3) 
4. The carbon evolved in a helium atmosphere between 450 and $550^{\circ} \mathrm{C}(\mathrm{OC} 4)$

5. The carbon evolved in an oxidizing atmosphere at $550^{\circ} \mathrm{C}(\mathrm{EC} 1)$

6. The carbon evolved in an oxidizing atmosphere between 550 and $700^{\circ} \mathrm{C}(\mathrm{EC} 2)$

7. The carbon evolved in an oxidizing atmosphere between 700 and $800^{\circ} \mathrm{C}(\mathrm{EC} 3)$

The thermal/optical reflectance carbon analyzer consisted of a thermal system and an optical system. The thermal system consisted of a quartz tube placed inside a coiled heater. Current through the heater was controlled to attain and maintain pre-set temperatures for given time periods. A portion of a quartz filter was placed in the heating zone and heated to different temperatures under non-oxidizing and oxidizing atmospheres. The optical system consisted of a He-Ne laser, a fiber optic transmitter and receiver and a photocell. The filter deposit faces a quartz light tube so that the intensity of the reflected laser beam can be monitored throughout the analysis.

As the temperature increased from ambient $\left(\sim 25^{\circ} \mathrm{C}\right)$ to $550^{\circ} \mathrm{C}\left(1022^{\circ} \mathrm{F}\right)$, organic compounds were volatilized from the filter in a non-oxidizing $(\mathrm{He})$ atmosphere while elemental carbon was not oxidized. When oxygen was added to the helium at temperatures greater than $550^{\circ} \mathrm{C}\left(1022^{\circ} \mathrm{F}\right)$, the elemental carbon burned and entered the sample stream. The evolved gases passed through an oxidizing bed of heated manganese dioxide where they were oxidized to carbon dioxide, and then across a heated nickel catalyst, which reduced the carbon dioxide to methane $\left(\mathrm{CH}_{4}\right)$. The methane was then quantified with a flame ionization detector (FID).

The reflected laser light was continuously monitored throughout the analysis cycle. The negative change in reflectance was proportional to the degree of pyrolytic conversion from organic to elemental carbon, which takes place during organic carbon 
analysis. After oxygen was introduced, the reflectance increased rapidly as the lightabsorbing carbon was burned off the filter. The carbon measured after the reflectance attained the value it had at the beginning of the analysis cycle was classified as elemental carbon. This adjustment for pyrolysis in the analysis was significant, as high as $25 \%$ of organic or elemental carbon, and was not ignored.

The system was calibrated by analyzing samples of known amounts of methane, carbon dioxide, and potassium hydrogen phthalate (KHP). The FID response was ratioed to a reference level of methane injected at the end of each sample analysis. Performance tests of the instrument calibration were conducted at the beginning and end of each day's operation. Intervening samples were re-analyzed when calibration changes of more than $\pm 10 \%$ were found.

Known amounts of American Chemical Society (ACS) certified reagent grade crystal sucrose and KHP were committed to TOR as a verification of the organic carbon fractions. Fifteen different standards were used for each calibration. Widely accepted primary standards for elemental and/or organic carbon are still lacking. Results of the TOR analysis of each filter were entered into the DRI database. Tables $\mathrm{C} 1$ to $\mathrm{C} 5$ [Appendix C] lists all the target chemical species analyzed. 


\section{Appendix C - LIST OF TARGET CHEMICAL SPECIES ANALYZED}

Table C1. List of Target Analytes in the Particulate and Semi-Volatile Fractions

\begin{tabular}{|c|c|c|c|}
\hline \multirow{2}{*}{\multicolumn{4}{|c|}{\begin{tabular}{|l|l|l} 
Mnemonic & Compound & Mnemonic \\
Polycyclic Aromatic Hydrocarbons (PAH)and oxy-PAH
\end{tabular}}} \\
\hline & & & \\
\hline NAPHTH & Naphthalene & ANTHONE & Anthrone \\
\hline MNAPH2 & 2-methylnaphthalene & ANRQUONE & Anthraquinone \\
\hline MNAPH1 & 1-methylnaphthalene & DM36PH & $\begin{array}{l}\text { 3,6- } \\
\text { dimethylphenanthrene }\end{array}$ \\
\hline BIPHEN & Biphenyl & A DMPH & A-dimethylphenanthrene \\
\hline ENAP12 & 1+2ethylnaphthalene & B DMPH & B-dimethylphenanthrene \\
\hline DMN267 & $\begin{array}{l}\text { 2,6+2,7- } \\
\text { dimethylnaphthalene }\end{array}$ & C_DMPH & C-dimethylphenanthrene \\
\hline DM1367 & $\begin{array}{l}\text { 1,3+1,6+1,7dimethylnap } \\
\text { hth }\end{array}$ & DM17PH & $\begin{array}{l}1,7- \\
\text { dimethylphenanthrene }\end{array}$ \\
\hline D14523 & $\begin{array}{l}1,4+1,5+2,3- \\
\text { dimethylnaphth }\end{array}$ & D_DMPH & D-dimethylphenanthrene \\
\hline DMN12 & 1,2-dimethylnaphthalene & E_DMPH & E-dimethylphenanthrene \\
\hline $\mathrm{M} 2 \mathrm{BPH}$ & 2-Methylbiphenyl & AN̄THRA & Anthracene \\
\hline $\mathrm{M} 3 \mathrm{BPH}$ & 3-Methylbiphenyl & M_9ANT & 9-methylanthracene \\
\hline M_4BPH & 4-Methylbiphenyl & FLUORA & Fluoranthene \\
\hline DBBZFUR & Dibenzofuran & PYRENE & Pyrene \\
\hline ATMNAP & A-trimethylnaphthalene & ANTAL9 & 9-Anthraaldehyde \\
\hline BTMNAP & B-trimethylnaphthalene & RETENE & Retene \\
\hline CTMNAP & C-trimethylnaphthalene & BNTIOP & Benzonaphthothiophene \\
\hline ETMNAP & E-trimethylnaphthalene & C1MFLPY & 1-MeFI+C-MeFl/Py \\
\hline FTMNAP & F-trimethylnaphthalene & BMPYFL & B-MePy/MeFI \\
\hline TMI235N & $\begin{array}{l}2,3,5+\mid- \\
\text { trimethylnaphthalene }\end{array}$ & CMPYFL & C-MePy/MeFI \\
\hline TM245N & $\begin{array}{l}2,4,5- \\
\text { trimethylnaphthalene }\end{array}$ & DMPYFL & D-MePy/MeFI \\
\hline JTMNAP & J-trimethylnaphthalene & M_4PYR & 4-methylpyrene \\
\hline TM145N & $\begin{array}{l}1,4,5- \\
\text { trimethylnaphthalene }\end{array}$ & M_1PYR & 1-methylpyrene \\
\hline ACNAPY & Acenaphthylene & BZCPHEN & Benzo(c)phenanthrene \\
\hline ACNAPE & Acenaphthene & BAANTH & Benz(a)anthracene \\
\hline FLUORE & Fluorene & M_7BAA & $\begin{array}{l}\text { 7- } \\
\text { methylbenz(a)anthracen } \\
\text { e }\end{array}$ \\
\hline PHENAN & Phenanthrene & CHRYSN & Chrysene \\
\hline A_MFLU & A-methylfluorene & BZANTHR & Benzanthrone \\
\hline M_1FLU & 1-methylfluorene & BAA7_12 & $\begin{array}{l}\text { Benz(a)anthracene- } \\
\text { 7,12-dione }\end{array}$ \\
\hline B_MFLU & B-methylfluorene & CHRY56M & 5+6-methylchrysene \\
\hline
\end{tabular}




\begin{tabular}{|c|c|c|c|}
\hline Mnemonic & Compound & Mnemonic & Compound \\
\hline FL9ONE & 9-fluorenone & BBJKFL & $\begin{array}{l}\text { Benzo }(b+j+k) f l u o r a n t h e n \\
\text { e }\end{array}$ \\
\hline XANONE & Xanthone & M 7BPY & 7-methylbenzo(a)pyrene \\
\hline ACQUONE & Acenaphthenequinone & BËPYRN & $\mathrm{BeP}$ \\
\hline PNAPONE & Perinaphthenone & PERYLE & Perylene \\
\hline A_MPHT & A-methylphenanthrene & BAPYRN & $\mathrm{BaP}$ \\
\hline M $2 \mathrm{PHT}$ & 2-methylphenanthrene & INCDPY & Indeno[123-cd]pyrene \\
\hline B MPHT & B-methylphenanthrene & BGHIPE & Benzo(ghi)perylene \\
\hline C_MPHT & C-methylphenanthrene & DBANTH & $\begin{array}{l}\text { Dibenzo(ah+ac)anthrace } \\
\text { ne }\end{array}$ \\
\hline M 1PHT & 1-methylphenanthrene & CORONE & Coronene \\
\hline \multicolumn{4}{|c|}{ Hopanes/Steranes } \\
\hline STER35 & $\begin{array}{l}\text { 20S-13ß(H),17a(H)- } \\
\text { diasterane }\end{array}$ & STER52 & $\begin{array}{l}\text { 20S5a }(\mathrm{H}), 14 ß(\mathrm{H}), 17 ß(\mathrm{H}) \\
\text {-stigmastane }\end{array}$ \\
\hline STER36 & $\begin{array}{l}\text { 20R-13ß(H),17a(H)- } \\
\text { diasterane }\end{array}$ & HOP13 & $\begin{array}{l}18 \mathrm{a}(\mathrm{H}), 21 ß(\mathrm{H})-22,29,30- \\
\text { Trisnorhopane }\end{array}$ \\
\hline STER37 & $\begin{array}{l}\text { 20S-13a(H),17ß(H)- } \\
\text { diasterane }\end{array}$ & HOP14 & $\begin{array}{l}\text { 17a(H),18a(H),21ß(H)- } \\
25,28,30 \text {-Trisnorhopane }\end{array}$ \\
\hline STER38 & $\begin{array}{l}\text { 20R-13a(H),17ß(H)- } \\
\text { diasterane }\end{array}$ & STER53 & $\begin{array}{l}\text { 20R5a }(\mathrm{H}), 14 a(\mathrm{H}), 17 \mathrm{a}(\mathrm{H}) \\
\text {-stigmastane }\end{array}$ \\
\hline STER39 & $\begin{array}{l}\text { 20S-13ß(H),17a(H)- } \\
\text { diasterane }\end{array}$ & HOP15 & $\begin{array}{l}\text { 17a(H),21ß(H)-22,29,30- } \\
\text { Trisnorhopane }\end{array}$ \\
\hline STER42 & $\begin{array}{l}\text { C27-20S5a }(H), 14 a(H)- \\
\text { cholestane }\end{array}$ & HOP16 & $\begin{array}{l}\text { 17a(H),18a(H),21ß(H)- } \\
\text { 28,30-Bisnorhopane }\end{array}$ \\
\hline STER43 & $\begin{array}{l}\text { 20R5a(H),14ß(H)- } \\
\text { cholestane }\end{array}$ & HOP17 & $\begin{array}{l}\text { 17a(H),21ß(H)-30- } \\
\text { Norhopane }\end{array}$ \\
\hline STER44 & $\begin{array}{l}\text { C27- } \\
\text { 20S5a(H),14ß(H),17ß(H) } \\
\text {-cholestane }\end{array}$ & HOP18 & $\begin{array}{l}\text { 18a(H),21ß(H)-30- } \\
\text { Norneohopane }\end{array}$ \\
\hline STER45_40 & $\begin{array}{l}\text { 20R5a }(\mathrm{H}), 14 a(H), 17 a(H) \\
\text {-cholestane\&C29- } \\
\text { 20S13ß }(\mathrm{H}), 17 a(H)- \\
\text { diasterane }\end{array}$ & HOP19 & 17a(H),21ß(H)-Hopane \\
\hline STER46 & $\begin{array}{l}\text { 20S5a }(\mathrm{H}), 14 \mathrm{a}(\mathrm{H}), 17 \mathrm{a}(\mathrm{H}) \\
\text {-ergostane }\end{array}$ & HOP20 & 17ß(H),21a(H)-hopane \\
\hline STER47 & $\begin{array}{l}\text { 20R5a }(H), 14 ß(H), 17 ß(H \\
\text { )-ergostane }\end{array}$ & HOP21 & $\begin{array}{l}\text { 22S-17a(H),21ß(H)-30- } \\
\text { Homohopane }\end{array}$ \\
\hline STER48 & $\begin{array}{l}20 S 5 a(H), 14 ß(H), 17 ß(H) \\
\text {-ergostane }\end{array}$ & HOP22 & $\begin{array}{l}\text { 22R-17a(H),21ß(H)-30- } \\
\text { Homohopane }\end{array}$ \\
\hline STER41 & $\begin{array}{l}\text { 20R-13a(H),17ß(H)- } \\
\text { diasterane }\end{array}$ & HOP23 & 17ß(H),21ß(H)-Hopane \\
\hline HOP9 & C27-tetracyclic terpane & HOP24 & $\begin{array}{l}\text { 22S-17a(H),21ß(H)- } \\
\text { 30,31-Bishomohopane }\end{array}$ \\
\hline STER49 & $\begin{array}{l}\text { 20R5a }(\mathrm{H}), 14 \mathrm{a}(\mathrm{H}), 17 \mathrm{a}(\mathrm{H}) \\
\text {-ergostane }\end{array}$ & HOP25 & $\begin{array}{l}\text { 22R-17a(H),21ß(H)- } \\
\text { 30,31-Bishomohopane }\end{array}$ \\
\hline
\end{tabular}




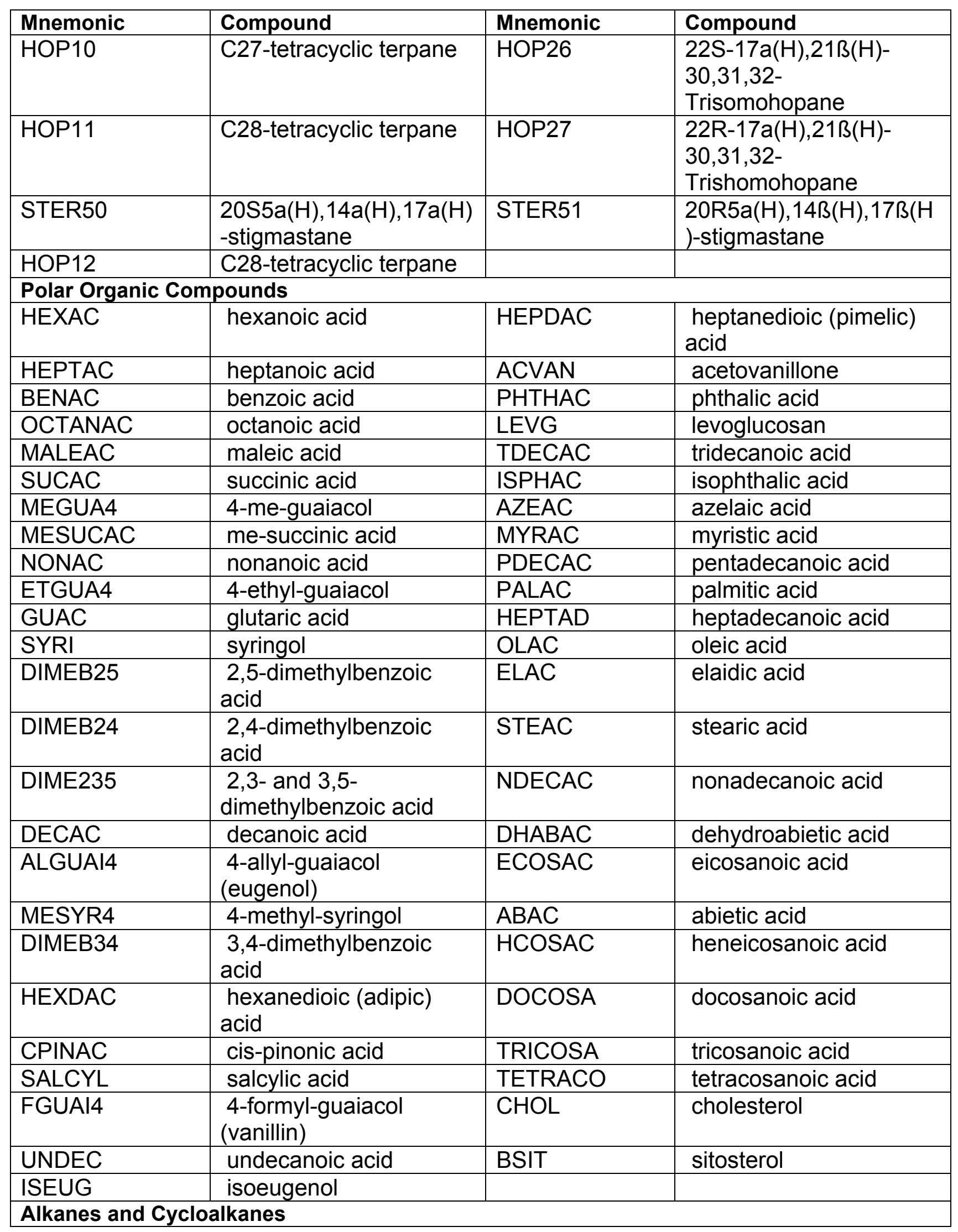




\begin{tabular}{|l|l|l|l|}
\hline Mnemonic & Compound & Mnemonic & Compound \\
\hline NOYCYHX & Nonylcyclohexane & EICOSA & Eicosane \\
\hline HPYCYHX & Heptylcyclohexane & HENEIC & Heneicosane \\
\hline OCYCYHX & Octylcyclohexane & DOCOSA & Docosane \\
\hline NORFARN & Norfarnesane & TRICOSA & Tricosane \\
\hline FARNES & Farnesane & DEC5YHX & Pentadecylcyclohexane \\
\hline TEDRAD & Tetradecane & DEC6YHX & Hexadecylcyclohexane \\
\hline PENTAD & Pentadecane & DEC7YHX & Heptadecylcyclohexane \\
\hline HEXAD & $\begin{array}{l}\text { Hexadecane_Norpristan } \\
\text { e }\end{array}$ & DEC8YHX & Octadecylcyclohexane \\
\hline HEPTAD & Heptadecane_Pristane & DEC9YHX & Nonadecylcyclohexane \\
\hline OCTAD & Octadecane & COSAN4 & Tetracosane \\
\hline NONAD & Nonadecane & COSAN5 & Pentacosane \\
\hline PHYTAN & Phytane & COSAN6 & Hexacosane \\
\hline DECYHX & Decylcyclohexane & COSAN7 & Heptacosane \\
\hline DEC1YHX & Undecylcyclohexane & CYHXEIC & Eicosylcyclohexane \\
\hline DEC2YHX & Dodecylcyclohexane & CYHXHEN & Heneicosylcyclohexane \\
\hline DEC3YHX & Tridecylcyclohexane & COSAN8 & Octacosane \\
\hline DEC4YHX & Tetradecylcyclohexane & & \\
\hline Nitro-PAH & & & \\
\hline NI1NAPTH & 1-nitronaphthalene & NI2FLUOR & 2-nitrofluoranthene \\
\hline NI2NAPTH & 2-nitronaphthalene & NI3FLUOR & 3-nitrofluoranthene \\
\hline NI2BIPH & 2-nitrobiphenyl & NI1PYRE & 1-nitropyrene \\
\hline NI3BIPH & 3-nitrobiphenyl & NI27FLUO & 2,7-dinitrofluorene \\
\hline NI4BPH & 4-nitrobiphenyl & NI27FL9ON & 2,7-dinitrofluoren-9-one \\
\hline NI13NAP & 1,3-dinitronaphthalene & NI7BZANTH & 7- \\
& & nitrobenz(a)anthracene \\
\hline NI15NAP & 1,5-dinitronaphthalene & NI6CHRY & 6-nitrochrysene \\
\hline NI5ACEN & 5-nitroacenaphthene & NI13PYR & 1,3-dinitropyrene \\
\hline NI9ANTHR & 9-nitroanthracene & NI16PYR & 1,6-dinitropyrene \\
\hline NI4PHEN & 4-nitrophenanthrene & NI18PYR & 1,8-dinitropyrene \\
\hline NI9PHEN & 9-nitrophenanthrene & NI910ANTH & 9,10-dinitroanthracene \\
\hline NI3PHEN & 3-nitrophenanthrene & NI6BAP & 6-nitrobenz[a]pyrene \\
\hline NI18NAP & 1,8-dinitronaphthalene & & \\
\hline & & & \\
\hline
\end{tabular}

Table C2. List of Gas-phase Volatile Organic Compounds Quantified by GC/MS Method from Canisters

\begin{tabular}{|l|l|l|l|}
\hline Mnemonic & Compound & Mnemonic & Compound \\
\hline ethane & ethane & pa224m & $\begin{array}{l}2,2,4- \\
\text { trimethylpentane }\end{array}$ \\
\hline ethene & ethene & n_hept & n-heptane \\
\hline acetyl & acetylene & p2e23m & $\begin{array}{l}2,3-\text { dimethyl-2- } \\
\text { pentene }\end{array}$ \\
\hline
\end{tabular}




\begin{tabular}{|c|c|c|c|}
\hline Mnemonic & Compound & Mnemonic & Compound \\
\hline Ipropa & propane & t13dcp & $\begin{array}{l}\mathrm{t}-1,3- \\
\text { dichloropropene }\end{array}$ \\
\hline Iprope & propene & mecyhx & methylcyclohexane \\
\hline Ipropy & propyne & pa234m & $\begin{array}{l}2,3,4- \\
\text { trimethylpentane }\end{array}$ \\
\hline ibuta & iso-butane & tolue & toluene \\
\hline but1e_ibute & 1-butene + isobutene & $\mathrm{h} \times 23 \mathrm{dm}$ & 2,3-dimethylhexane \\
\hline bud13 & 1,3-butadiene & hep2me & 2-methylheptane \\
\hline butan & n-butane & hep4me & 4-methylheptane \\
\hline t2but & t-2-butene & hep3me & 3-methylheptane \\
\hline c2but & c-2-butene & hex225 & $\begin{array}{l}2,2,5- \\
\text { trimethylhexane }\end{array}$ \\
\hline bud12 & 1,2-butadiene & n_oct & n-octane \\
\hline ipent & iso-pentane & etbz & ethylbenzene \\
\hline pente1 & 1-pentene & $m p \_x y l$ & $\mathrm{~m} / \mathrm{p}$-xylene \\
\hline b1e2m & 2-methyl-1-butene & oct3me & 3-methyloctane \\
\hline n_pent & n-pentane & styr & styrene \\
\hline i_pren & isoprene & o_xyl & o-xylene \\
\hline t2pene & t-2-pentene & n_non & n-nonane \\
\hline c2pene & c-2-pentene & iprbz & i-propylbenzene \\
\hline b2e2m & 2-methyl-2-butene & ipcyhex & $\begin{array}{l}\text { isopropylcyclohexan } \\
\text { e }\end{array}$ \\
\hline bu22dm & 2,2-dimethylbutane & a_pine & alpha-pinene \\
\hline cpente & cyclopentene & n_prbz & propylbenzene \\
\hline cpenta & cyclopentane & m_etol & 3-ethyltoluene \\
\hline bu23dm & 2,3-dimethylbutane & p_etol & 4-ethyltoluene \\
\hline pena2m & 2-methylpentane & $\mathrm{bz} 135 \mathrm{~m}$ & $\begin{array}{l}1,3,5- \\
\text { trimethylbenzene }\end{array}$ \\
\hline pena3m & 3-methylpentane & o_etol & 2-ethyltoluene \\
\hline p1e2me & 2-methyl-1-pentene & b_pine & beta-pinene \\
\hline n_hex & n-hexane & $\begin{array}{l}\text { bz124m_tbut } \\
\text { bz }\end{array}$ & $\begin{array}{l}1,2,4- \\
\text { trimethylbenzene+t- } \\
\text { butylbenzene }\end{array}$ \\
\hline t2hexe & t-2-hexene & n_dec & n-decane \\
\hline p2e2me & 2-methyl-2-pentene & $\mathrm{bz} 123 \mathrm{~m}$ & $\begin{array}{l}1,2,3- \\
\text { trimethylbenzene }\end{array}$ \\
\hline p2e3mt & 3-methyl-2-pentene & limon & limonene \\
\hline c2hexe & c-2-hexene & indan & indan \\
\hline p2e3mc & cis-3-methyl-2-pentene & detbz13 & 1,3-diethylbenzene \\
\hline hxdi13 & 1,3-hexadiene (trans) & detbz14 & 1,4-diethylbenzene \\
\hline mcypna & methylcyclopentane & n_bubz & butylbenzene \\
\hline pen24m & 2,4-dimethylpentane & prtol & propyltoluene \\
\hline cpene1 & cyclopentene & iprtol & isopropyltoluene \\
\hline benze & benzene & n_unde & n-undecane \\
\hline
\end{tabular}




\begin{tabular}{|l|l|l|l|}
\hline Mnemonic & Compound & Mnemonic & Compound \\
\hline cyhexa & cyclohexane & bz1245 & $\begin{array}{l}1,2,4,5- \\
\text { tetramethylbenzene }\end{array}$ \\
\hline hexa2m & 2-methylhexane & bz1235 & $\begin{array}{l}1,2,3,5- \\
\text { tetramethylbenzene }\end{array}$ \\
\hline pen23m & 2,3-dimethylpentane & ind_2m & 2-methylindan \\
\hline hexa3m & 3-methylhexane & ind_1m & 1-methylindan \\
\hline cyhexe & cyclohexene & & \\
\hline cpa13m & $\begin{array}{l}\text { 1,3-dimethylcyclopentane } \\
\text { (cis) }\end{array}$ & & \\
\hline hep1e & 1-heptene & & \\
\hline
\end{tabular}

Table C3. List of Target Analytes in the Gas-Phase Carbonyl Compound Fraction

\begin{tabular}{|l|l|}
\hline Mnemonic & Compound \\
\hline FORMAL & Formaldehyde \\
\hline ACETAL & Acetaldehyde \\
\hline ACETO & Acetone \\
\hline ACROLN & Acrolein \\
\hline PROAL & Propionaldehyde \\
\hline CROTON & Crotonaldehyde \\
\hline MEK & Methyl ethyl ketone \\
\hline MACROL & Methacrolein \\
\hline BUTAL & Butyraldehyde \\
\hline BENZAL & Benzaldehyde \\
\hline GLYOXL & Glyoxal \\
\hline VALAL & Valeraldehyde \\
\hline TOLUAL & M-tolualdehyde \\
\hline HEXAL & Hexanaldehyde \\
\hline
\end{tabular}

Table C4. Nitrosoamines Targeted for Analysis in the Vehicle Exhaust

\begin{tabular}{|l|c|}
\hline Compound Name & LQL $^{\text {a }}(\mu \mathbf{g} / \mathbf{s a m p l e})$ \\
\hline \multicolumn{1}{|c|}{ Nitrosoamines } & \\
\hline n-nitrosomorpholine & 0.01 \\
\hline n-nitrosodiethylamine & 0.01 \\
\hline n-nitrosodimethylamine & 0.01 \\
\hline n-nitrosodibutylamine & 0.01 \\
\hline n-nitrosopyrolidine & 0.01 \\
\hline
\end{tabular}


Table C5. List of Heavy Hydrocarbons for Tenax Samples

\begin{tabular}{|c|c|c|c|}
\hline Mnemonic & Compound & Mnemonic & Compound \\
\hline HEPAL & Heptanal & IPRXYL_5 & 5-isopropyl-m-xylene \\
\hline N_NON & Nonane & BZ1245 & 1,2,4,5-tetramethylbenzene \\
\hline IPRBZ & Isopropylbenzene & BZ1235 & 1,2,3,5-tetramethylbenzene \\
\hline N PRBZ & Propylbenzene & IAMBZ & Isoamylbenzene \\
\hline M_ETOL & m-ethyltoluene & IND_2M & 2-methylindan \\
\hline P_ETOL & p-ethyltoluene & IND $1 \mathrm{M}$ & 1-methylindan \\
\hline $\mathrm{BZ} 135 \mathrm{M}$ & 1,3,5-trimethylbenzene & BZ1234 & 1,2,3,4-tetramethylbenzene \\
\hline PHENOL & Phenol & DIPRB 13 & 1,3-diisopropylbenzene \\
\hline O_ETOL & o-ethyltoluene & C5BZ_3 & Pentylbenzene \\
\hline FURBZ & 2,3-benzofuran & THNAPH & 1,2,3,4-tetrahydronaphthalene \\
\hline FURPEN & 2-pentylfuran & DHNAPH & 1,2-dihydronaphthalene \\
\hline T_BUBZ & t-butylbenzene & DIPRB_14 & 1,4-diisopropylbenzene \\
\hline$\overline{\text { OCTAL }}$ & Octanal & NAPHTH & Naphthalene \\
\hline BZ124M & 1,2,4-trimethylbenzene & INDDMA & A-dimethylindane \\
\hline MESTYR & 4-methylstyrene & INDDMB & B-dimethylindane \\
\hline MPCBZ & 1,3-dichlorobenzene & INDDMC & C-dimethylindane \\
\hline DEC1E & 1-decene & INDDMD & D-dimethylindan \\
\hline I BUBZ & Isobutylbenzene & DECONE2 & 2-decanone \\
\hline $\bar{N} \mathrm{DEC}$ & Decane & DECAL & Decanal \\
\hline S_BUBZ & Sec-butylbenzene & DODE1E & Dodecene \\
\hline BZ123M & 1,2,3-trimethylbenzene & N_DODE & Dodecane \\
\hline M_IPRTOL & m-isopropyltoluene & PMEBZ & Pentamethylbenzene \\
\hline P IPRTOL & p-isopropyltoluene & NAP 2M & 2-methylnaphthalene \\
\hline ODCBZ & 1,2-dichlorobenzene & NAP_1M & 1-methylnaphthalene \\
\hline INDAN & Indan & N_TRID & Tridecane \\
\hline INDENE & Indene & BIPHEN & Biphenyl \\
\hline O IPRTOL & o-isopropyltoluene & ENAP12 & 1+2-ethylnaphthalene \\
\hline O_MEPHO & o-methylphenol & DMN267 & 2,6+2,7-dimethylnaphthalene \\
\hline DETBZ1 & 1,3-diethylbenzene & $\mathrm{N}$ TETD & Tetradecane \\
\hline $\begin{array}{l}\text { M_TOLAL } \\
D^{-}\end{array}$ & m-tolualdehyde & DM1367 & $\begin{array}{l}1,6+1,3+1,7- \\
\text { dimethylnaphthalene }\end{array}$ \\
\hline TOL4PR & $\begin{array}{l}\text { 4-n-propyltoluene + 1,4- } \\
\text { diethylbenzene }\end{array}$ & D14523 & $\begin{array}{l}2,3+1,5+1,4- \\
\text { dimethylnaphthalene }\end{array}$ \\
\hline BUTBZ & Butylbenzene & ACENAP & Acenaphthylene \\
\hline M_XYLET5 & 5-ethyl-m-xylene & DMN12 & 1,2-dimethylnaphthalene \\
\hline DĒTBZ3 & 1,2-diethylbenzene & ACENPE & Acenaphthene \\
\hline $\begin{array}{l}\text { MP_MEPH } \\
\text { O }\end{array}$ & $\mathrm{m} / \mathrm{p}$-methylphenol & N_PEND & Pentadecane \\
\hline TOL2PR & 2-n-propyltoluene & FLUORE & Fluorene \\
\hline P_XYLET2 & 2-ethyl-p-xylene & N_HEXD & Hexadecane \\
\hline O XYLET4 & 4-ethyl-o-xylene & $\mathrm{N}$ HEPD & Heptadecane \\
\hline
\end{tabular}




\begin{tabular}{|l|l|l|l|}
\hline Mnemonic & Compound & Mnemonic & Compound \\
\hline TBUTOL_4 & 4-tert-butyltoluene & PHENA & Phenanthrene \\
\hline NONAL & Nonanal & N_OCTD & Octadecane \\
\hline UNDE1E & 1-undecene & N_NOND & Nonadecane \\
\hline FUBZ2ME & 2-methylbenzofuran & N_EICO & Eicosane \\
\hline N_UNDE & Undecane & & \\
\hline & & & \\
\hline
\end{tabular}




\section{Appendix D - CHEMICAL SPECIATION RESULTS}

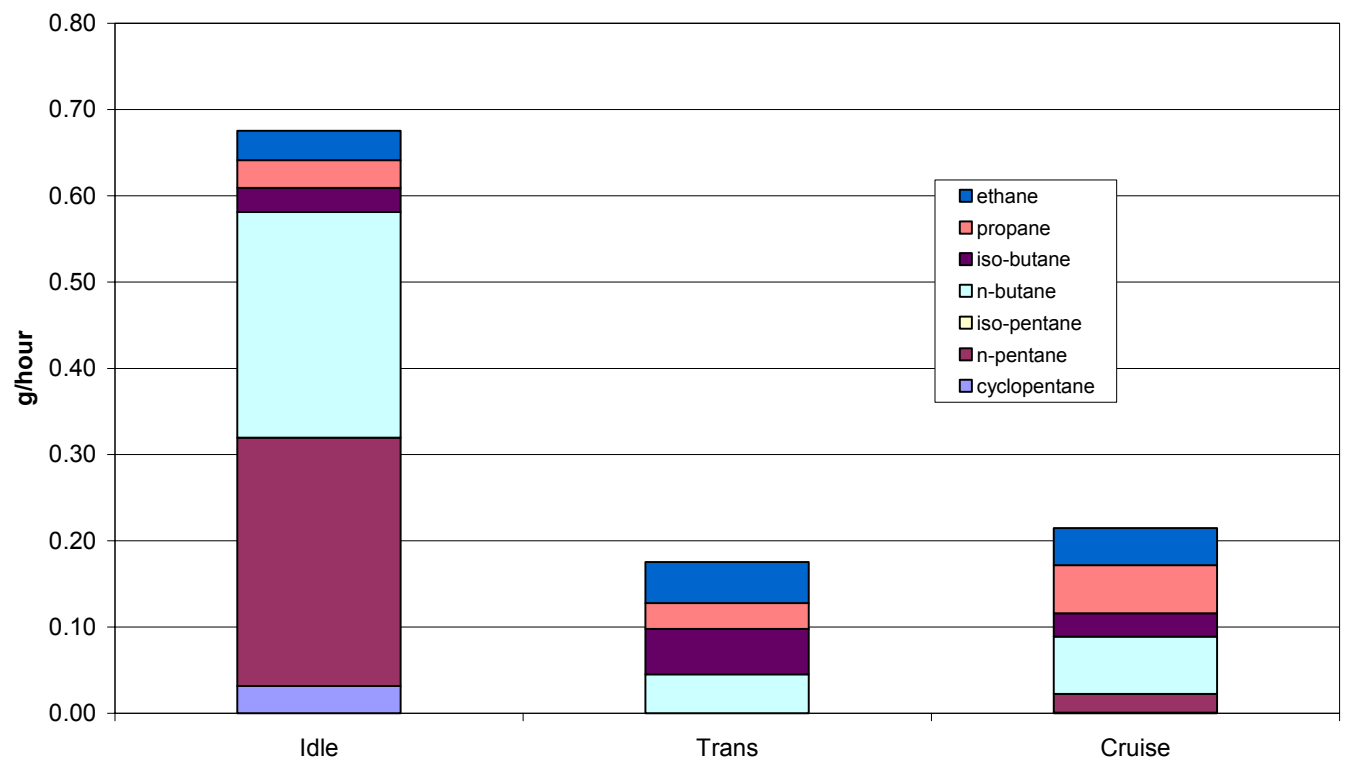

Figure D1: VOC Results (C2 to C5 Alkanes) for CRC 39

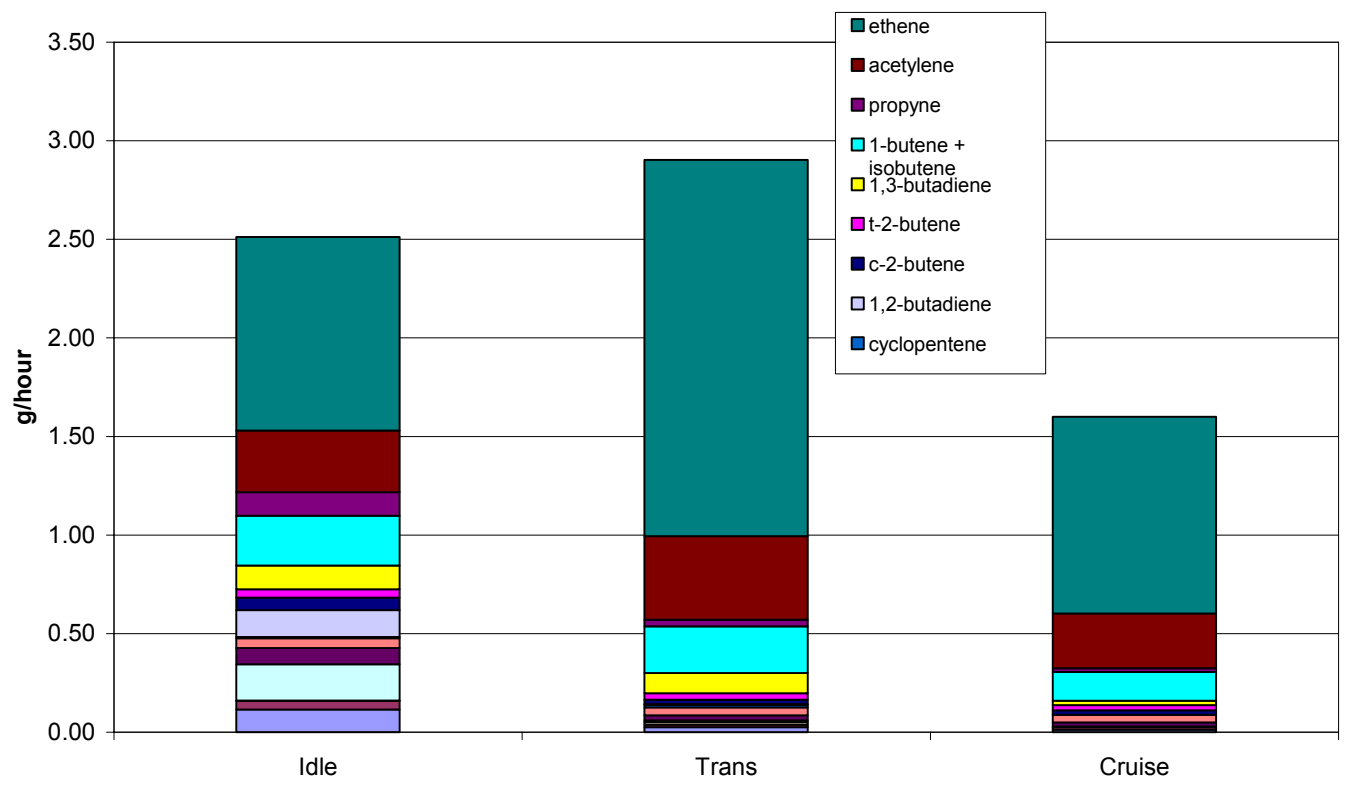

Figure D2: VOC Results (C2 to C5 Olefins) for CRC 39 


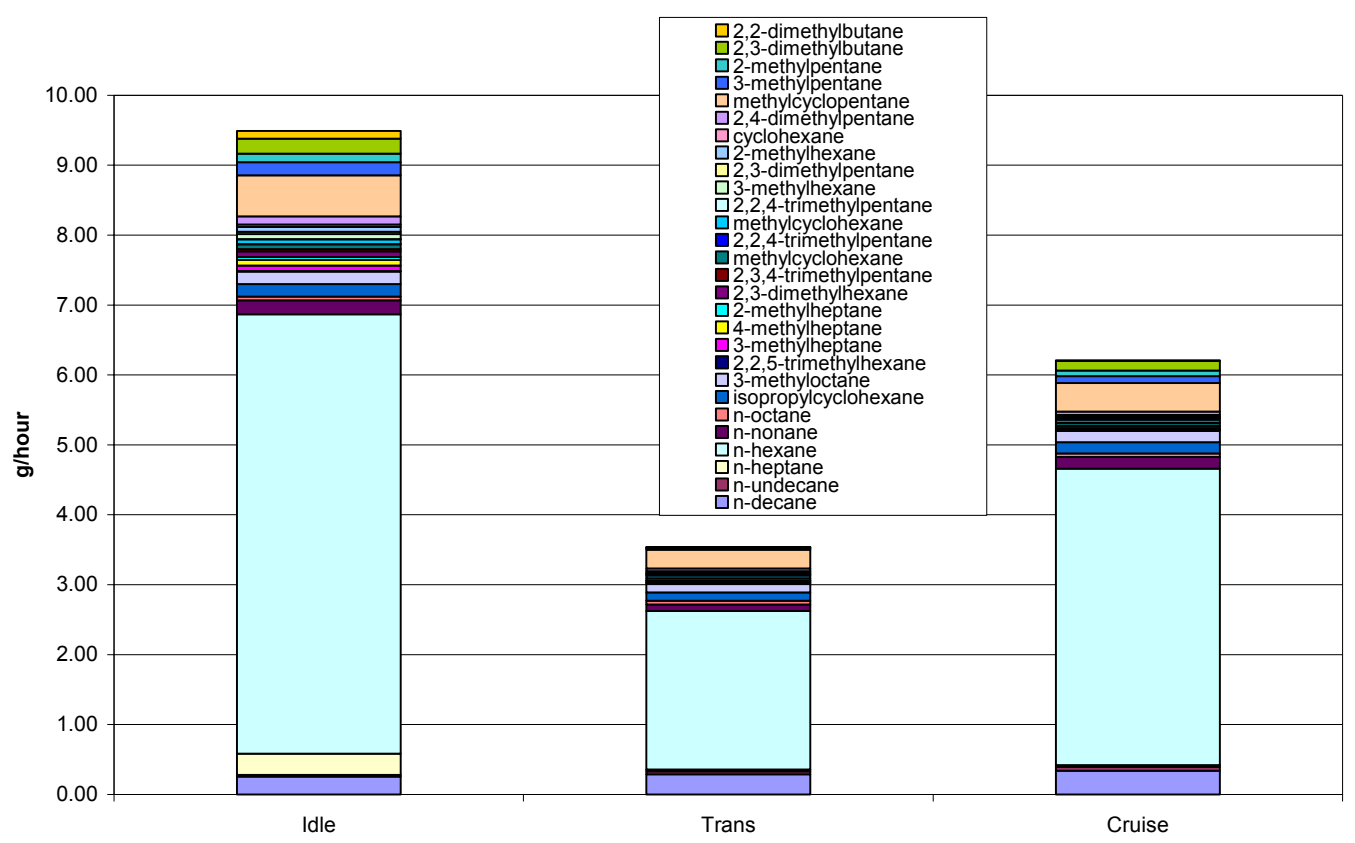

Figure D3: VOC Results (C6 and higher alkanes) for CRC 39

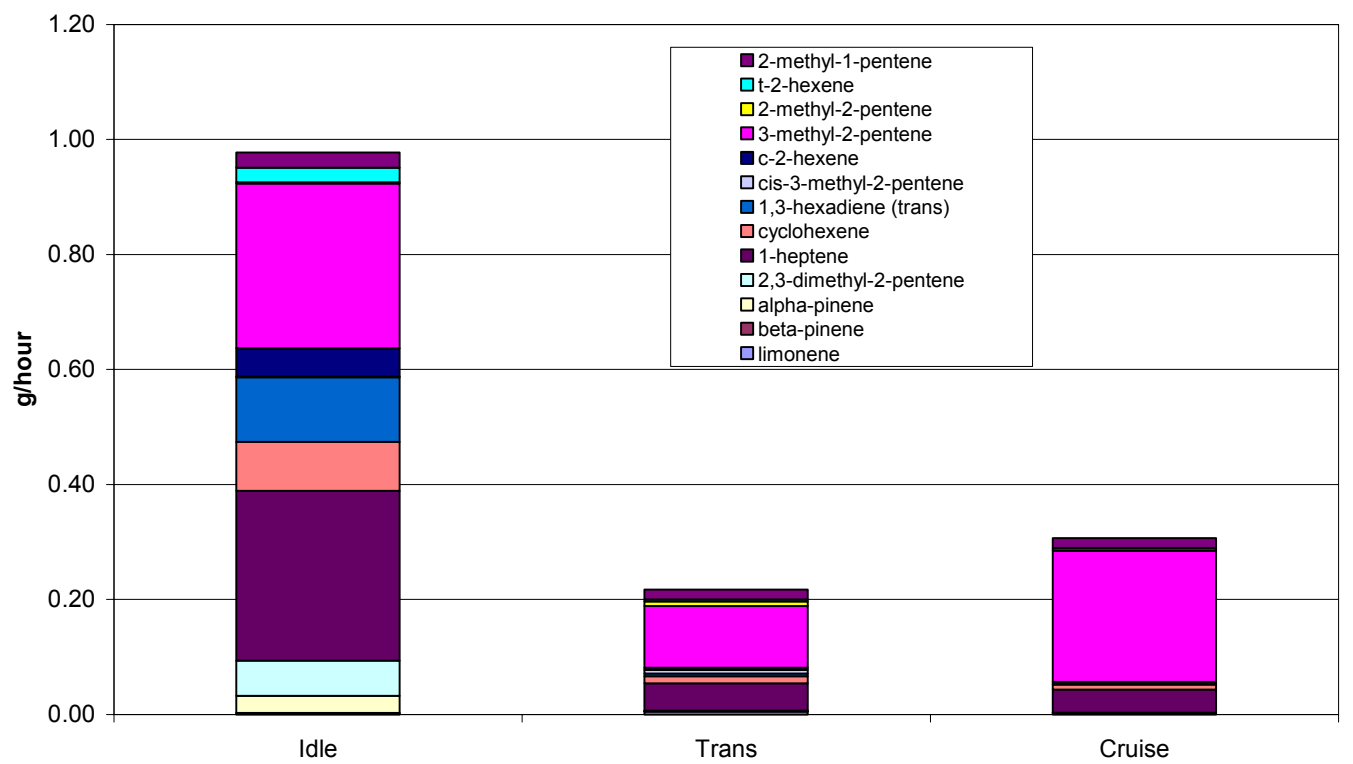

Figure D4: VOC Results (C6 and higher olefins) for CRC 39 


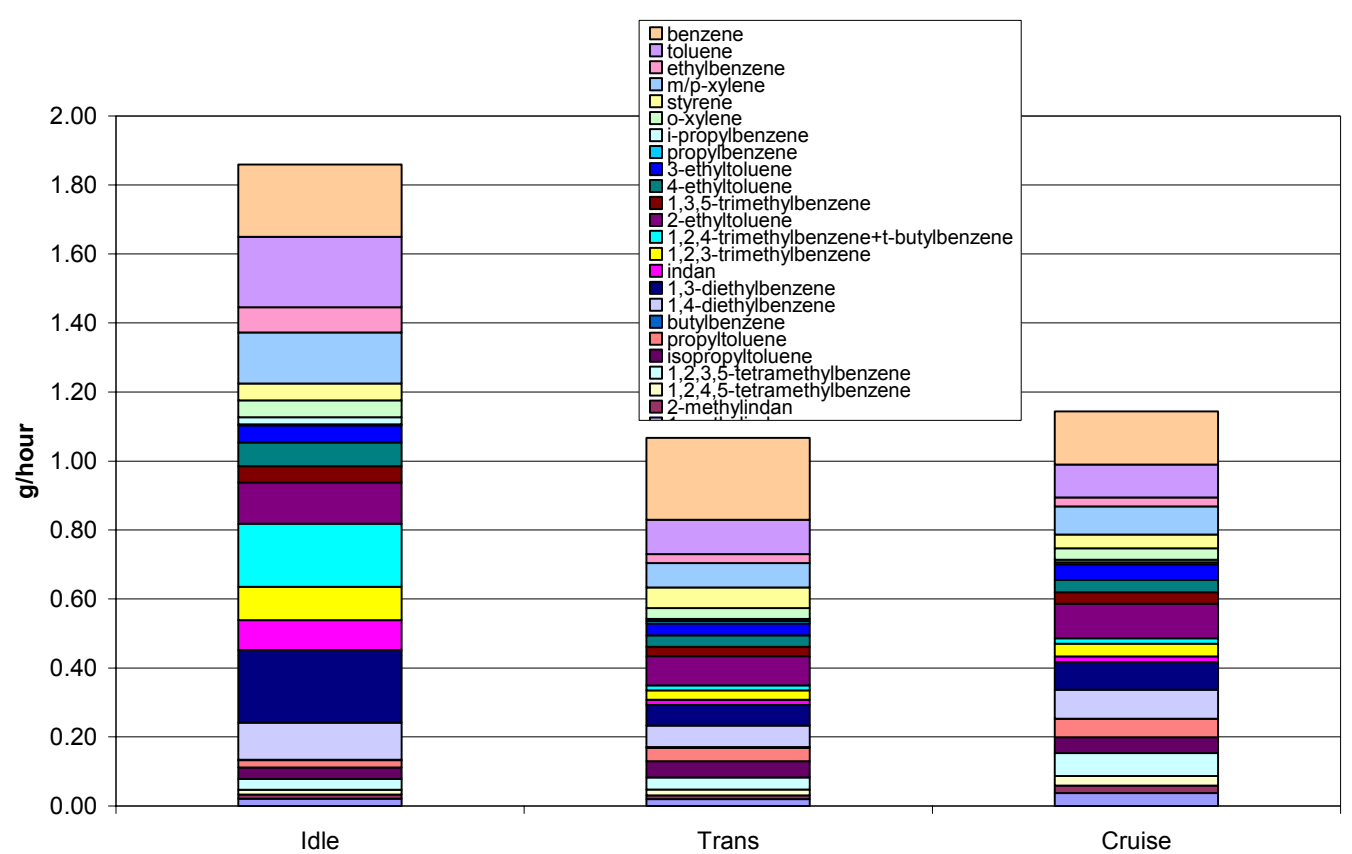

Figure D5: VOC Results (Aromatics) for CRC 39

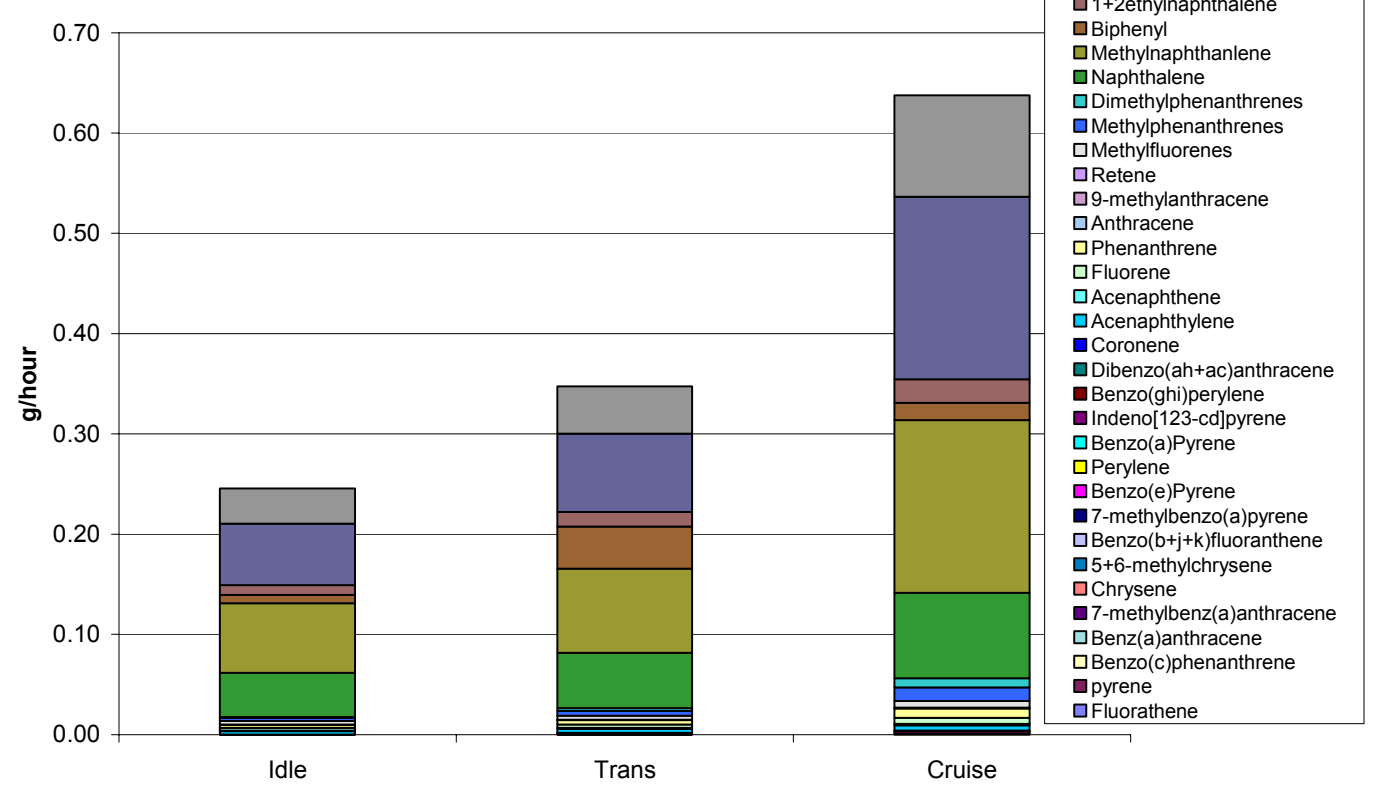

Figure D6: PAH Results for CRC 39 


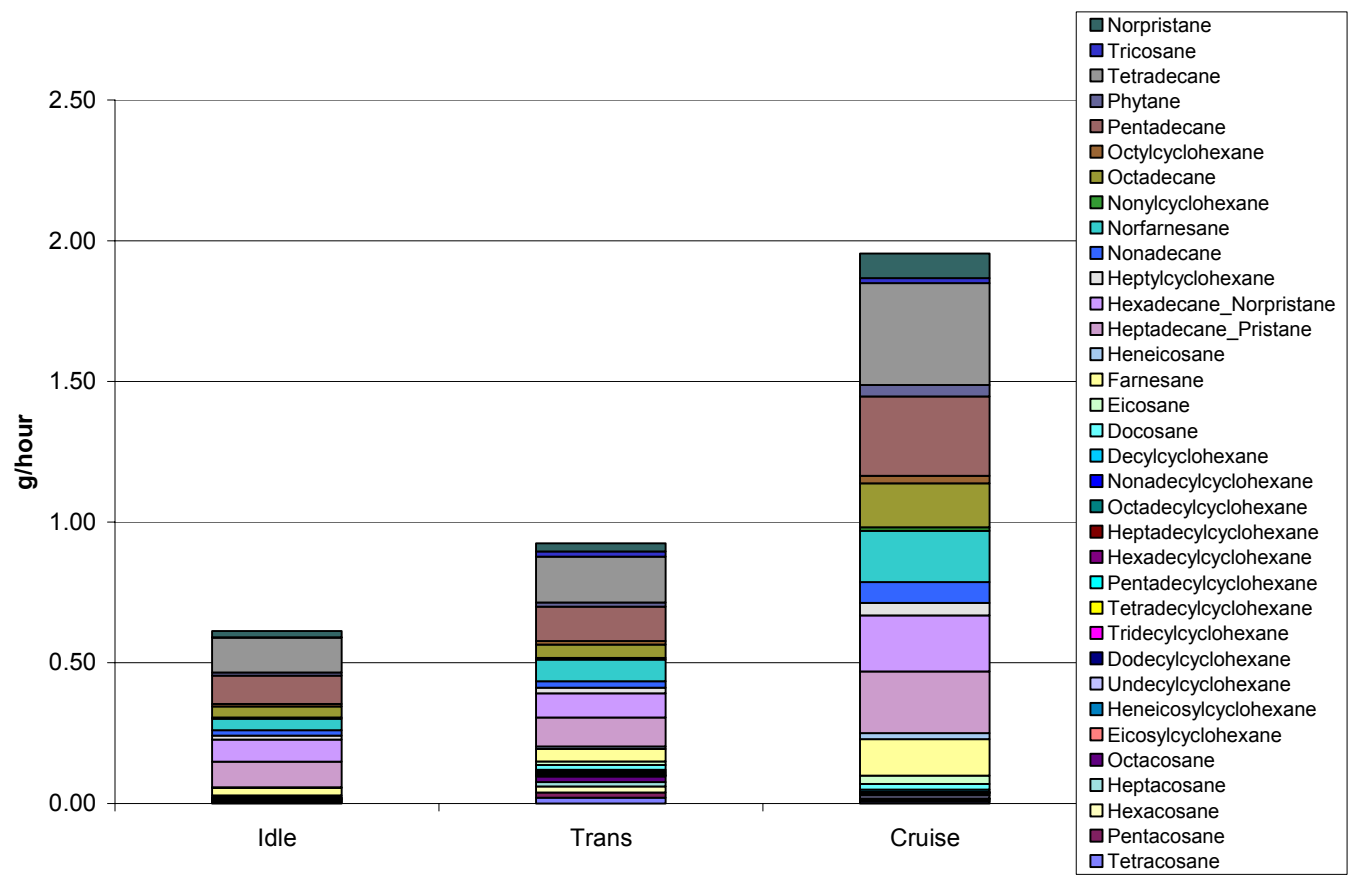

Figure D7: Alkanes Results for CRC 39

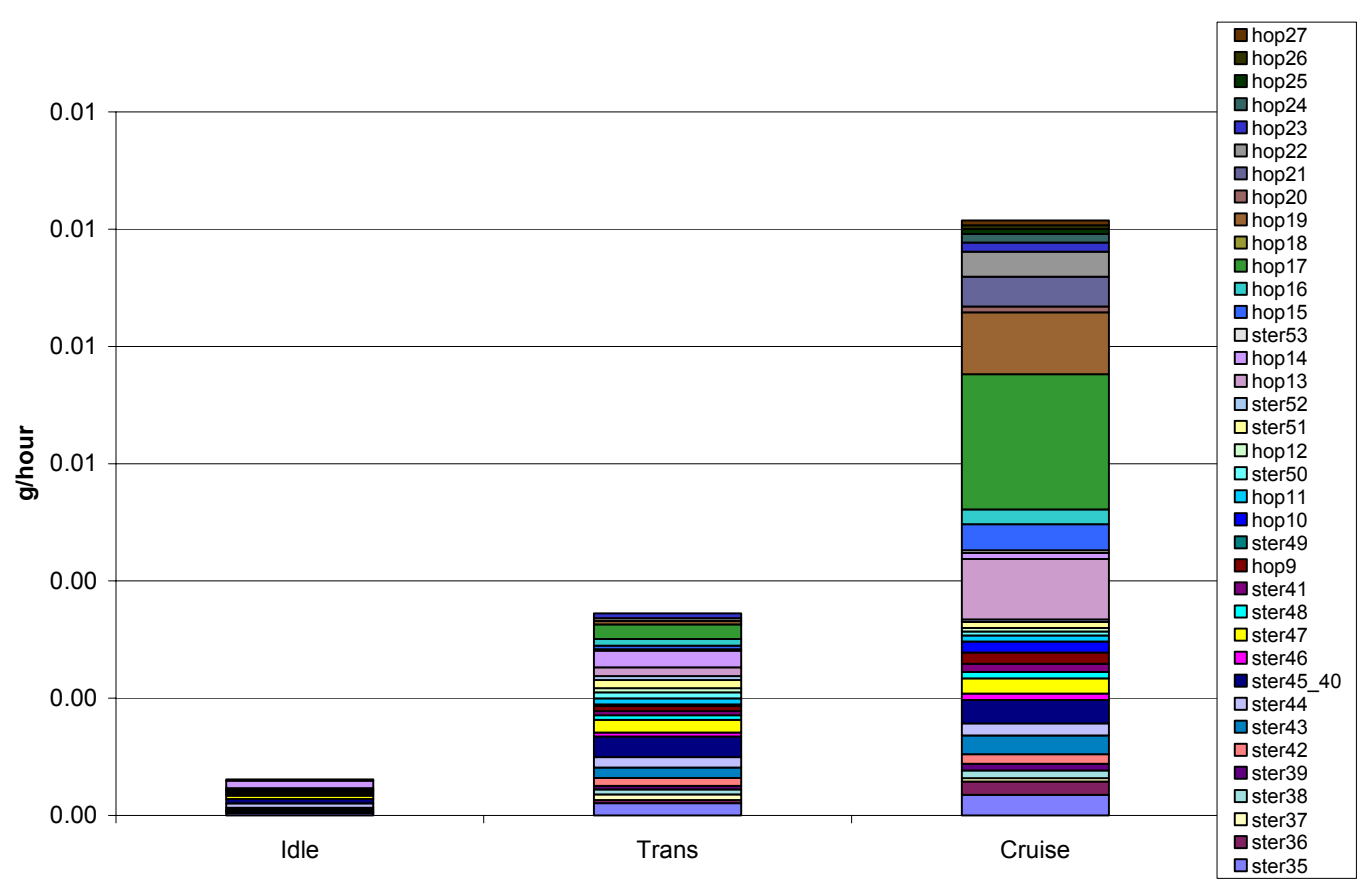

Figure D8: Hopanes and Steranes Results for CRC 39 


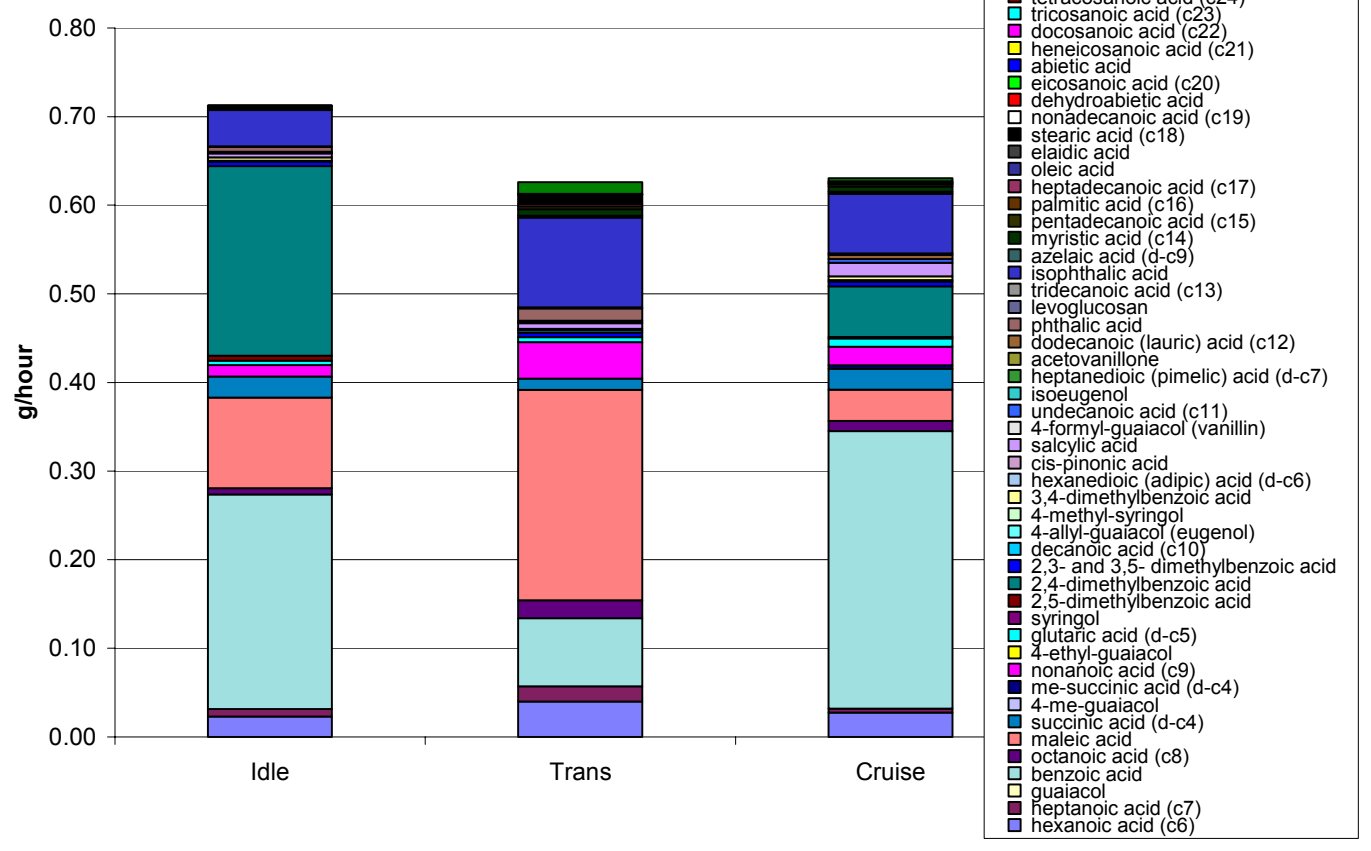

Figure D9: Polar Results for CRC 39

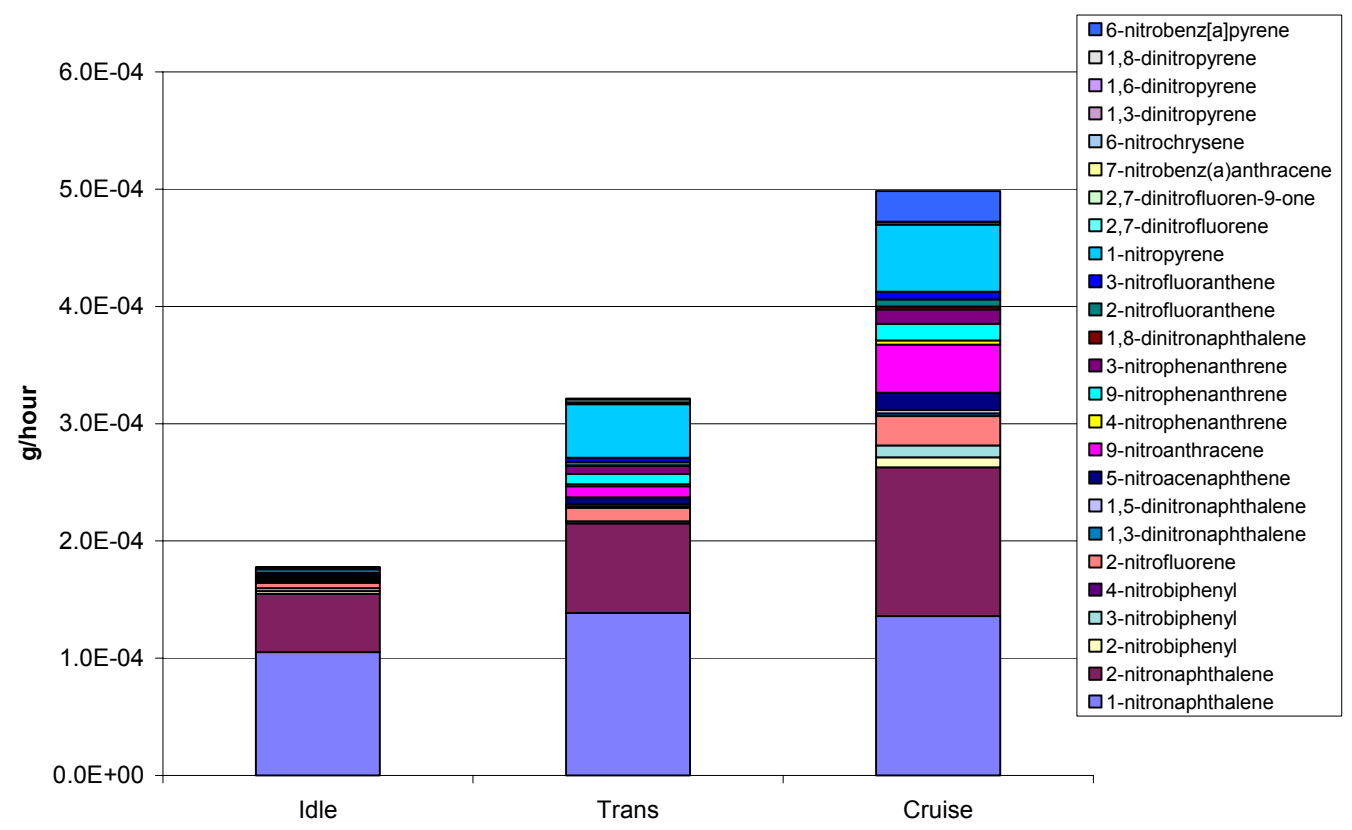

Figure D10: Nitro PAH Results for CRC 39 


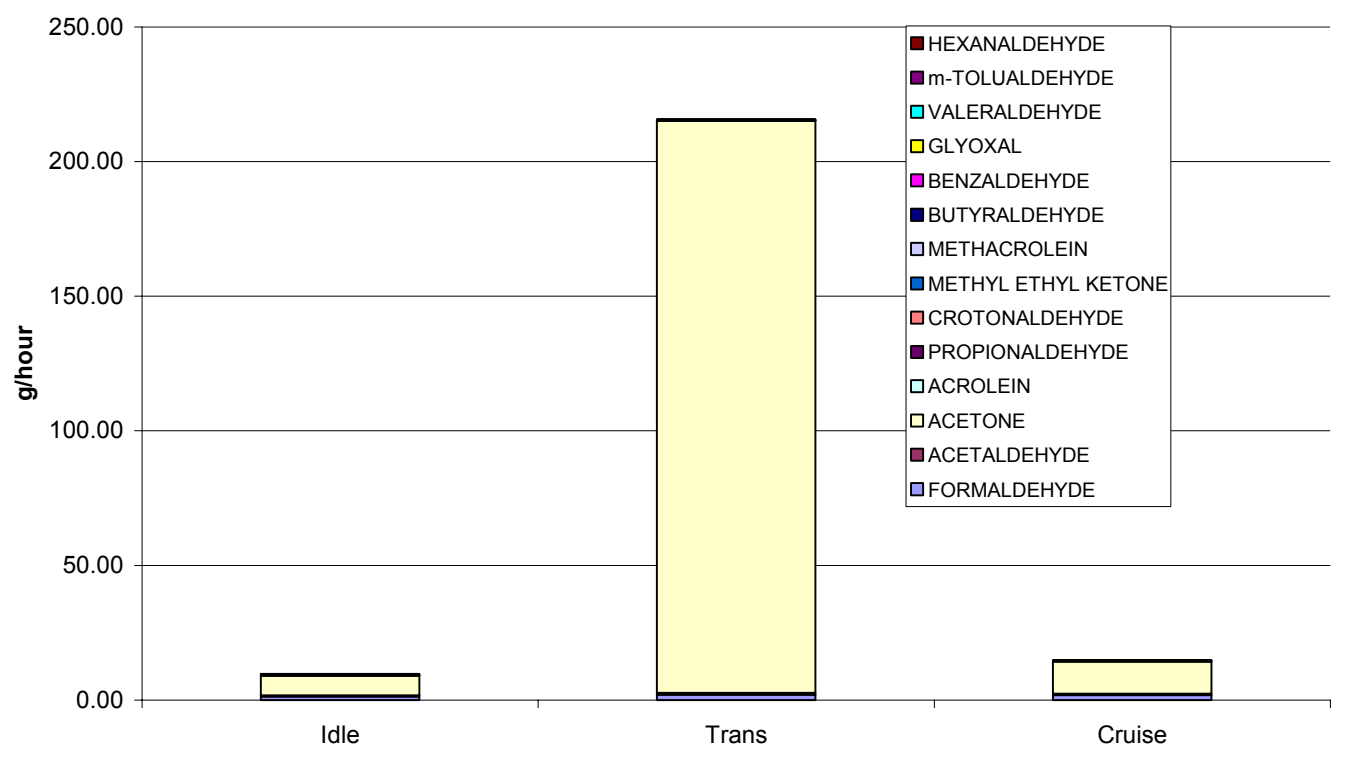

Figure D11: Carbonyl Results for CRC 39

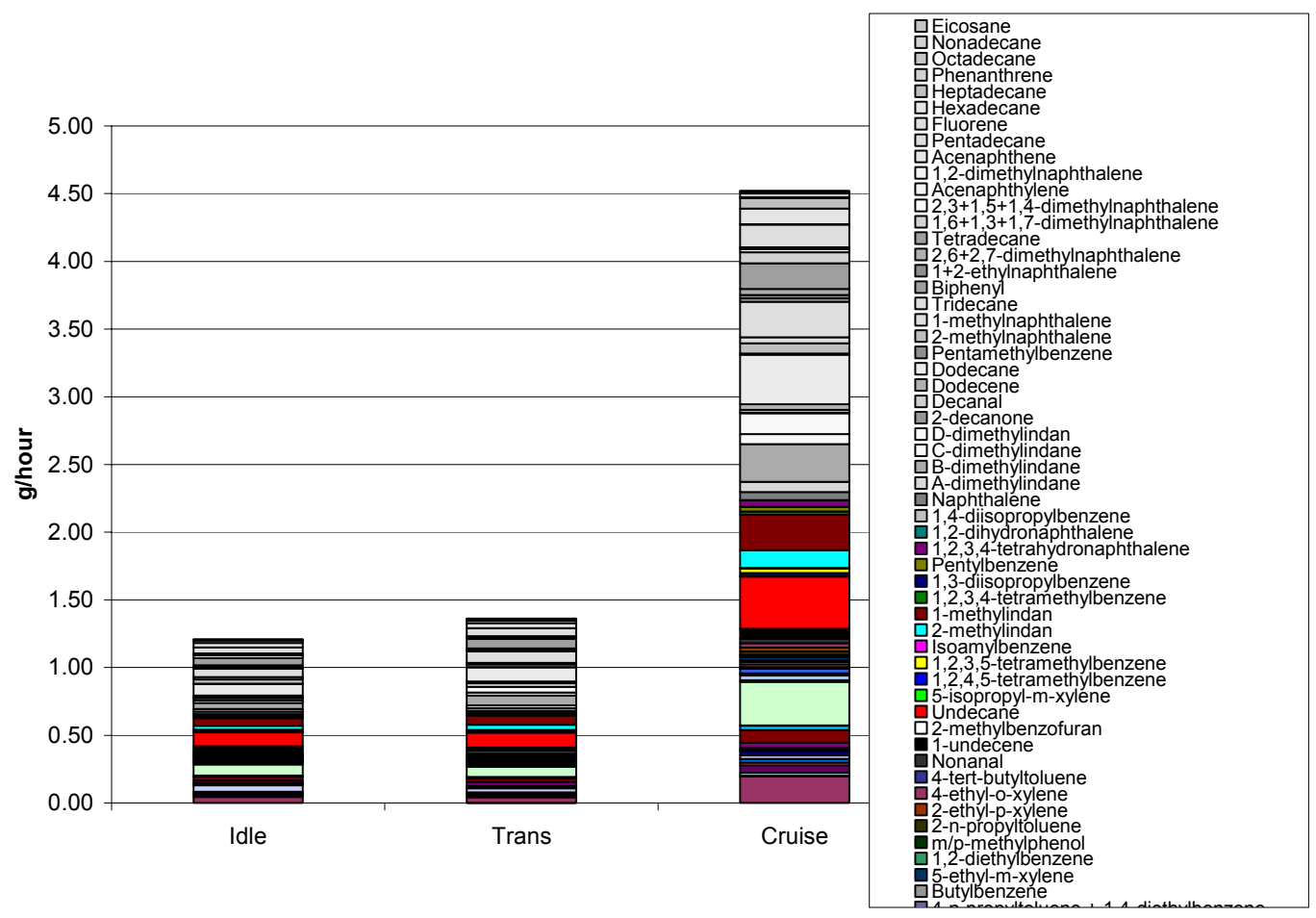

Figure D12: Tenax Results for CRC 39 


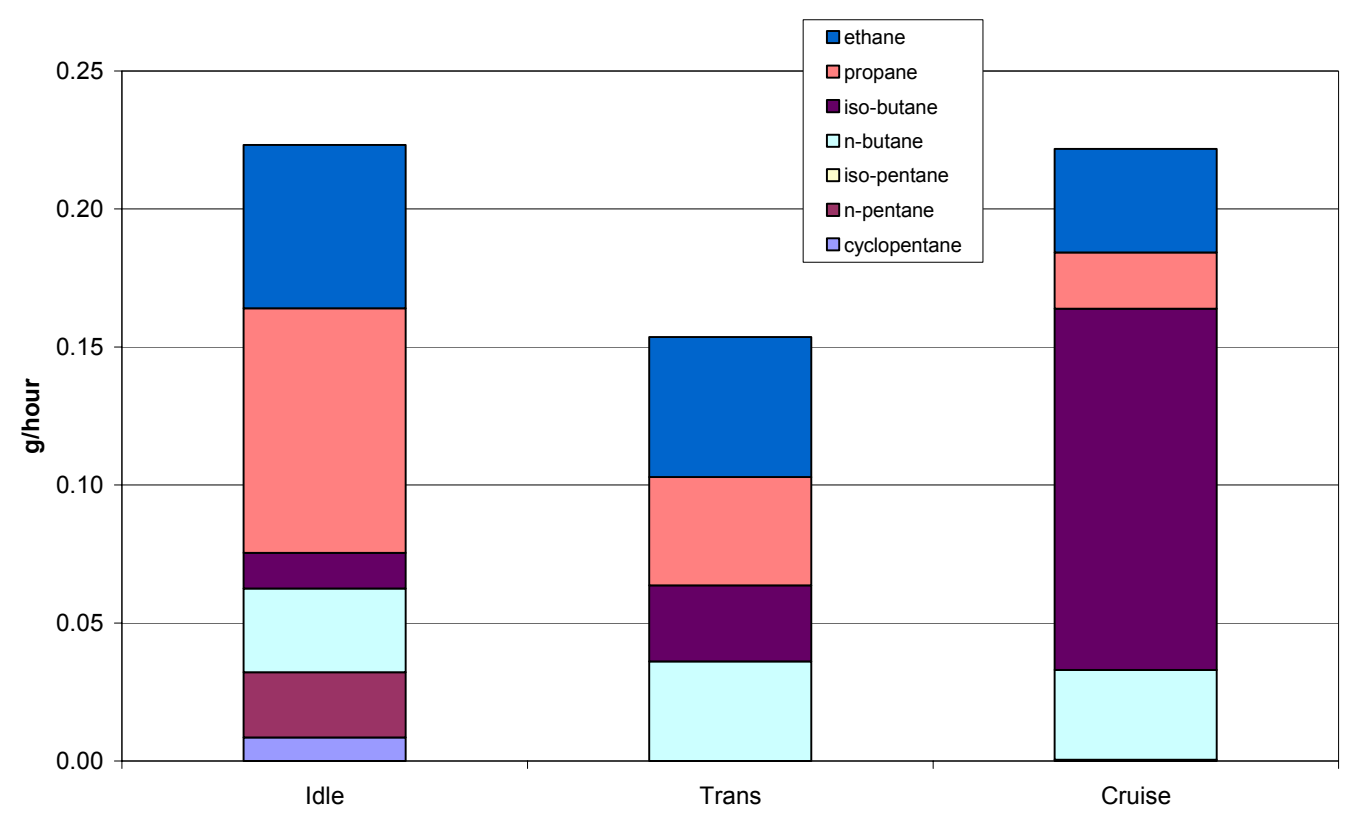

Figure D13: VOC results (C2 to C5 Alkanes) for CRC 40

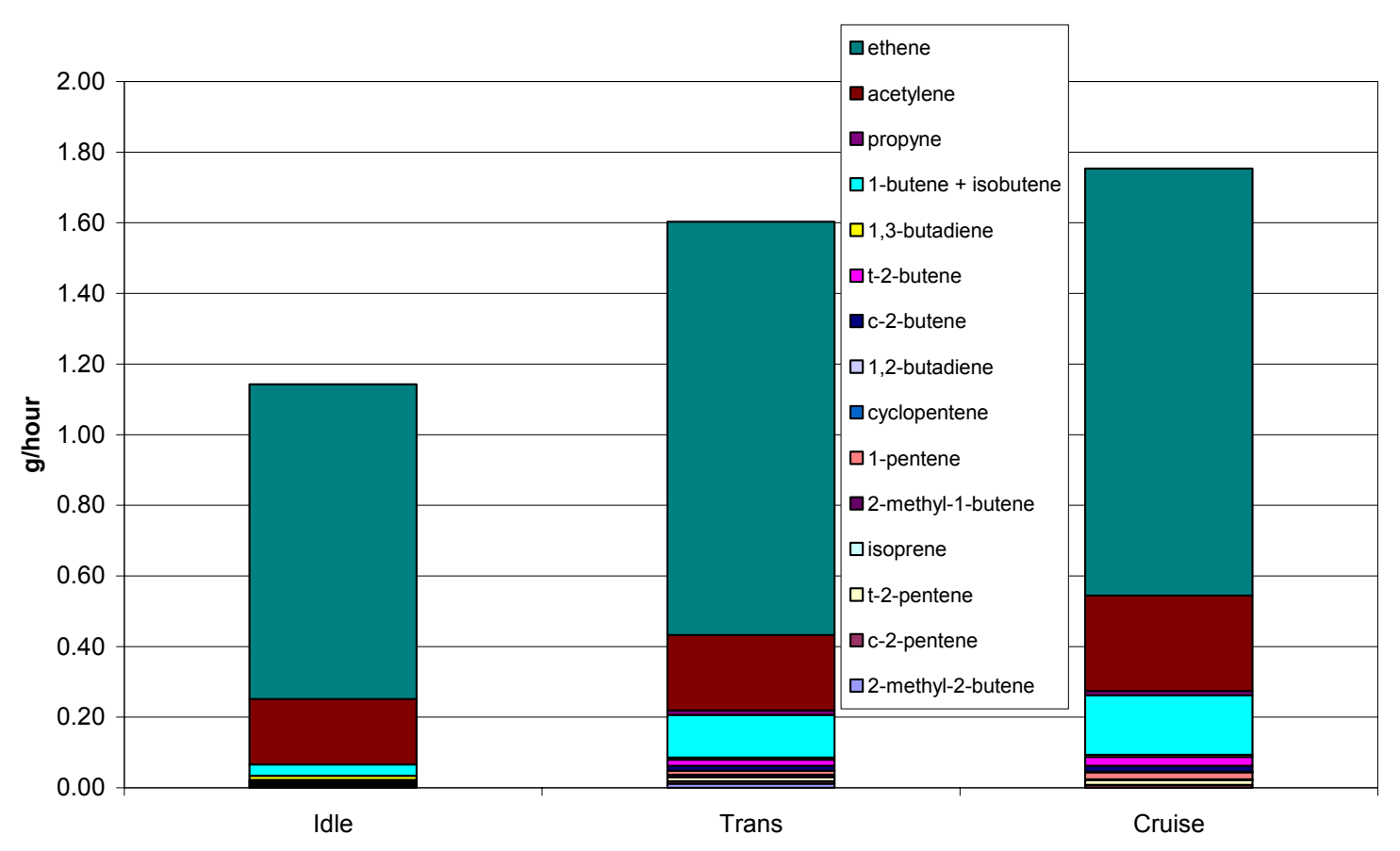

Figure D14: VOC results (C2 to C5 Olefins) for CRC 40 


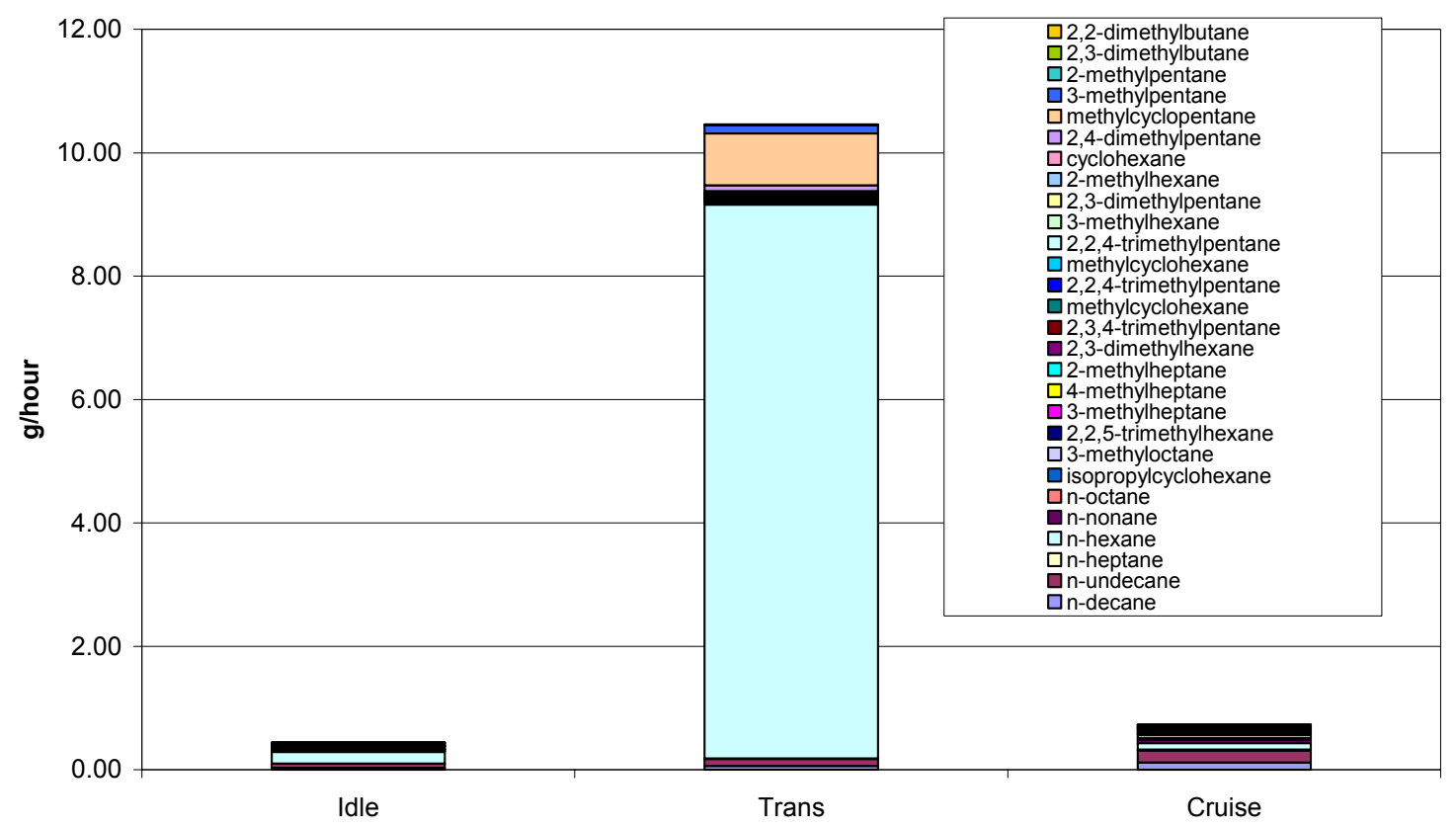

Figure D15: VOC Results (C6 and higher Alkanes) for CRC 40

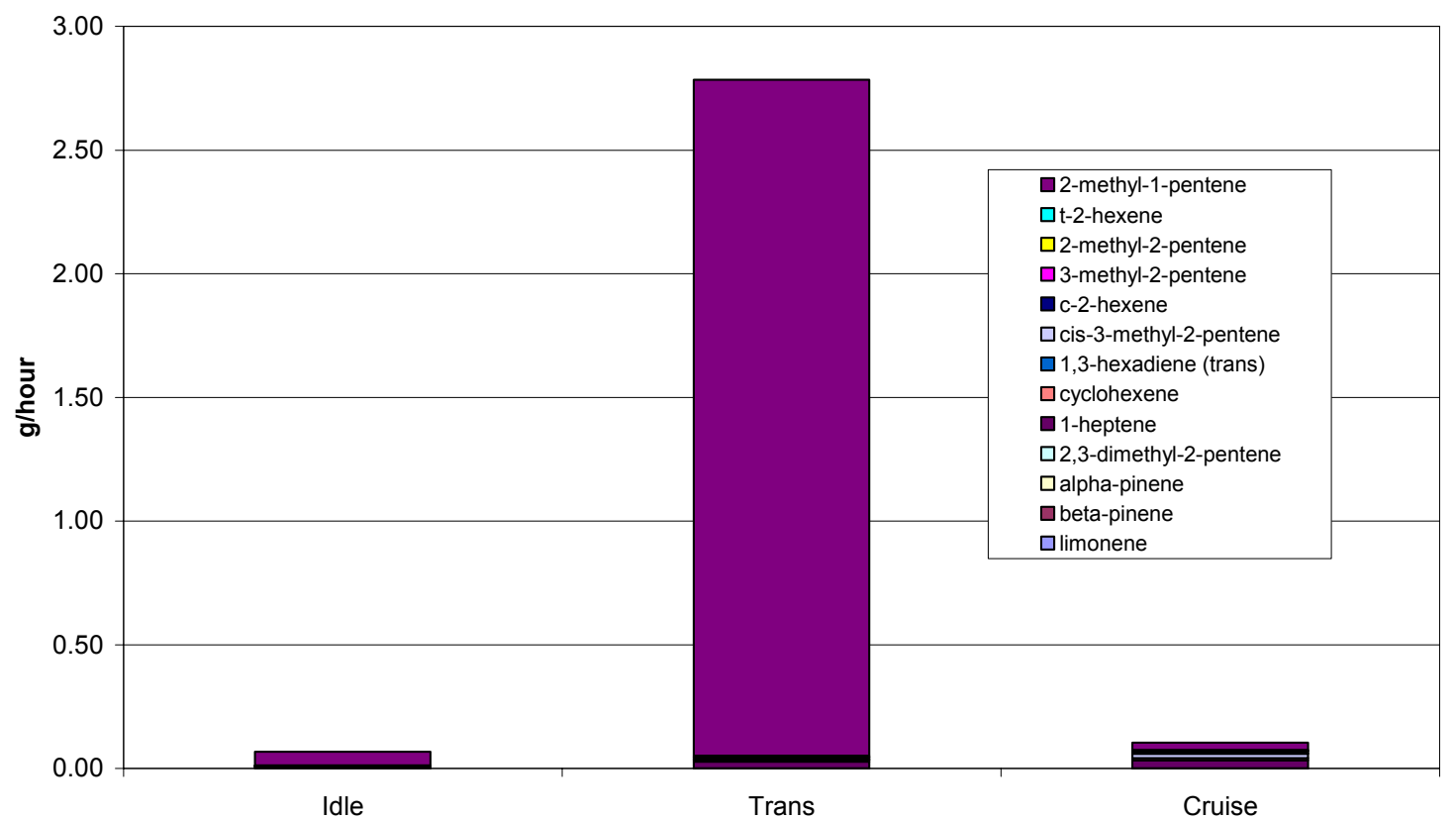

Figure D16: VOC Results (C6 and higher Olefins) for CRC 40 


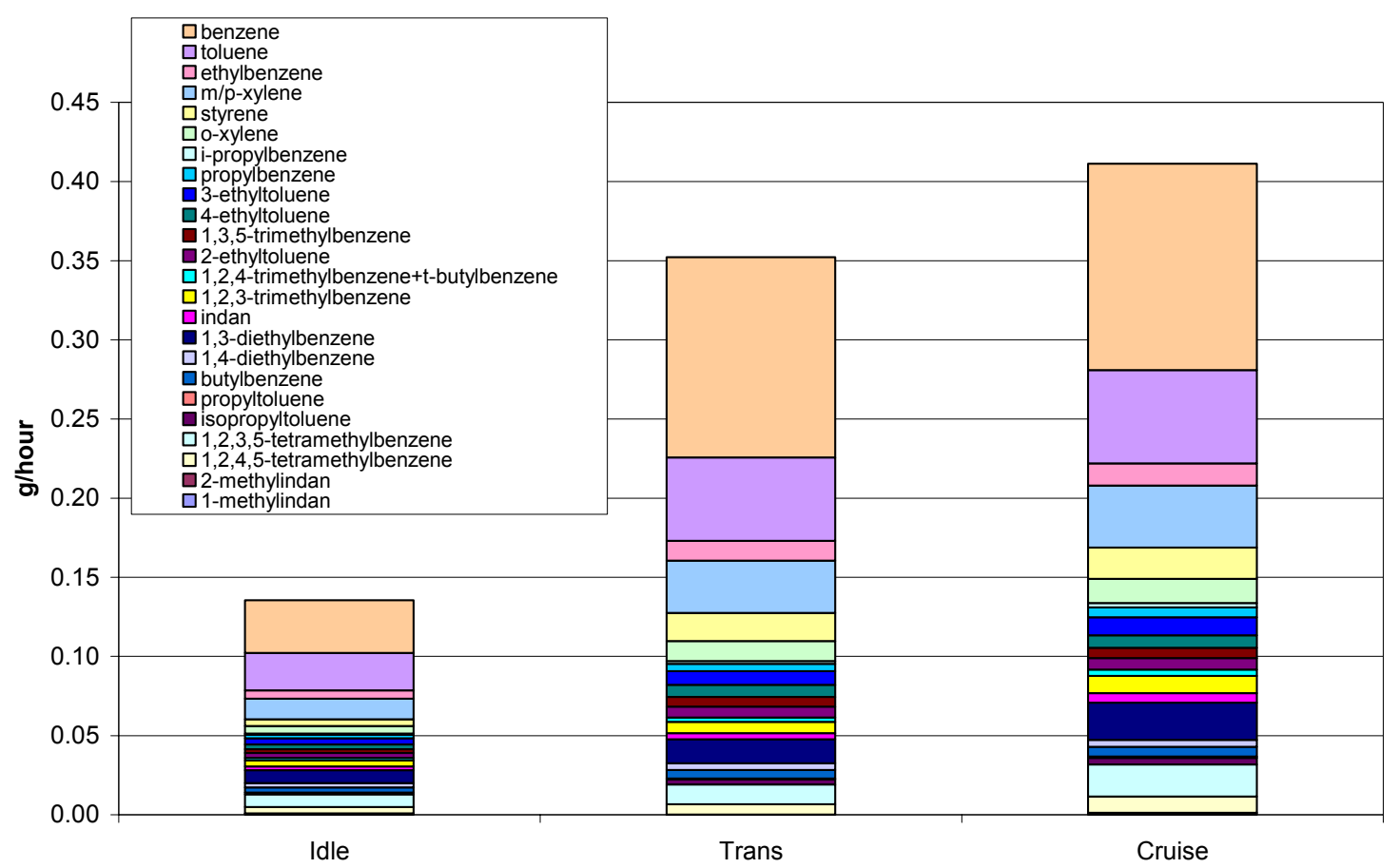

Figure D17: VOC Results (Aromatics) for CRC 40

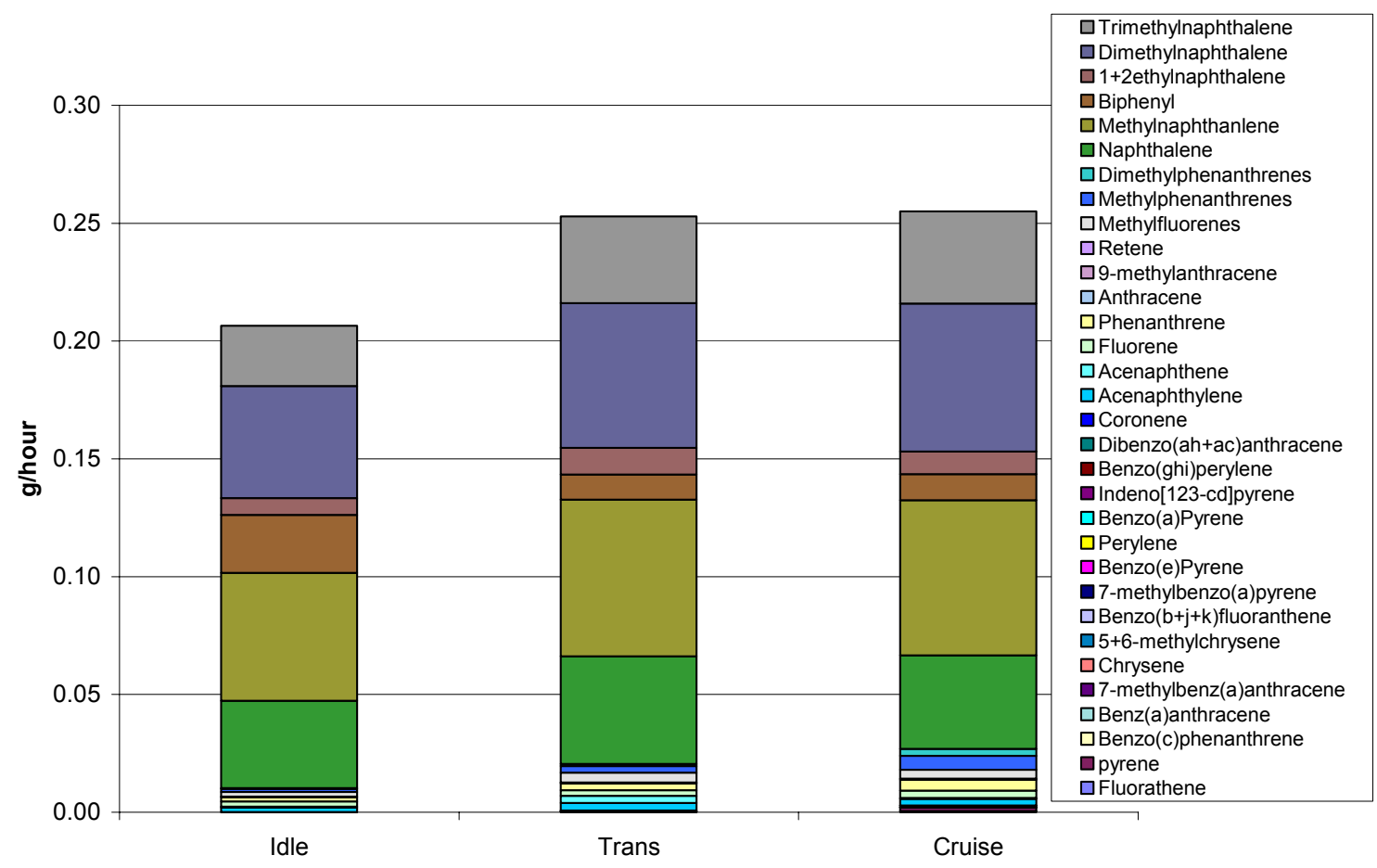

Figure D18: PAH Results for CRC 40 


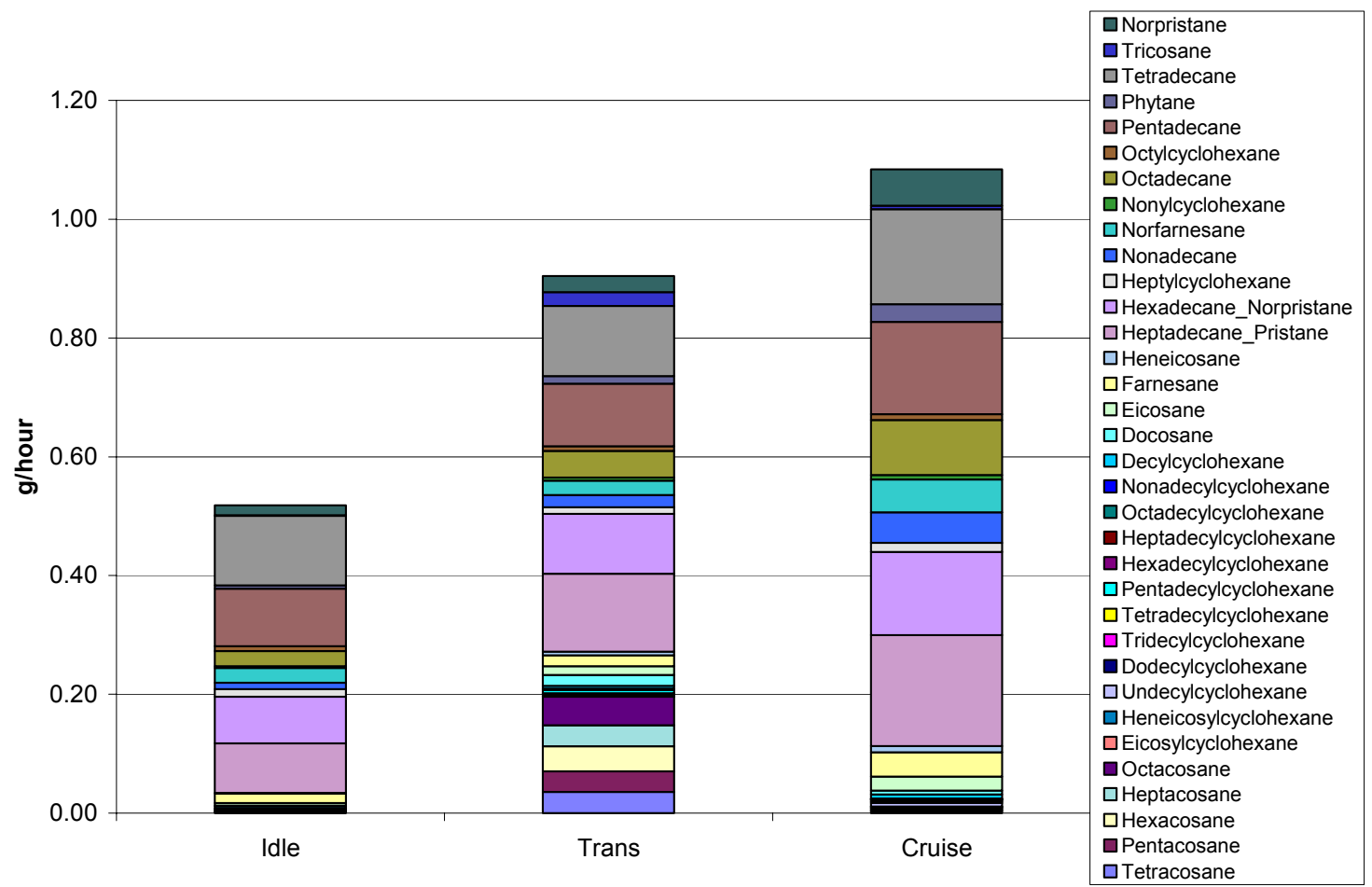

Figure D19: Alkanes Results for CRC 40

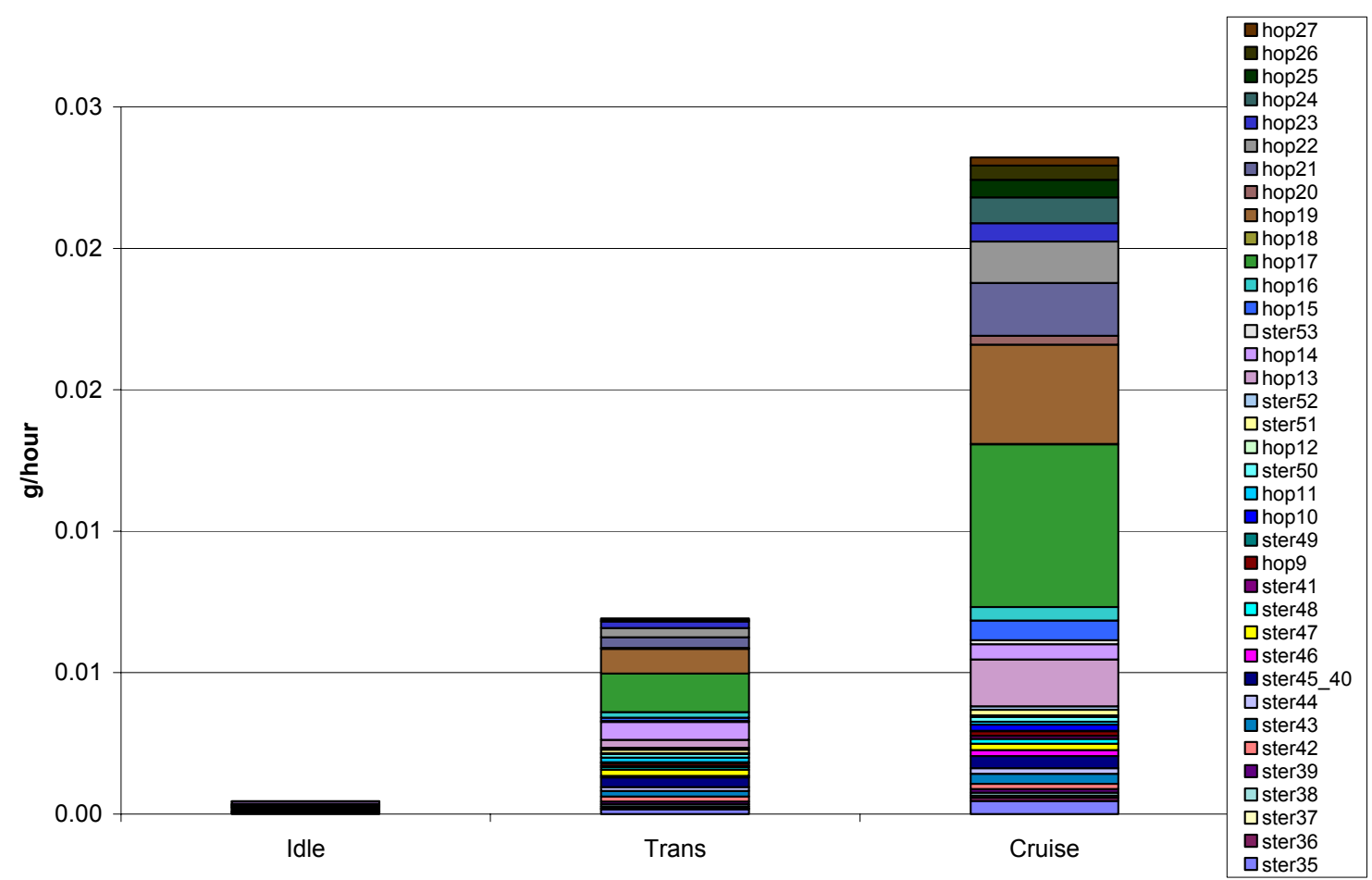

Figure D20: Hopanes and Steranes Results for CRC 40 


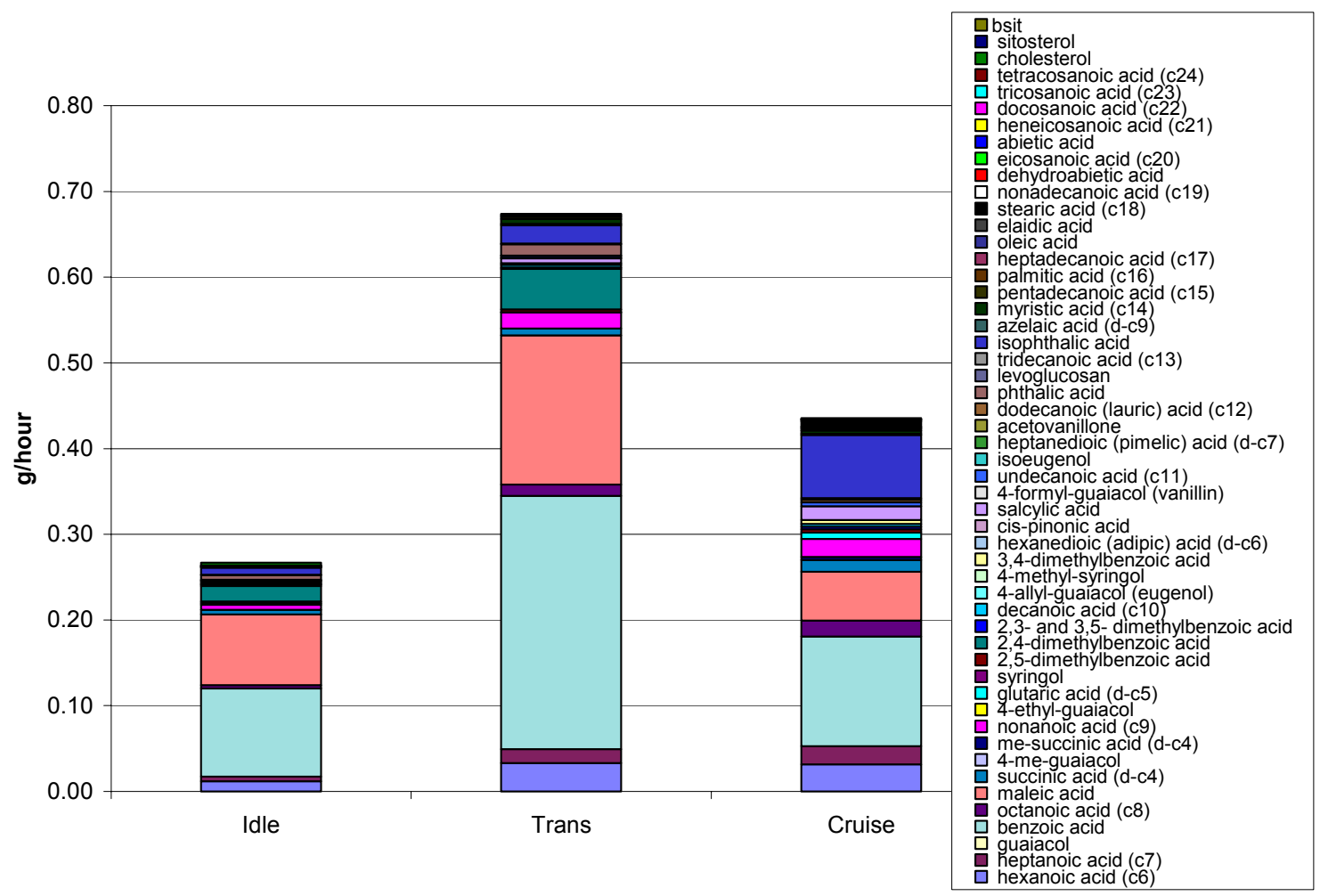

Figure D21: Polar Results for CRC 40

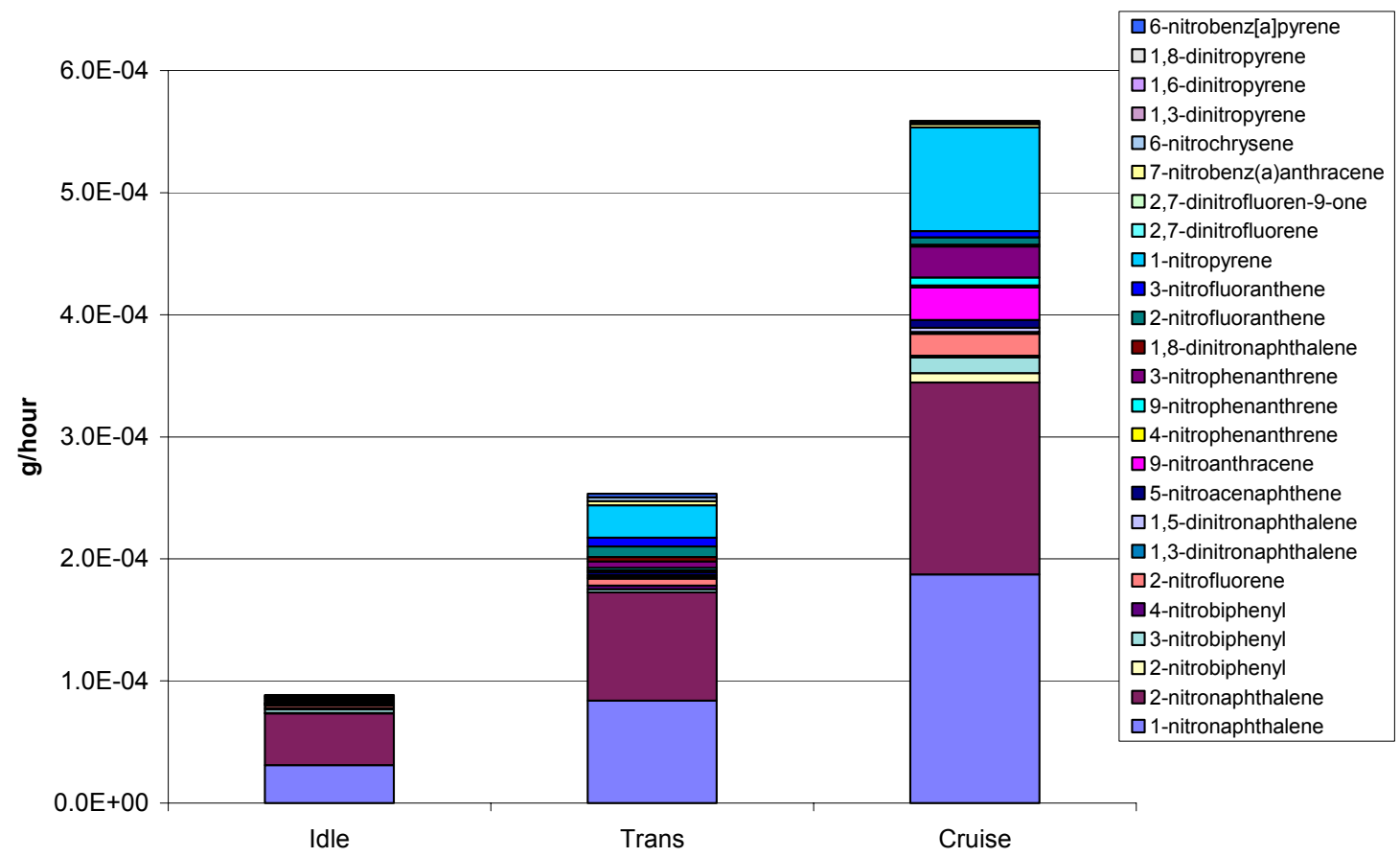

Figure D22: Nitro-PAH Results for CRC 40 


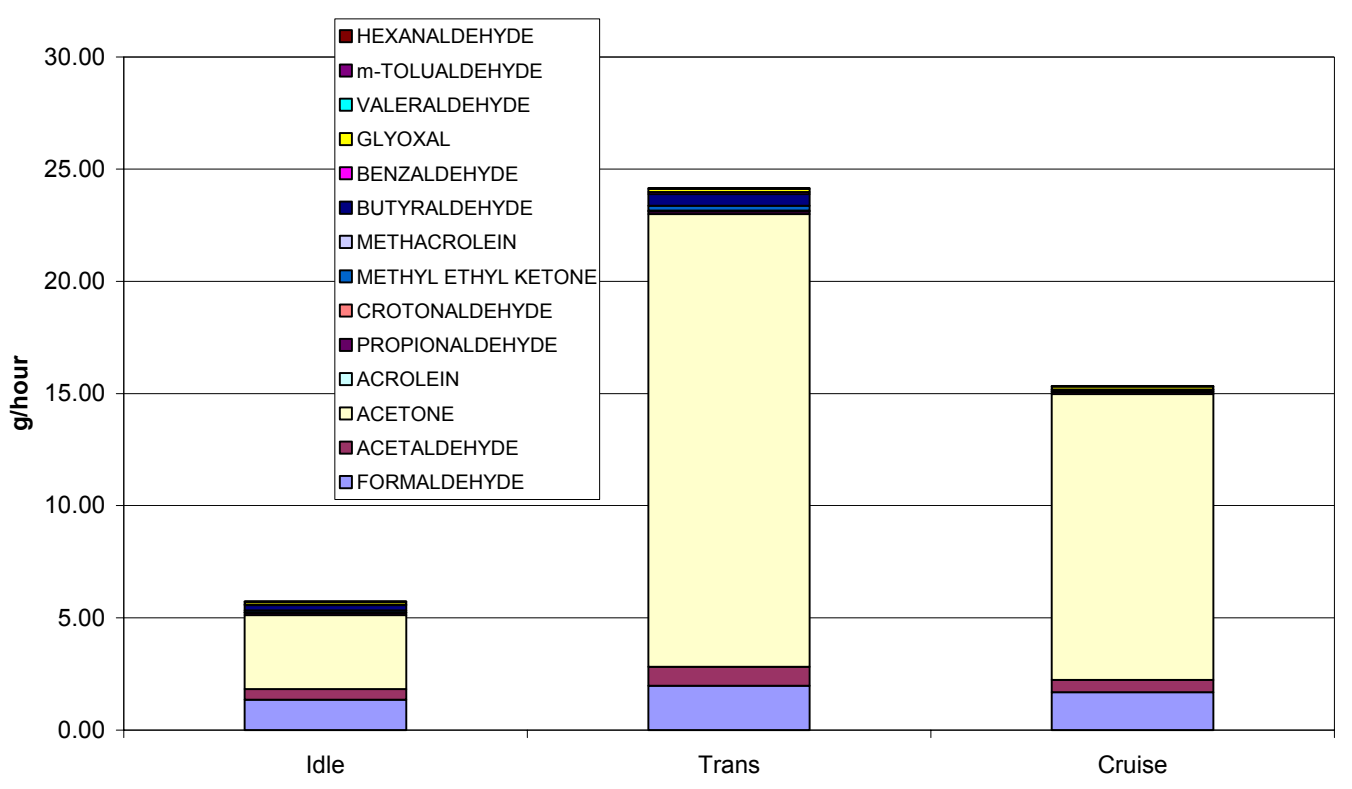

Figure D23: Carbonyls Results for CRC 40

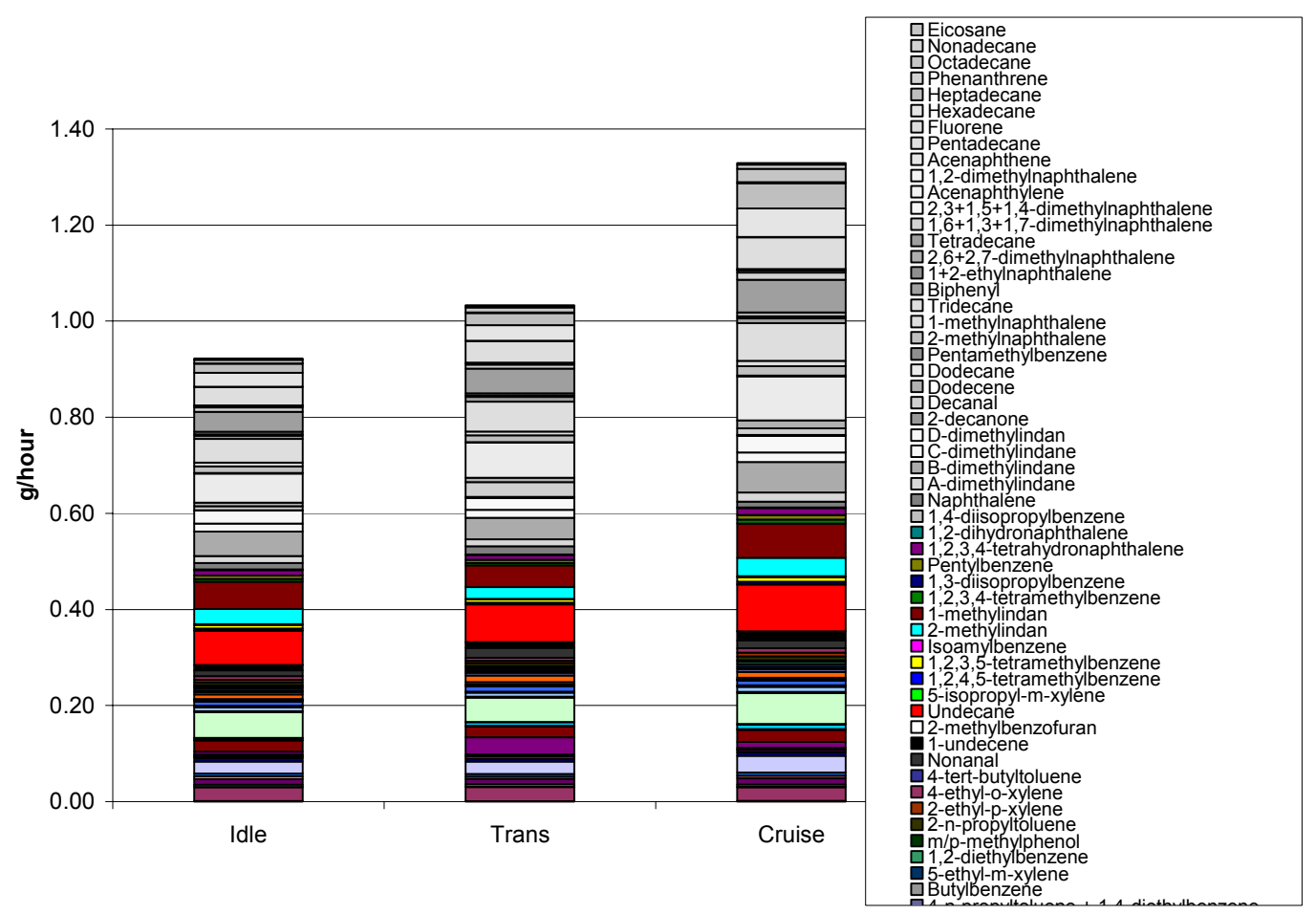

Figure D24: Tenax Results for CRC 40 


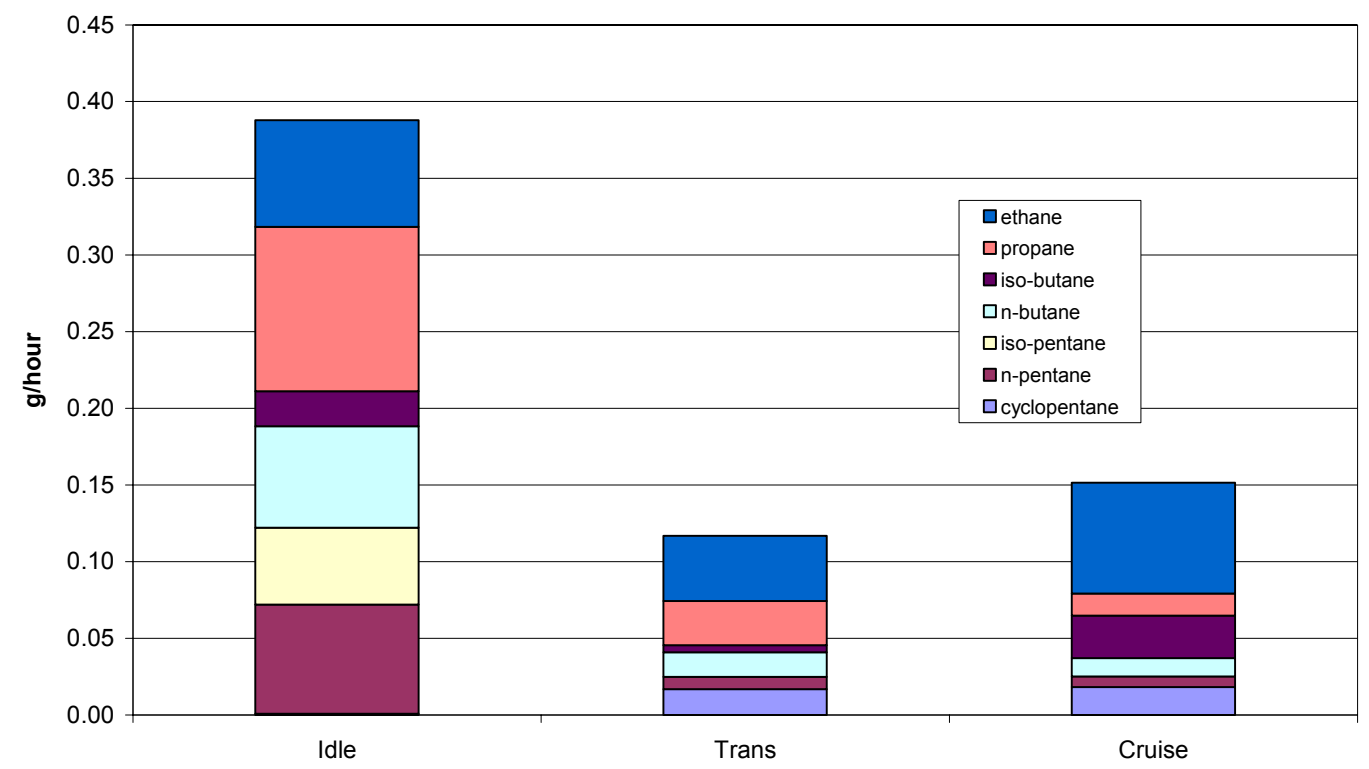

Figure D25: VOC Results (C2 to C5 Alkanes) for CRC 42

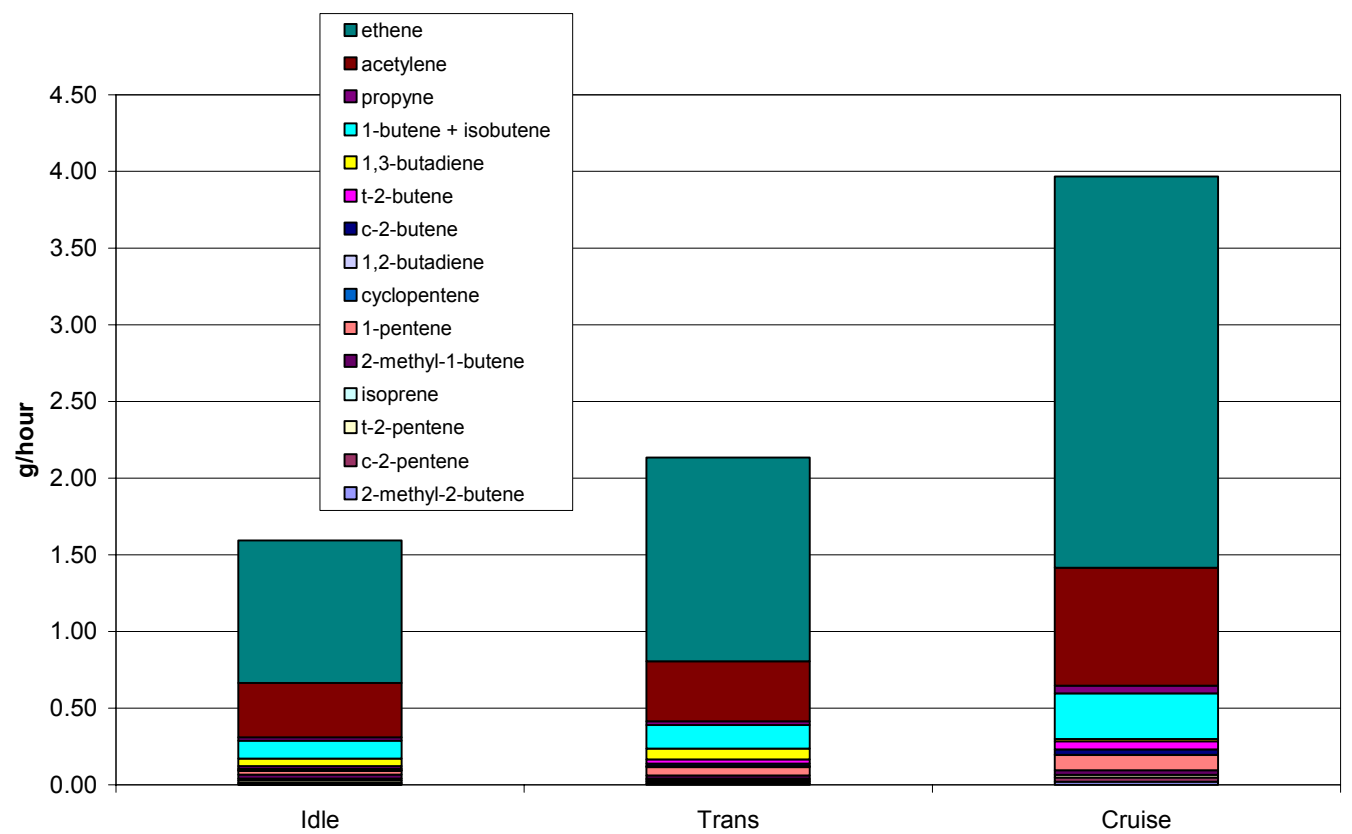

Figure D26: VOC Results (C2 to C5 Olefins) for CRC 42 


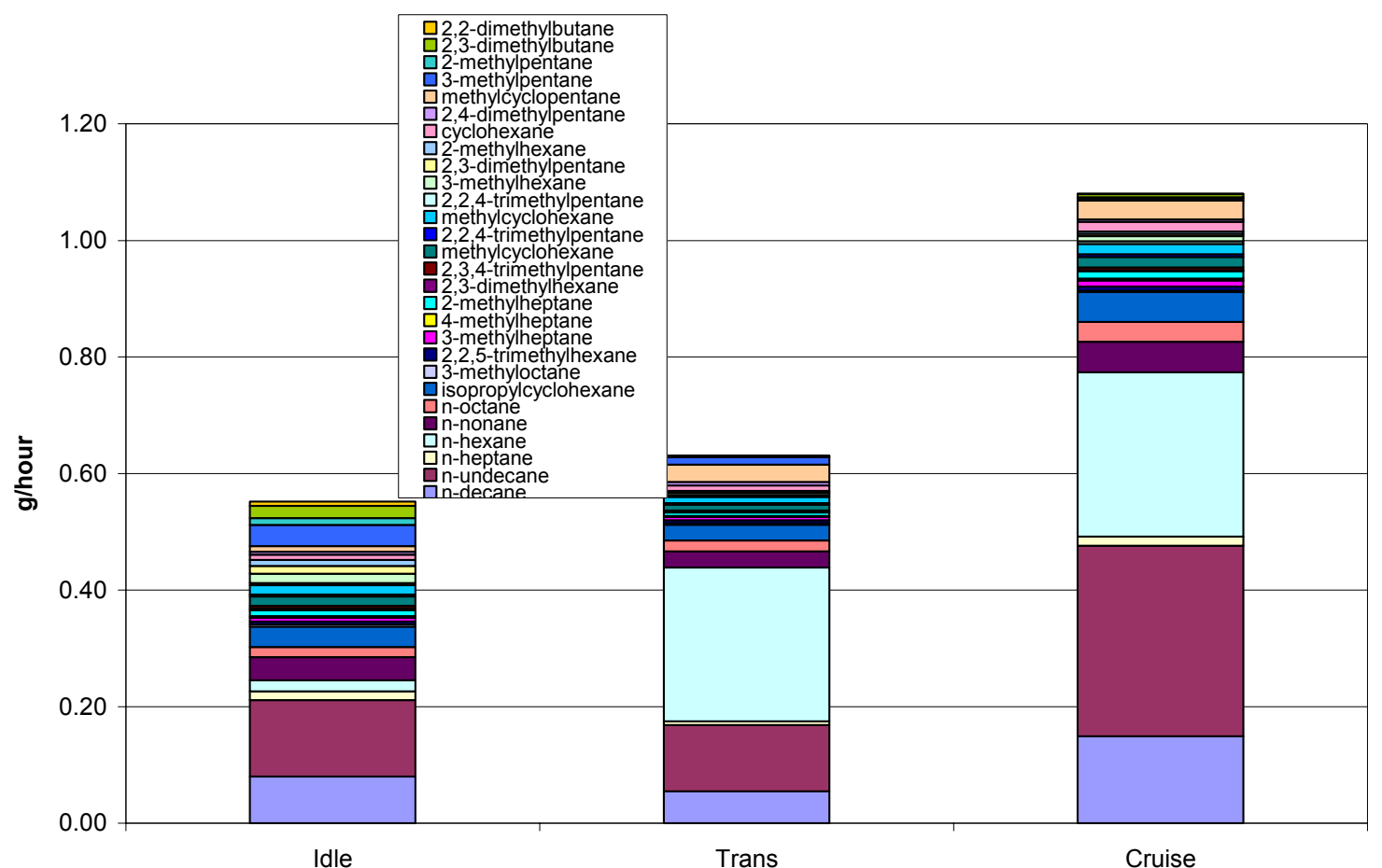

Figure D27: VOC Results (C6 and Higher Alkanes) for CRC 42

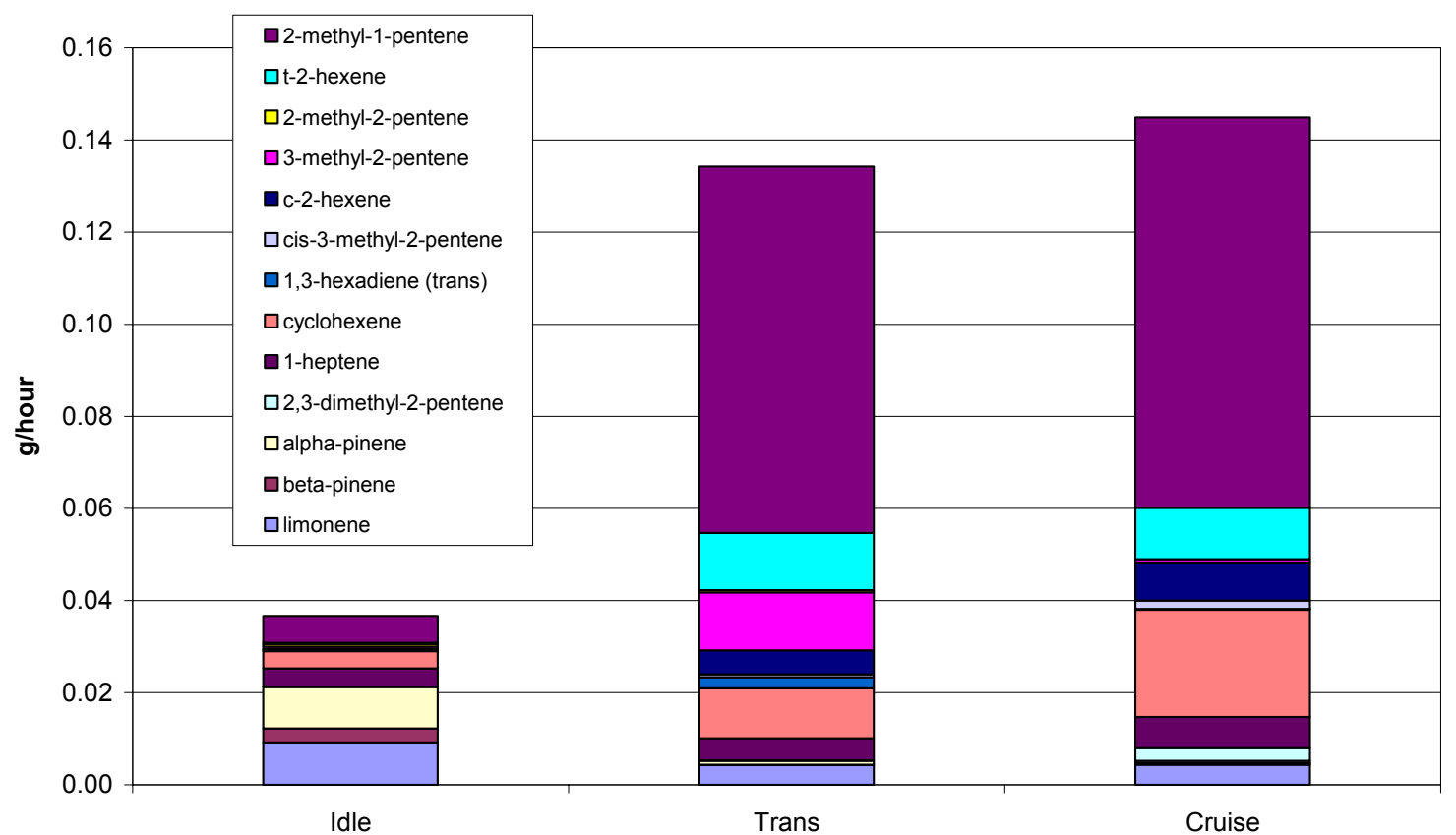

Figure D28: VOC Results (C6 and Higher Olefins) for CRC 42 


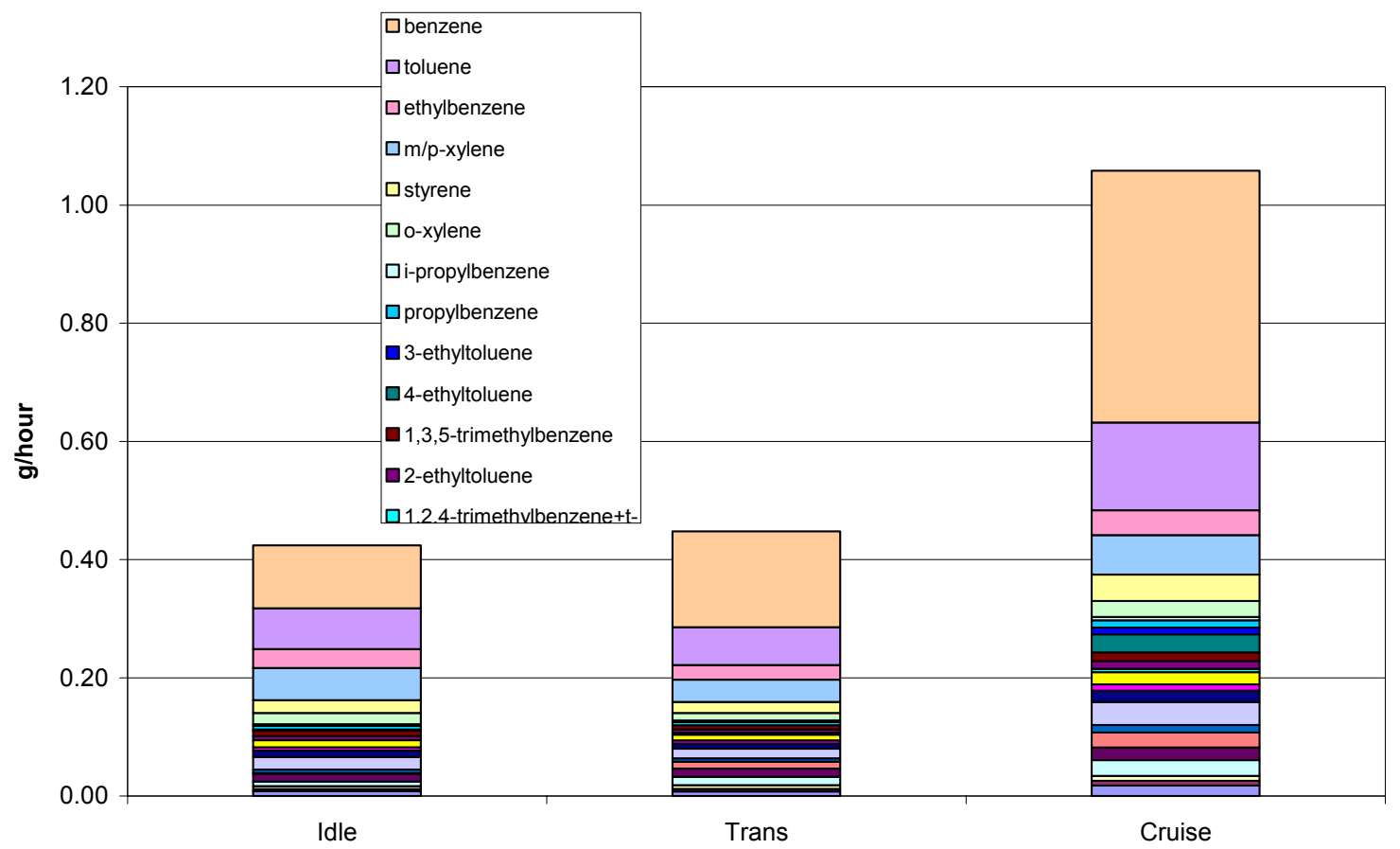

Figure D29: VOC Results (Aromatics) for CRC 42

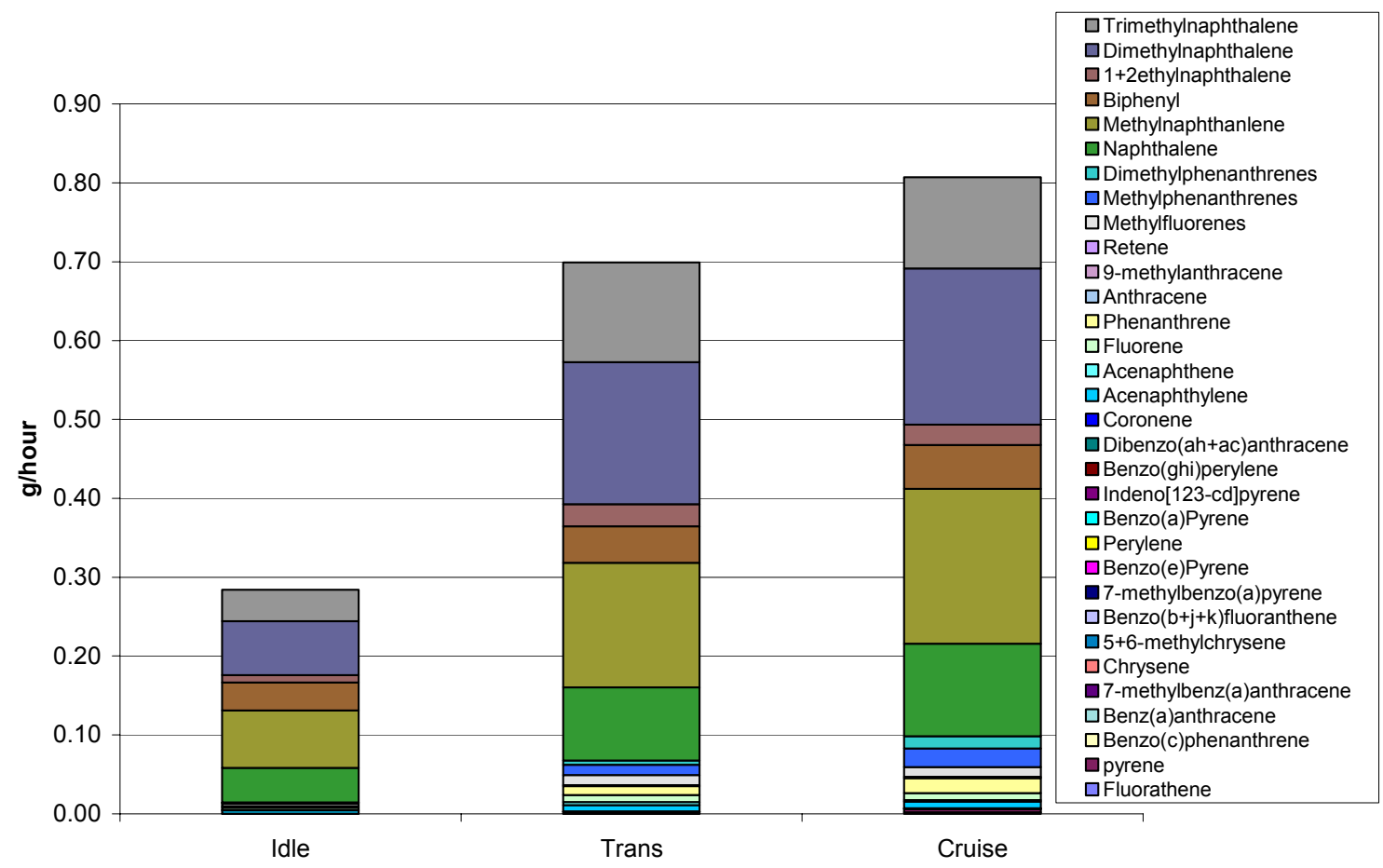

Figure D30: PAH Results for CRC 42 


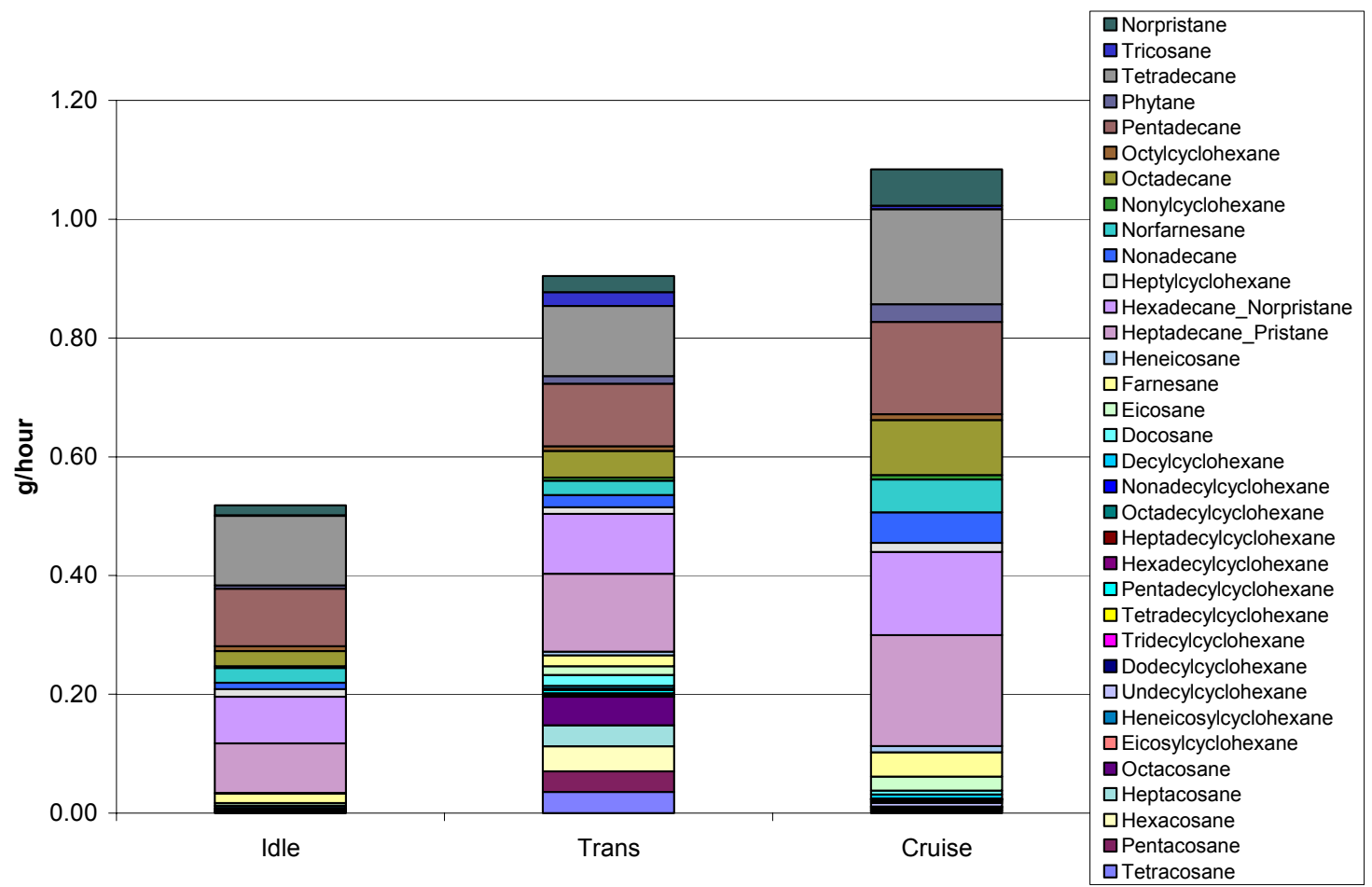

Figure D31: Alkanes Results for CRC 42

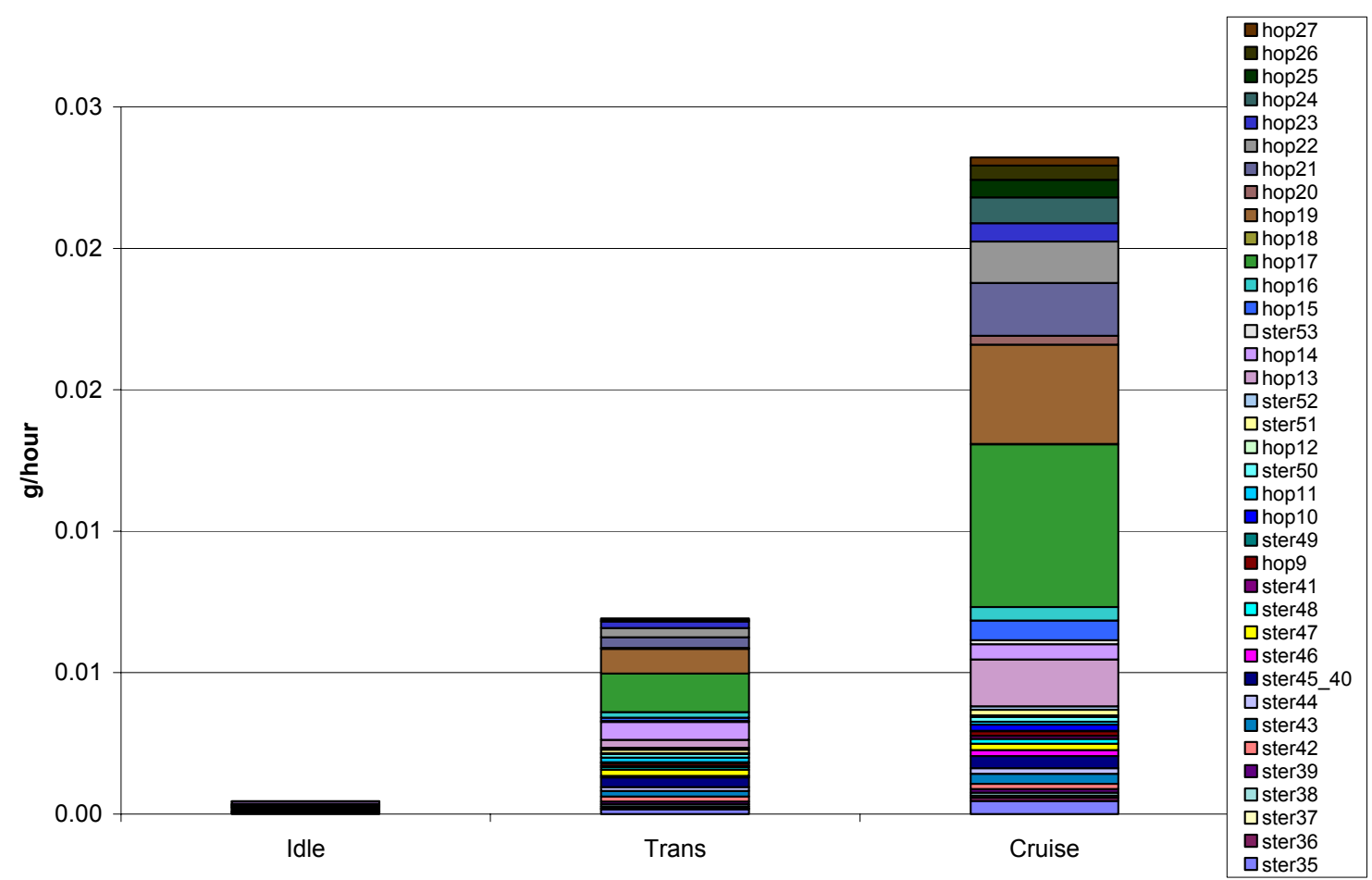

Figure D32: Hopanes and Steranes Results for CRC 42 


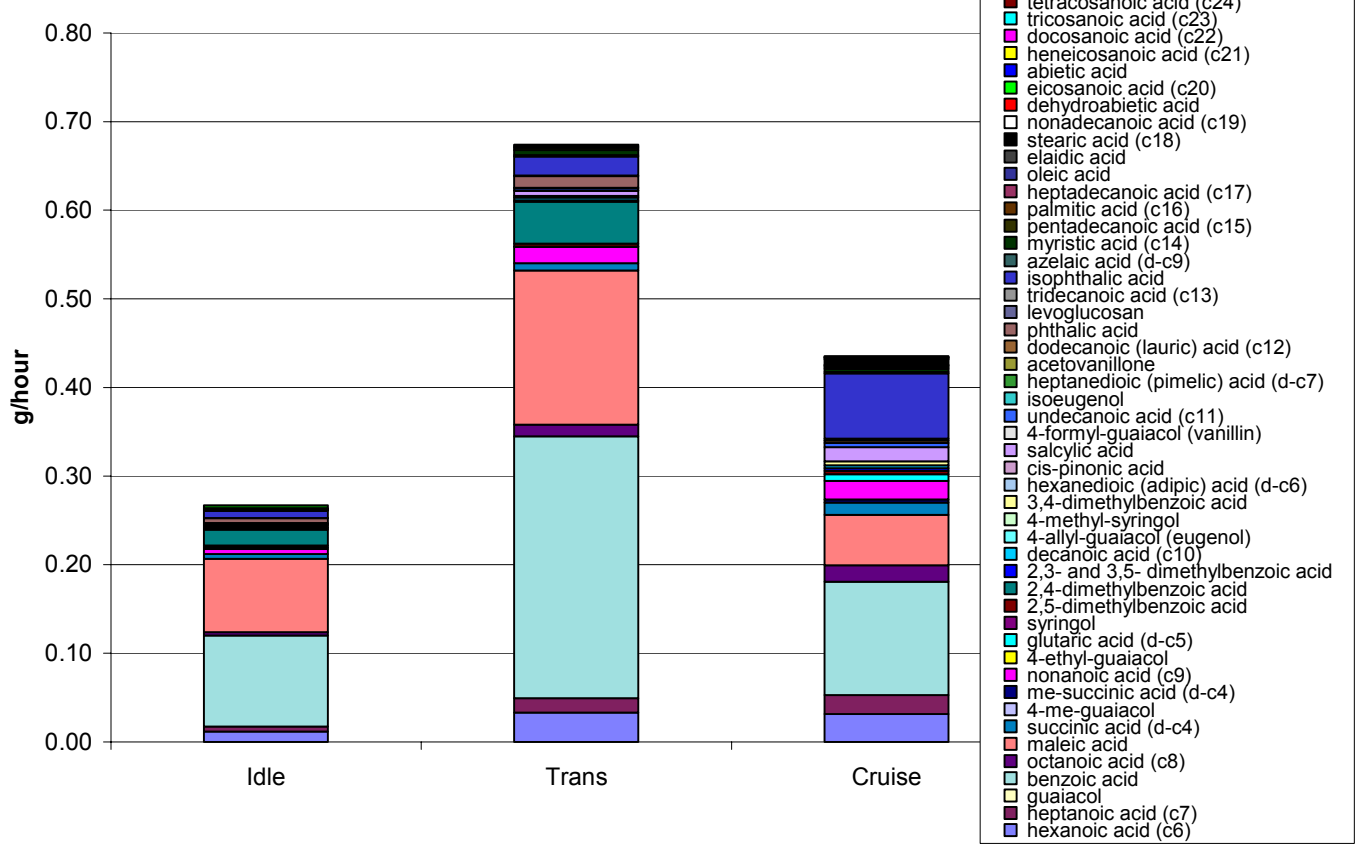

Figure D33: Polar Results for CRC 42

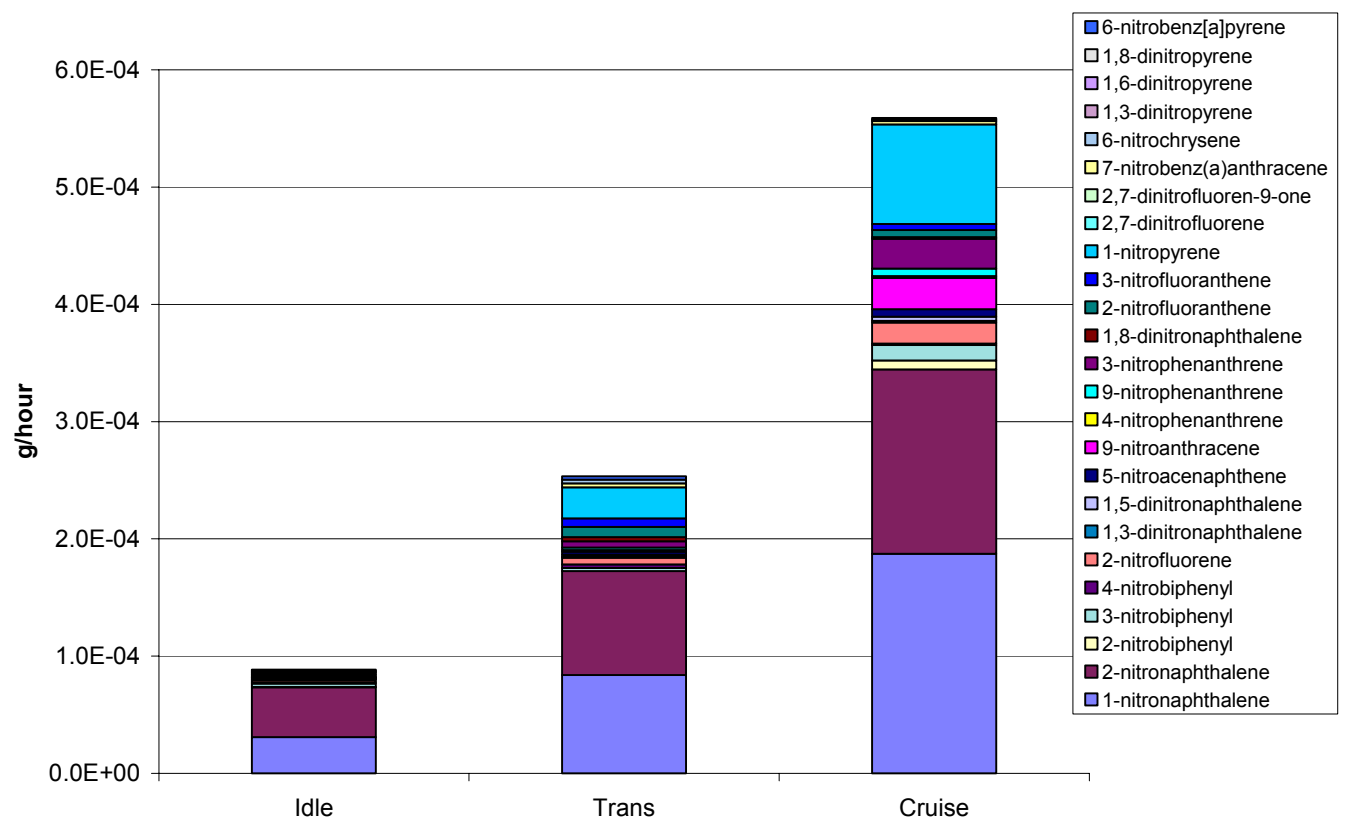

Figure D34: Nitro-PAH Results for CRC 42 


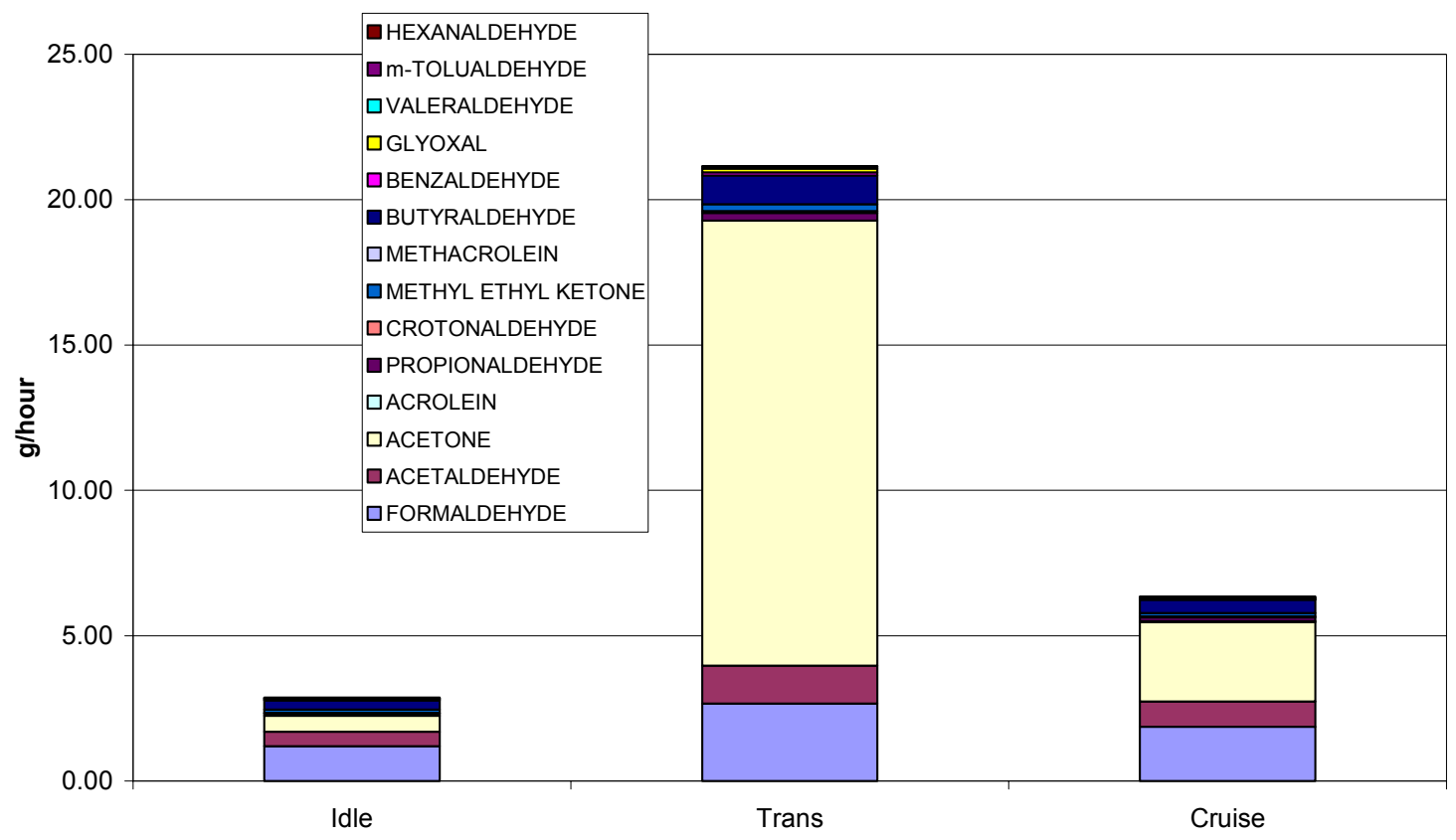

Figure D35: Carbonyl Results for CRC 42

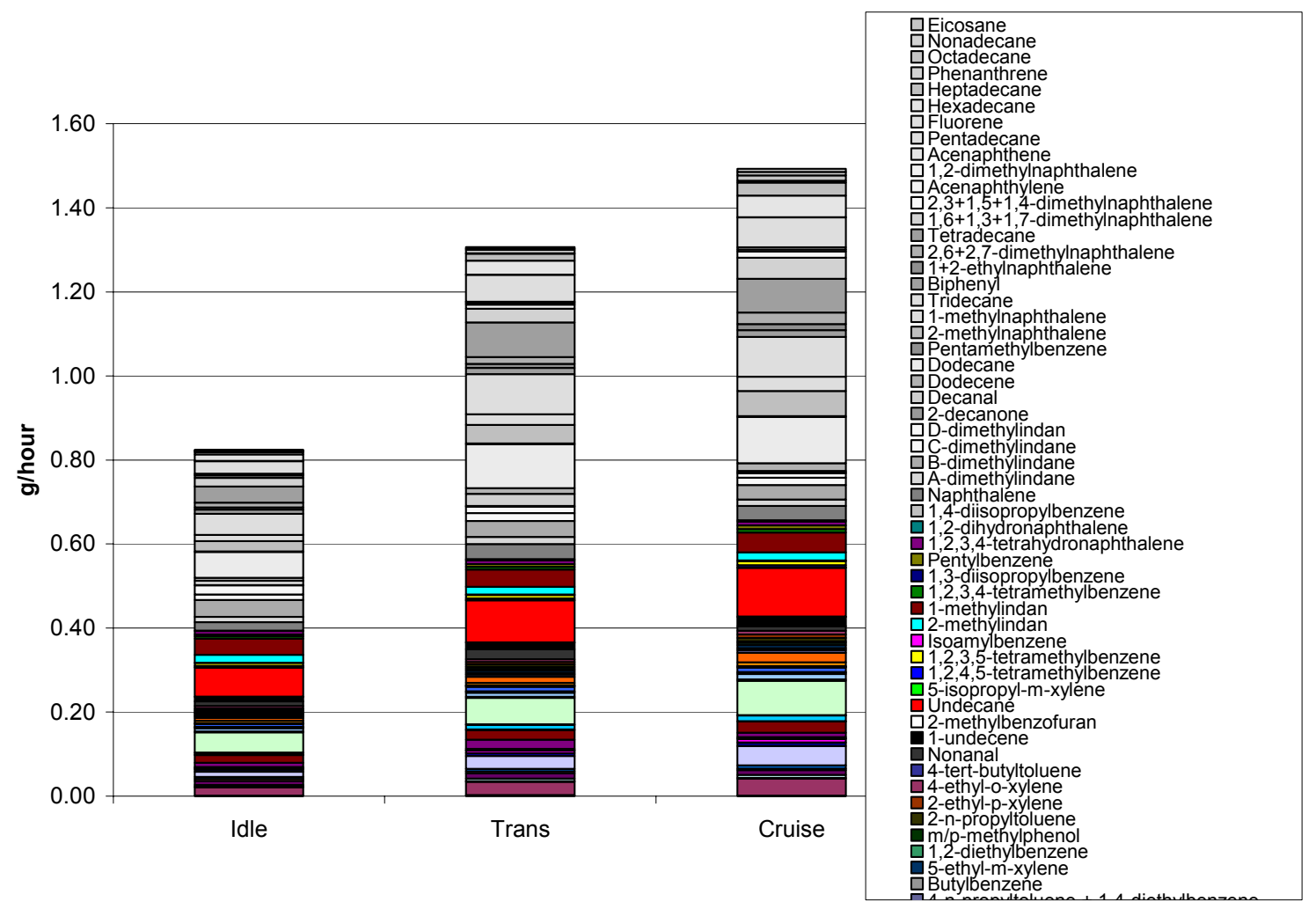

Figure D36: Tenax Results for CRC 42 


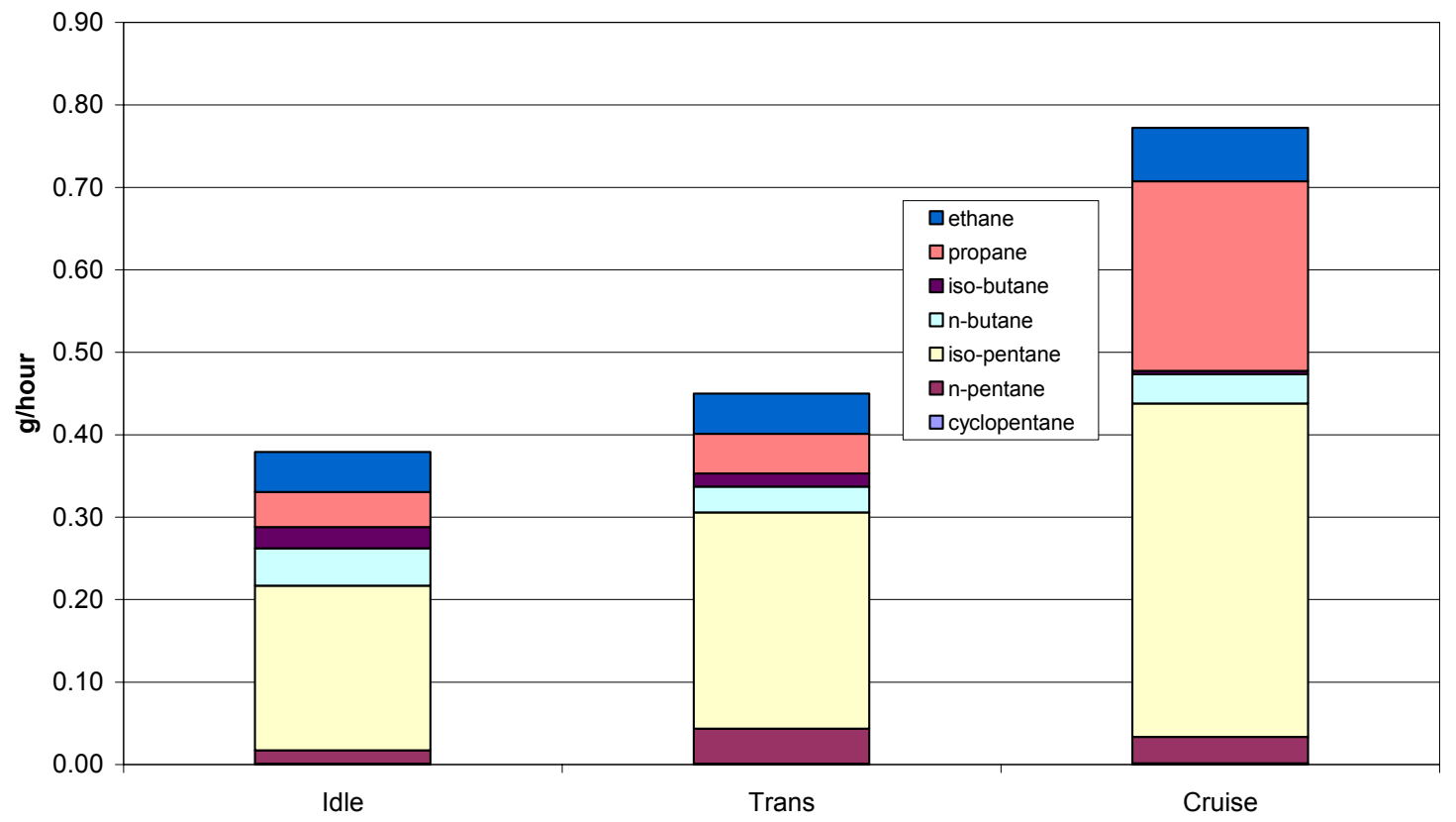

Figure D37: VOC Results (C2 to C5 Alkanes) for CRC 43

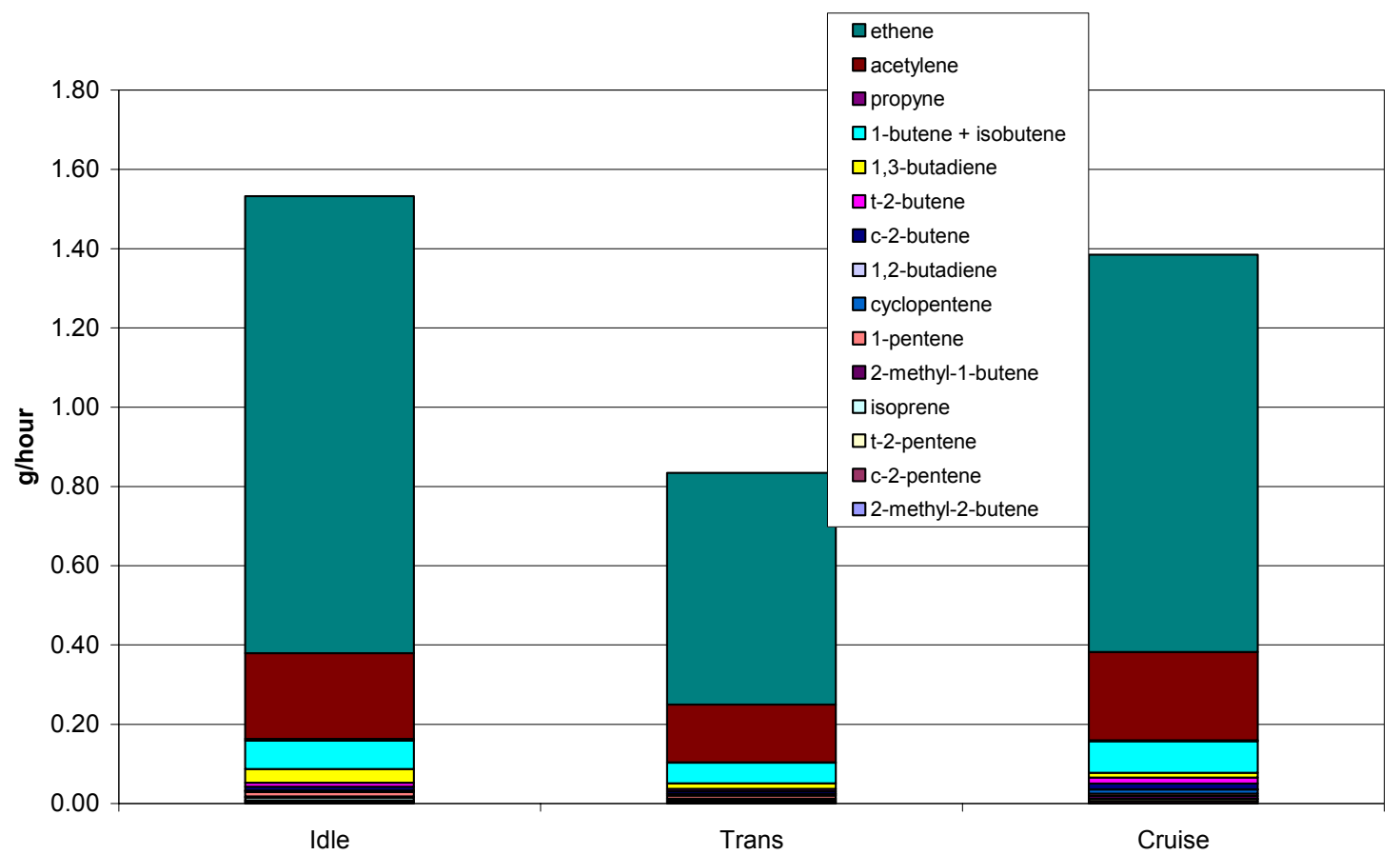

Figure D38: VOC Results (C2 to C5 Olefins) for CRC 43 


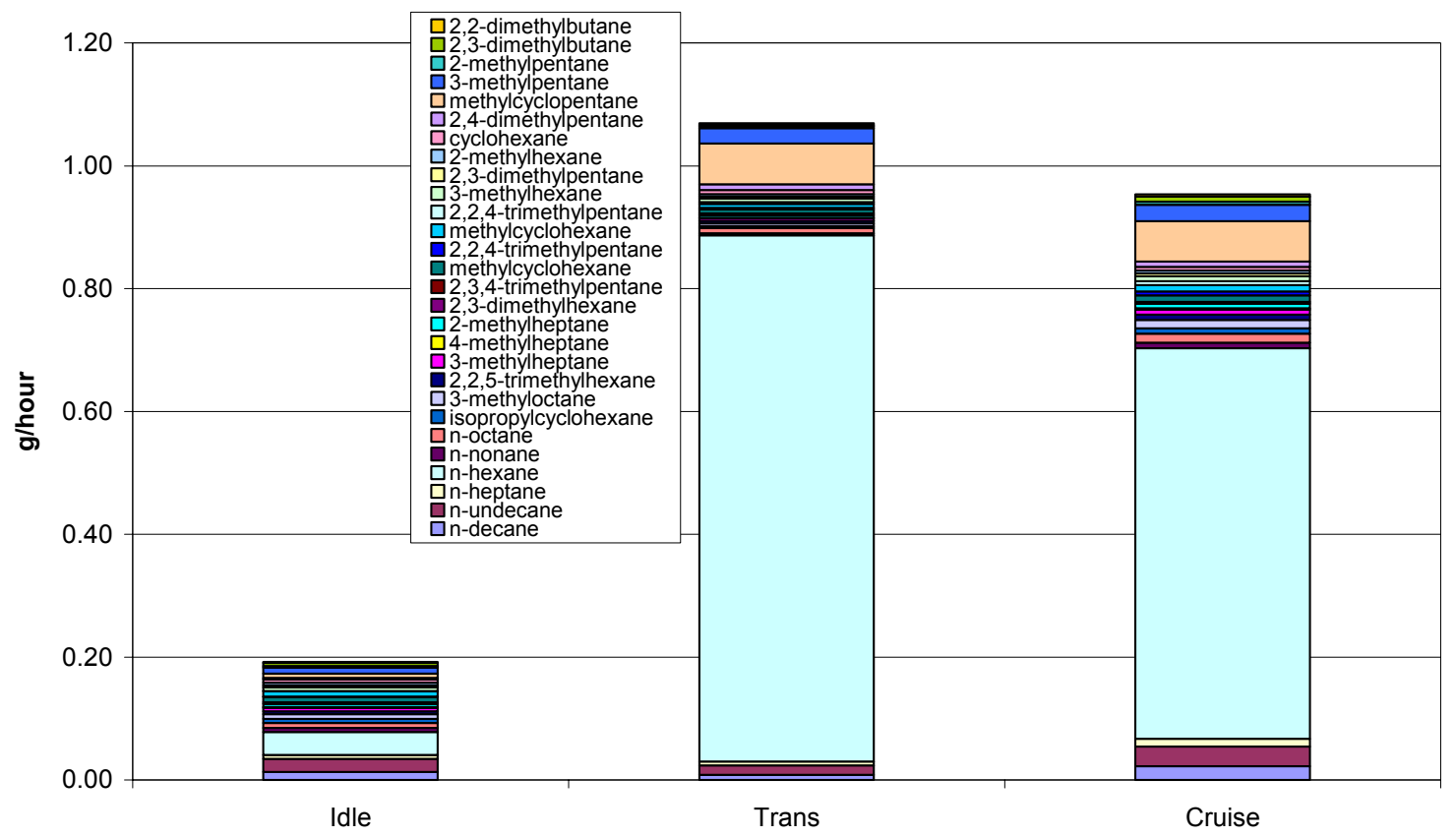

Figure D39: VOC Results (C6 and higher Alkanes) for CRC 43

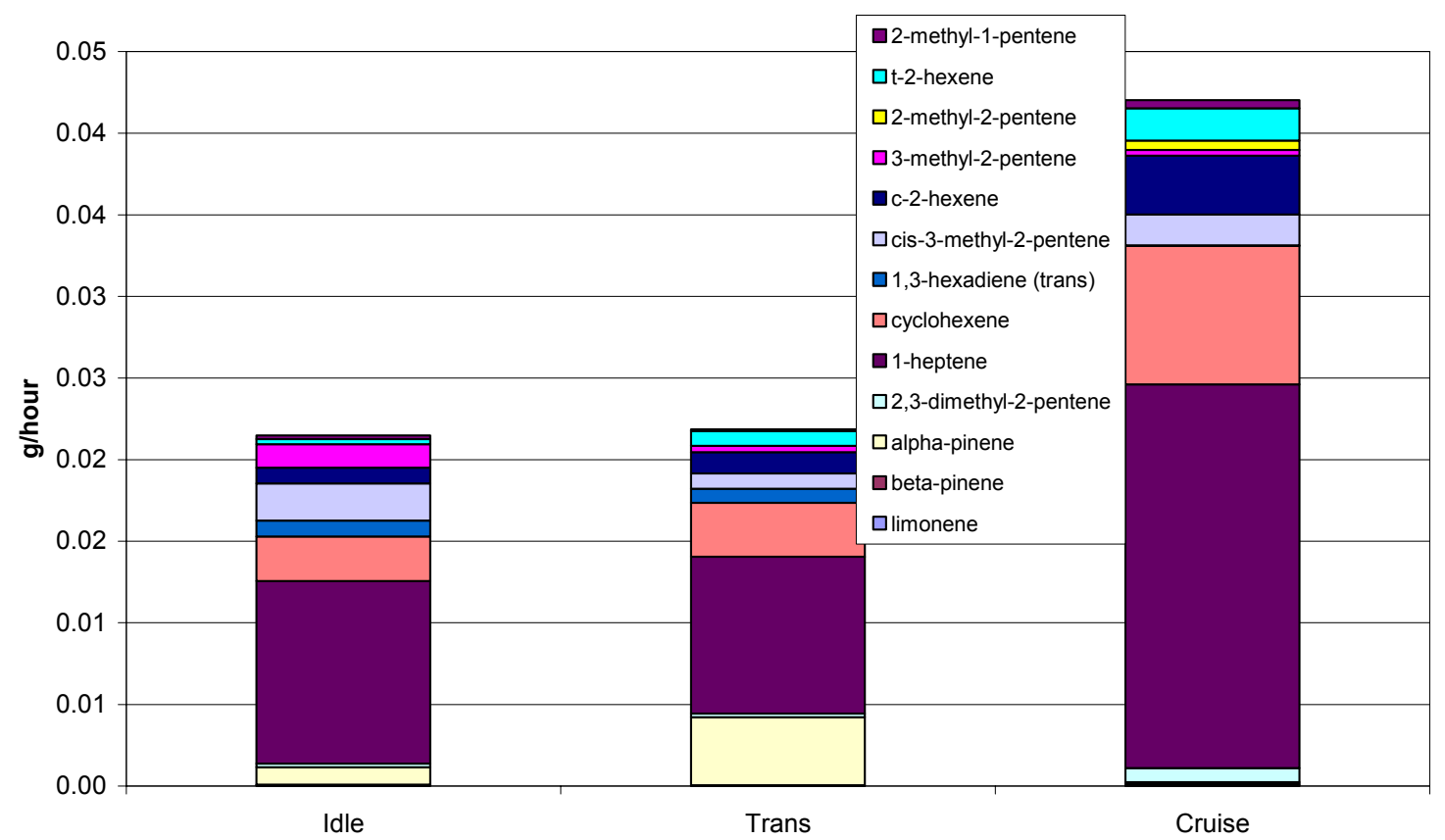

Figure D40: VOC Results (C6 and higher Olefins) for CRC 43 


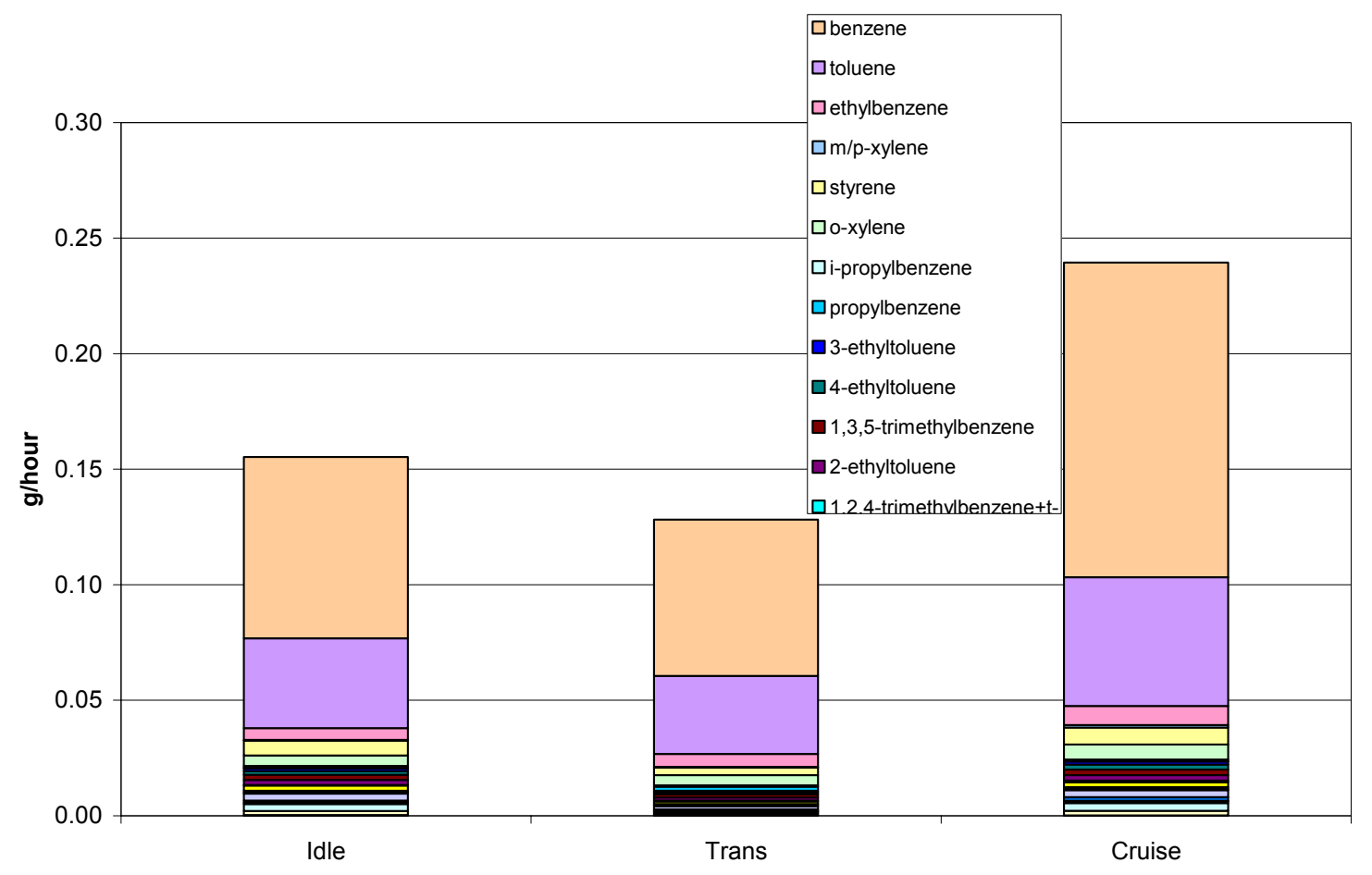

Figure D41: VOC Results (Aromatics) for CRC 43

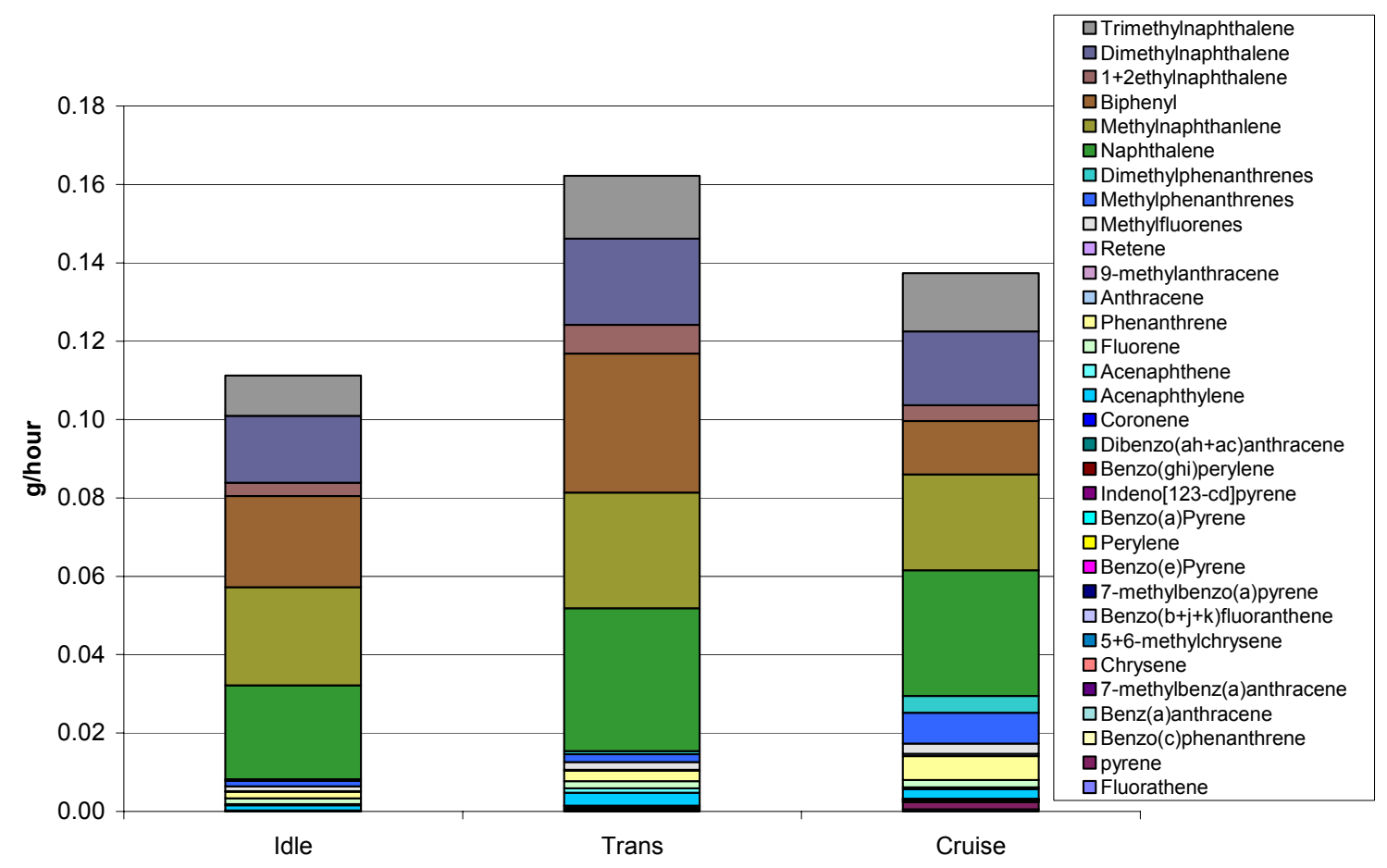

Figure D42: PAH Results for CRC 43 


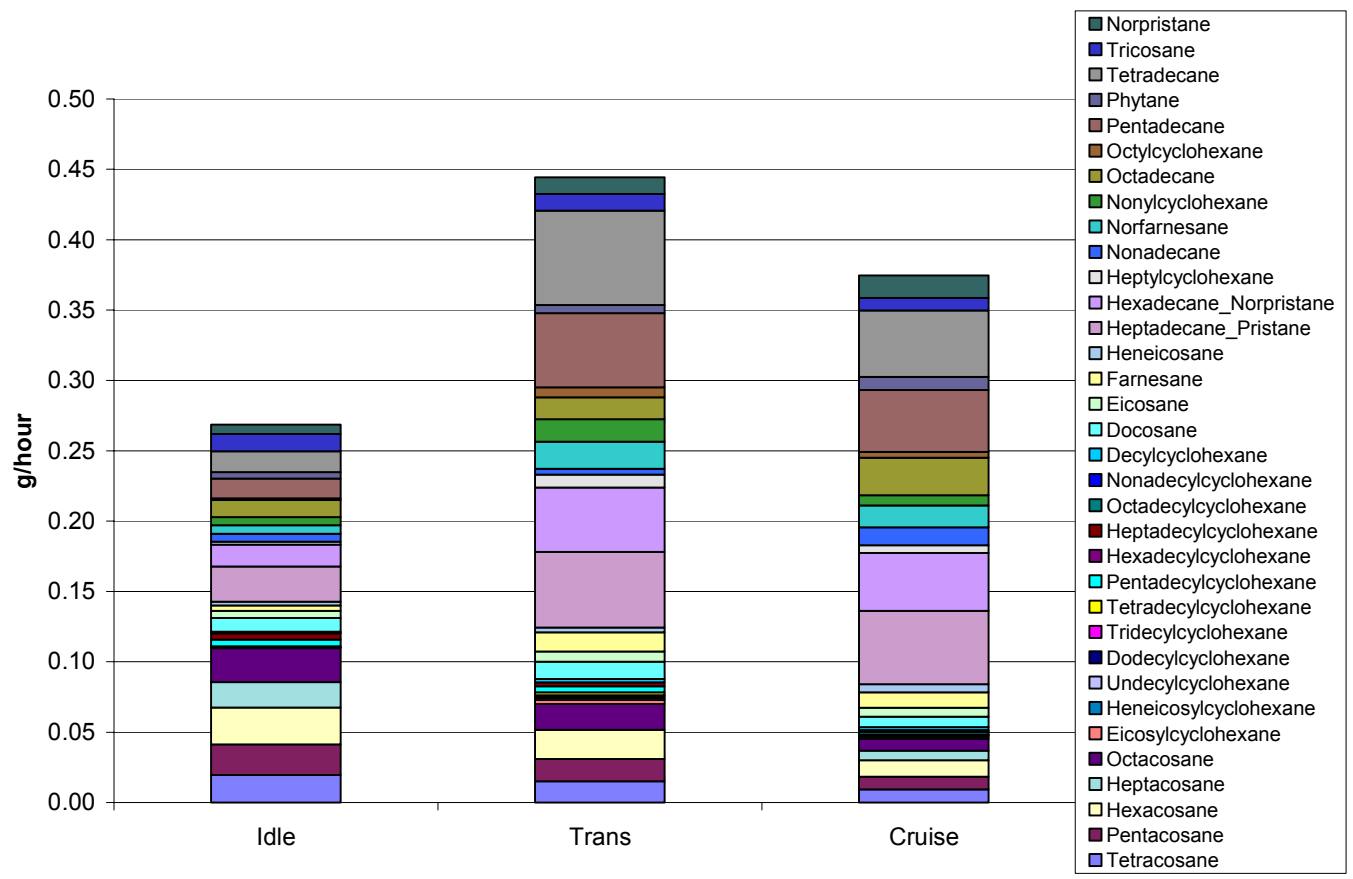

Figure D43: Alkanes Results for CRC 43

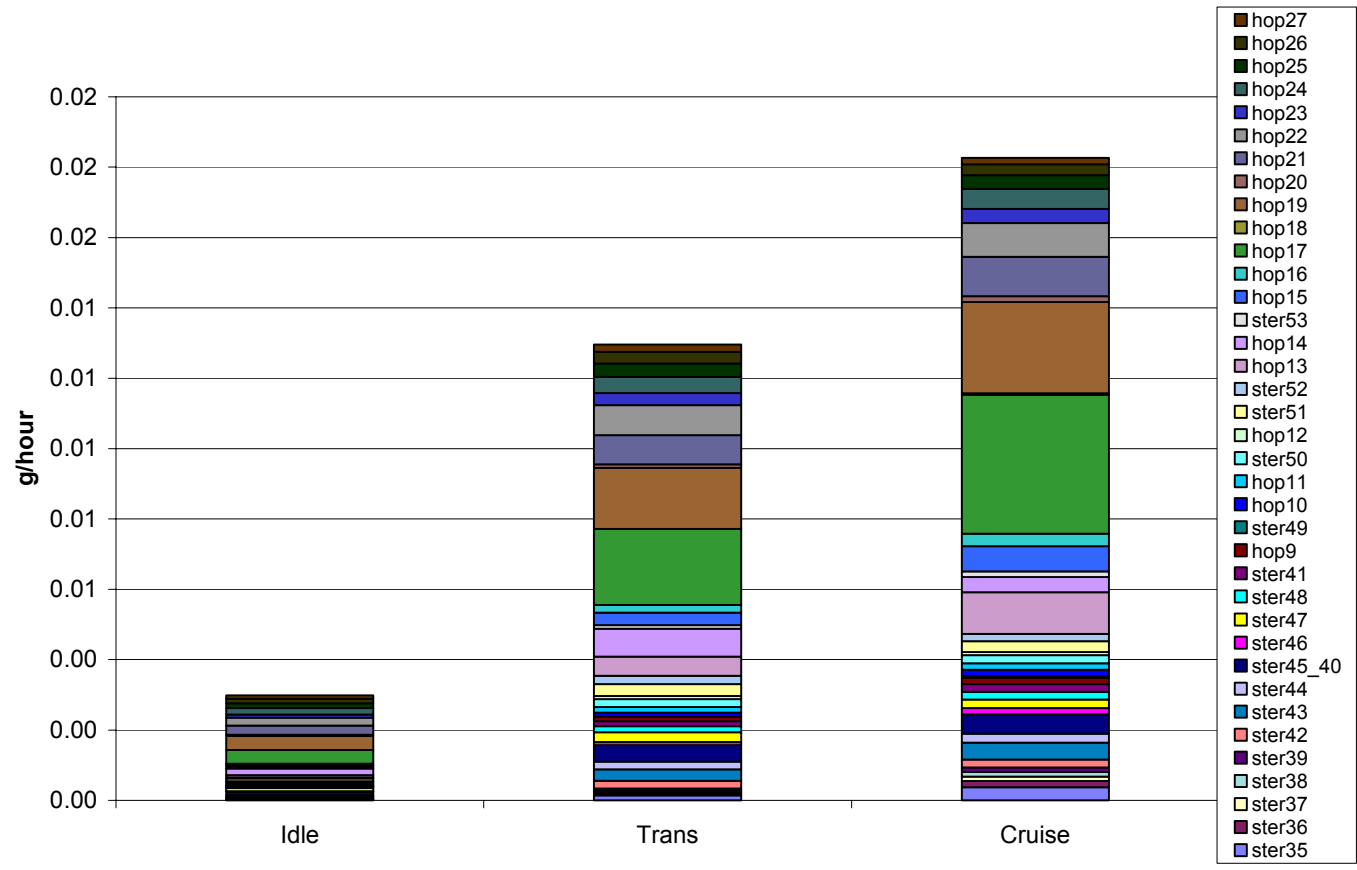

Figure D44: Hopanes and Steranes Results for CRC 43 


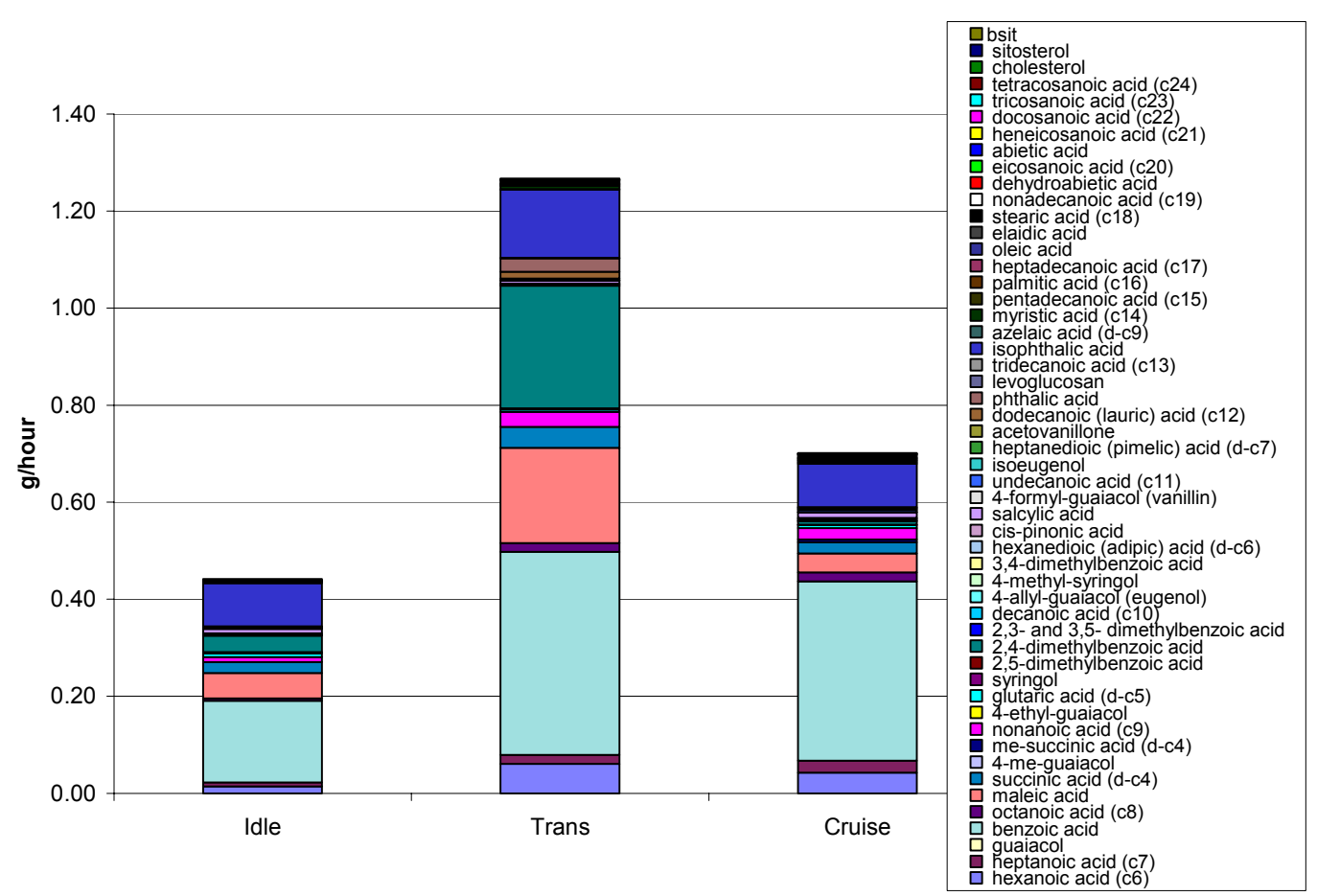

Figure D45: Polar Results for CRC 43

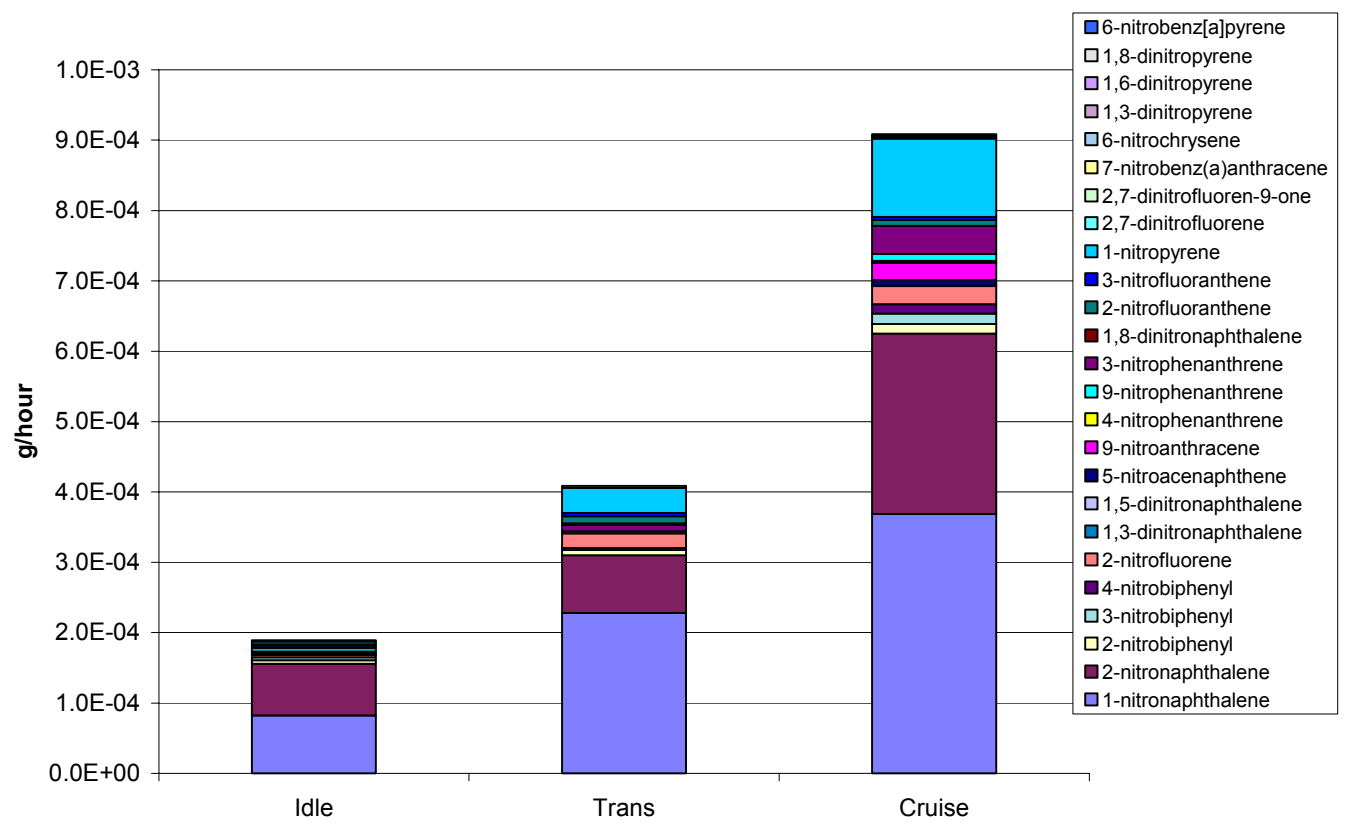

Figure D46: Nitro PAH Results for CRC 43 


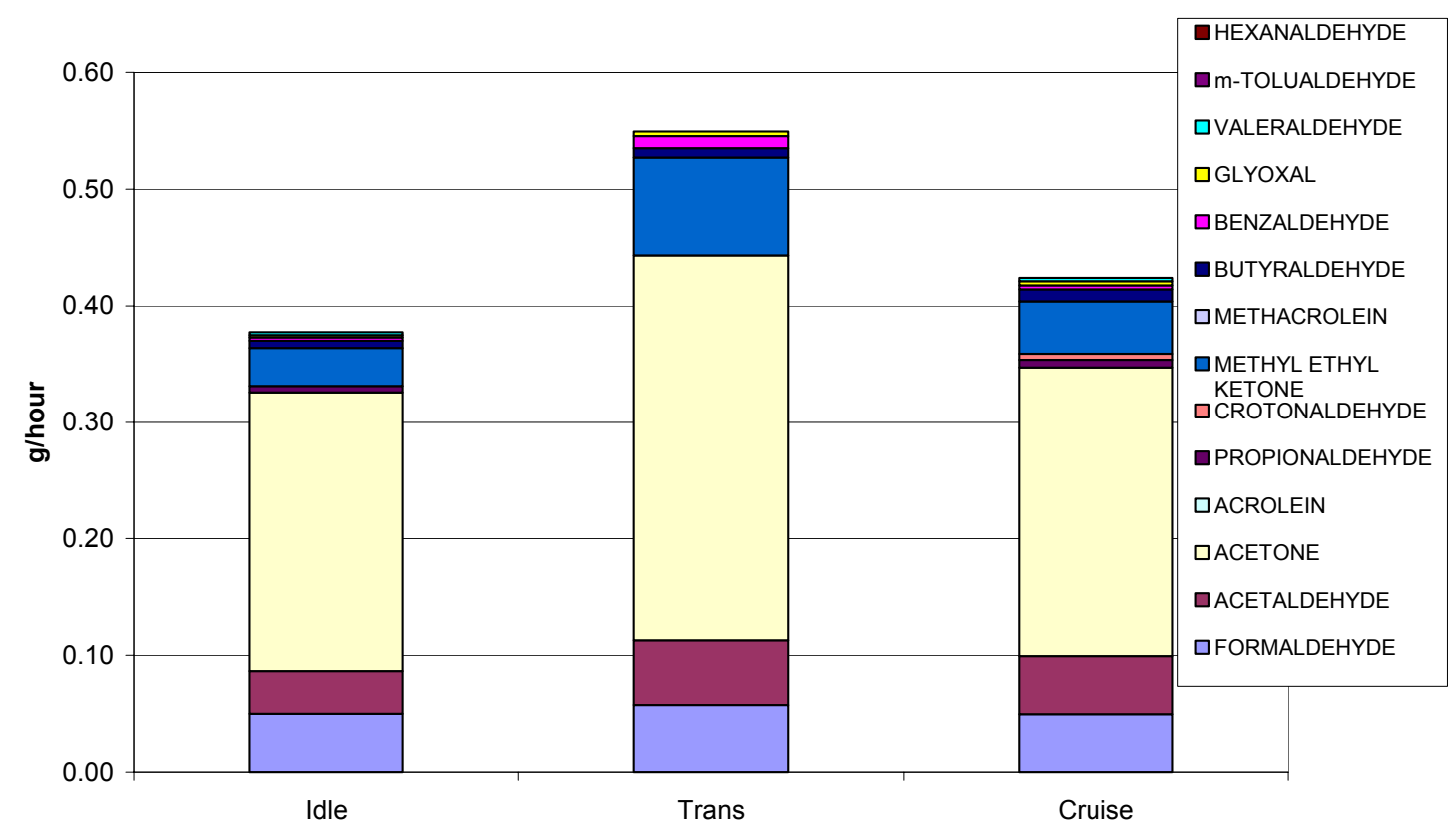

Figure D47: Carbonyl Results for CRC 43

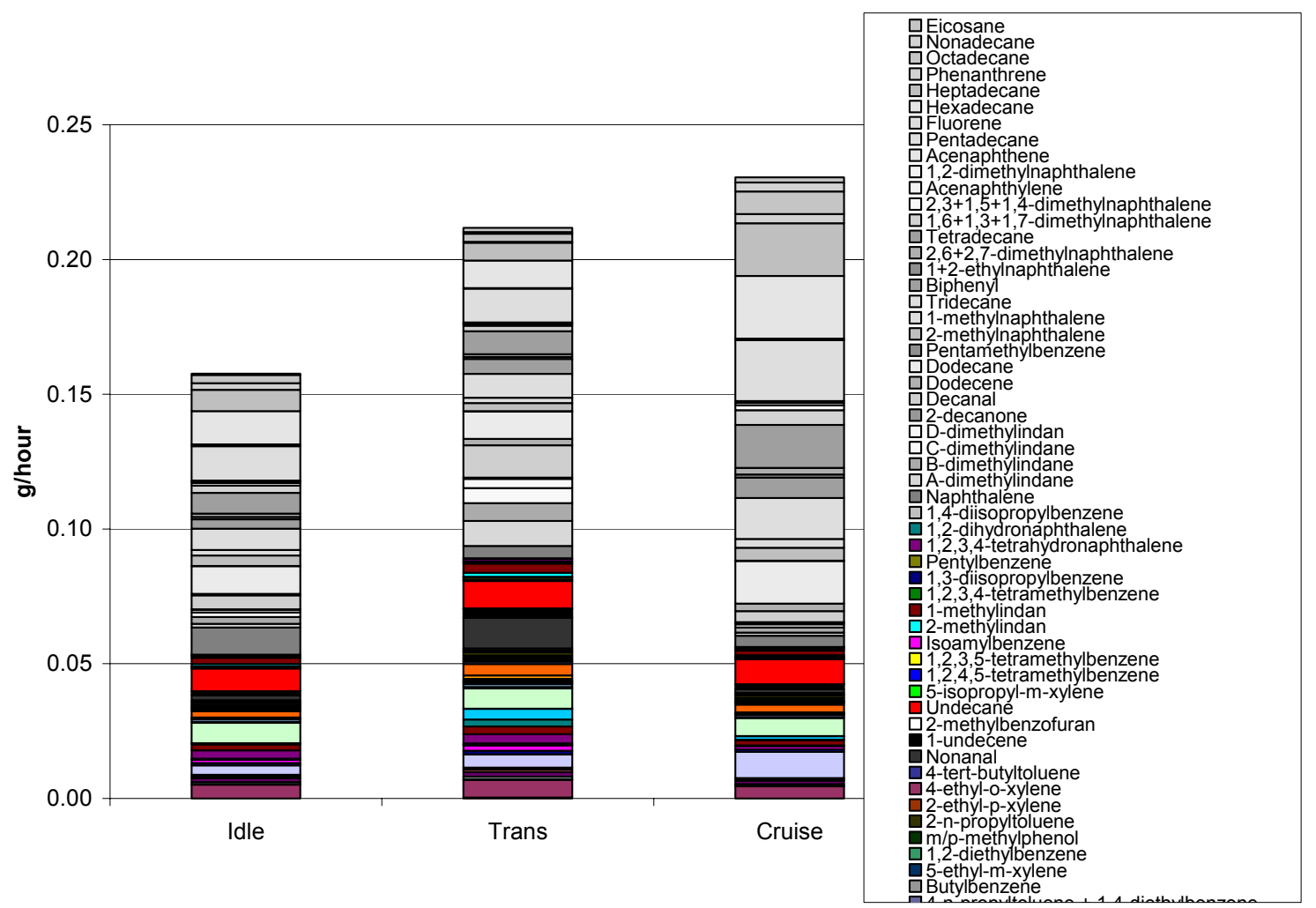

Figure D48: Tenax Results for CRC 43 


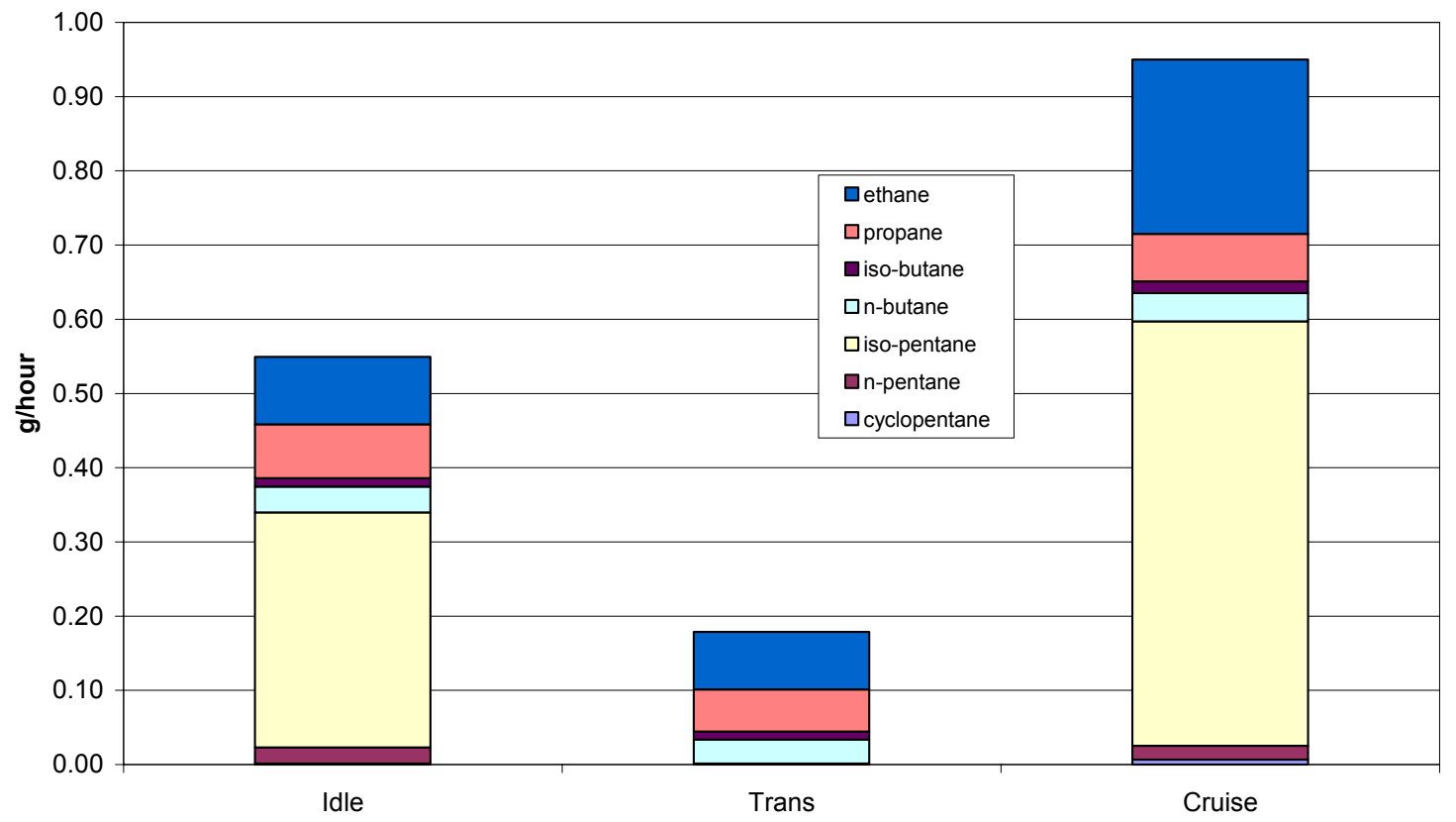

Figure D49: VOC Results (C2 to C5 Alkanes) for CRC 44

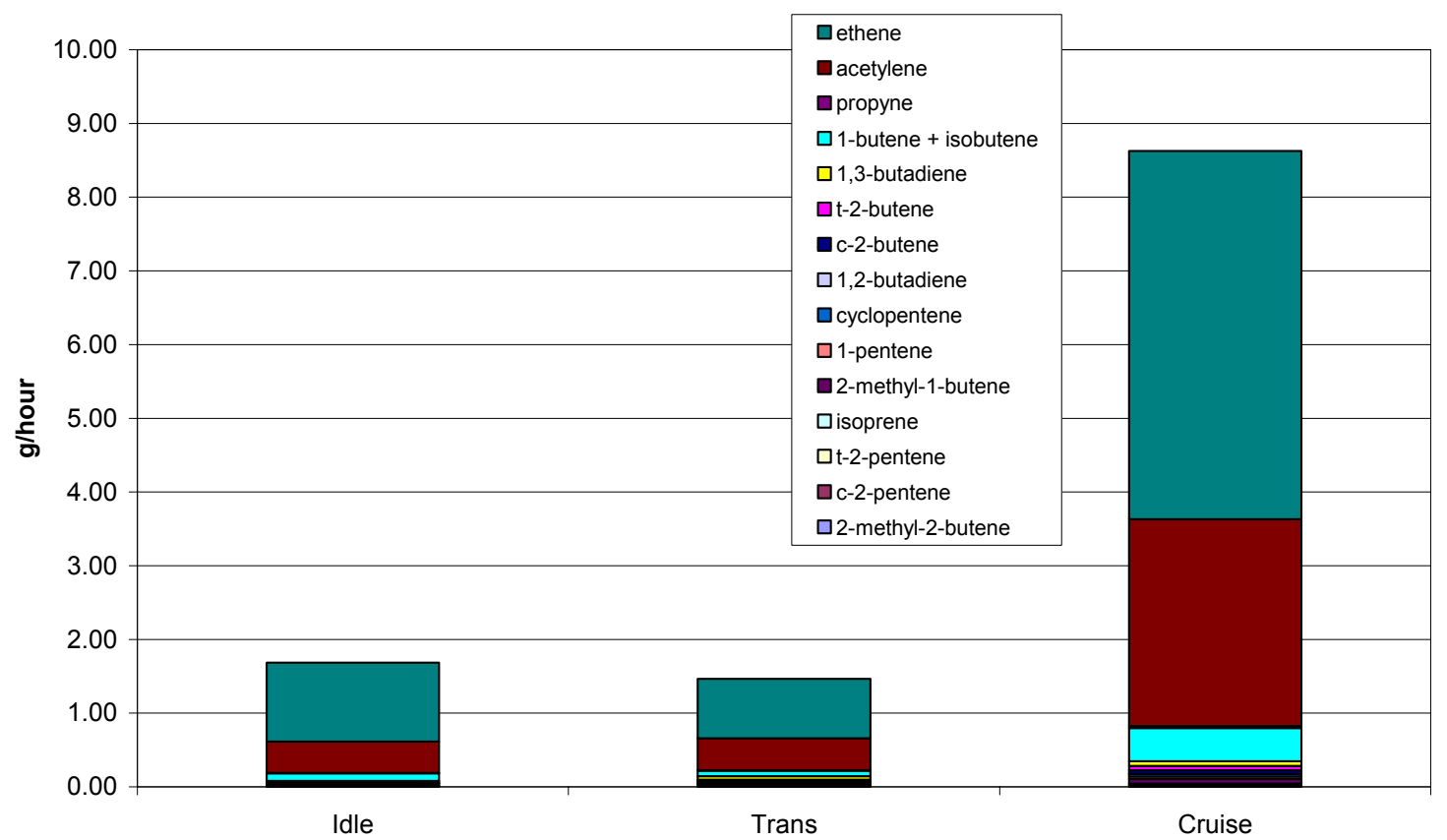

Figure D50: VOC Results (C2 to C5 Olefins) for CRC 44 


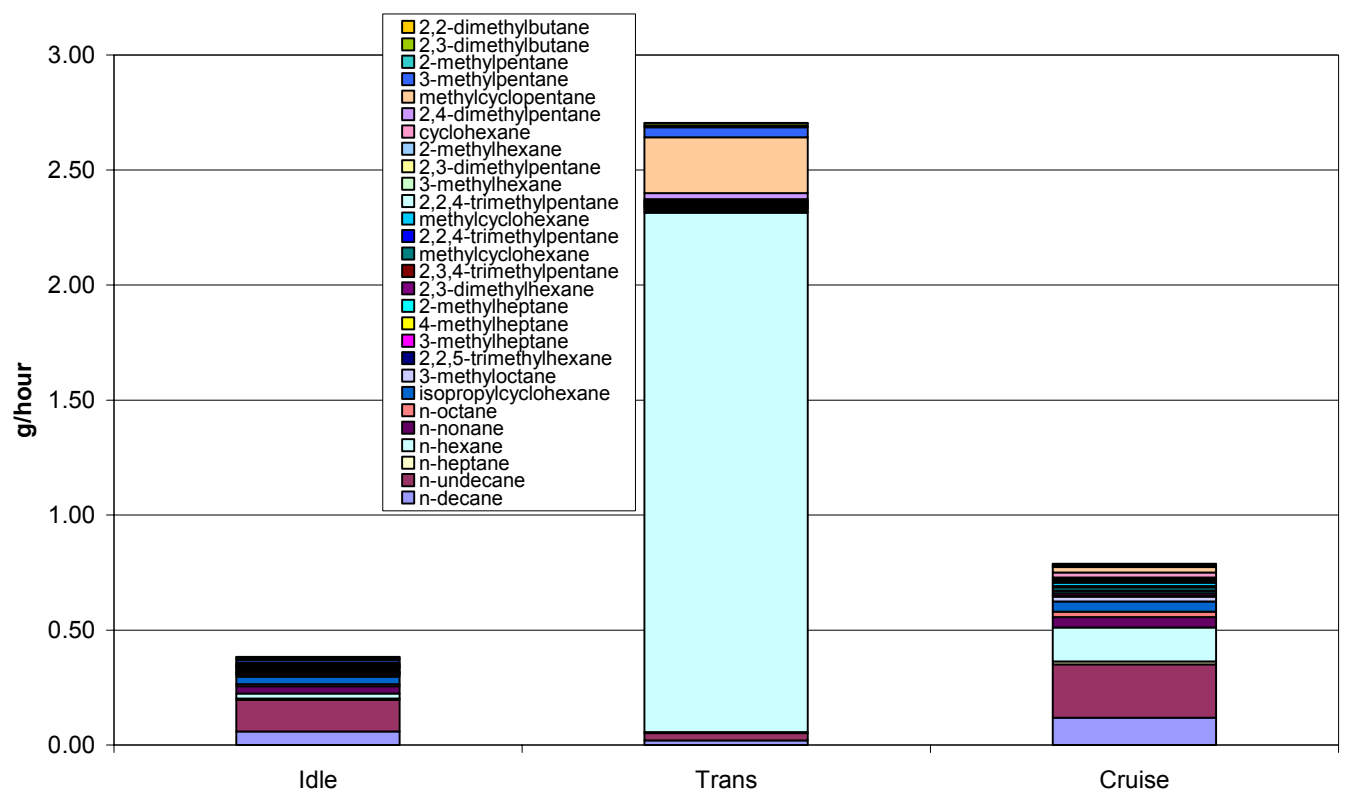

Figure D51: VOC Results (C6 and higher Alkanes) for CRC 44

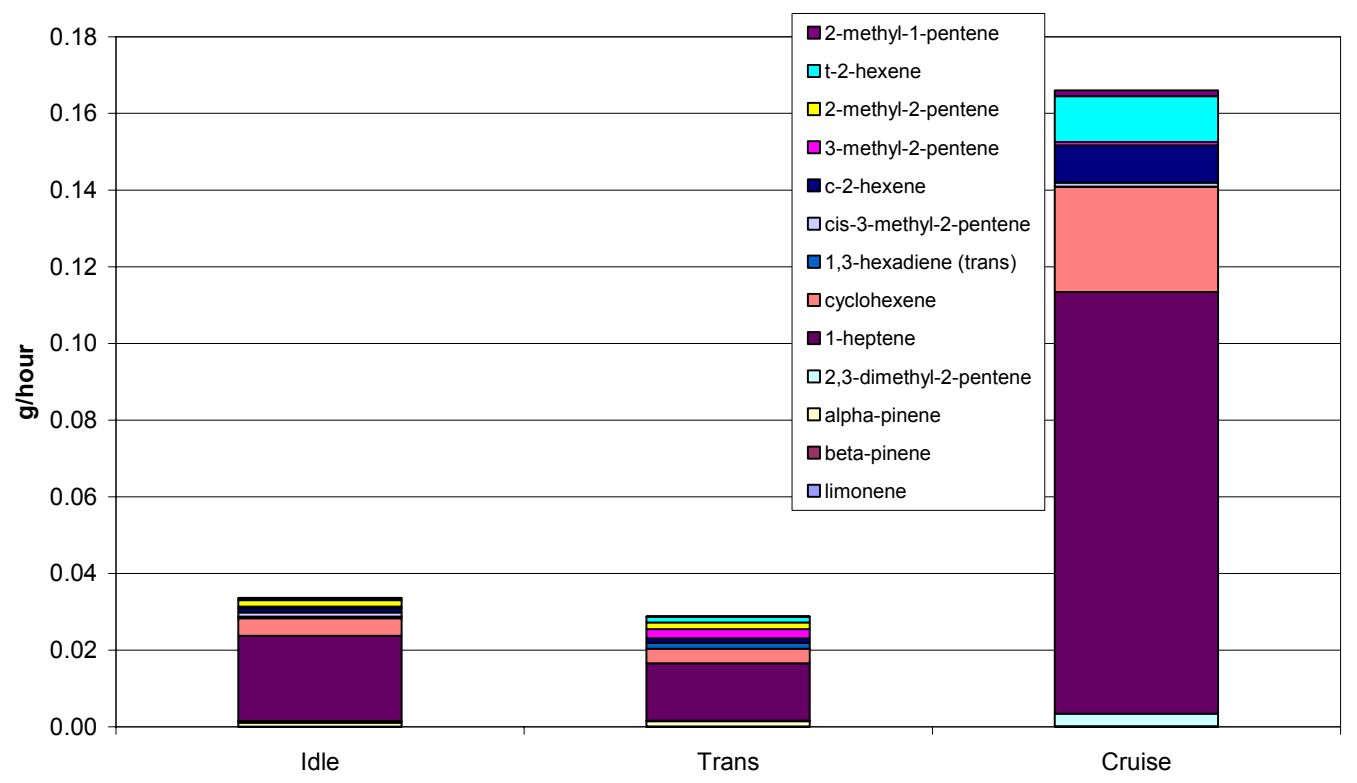

Figure D52: VOC Results (C6 and higher Olefins) for CRC 44 


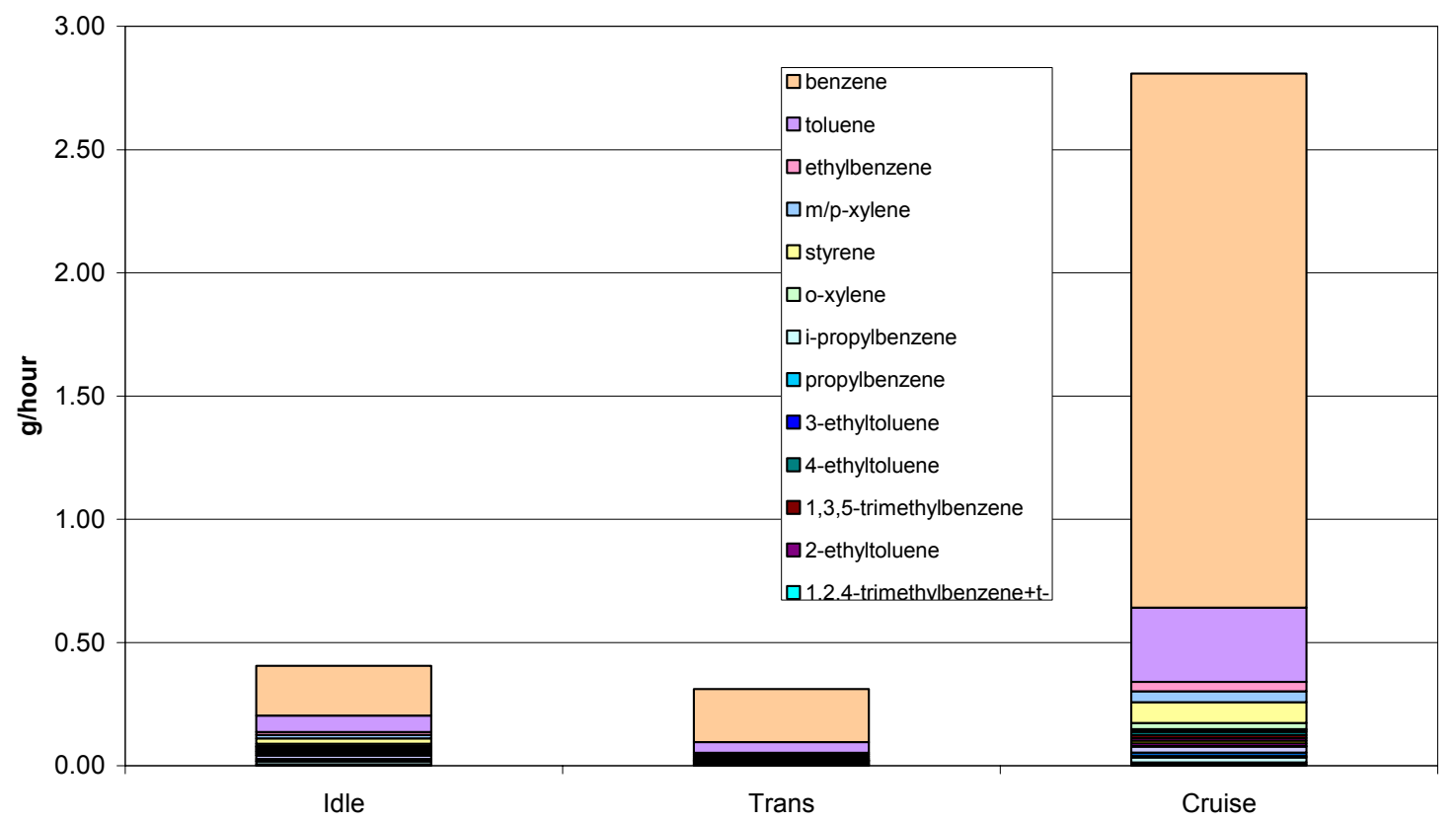

Figure D53: VOC Results (Aromatics) for CRC 44

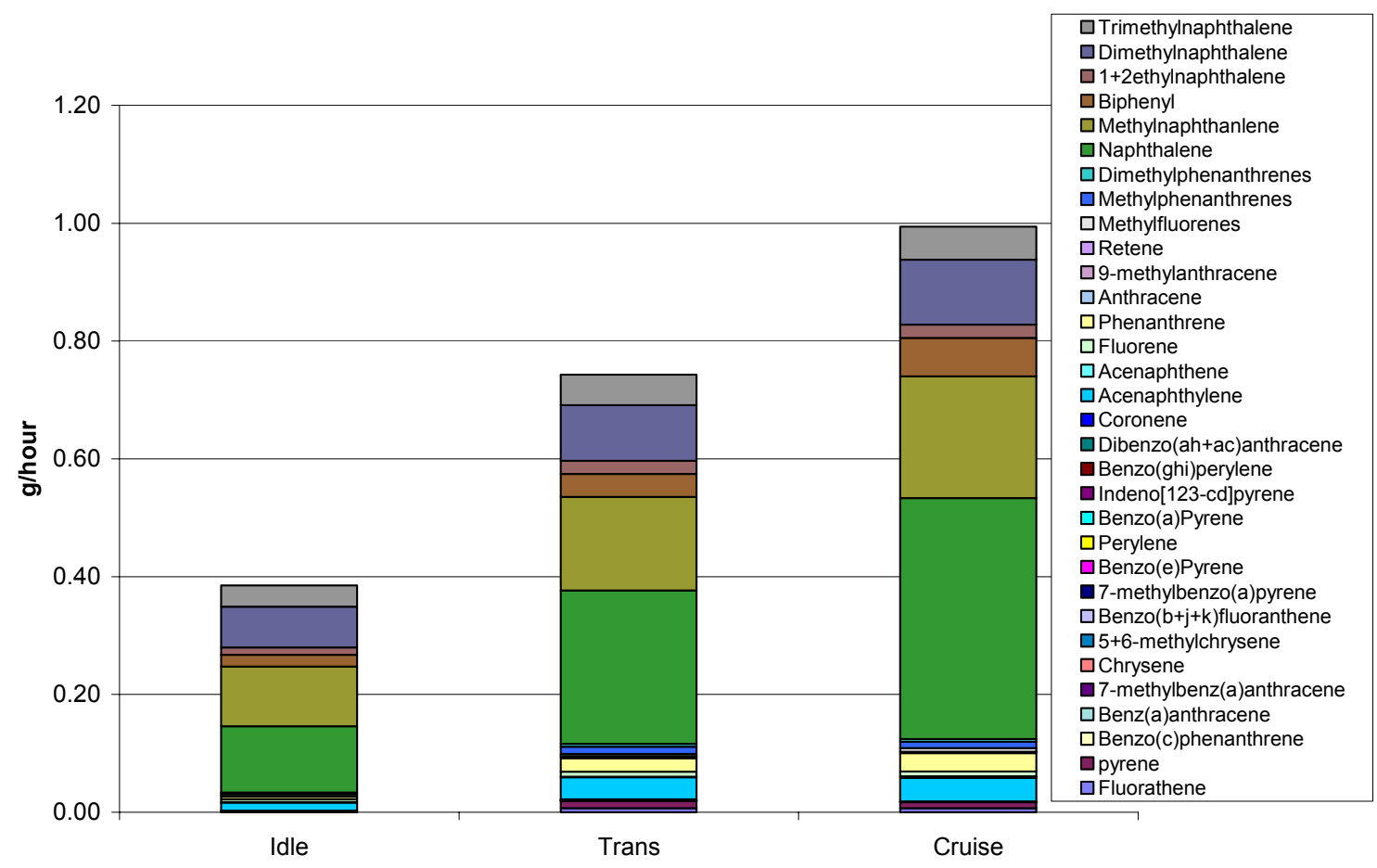

Figure D54: PAH Results for CRC 44 


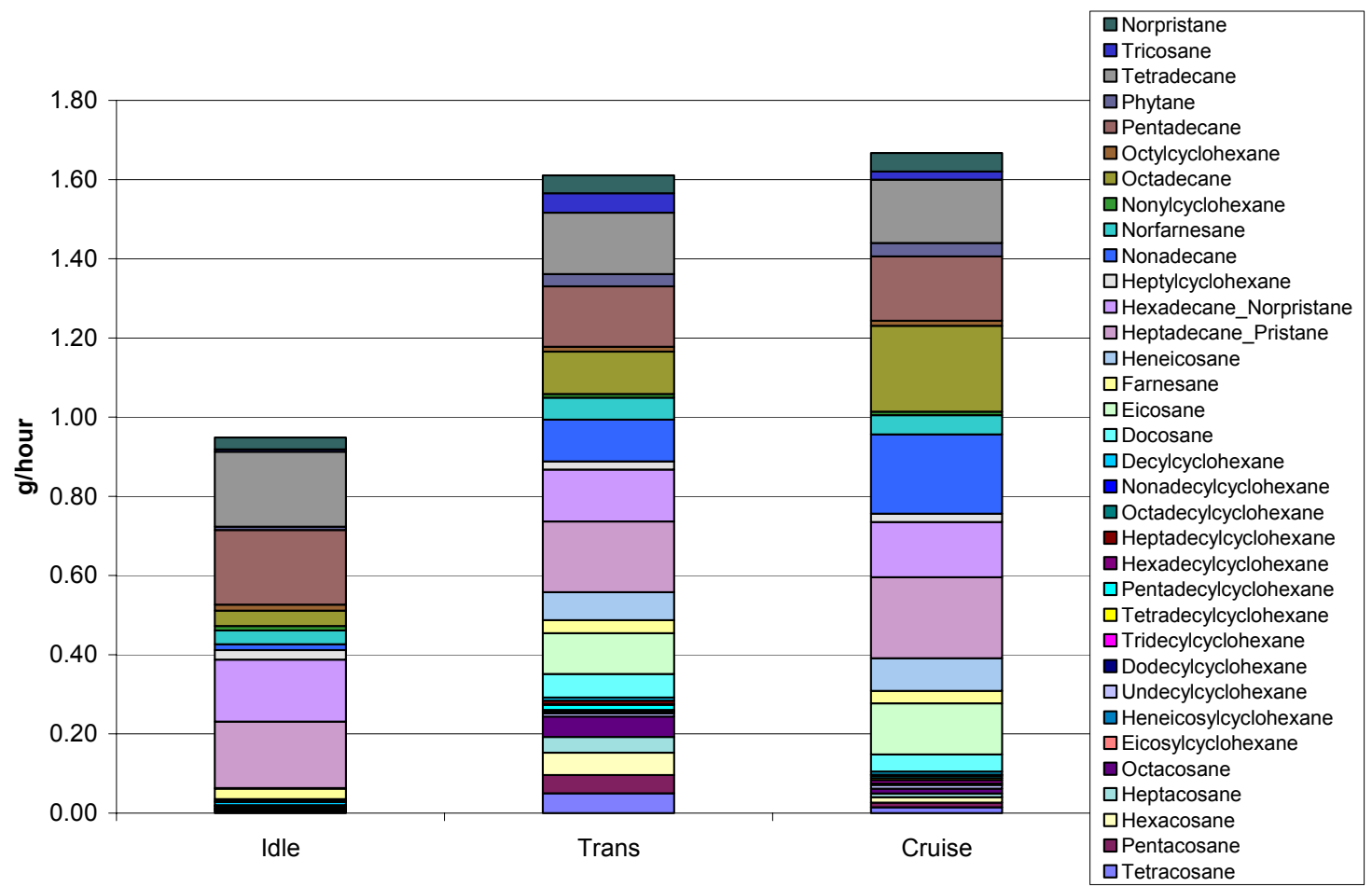

Figure D55: Alkanes Results for CRC 44

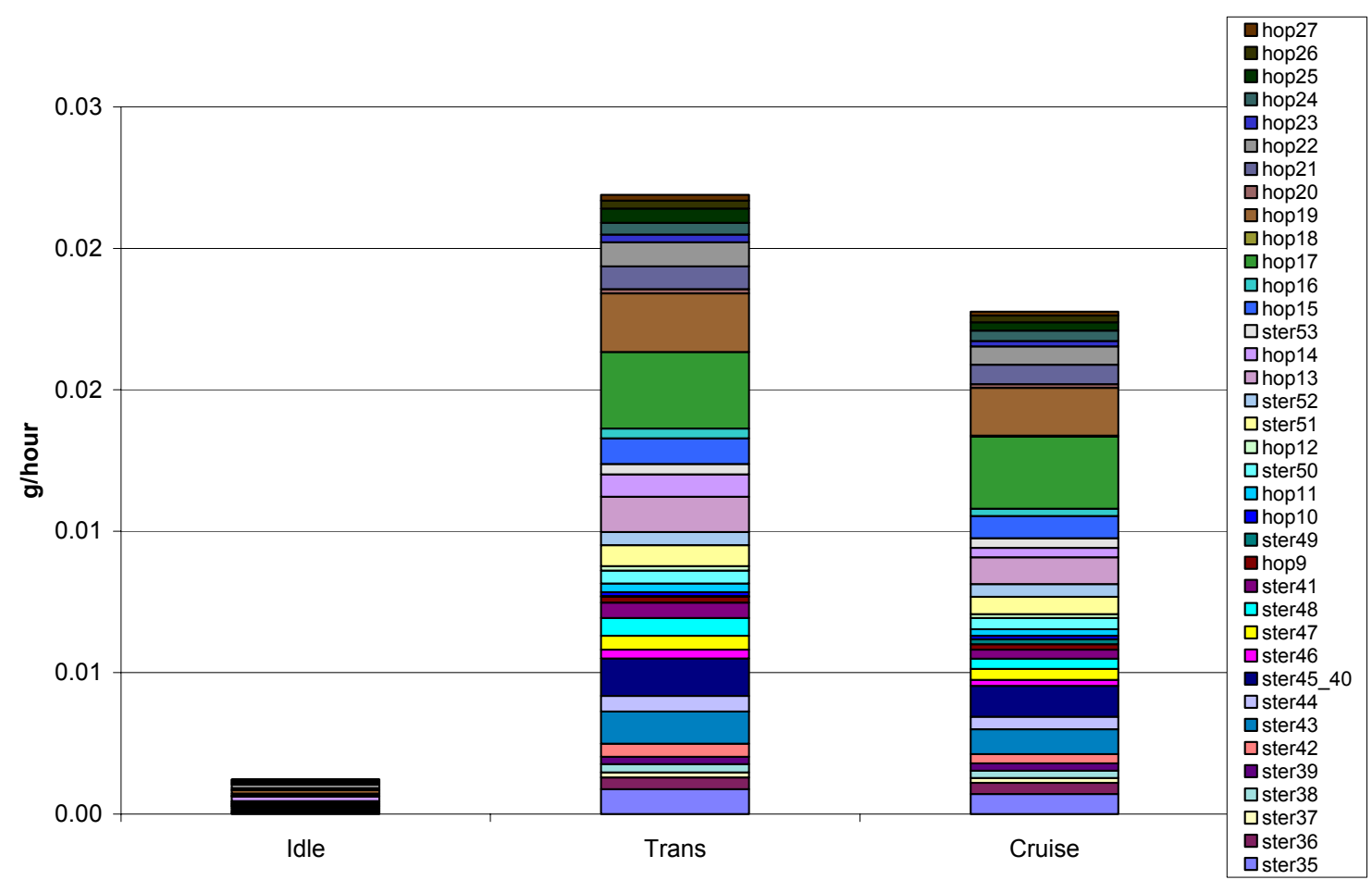

Figure D56: Hopanes and Steranes Results for CRC 44 


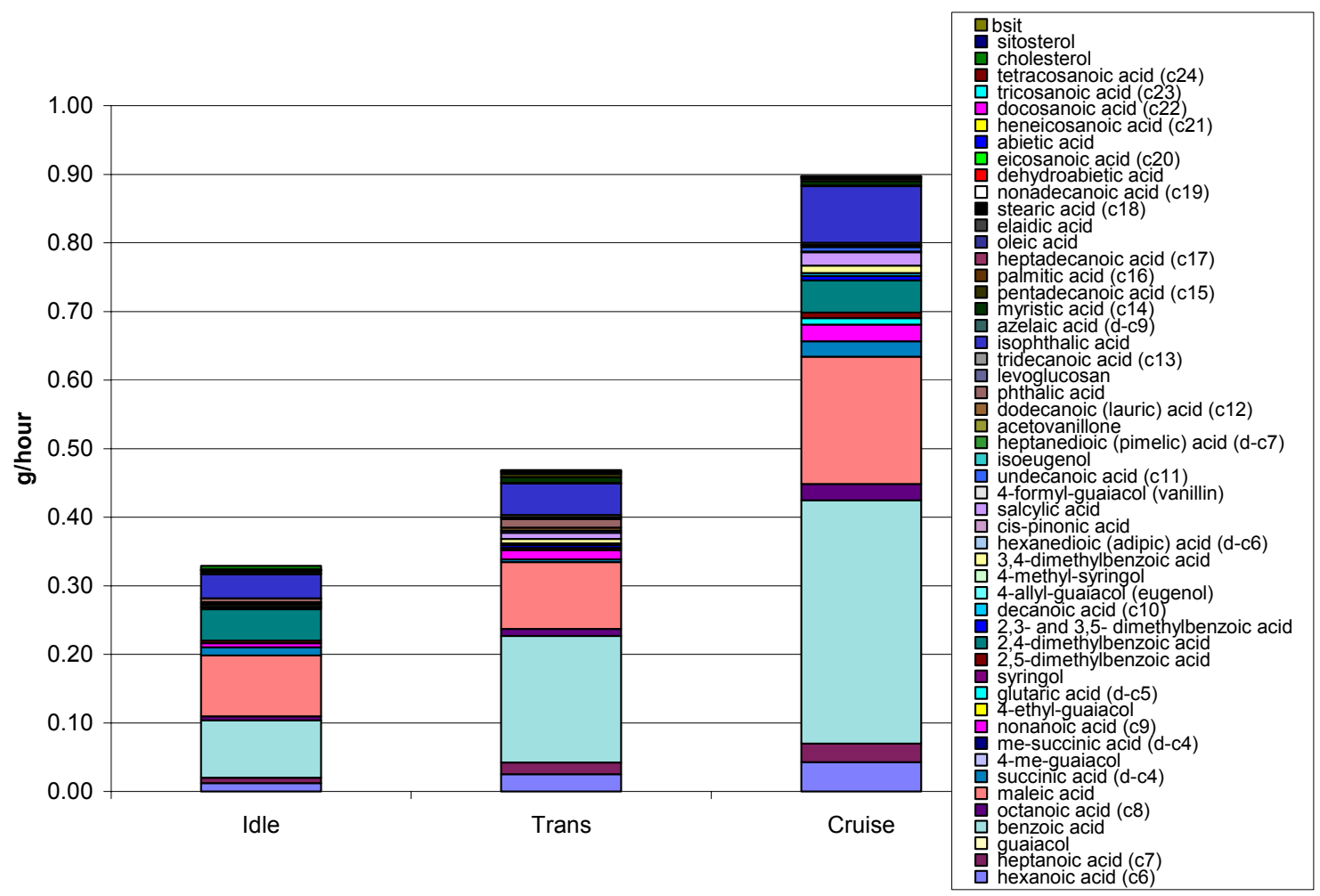

Figure D57: Polar Results for CRC 44

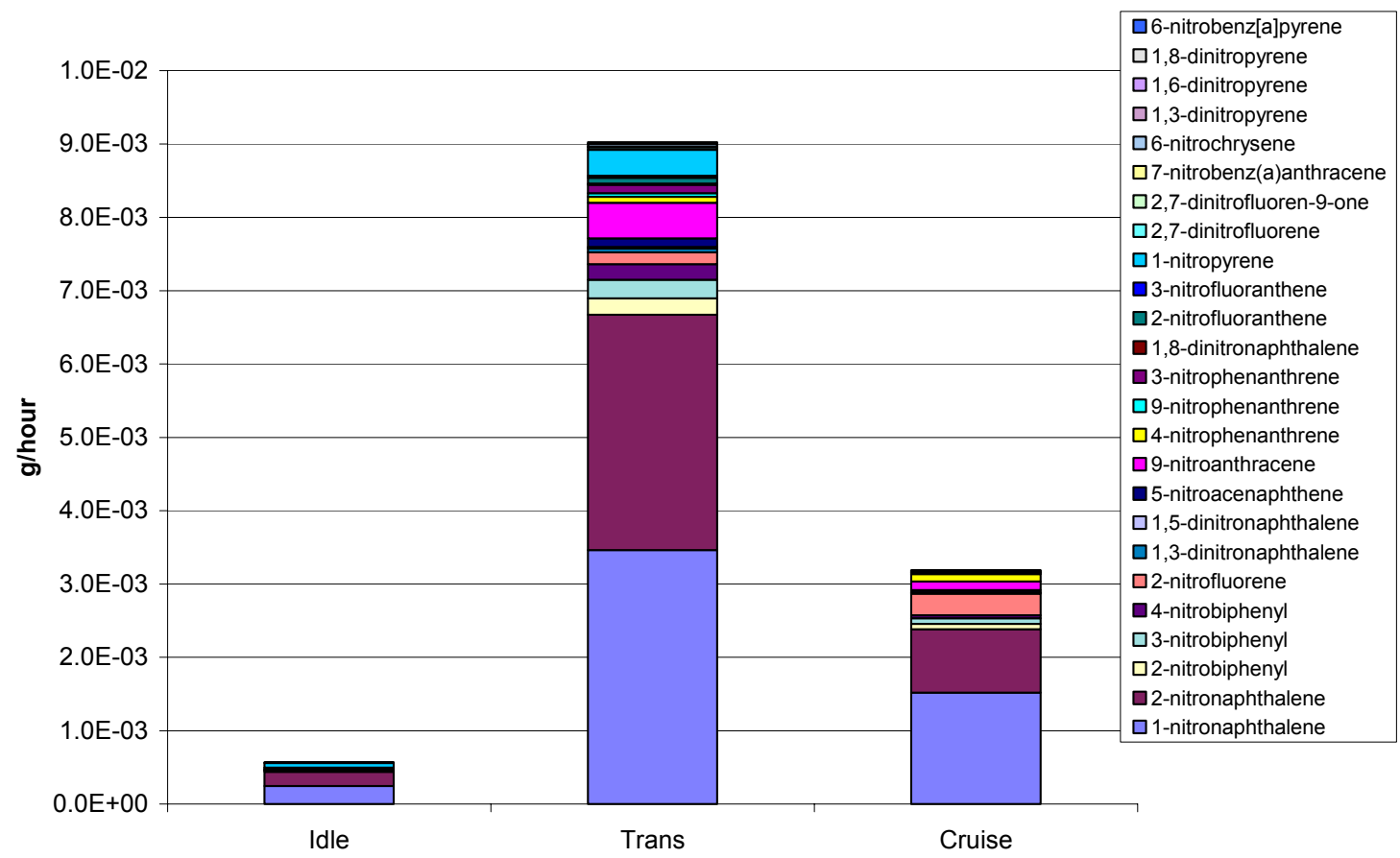

Figure D58: Nitro-PAH Results for CRC 44 


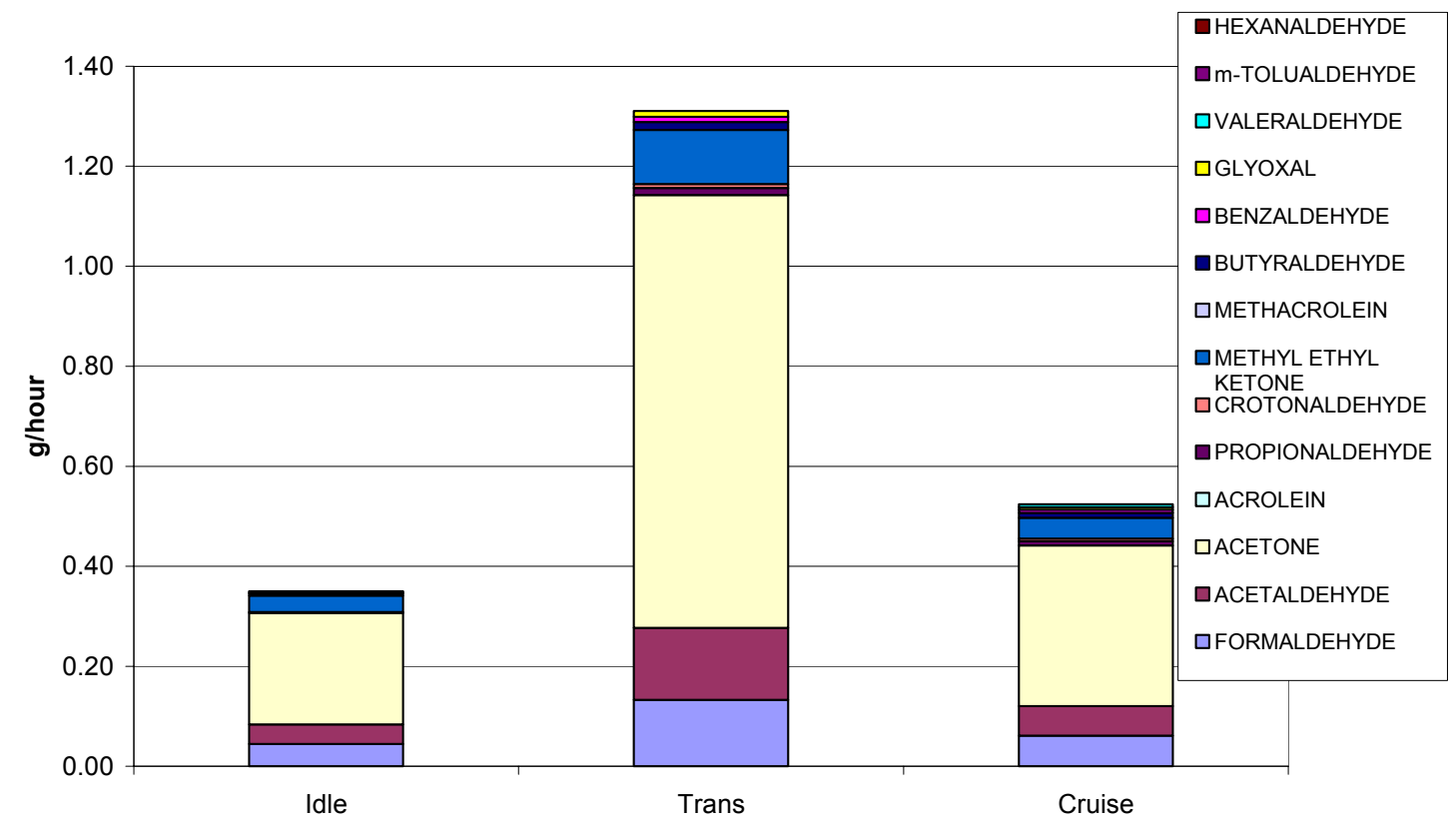

Figure D59: Carbonyls Results for CRC 44 